1

HENRIK BERLIN

PROCEDURAL AND

POSTOPERATIVE PAIN

IN PAEDIATRIC DENTISTRY

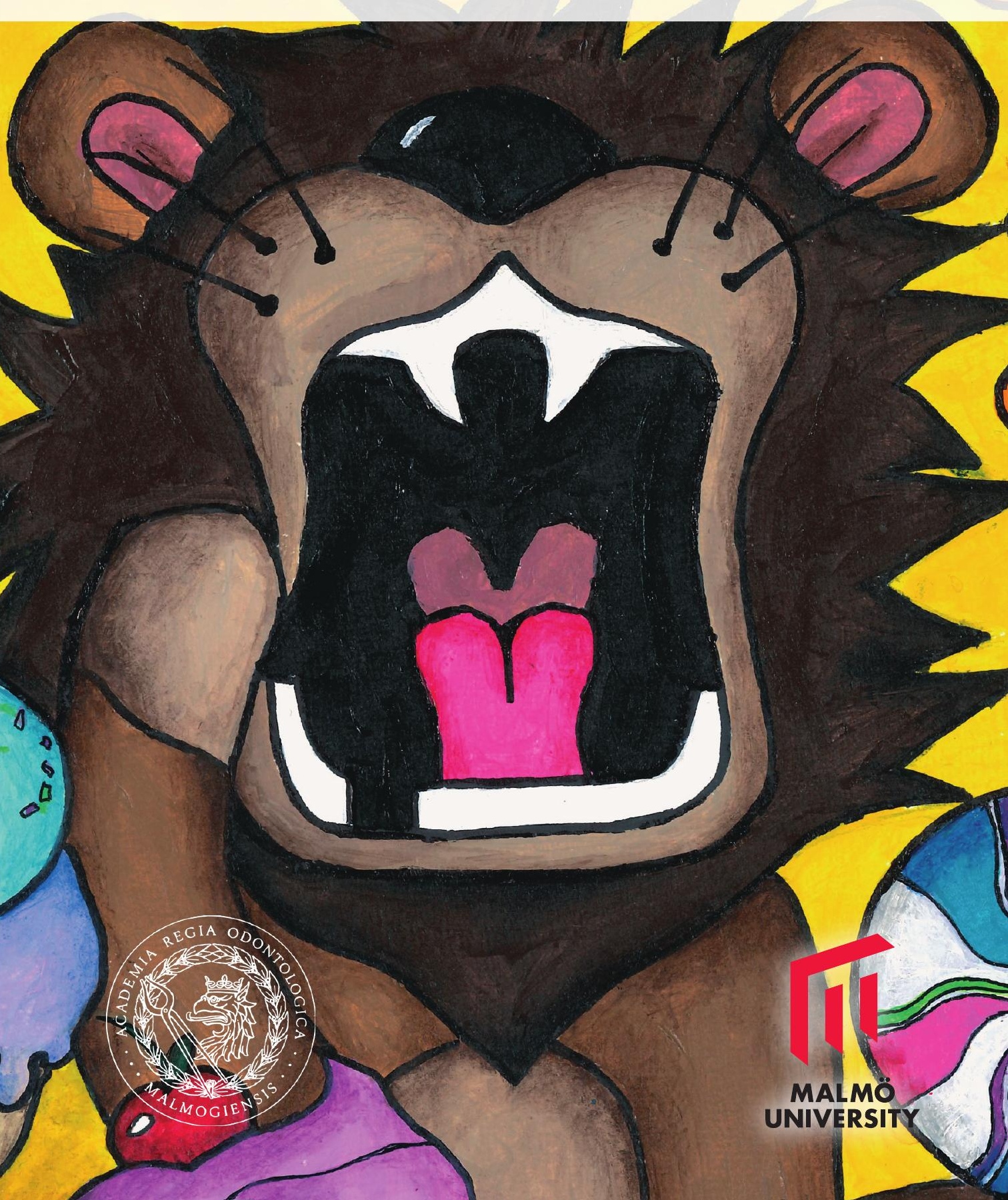



PROCEDURAL AND POSTOPERATIVE PAIN IN PAEDIATRIC DENTISTRY 


\section{Malmö University, Faculty of Odontology}

Doctoral Dissertations 2020

(C) Copyright Henrik Berlin, 2020

Cover illustration: Ida Olsson

Illustrations: Henrik Berlin

Model: Filip Olsson

ISBN 978-91-7877-133-2 (print)

ISBN 978-91-7877-134-9 (pdf)

Holmbergs, Malmö 2020 


\title{
HENRIK BERLIN PROCEDURAL AND POSTOPERATIVE PAIN IN PAEDIATRIC DENTISTRY
}

\author{
Malmö University, 2020 \\ Faculty of Odontology \\ Department of Pediatric Dentistry
}


This publication is also available in electronic format at http://muep.mau.se 
To Göran, Okkie and Dante 



\section{TABLE OF CONTENTS}

PREFACE

THE RESEARCH PROCESS OF THIS THESIS

(THESIS AT A GLANCE) …...................................... 12

DEFINITIONS AND ABBREVIATIONS .......................... 14

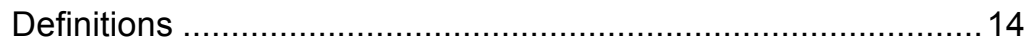

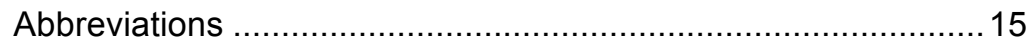

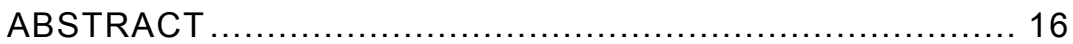

POPULÄRVETENSKAPLIG SAMMANFATTNING .............. 19

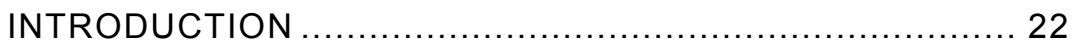

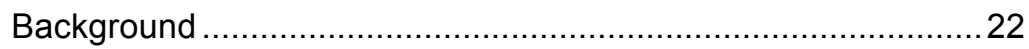

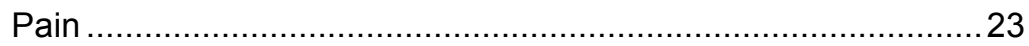

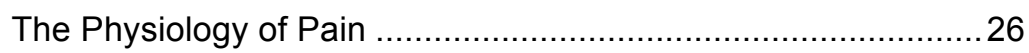

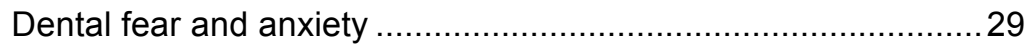

Dental Behaviour Management Problems ................................... 30

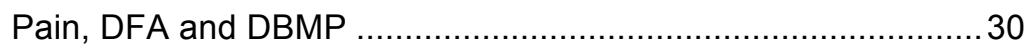

Child psychological development and the

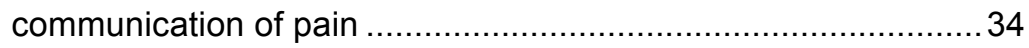

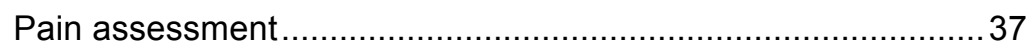

Dentists' knowledge and attitudes............................................. 40

Prevention of procedural pain and postoperative

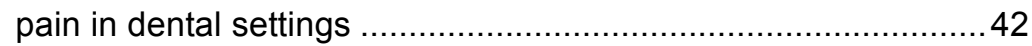

Questionnaires as a sampling method....................................... 44

Systematic review and health technology assessment................46

Quantitative and qualitative research methods ..........................47 


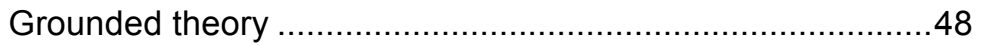

Ethical considerations ….................................................. 50

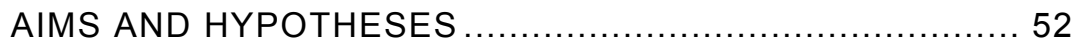

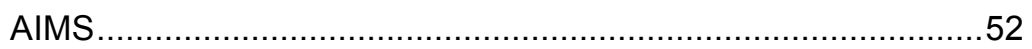

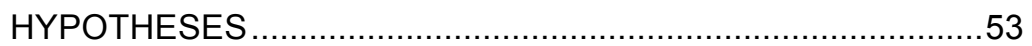

MATERIAL AND METHODS ..................................... 54

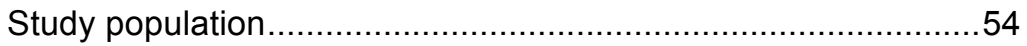

Pain management in clinical practice (Paper I) ....................54

The natural course of pain (Paper II)......................................55

Postoperative pain management - systematic review and health technology assessment (Paper III) .......................55

Children's perceptions of pain (Paper IV) ............................... 55

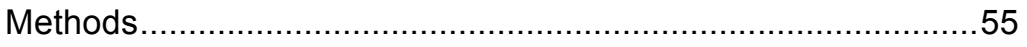

Pain management in clinical practice (Paper I) .....................55

The natural course of pain (Paper II)...................................56

Postoperative pain management - systematic review and health technology assessment (Paper III) ......................60

Children's perceptions of pain (Paper IV)............................62

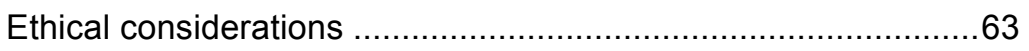

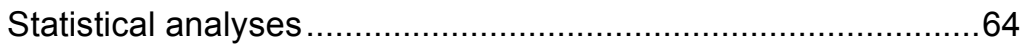

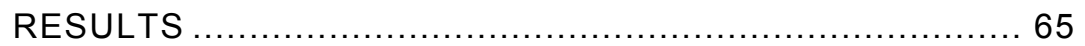

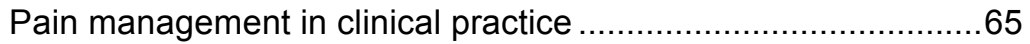

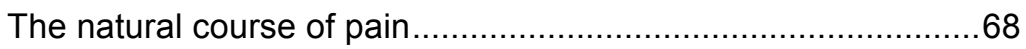

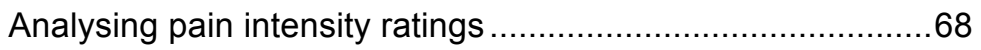

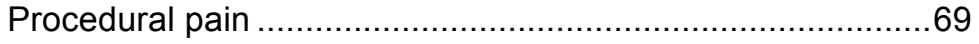

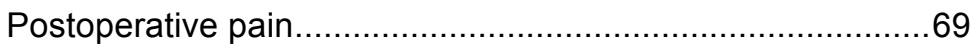

Health and economic analysis............................................ 71

Postoperative pain management - systematic review

and health technology assessment ........................................

Children's perceptions of pain ................................................

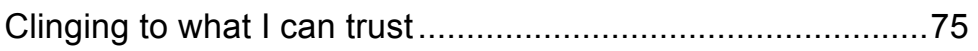

Clinging to earlier experiences ........................................... 75

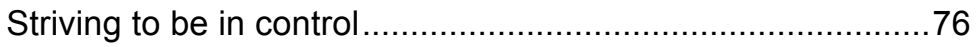

Longing to get it over with .................................................

Looking forward to a treat.................................................... 


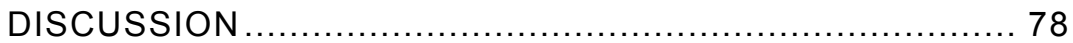

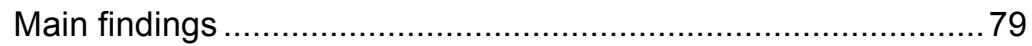

Methodological aspects of the four papers ……............................ 80

Pain management in clinical practice ................................... 81

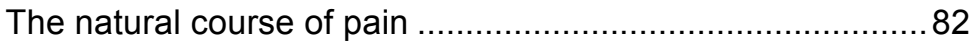

Postoperative pain management - systematic review and health technology assessment....................................... 84

Children's perceptions of pain .............................................. 86

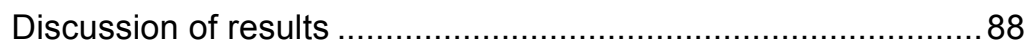

Pain management in clinical practice ................................. 88

The natural course of pain ................................................. 91

Postoperative pain management - systematic review

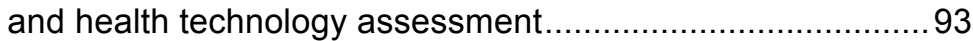

Children's perceptions of pain ..............................................94

Ethical consideration in research involving children....................96

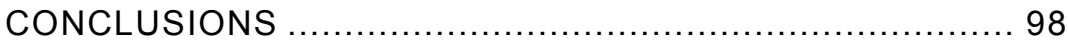

CLINICAL IMPLICATIONS AND

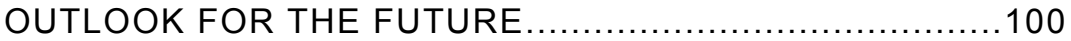

ACKNOWLEDGEMENTS .........................................102

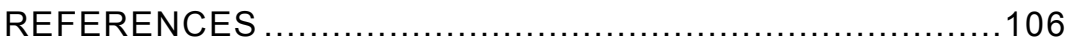

APPENDENCIES .................................................... 125

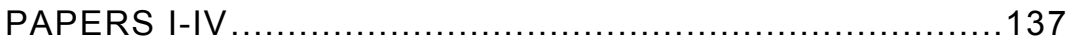





\section{PREFACE}

This thesis is based upon the following four papers, referred to in the text by their Roman numerals.

I. Berlin, H., List, T., Ridell, K. \& Klingberg G. (2018) 'Dentists' attitudes towards acute pharmacological pain management in children and adolescents', International Journal of Paediatric Dentistry, 28(2), pp. 152-160. PMID: 28691744. doi: 10.1111/ipd.12316. Epub 2017 Jul 10.

II. Berlin, H., List, T., Ridell, K., Davidson, T., Toft, D. \& Klingberg, G. (2019) 'Postoperative pain profile in 10-15-year-olds after bilateral extraction of maxillary premolars', European Archives of Paediatric Dentistry, 20(6), pp. 545-555. PMID: 30963511. doi: 10.1007/s40368-019-00425-9. Epub 2019 Apr 8.

III. Berlin, H., Vall, M., Bergenäs, E., Ridell, K., Brogårdh-Roth, S., Lager, E., List, T., Davidson, T. \& Klingberg, G. (2019) 'Effects and cost-effectiveness of postoperative oral analgesics for additional postoperative pain relief in children and adolescents undergoing dental treatment: Health technology assessment including a systematic review', PLoS One, 14(12), e0227027. PMID: 31891621; PMCID: PMC6938383. doi:

10.1371/journal.pone.0227027.

IV. Berlin, H., Hallberg, U., Ridell, K., Toft, D. \& Klingberg, G. Children's perceptions and coping of pain in conjunction with orthodontically indicated tooth extractions - a grounded theory study. Submitted

All papers are reprinted with the kind permission from the copyright holders and are appended to the end of this thesis. 


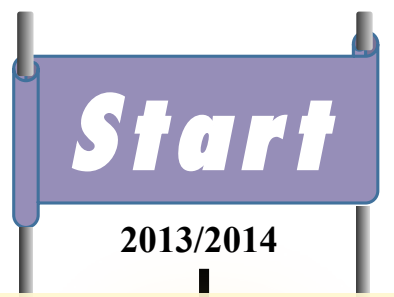

\section{THE RESEARCH PROCESS OF THIS THESIS (THESIS AT A GLANCE)}

Evidence gaps are identified by SBU, both regarding preand postoperative pain relief in conjunction with dental treatments and minor oral surgery therapies in children and adolescents.

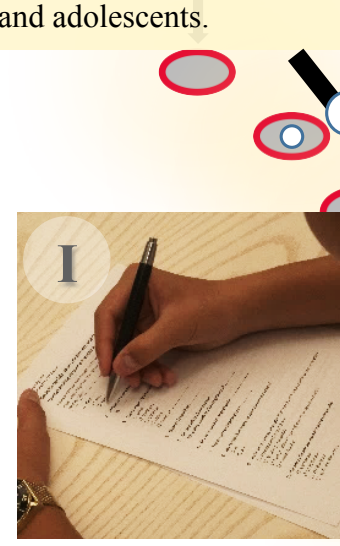

807 GDPs and 122 SPDs were sent a 19-item questionnaire on attitudes about pain management strategies when treating children.

The response rate was $60.5 \%$ for the whole group. SPDs had a higher response rate compared to GDPs $(83 \%$ vs. $57 \%$, respectively).

The study raises questions about dentists' use of painreducing strategies during dental treatments in children and adolescents. These differ between GDPs and SPDs, but also within the group of GDPs.
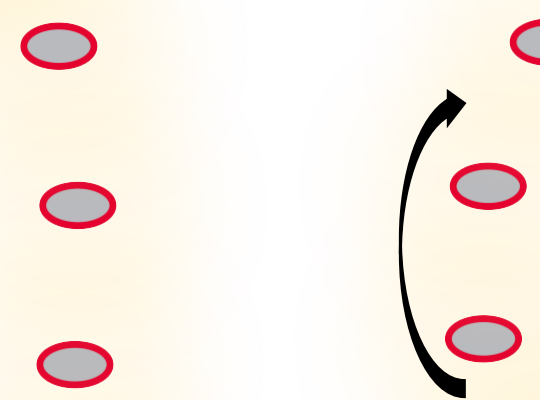

Maybe I should do an RCT to elucidate the effect of preoperatively administered analgesics in order to reducel prevent procedural and/or postoperative pain? But how do dentists use this strategy today?
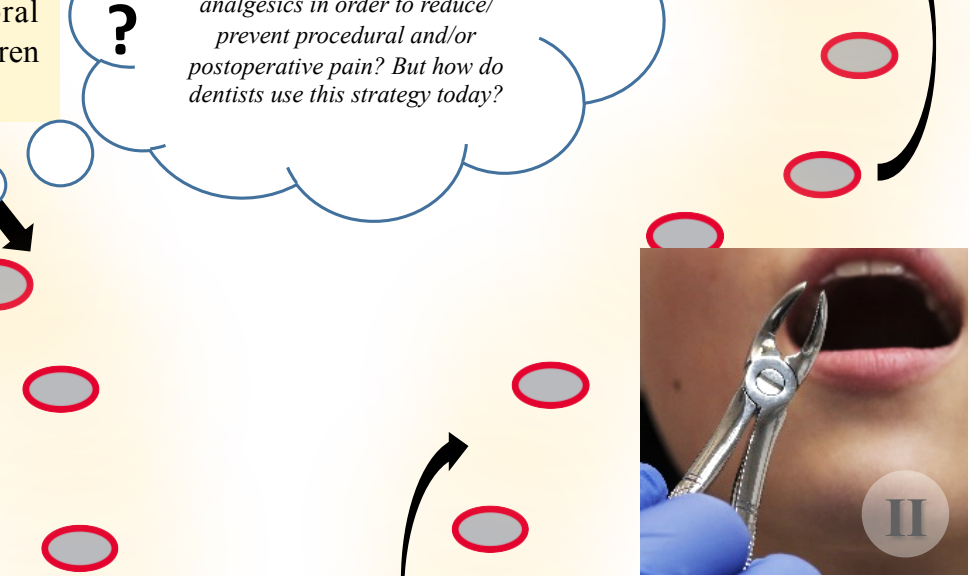

Thirty-one 10-15-year-olds rated their pain intensity during and after uncomplicated bilateral maxillary extractions. They rated their pain at different time points, from injection of local anaesthetics up to 7 days after both extractions.

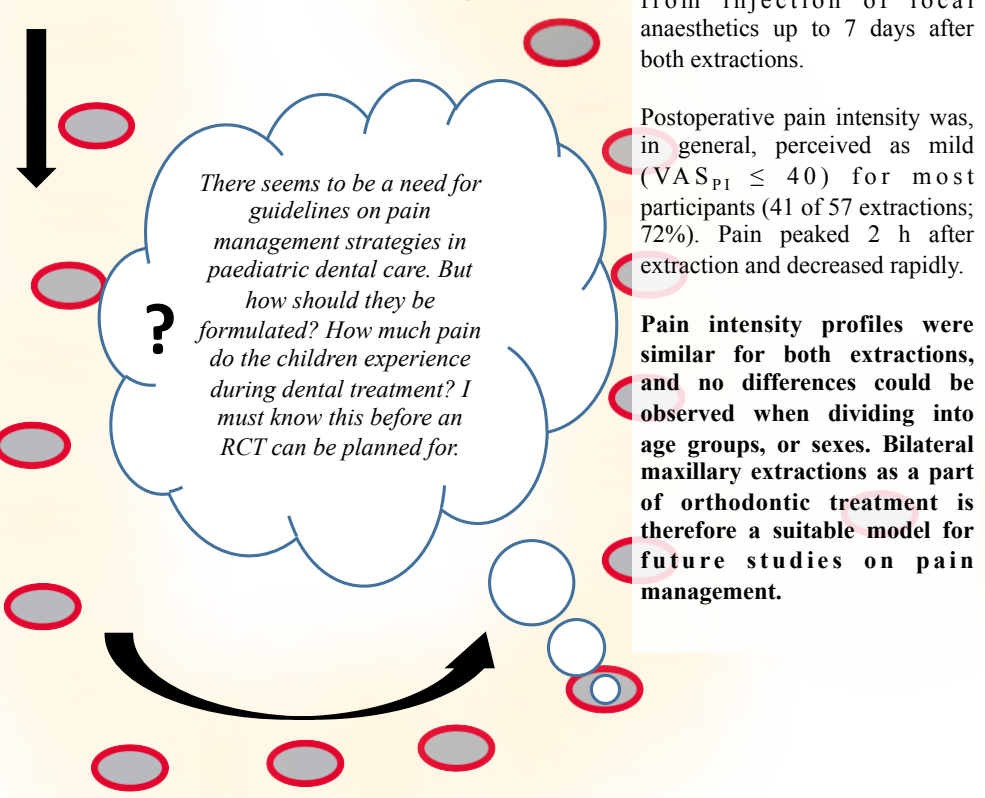




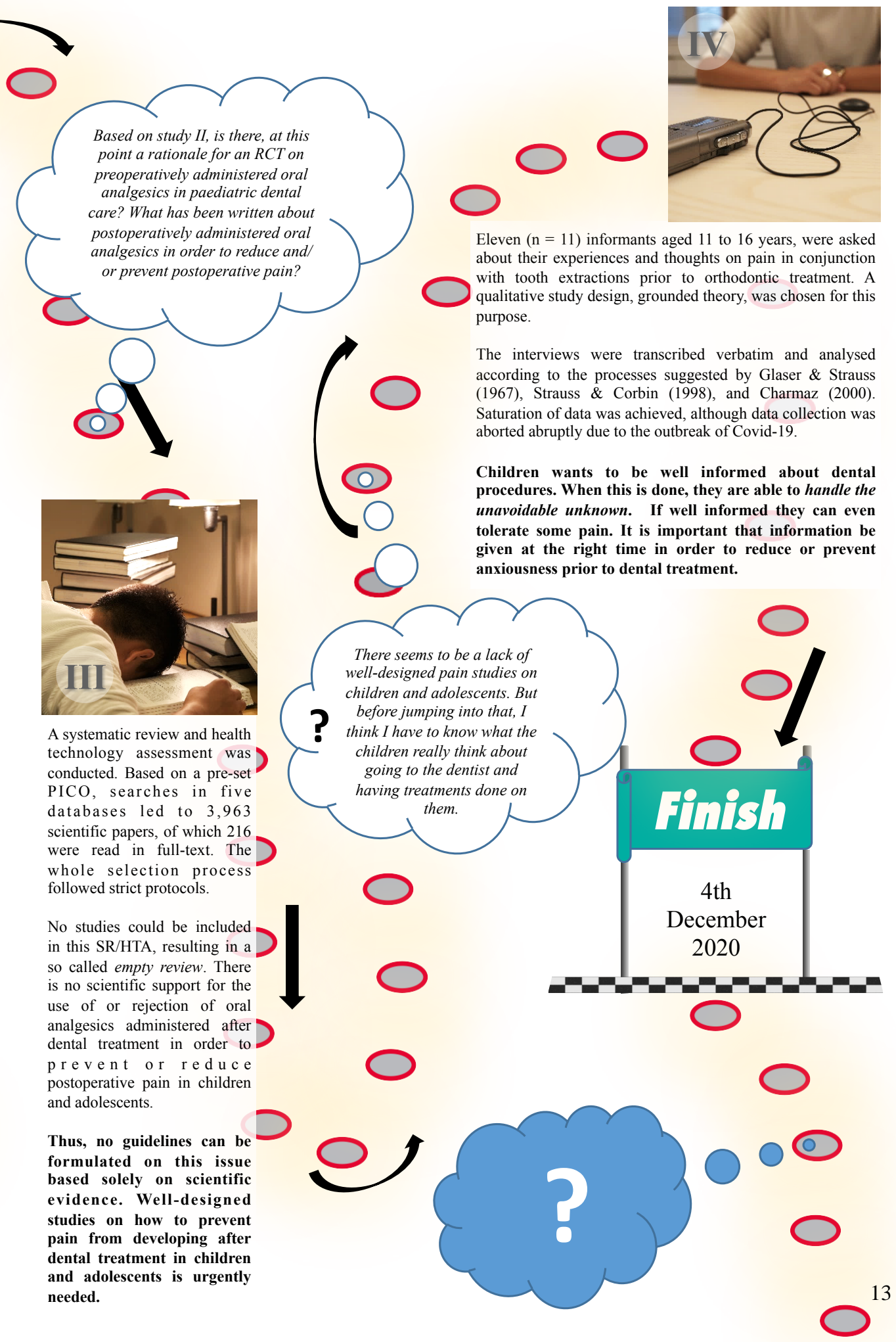




\section{DEFINITIONS AND ABBREVIATIONS}

\section{Definitions}

Analgesia '1. Absence of sensibility to pain; absence of pain on noxious stimulation. 2 . The relief of pain without loss of consciousness.' (Dorland, 2020)

Analgesic '1. Relieving pain. 2. Not sensitive to pain. 3. An agent that alleviates pain without causing loss of consciousness.' (Dorland, 2020)

Anaesthesia ' 1 . The loss of sensation, usually by damage to a nerve or receptor. 2. Loss of the ability to feel pain, caused by administration of a drug or by other medical interventions.' (Dorland, 2020)

Anaesthetic '1. Characterized by anaesthesia. 2. Producing anaesthesia. 3. A drug or agent that is used to abolish the sensation of pain.' (Dorland, 2020) 


\section{Abbreviations}

CAS Colour Analogue Scale

CFSS-DS Children's Fear Survey Schedule - Dental Subscale

CNS Central Nervous System

CHEOPS Children's Hospital of Eastern Ontario Pain Scale

DA Dental Anxiety

DBMP Dental Behaviour Management Problems

DF Dental Fear

DFA Dental Fear and Anxiety

DP Dental Phobia

FPS-R Faces Pain Scale - Revised

GDP General Dental Practitioner

GT Grounded Theory

HTA Health Technology Assessment

IASP International Association for the Study of Pain

INAHTA International Network of Agencies for Health

Technology Assessment

LA Local anaesthetic

NRS Numeric Rating Scale

NSAID Non-steroidal anti-inflammatory drug

PICO Population, Intervention, Control, Outcome

PNS Peripheral nervous system

RCT Randomized Controlled Trial

SBU Swedish Agency for Health Technology Assessment and Assessment of Social Services

SPD Specialist in Paediatric Dentistry

SCB Statistiska centralbyrån [eng. Statistics Sweden]

SR Systematic Review

GT Grounded theory

FLACC Face, Legs, Activity, Cry, Consolability

VAS Visual Analogue Scale

VAS $_{\text {PI }}$ Pain Intensity measured with VAS 


\section{ABSTRACT}

Tooth extraction is one of the most commonly performed dental treatments and there is always a risk of pain during and after this procedure. Pain is a major contributor to the development of dental fear and anxiety (DFA) and dental behaviour management problems (DBMP) in children and adolescents. These, in turn, are two of the most common reasons for referrals to specialist in paediatric dentistry. DFA and DBMP lead to reduced oral health and possibly suffering for the individual, as well as huge costs for society as a whole. It is therefore of uttermost importance that all dental treatments be performed with the aim of avoiding or minimising pain.

The aims of this thesis were to (i) investigate how and to what extent Swedish dentists (both general dental practitioners and specialists in paediatric dentistry) use different pain management strategies when treating children and adolescents, (ii) explain the natural course of pain after uncomplicated bilateral extractions of maxillary premolars in children between the ages of 10 and 15, (iii) systematically evaluate the effect of postoperatively administered over-the-counter oral analgesics as a means to minimise postoperative pain after oral surgery in children between the ages of 0 and 18, and finally (iv) gain greater insight into how children between the ages of 10 and 16 perceive the whole process of tooth extraction (during the procedure and after extraction) as part of orthodontic treatment.

In the first study, a postal survey was sent to all active general dental practitioners (GDPs) in Skåne County, and to all specialists in paediatric dentistry (SPDs) in Sweden. The main findings were that pain manage- 
ment strategies differ between the two groups; in addition, GDPs used different strategies depending on whether primary or permanent teeth were being treated. In general, the survey found an underuse of local anaesthesia by general dentists. This calls for guidelines on pain management strategies in paediatric dental care. In the second study, pain intensity was measured at 14 different time points after tooth extraction performed prior to orthodontic treatment, in a sample of 31 children 10 to 15 years of age. Pain intensity after extraction of an upper tooth was generally mild to moderate. The natural course of pain intensity followed the same pattern regardless of how the data were analysed. Pain peaked at 2 hours after treatment, then decreasing rapidly until the next measurement that took place 4 hours after treatment. There was no difference between the first and second extraction, indicating that this model is an excellent one for further research on pain management strategies, with no carryover effect. The third study was a systematic review (SR) and health technology assessment (HTA). A systematic review regarding preoperatively administered oral analgesics has been previously published, but it does not present any scientific evidence showing their administration as providing additional pain relief in children after dental treatment. An SR/HTA looked at postoperatively administered oral analgesics with the goal of minimising postoperative pain after oral surgical therapies in children. This SR/HTA yielded an empty review. As of today, there is no scientific evidence for the effectiveness of the administration of oral analgesics postoperatively in order to minimise postoperative pain after oral surgical therapies in children aged 0-18 years. Neither is there any evidence to reject this strategy. This highlights the need for well-designed primary studies on this topic. In the fourth and final study of this thesis, children's perception of tooth extraction and the postoperative period was investigated in order to better understand the child's perspective regarding this treatment. A qualitative research approach, using grounded theory, was used. Although the subjects were a bit anxious before the procedure, they all managed to handle the treatment using different types of coping strategies. One central theme that emerged from analysing the interviews was the importance of getting proper information from dental staff, at the right time. Children who received adequate information were able to withstand some pain and 
discomfort. Having some form of control over the situation also emerged as a coping strategy.

\section{Conclusions}

Among Swedish dentists (both GDPs and SPDs), there seems to be uncertainty regarding pain management strategies in children and adolescents in terms of the use of local anaesthetics and oral analgesics. There are differences in pain management strategies between GDPs and SPDs.

The majority of the participants perceived pain intensity after tooth extraction due to orthodontic indication to be mild to moderate.

These types of extractions can serve as a good model for future pain research.

The amount of pain research on paediatric populations in dentistry is scarce. We need more well-designed primary studies before guidelines on pain management strategies for paediatric dental care can be formulated.

When given proper and honest information at the right time, children are able to cope with dental treatments, even if they are a bit anxious beforehand and even if they perceive pain or discomfort during and after treatment. 


\section{POPULÄRVETENSKAPLIG SAMMANFATTNING}

Tandutdragning är en av de vanligaste behandlingarna inom tandvården. Det finns alltid en risk att smärta uppstår i samband med denna behandling. Smärta är en av vanligaste orsakerna till att tandvårdsrädsla (eng. Dental Fear and Anxiety (DFA)) och dentalt relaterade behandlingssvårigheter (eng. Dental Behaviour Management Problems (DBMP)) bland barn och ungdomar. Detta är i sin tur några av de vanligaste skälen till att barn remitteras till specialist $\mathrm{i}$ barn- och ungdomstandvård. DFA och BMP leder till försämrad oral hälsa och potentiellt lidande för patienten samt till stora kostnader för samhället i stort. Det är därför av yttersta vikt att all tandbehandling utförs med målet att vara så smärtfri som möjligt.

Målen var att (i) undersöka hur och i vilken utsträckning svenska tandläkare (både allmäntandläkare och specialister i barn- och ungdomstandvård) använder sig av olika smärtbehandlande terapier då de behandlar barn och ungdomar, (ii) beskriva smärtans naturalförlopp under och efter okomplicerad tandutdragning utförts på båda sidor i överkäken på 10-15-åringar, (iii) systematiskt utvärdera effekten av oral analgetika som administreras direkt efter tandbehandling i syfte att förebygga/reducera postoperativ smärta efter oralkirurgiska ingrepp på barn i åldrarna 0 till 18 år, och slutligen (iv) få ökad insikt om hur barn, i åldrarna 10-16 år, upplever hela processen kring tandutdragning på grund av förestående ortodontisk behandling.

I första studien skickades en enkät per post till alla aktiva allmäntandläkare i Region Skåne samt till alla specialister inom pedodonti (barnoch ungdomstandvård) i Sverige. Huvudresultaten var att smärtbehand- 
lingsprinciperna skiljer sig mellan de två grupperna, och inom allmäntandläkargruppen skiljer det sig också mellan då de behandlar primära och permanenta tänder. Det är också ett underanvändande av lokalanestesi inom allmäntandvården. Detta pekar på behovet av riktlinjer för smärtbehandling inom barntandvården. I den andra studien mättes smärtintensiteten vid 14 olika tidpunkter, under och efter tandutdragning som utförts på ortodontisk indikation på 31 barn, 10 till 15 år gamla. Smärtintensiteten efter tandutdragning i överkäken rapporterades vara mild till moderat generellt sett. Smärtans naturalförlopp följde samma mönster oavsett hur data delades in. Smärtan peakade vid 2 timmar efter tandutdragning för att sedan snabbt minska till nästa mättillfälle, 4 timmar efter tandbehandling. Det var ingen skillnad i smärtintensitet mellan första tandutdragningen och andra tandutdragningen. Detta visar att detta är en bra modell för fortsatta smärtstudier då ingen carry-over effekt föreligger. Tredje studien är en systematisk översiktsartikel (SR) och health technology assessment (HTA). Det har tidigare publicerats systematisk översiktsartikel angående preoperativt administrerad oral analgetika, vilken visade på inget vetenskapligt stöd för att det skulle vara fördelaktigt för den postoperativa smärtbilden. En SR och HTA utfördes angående postoperativt administrerad oral analgetika med syftet att reducera/förhindra postoperativ smärta från att uppstå efter oralkirurgiska ingrepp på barn. Denna SR/HTA föll ut som en tom review, dvs inga artiklar kunde inkluderas. Till dags dato finns det alltså inget vetenskapligt stöd för effekten av postoperativt administrerad oral analgetika, med syfte att reducera/förhindra uppkomst av postoperativ smärta efter oralkirurgiska ingrepp på barn 0-18 år. Det finns å andra sidan inte heller något som talar emot ovan nämnda ingrepp. Detta pekar på ett skriande behov av primärstudier inom detta område. I fjärde och sista delarbetet $\mathrm{i}$ denna avhandling undersöktes barns upplevelser av tandutdragning och den postoperativa perioden med syfte att bättre förstå deras perspektiv på denna behandling. En kvalitativ forskningsansats där metoden grundad teori (eng. grounded theory) användes. Trots viss oro inför behandlingen, så klarade alla deltagare att hantera behandlingen genom att använda olika coping-strategier. Ett centralt tema framträdde då intervjuerna analyserades - att få korrekt information från tandvårdspersonalen vid rätt tidpunkt. Om detta gavs klarade barnet av att hantera 
visst mått av smärta och obehag. Att få känslan av att ha kontroll i behandlingssituationen framträdde också som en coping-strategi.

\section{Konklusioner}

Bland svenska tandläkare (allmäntandläkare och specialister i barn- och ungdomstandvård) förefaller det finnas en viss osäkerhet kring smärtbehandlande strategier vid behandling av barn och ungdomar gällande användande av lokalanestesi och rekommendation av oral analgetika. Det finns skillnader i omhändertagande mellan allmäntandläkare och specialister i barn- och ungdomstandvård.

Smärtintensiteten efter tandutdragning upplevs överlag som mild till moderat bland flertalet av deltagarna. Tandutdragning som ett led i tandregleringsbehandling är en bra modell för framtida smärtstudier.

Omfattningen smärtstudier på barn- och ungdomar är skral. Det finns ett stort behov av väldesignade primärstudier innan riktlinjer kring smärtbehandling inom barntandvård kan utformas.

Med uppriktig och korrekt information, given vid rätt tidpunkt, kan barn hantera tandbehandlingar även om de är lite oroliga inför behandling och upplever smärta/obehag under och efter tandbehandling. 


\section{INTRODUCTION}

\section{Background}

In Sweden, dental care is free of charge for all individuals from birth until December 31 of the year they turn 23 years old (amendment of regulation dated 1 January 2019). Previously, the upper age limit for free dental care was 19 , which is still the upper age for referring patients to a paediatric specialist dental clinic. Sweden had a total population of $10,327,859$ at 31 December 2019, of whom 2,403,730 were 19 years of age or younger (23.3\%; www.scb.se). In 2008, the number of referrals corresponded to $0.8 \%$ of the child population aged $0-19$ years (Klingberg et al., 2010). Of these, $27 \%$ were referred due to DFA/DBMP (Klingberg et al., 2010). Extrapolated to the current population of children ages 0 to 19 , we find that 19,230 individuals would be expected to be referred to a paediatric dental specialist today. Of these, 5,192 suffer from dental fear and anxiety (DFA) or dental behaviour management problems (DBMP), often due to a history of pain during dental treatment (Klingberg \& Broberg, 2007). Therefore, it is crucial that pain during treatment be minimised to the greatest possible extent among paediatric patients.

Even though tooth extraction is one of the most frequently performed oral surgeries (Al-Khateeb \& Alnahar, 2008; Ghanei et al., 2018), little attention has been paid to the prevalence of pain during and after this treatment in children and adolescents. Most studies have focused on the outcome after surgical removal of impacted third molars or the effect of 
different pharmaceutical agents to reduce postoperative pain after such molar extractions in adults (Al-Khateeb \& Alnahar, 2008).

Historically, children were thought to be able to withstand pain and discomfort better than adults, since it was thought that children's immature nervous systems meant they did not feel pain the same way as adults (Rey, 1993). Today this has been shown to be totally erroneous (Anand \& Hickey, 1987). It has also been said, falsely, that young children do not have any memory of pain and therefore do not suffer long-lasting effects from experiencing pain (Johnston et al., 2003; McGrath, 2005). Today we know that it is especially important to minimise pain in children and adolescents, given the knowledge that the perception and understanding of pain are already established in young children (Rasmussen et al., 2005; Young, 2005). Research has since refuted all these myths. Indeed, children can feel as much pain as adults do and might suffer even more because they cannot rationalise and cope with pain as well as adults do. Moreover, the descending inhibitory pain controls of the nervous system are not fully developed and continue to mature throughout childhood and well into adolescence (Oakes, 2011; Twycross \& Williams, 2013; London et al., 2014).

Painful medical or dental experiences, along with minor everyday pain experiences such as bumps and falls, are likely to play a significant role in shaping individuals' experience of pain in future events (Young, 2005). For example, research has shown that boys who received an immunisation at 4-5 months were reported as experiencing more pain if they had been circumcised without any local anaesthetic versus those who had not been circumcised or had undergone the procedure with analgesics (Taddio et al., 1997). Thus, pain is harmful and should be avoided, especially in children (Olsson \& Lundeberg, 2019).

\section{Pain}

One current definition of pain is '[a]n unpleasant sensory and emotional experience with actual or potential tissue damage, or described in terms of such damage' (IASP Subcommittee on Taxonomy). Another newly proposed definition is '[a]n aversive sensory and emotional experience typically caused by, or resembling that caused by, actual or potential tissue injury' (Raja et al., 2020). This change in definition is due to the 
wording of the previous definition, which excluded infants, elderly, and others - even animals - unable to verbally express pain (IASP, 2017).

No matter which definition is accepted in the future, pain is, by nature, subjective. Each individual learns the association of the word through experiences related to injury in early life. Pain is, without doubt, based on sensation in a part of the body. With this comes a feeling of unpleasantness, which also makes it an emotional experience. Events that resembles pain but are not unpleasant should not be called pain. If a patient reports pain but there is no obvious tissue damage or any likely pathophysiological cause, the origin is usually psychological. In these cases, there is usually no way, based on the subjective report, to separate their experience from one caused by actual tissue damage. Hence, if they experience an event as painful and they report it in the same manner as pain caused by tissue damage, it should be accepted as pain. Thus, the definition is not tied to the stimulus. The other aspect of this is that activity that is induced in the nociceptor or nociceptive pathways by a noxious stimulus, is not to be considered as pain per definition, since pain is always connected to a psychological state. One other important note on this is that the inability to communicate verbally does not negate the possibility that an individual is experiencing pain and is in need of appropriate pain-relieving treatment. (IASP, 2017). Pain can be categorized in many different ways (IASP, 2017) and is a complex phenomenon. In Sweden, pain has traditionally been divided into four different types: nociceptive pain, neuropathic pain, psychogenic pain, and idiopathic pain. Pain is also commonly classified into nociceptive pain, inflammatory pain, and neuropathic pain. Clinical contexts use a simpler classification: nociceptive pain versus neuropathic pain (Persson, 2016). It is also important to distinguish between nociception and pain, where the former is a neuro-biological process involving activation of nociceptors. Nociception can occur without pain. Pain, however, is a subjective, whole experience. Pain encompasses different qualities, including sensory-discriminative, emotional-affective, and cognitive-evaluation properties. Pain can be described in different ways: by intensity (mild, moderate or severe), quality (sharp, burning or dull), referral (superficial or deep, localized or diffuse) and duration (transient, intermittent or persistent). The emotional aspect is described using adjectives such as excruciating, frightening or horrible, and, finally, the cognitive component 
results in a global assessment of the pain, such as irritating, disturbing or unbearable (Bäckryd \& Werner, 2019).

Although pain is unpleasant, it serves important purposes for the body: it both acts as a warning signal of disease or tissue damage and prompts responses (e.g. withdrawal from the source of pain) that aim to protect the body from further harm (Huguet et al., 2010; Twycross \& Williams, 2013).

In the context of paediatric dentistry, acute pain can occur in association with dental procedures (e.g., tooth extractions), injury (e.g., tooth fracture/trauma) or disease (e.g., toothache due to deep caries lesions) (Manworren \& Stinson, 2016). Research has revealed that almost 25\% of five-year-olds have experienced dental-related pain (Hosey et al., 2012).

Some authors (e.g., Nutter, 2010) differentiate the terms acute pain and procedural pain, while others (Jain, 2012) include procedural pain in the overall concept of acute pain. Procedural pain is pain related to an intervention: for example, in the course of medical or dental procedures (McGrath \& DeVeber, 1986; Zeltzer et al., 1989; Yaster et al., 1997; Young, 2005; Olsson, 2019). This type of pain requires special attention. It is also among the most difficult forms of pain to deal with by both the patient experiencing it and the health care professionals who must inflict it. Dental procedures such as the injection of local anaesthetics can lead to different pain reactions for different patients. It is important that dentists do not make the mistake of assuming they can predict the amount of pain a patient will experience during a given intervention; rather, this depends on intrapersonal factors such as level of dental fear and anxiety, previous experiences, temperament, cognitive development and maturity. Interpersonal factors also play a role: for example, how dental staff or parents behave and communicate (or if parents are present at all), and whether a calming and reassuring atmosphere has been created. Successful pain management and treatment depend on communication. Dentists can choose from an array of pain management techniques, both pharmacological and nonpharmacological. The choice depends on the dentist's professional knowledge and skills in judgment. Of course, this choice can also be influenced by 'common practice' in clinical settings. Successful communication and pain management is critical for the success of current and 
future dental appointments (Versloot \& Craig, 2009; Jain, 2012; Klingberg \& Arnrup, 2017; Uhl et al., 2019).

\section{The Physiology of Pain}

Anatomically, the human nervous system is divided into two circuits the central nervous system (CNS), consisting of the brain and the spinal cord, and the peripheral nervous system (PNS) that includes the sensory neurons that link sensory receptors on the body surface or deeper within it with relevant processing circuits in the CNS. PNS includes also a motor portion that consists of two parts - the somatic motor division and autonomic motor division (Purves et al., 2018). Focus will however be on the sensory parts of PNS and CNS. It is the sensory part of PNS, which manages inputs from a variety of somatic modalities, including touch, proprioception, thermoreception and nociception (i.e. harmful/painful stimuli). The sensory system's job is to transmit information about the outer and inner environment to the CNS. The nervous system is dependent on communication between nerve cells, each of which consists of a cell body, dendrites and axons (Purves et al., 2018). These sensory nerve fibres terminate in specific pain receptors called nociceptors. These can be found in numerous types of somatic tissue around the body (including the skin, corneas, mucous membranes, bones, and tooth pulp), as well as in visceral organs such as the gastrointestinal tract.

Mechanical, chemical or thermal stimuli can all activate the nociceptors. These nociceptors are not uniformly sensitive, and receptor sites will only be activated by a stimulus (mechanical, chemical, or thermal) sufficiently strong enough to surpass a threshold. Nociceptors require strong stimuli to become activated compared to tactile receptors. Nociceptors can also have specific sensitivity to thermal, mechanical or chemical stimuli (Norrbrink \& Lundeberg, 2012; Purves et al., 2018). When at rest, the interior of the sensory receptor is negatively charged compared to the outer environment. This is due to an excess of negatively charged ions inside the cell membrane compared to outside the membrane, where there are more positively charged ions. The difference is called resting potential and is about $-70 \mathrm{mV}$. When a receptor is stimulated, a depolarization occurs, and when the resting potential reaches -55 
$\mathrm{mV}$, a cascade of changes takes place and an action potential is created (Norrbrink \& Lundeberg, 2012; Purves et al., 2018). Tissue damage also unleashes a number of events in the peripheral and central pain pathways. Pain-promoting substances (bradykinin, serotonin, prostaglandin, substance $\mathrm{P}$, or histamines) from the peripheral nerve endings and extraneural sources lead to a sensitization of the nociceptors, which creates impulses towards the CSN. The spinal cord contains a specific type of neuron that is activated by these impulses. This activation leads to an alteration in the responsiveness of these neurons, which then results in an amplification of the signals from $\mathrm{A} \delta$ - and C-fibres. Pain memory is a type of central sensitization, which means that there is an up-regulation of incoming pain signals when they reach the CNS (Woolf \& Salter, 2000).

There are four major processes involved in the registration of pain: transduction, transmission, modulation, and perception. Transduction is the process whereby tissue-damaging stimuli activate nerve endings. Transmission is the relay function, whereby the message is carried from the site of tissue injury to the brain regions underlying perception. Modulation is a neural process that acts specifically to reduce activity in the transmission system. Perception is the subjective awareness produced by sensory signals. It involves the integration of many sensory messages into a coherent and meaningful whole. Perception is a complex function of several processes, including attention, expectation, and interpretation. The three first processes are associated with neural processes that can be studied objectively using methods that involve direct observation. This is not possible for perception, which is subjective and therefore cannot be measured objectively. The nociceptive message is transmitted from the PNS to the CNS by the axon of the primary afferent nociceptor. This neuron has its cell body in the central dorsal root ganglion, and through a lengthy process the axon divides and sends one branch out to the periphery and one to the spinal cord. Primary afferent nociceptors transmit impulses to the spinal cord. If the impulses derive from the head, however, the spinal cord is not involved. Rather, the signal is transmitted into the medulla oblongata of the brain stem (Osterweis et al., 1987). Pain from the orofacial region is transmitted through cranial nerve $\mathrm{V}$ (trigeminal nerve). The maxillary teeth are innervated by branches from the superior alveolar nerves, and the inferior alveolar nerves innervate the 
mandibular teeth. When nociceptive signals arise from these areas, the first-order neurons are triggered, and the signal is transported along the central processes of the nerve, which enter the pons. When they enter the brain stem, they turn caudally and descend within the brain stem, where the signals are referred to the second-order neurons (WilsonPauwels, 2010). From there the signal is sent up to the thalamus and finally to different areas of the brain. The brain does not seem to have a specific 'pain centre'; rather, pain perception is the sum of activity in several areas in the brain. Activity in the somatosensory cortex, S1 (primary) and SII (secondary) handles sensory-discriminative information, whilst IC (insular cortex) and ACC (anterior cingulate cortex) mediates affective-motivational information (Norrbrink \& Lundeberg, 2012; Persson, 2016; see Figure 1).

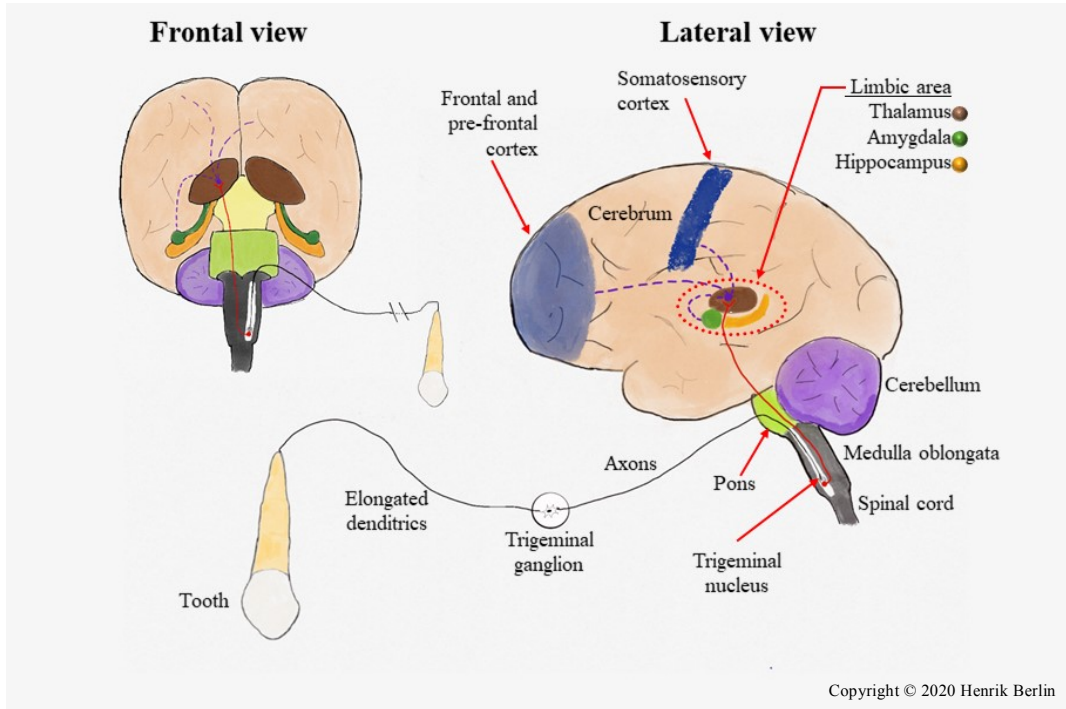

Figure 1. Schematic illustration of the pathway of pain from tooth to different areas in the brain. 


\section{Dental fear and anxiety}

Fear is an expected experience and is consistent with normal child and adolescent development. However, fear and anxiety become a problem that might need intervention when they are disproportionate to the actual threat and daily functioning becomes impaired. Anxiety is a multidimensional construct that consists of somatic, cognitive and emotional elements (Kendall, 2006). Dental fear (DF) is an emotionally normal reaction to one or more specific threatening stimuli in the dental situation. Dental anxiety (DA) represents a state of apprehension that something dreadful is going to happen in relation to dental treatment and includes a sense of loss of control (Klingberg \& Broberg, 2007). Dental phobia (DP) is a severe type of DA and is characterized by marked and persistent anxiety in relation either to clearly obvious situations/objects (such as drilling, injections) or to the dental situation in general (Klingberg \& Broberg, 2007). The concepts of DF and DA are often used interchangeably in the dental literature, but the term dental fear and anxiety (DFA) is used when referring to strong negative feelings associated with dental treatment in children and adolescents, whether or not the diagnostic criteria for dental phobia are met (Klingberg \& Broberg, 2007).

The dental setting is a common example of a potent fear-provoking situation that children often encounter early in life when they are especially vulnerable. The risk of developing DFA is present throughout all stages of childhood and adolescence, due to insecurity, discomfort and pain caused by dental interventions. Traumatic and painful dental treatment experienced early in childhood has been identified as a factor associated with the development of DFA. This, in turn, can influence patients' views toward dental care in adulthood (Arnrup et al., 2002; Gustafsson et al., 2007; Ten Berge et al., 2002; Berggren \& Meynert, 1984).

There are a variety of instruments to measure dental fear and anxiety. One of the most frequently used is the Children's Fear Survey Schedule - Dental Subscale (CFSS-DS) (Cuthbert \& Melamed, 1982). This instrument is available in different versions. The parental version has been tested for validity and reliability and has been shown to be both reliable and valid (Klingberg, 1994). The CFSS-DS also seems to be preferable to other instruments, such self-report measures of dental fear and anxiety in children (Aartman et al., 1998). 


\section{Dental Behaviour Management Problems}

In the developmental psychopathology literature, behaviour management problems denotes externalized behavioural problems in general. The term dental behaviour management problem (DBMP) refers specifically to behaviour management problems in dental situations; children with DBMP may or may not have behaviour management problems in other situations (Klingberg \& Broberg, 2007). DBMP is defined by the dentist's experience when treating the patient and contrasts with DFA, which describes the patient's own perception and experience. DBMP is defined as uncooperative and disruptive behaviour which leads to delay in treatment or makes treatment impossible (Klingberg et al., 1994). There are many situations in the dental setting that are demanding on and stressful for young children. They may experience a wide range of stress-evoking moments, such as unfamiliar surroundings, unfamiliar people, new sounds and tastes, strong lighting, lack of control, and apparent risk of stress, discomfort and pain. Earlier reviews (Klingberg \& Brogren, 2007) found that young children's acceptance of dental treatment increases with mental development and that some children are tolerant whilst others are more vulnerable in stressful situations. There are many different factors that play a role in this, including age, maturity and temperament. Various studies have found the prevalence of DBMP to vary between 8 and $18 \%$ in children between the ages of 4 and 11, making it a common occurrence (Holst and Crossner, 1987; Klingberg et al., 1994; Klingberg \& Broberg, 2007). DBMP is more common in children who have experienced painful treatments than in those who have little or no exposure to such treatments (Klingberg et al., 1994; Raadal et al., 2002; Young, 2005).

\section{Pain, DFA and DBMP}

Pain during dental treatments is regarded as an important concomitant factor for the development of DFA and DBMP in children and adolescents. Children with many caries lesions have been reported to be at higher risk of developing DFA due to procedural pain and other negative experiences during dental treatment (Raadal et al., 2002; Ashley et al., 2016). A 2007 review estimated the prevalence of both DFA and 
DBMP at 9\% (Klingberg \& Broberg, 2007). DFA and DBMP are also the major reasons for referral to specialists in paediatric dentistry (Klingberg et al., 2010). Thus, it is important to find ways to minimise pain during and after dental procedures. In this context, it is important to stress the use of local anaesthetic (LA) when performing invasive treatments on children. A Swedish study involving more than 4,500 children found that children who did not receive LA during restorative treatment were more likely to develop DBMP that those who did receive LA (Klingberg, 1995). This also shows the importance of delivering painfree dental care for children, since such positive experiences can 'inoculate' children against DFA, giving rise to latent inhibition (Davey, 1989). If a child has experienced repeated pain-free appointments and suddenly experience a treatment that involves pain or discomfort, latent inhibition might protect them from developing DFA/DBMP (Davey, 1989). Latent inhibition is a strong argument for providing regular dental visits and care to all children, with a focus on maintaining good oral health.

It is not easy to distinguish between DFA and DBMP in the clinical setting. A dentist is not likely to overlook a child that presents dental behaviour management problems. However, fearful children can sometimes be overlooked. They may not always cry, avoid eye contact, act out, or distance themselves from the interaction. Sometimes fearful patients become more passive and silent during treatment. The latter responses increase the risk that dental personnel might overlook the patient's anxiety. This might, in turn, increase the risk of unintentionally harming the child (Klingberg \& Arnrup, 2017).

Dental fear in children is associated with missed dental appointments and more caries on tooth surfaces. The relationship between DFA and DBMP is elusive, since dental fear is discovered in only one out of four children with DBMP, whilst fear is expressed by uncooperativeness in just over $60 \%$ of the children with dental fear (Klingberg et al., 1995; see Figure 2).

Versloot et al. (2008) showed a correlation between dental anxiety and self-reported pain during injection of LA. Young children $(<6$ years of age) who are highly anxious reported more pain after injection than children with lower levels of anxiety. Older children (ages 6-11) reported higher pain scores if they had previously had a dental injection, com- 
pared to those who had never experienced one. In addition, Krekmanova et al. (2009) showed a relation between dental anxiety and the perception of pain.

Pain, distress and anxiety are the most likely causes of the development of a pain memory (Rocha et al., 2009). Children who undergo repeated painful procedures develop a pain memory that makes it easier for them to recognize painful stimuli in the future. It is known that repeated painful childhood procedures, if not addressed, lead to pain sensitization and more pain experiences in adulthood (Bradley \& McKendree-Smith, 2002; Rocha et al., 2009). The goal of pain-reducing interventions used in conjunction with medical or surgical procedures is to improve well-being, functioning and the ability to cope with the examination or treatment in question (von Baeyer et al., 2004).

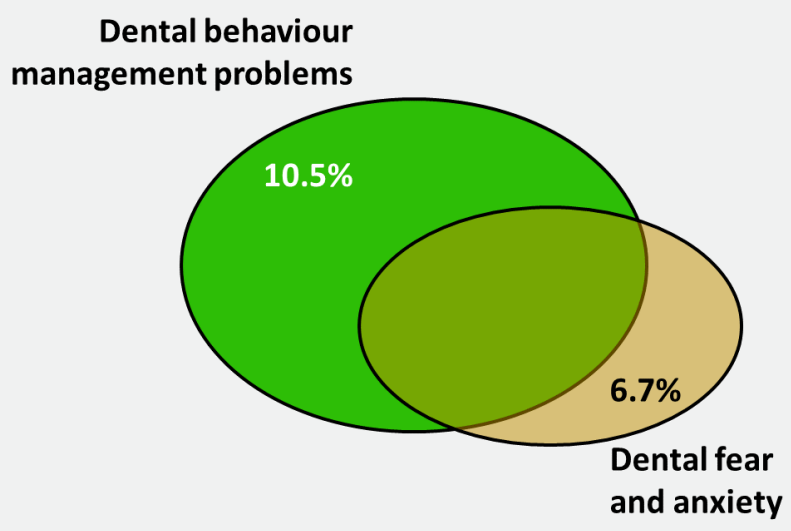

Figure 2. The relationship between dental fear and anxiety (DFA) and dental behaviour management problems (DBMP) (drawing adapted from Klingberg et al., 1995). Of the children with DBMP (10.5\%), 27\% also suffered from DFA, and among the children with DFA (6.7\%), 61\% also displayed DBMP.

Pain is a common reason for the development of DFA (Klingberg \& Broberg, 2007). DFA and/or DBMP, in combination with the need for dental treatment, are still the most common reasons for referral to spe- 
cialist in paediatric dentistry (Klingberg et al., 2010). In the 1980s, this group of patients made up $46 \%$ of referrals, but its share has then gradually decreased since then. The latest data on this topic are from 2008, when $27 \%$ of referrals were due to DFA/DBMP (Klingberg et al., 2010). Pain or discomfort during dental treatment occurs in one-third of all treatment occasions (Ghanei et al., 2018). The main reason for pain was injection of local anaesthesia prior to extraction. During restorative treatment, drilling was the most common cause of pain. Therefore, it is crucial that the dentist try to minimize pain and discomfort by introducing and performing pain-free, effective dental injections (Ghanei et al., 2018).

The number of referrals has increased over the years (Klingberg et al., 2010). This can be attributed to greater awareness among GDPs (Klingberg et al., 2010). Despite this, reports show dentists are uncertain regarding pain management for children (Wondimu \& Dahllöf, 2005; Rasmussen et al., 2005).

DFA and DMBP are multifactorial and complex in their aetiology. Three main classes of causes have been identified: personal, parental/family, and dental team (Klingberg \& Arnrup, 2017; see Figure 3). One important personal factor in the development of DFA and DBMP is the age of the child. Younger children are more likely to present DFA/DBMP, which is influenced by the child's psychological development and therefore their ability to cope with dental treatment (Klingberg \& Broberg, 2007). Temperament is another personal trait that is apparent from birth and that affects how children respond to and take on different tasks they are presented with in their surroundings. Temperament can be divided into three different groups. In one classic study (Thomas et al., 1963), the majority of children were labelled as easy (40\%), while $10 \%$ were labelled difficult and $15 \%$ slow to warm up. One-third were considered to have a mix of these three temperaments. It appears that to some degree, these different traits may be an indicator of which individuals will develop DFA and/or DBMP; however, the strongest predictor of dental anxiety is gender and reported painful or unpleasant dental treatments (Stenebrand et al., 2013). Children presenting DBMP can be divided into subgroups: children with high dental and general fear, children with fear combined with an inhibited temperamental profile (shyness, negative emotionality, etc.) and children with less-pronounced fear 
combined with impulsiveness and acting-out behaviour (Arnrup et al., 2002, Arnrup et al., 2007). Labelled something as a temperament trait does not, however, dictate how a given child will react in certain situations due to 'goodness of fit' (Chess \& Thomas, 1999). This describes how the innate temperament trait affects continuing development differently depending on how the environment/society around the child meets the child. The better that parents or other adults with close relationships to a child can adapt to that child's specific traits (in an age-appropriate way), the less impact temperament has on that child's development (Broberg et al., 2003).

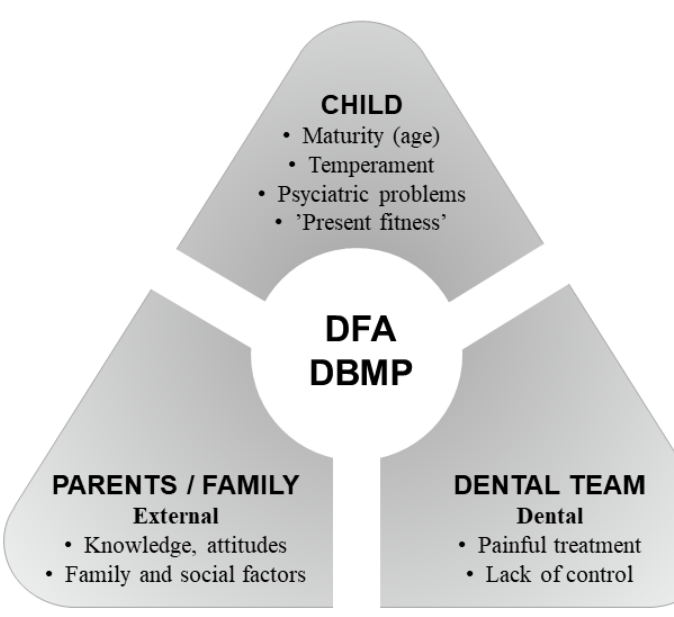

Figure 3. Dental behaviour management problems and dental fear and anxiety can be related to different factors (Klingberg \& Arnrup, 2017).

\section{Child psychological development and the communication of pain}

Working with children and adolescents requires serving the needs of a very diverse group, from pre-verbal young children to articulate adolescents on the verge to adulthood. As children grow up they undergo remarkable cognitive, emotional and behavioural development. This, of 
course, affects how they handle their pain experiences and communicate them with others.

Children's development is not easy to describe in a few words. It consists of various components that all interact with each other. Human life is produced by the interaction and modification of three major systems: biological, psychological and social. Changes in one of the systems generally lead to changes in the others as well. This introduction focuses on the cognitive and psychological aspects of child development. Children's cognitive abilities affect how they perceive, understand, report and remember pain. Their understanding of pain is hypothesized to follow a sequence of stages similar to the general cognitive sequence described by Piaget (Harbeck \& Peterson, 1992). Piaget describes child development as consisting of four different stages: (i) the sensorimotor stage ( 0 to 24 months of age), (ii) the preoperational stage ( 24 months to 6 years of age), (iii) the concrete operations stage (6 to 12 years of age), and (iv) the formal operational stage (older than 12 years of age) (Piaget \& Inhelder, 1969; Bee \& Boyd, 2014). Pain is communicated in widely different ways at different stages, from the preoperational stage when pain can be assumed to be described in terms of global, phenomenological emotions such as 'sad', 'mad', etc., to the final, formal operational stage, when children can express themselves using sophisticated psychological and physiological concepts to describe their pain. At this point, children can also understand why pain hurts and explain its value. Between these stages there is, of course, a gradual improvement in children's understanding of pain (Harbeck \& Peterson, 1992). Piaget's four stages of cognitive development have influenced our understanding of the cognitive and reasoning capacities of children and adolescents tremendously. Children's current developmental stage affects their ability to understand and interact with their surroundings, as well as their ability to communicate their perception of pain (Hwang \& Frisén, 2005; Broberg \& Klingberg, 2017).

Most preschoolers, around the age of two years, can communicate the presence of pain, and they gradually develop the ability to differentiate pain intensity in simple terms, such as 'none', 'a little', and 'a lot' when they reach the age of three to four (McGrath, 2005; Jain, 2012). However, such young children cannot fully comprehend the cause and meaning of pain, which is why they might exhibit irrational fear and resistance in 
painful situations. They also have limited self-control and coping skills, which can lead to loud crying and screaming in the presence of pain (Oakes, 2011; Jacob, 2013; London et al., 2014).

At the age of five or six, children can normally differentiate a broader range of pain intensities and are able to make use of pain scales that employ simple intervals of 4-5 items (Jain, 2012; McGrath, 2015). Children at this age have also developed additional verbal skills, but they still lack an understanding of pain and why some painful procedures might be necessary for their health (Jacob, 2013; London et al., 2014). When children reach school age (7-12 years of age), they have an improved understanding numbers and therefore can be introduced to more complex selfreporting tools. At this point, pain questionnaires can be used. Even if their verbal skills have developed immensely, it is important not to forget that grade-school children still lack the verbal skills of an adult (Jain, 2012). Their understanding of pain is gradually maturing, in conjunction with better control over their behaviour and better use of coping strategies. These advancements can, however, crumble under the influence of stress and anxiety (Oakes, 2011; Jacob, 2013; London et al., 2014).

As the individual reaches adolescence, their abstract thinking and reasoning, including problem-solving skills, gradually improve. This is accompanied by enhanced self-awareness and self-consciousness, which sometimes leads them to act 'brave' and minimize pain, especially in front of peers, if they think it is socially expected to do so. Stressful episodes - for example, pain experiences - can cause children and adolescents to regress to more-childlike behaviour and reasoning (Oakes, 2011; Jain, 2012). In contrast with younger children, adolescents are better able to understand and accept the cause of pain and the need for medical procedures. They are also less prone to protest vocally and resist care. Their ability to give sophisticated descriptions of their pain experience is well developed (Jacob, 2013; London et al., 2014). In this context, it is also of great value to mention both Piaget and Vygotsky, a Russian psychologist. In order to minimise the stress of dental experiences (as it is to prevent stressful experiences in other contexts), it is important that the child be familiar with what is going to happen. Adapting to new situations is a two-part process, according to Piaget, in which assimilation and accommodation are key concepts in order to reach equilibrium. Assimilation means that new experiences are interpreted in 
terms of existing mental structures. This is, in turn, balanced with accommodation, which means a tendency to modify one's understanding of familiar structures in order to account for new dimensions of objects or events that are revealed through experience (Broberg, 2003; Hwang \& Frisén, 2005; Bee \& Boyd, 2014; Broberg \& Klingberg, 2017).

Children can learn new things through guidance from adults or moreexperienced peers: for example, a sibling. Vygotsky offered the concept of zone of proximal development. This is a form of cognitive scaffolding that bridges the gap between the level of difficulty children experience in solving a given problem on their own versus solving a problem with adult guidance or collaboration from a capable peer. Learning within the zone of proximal development sets into motion the reorganization and internalization of existing developmental competencies, which then become synthesized at a new, higher intra-mental level (Hwang \& Frisén, 2005; Bee \& Boyd, 2014; Broberg \& Klingberg, 2017).

Since pain is subjective in nature, it is perceived 'internally' and cannot easily be noticed by an external observer unless the patient communicates the feeling of pain verbally or nonverbally. The social communication model of pain (Versloot \& Craig, 2009) describes the interaction between children and their surroundings. This model is also applicable to paediatric patients experiencing toothaches or undergoing dental treatment (Jain, 2012). The model describes a series of stages between when a child experiences a physical trauma and when their pain is successfully managed. A wide range of intrapersonal and interpersonal factors influences all these steps. The model explains why the pathway from a patient's pain experience to their expression of that pain is a unique and individual process (Versloot \& Craig, 2009).

\section{Pain assessment}

Pain assessment is necessary because it is the first step in proper pain management. It is important to evaluate a patient's level of pain in order to be able to decide which actions to take to achieve pain relief. After that, the actions taken must also be assessed in order to measure the effectiveness of the chosen strategy, since patients do not react identically to specific measures (Nutter, 2010; Oakes, 2011; Twycross \& Williams, 2013; Manworren \& Stinson, 2016). 
There are numerous pain assessment scales. However, there is no one tool that is reliable and valid across all ages and types of pain (McGrath, 2005; Stinson et al., 2006; Manworren \& Stinson, 2016). Pain scales can be divided into two main categories: observational tools and self-report tools. Table 1 introduces various pain scales, some of which are explained more in detail below.

Self-report instruments are regarded as the gold standard in pain assessment, since pain is a subjective experience that can only be described by the person experiencing it. Self-report instruments are only useful with children who have reached a sufficient level of cognitive developmental to be able to accurately rate and express their pain experience. Such instruments require skills such as quantification, classification and matching in order to be able to report pain intensity (Huguet et al., 2010; Jain, 2012; London et al., 2014, Freund \& Bolick, 2019).

Table 1. Examples of pain assessment scales (adapted from Stinson et al., 2006; Huguet et al., 2010; Twycross, 2017; and Beltramini et al., 2017).

\begin{tabular}{llll}
\hline Name of Scale & Type & Suitable age & Reference \\
\hline COMFORT & Observational & $0-18$ & Ambuel et al., 1992 \\
FLACC & Observational & $0-18$ & Merkel et al., 1997 \\
CHEOPS & Observational & $1-12$ & McGrath et al., 1985 \\
$\begin{array}{l}\text { Pieces of Hurt Tool } \\
\text { Wong-Baker FACES }\end{array}$ & Self-report & $3-18$ & Hester, 1979 \\
Pain Scale & Self-report & $3-18$ & Wong \& Baker, 1988 \\
Oucher & & & \\
Faces Pain Scale - & Self-report & $3-12$ & Beyer \& Aradine, 1986 \\
$\begin{array}{l}\text { Revised } \\
\text { Visual Analogue Scale }\end{array}$ & Self-report & $4-12$ & Hicks et al., 2001 \\
Color Analogue Scale & Self-report & 6 years and older & Scott and Huskisson, 1976 \\
Numeric Rating Scale & Self-report & 7 years and older & McGrath et al., 1996 \\
\hline
\end{tabular}

Self-report instruments can be further subdivided into two types: (i) facial expression scales, and (ii) visual and numeric scales. Examples of facial expression scales are the Faces Pain Scale - Revised (Hicks et al., 2001), and the Wong-Baker Faces ${ }^{\circledR}$ scale (Wong-Baker Faces Foundation, 2018). An example of a visual/numeric scale is the Visual Analogue Scale (VAS), which has been used for nearly 100 years in both social and behavioural sciences to measure subjective phenomena such as quality of 
life, mood or stress. The VAS has also been used for pain assessment and has been shown to be valid and reliable for individuals aged 8 years and older (McGrath, 1990; McGrath et al., 1996; Bailey et al., 2012). However, some studies recommend the use of the VAS as early as 6 years of age (Castarlenas et al., 2013). The VAS uses a horizontal line measuring 100 $\mathrm{mm}$, with defined anchor endpoints: the left being 'No Pain' (0) and at the right being 'Worst Possible Pain' (100). Pain intensity is indicated by placing a mark on the line. The VAS score is then calculated by measuring the distance from the left endpoint to the mark, in millimetres.

The VAS scale can be used either horizontally or vertically, with different wording at the endpoints, and the length of the line can be varied. However, the horizontal VAS has been shown to produce a more uniform distribution (Scott \& Huskisson, 1976). It has also been shown that the wording as above gives fewer extremes compared to other possible phrases (Seymour et al., 1985). Indication of mild or moderate pain on the VAS has been proposed to be 35 and 60 , respectively (Hirschfeld \& Zernikow, 2013).

Other scales used for pain assessment in children include the Numerical Rating Scale (NRS) (Jensen et al., 1986) and the Colour Analogue Scale (CAS) (McGrath et al., 1996), among others. Figure 4a-e illustrates these scales. The Faces Pain Scale - Revised has been translated into several languages (IASP, 2018).

The NRS is similar to the VAS but uses numerical values in a stepwise fashion. The NRS is a valuable tool for older children but can also be used for children with autism spectrum disorders (Bandstra et al., 2012). There are also other ways to try to make the rating more obvious and concrete. One instrument that attempts to do so is the CAS (McGrath et al., 1996). However, studies have shown that there is no evidence that the CAS is easier to use compared to the VAS or face scales such as the FPS-R (de Tovar et al., 2010). Both the CAS and the FPS-R has been shown to be valid in children as young as 4 years old (Tsze et al., 2013). Self-reporting scales can even be used with 3-year-olds, but scales that use graphics such as the FPS-R or Wong-Baker ${ }^{\circledR}$ FACES pain scale must be used with children of this age (Nilsson, 2014).

When a child is unable to self-report their pain for some reason young age, a high level of distress or cognitive or communication impairment - observational tools must be used for pain assessment. These 
tools rate distress behaviours in children suffering from pain (crying, facial expression and body movement, etc.) and use these behaviours to measure pain indirectly. One shortcoming with these instruments is the difficulty in distinguishing pain from other behaviours arising from distress or discomfort. These behaviourally based instruments are often lower in specificity and sensitivity compared to self-reporting (Ghai et al., 2008; Oakes, 2011; Jain, 2012; Jacob, 2013). One example of an observational tool is the FLACC (Face, Legs, Activity, Cry, Consolability), which is often used to assess acute procedural and postoperative pain. This scale can be used starting in infancy and with older children who are unable to verbalise their pain using a self-report instrument for any reason. Each parameter (face, legs, activity, etc.) is scored on a scale from zero to two. Then the scores for each parameter are summed, creating a full scale ranging from zero to ten (Jain 2012; Jacob 2013; London et al., 2014), see Figure 4f.

\section{Dentists' knowledge and attitudes}

There are only a few studies that have investigated how and to what extent dentists use procedural and postoperative pain-reducing strategies (Milgrom et al., 1994; Murtomaa et al., 1996; Wondimu \& Dahllöf, 2005; Rasmussen et al., 2005; Schorer-Jensma \& Veerkamp, 2010). Wondimu \& Dahllöf (2005) queried 700 Swedish GDPs about their views on pain and various pain-reducing regimes. Rasmussen et al. (2005) performed a similar study in Denmark. Both studies found that a considerable number of GDPs did not think that children could report pain with any degree of certainty. A rather large portion of Swedish and Danish GDPs also reported that pain-free dental treatment was simply an ideal that was not achievable in practice. Wondimu \& Dahllöf (2005) concluded that there was a general underuse of LA, analgesics and sedatives when treating children and adolescents. LA use was even lower among Danish GDPs. Rasmussen et al. (2005) suggested that female practitioners were more empathetic; however, this is debatable, since the Swedish study found that female GDPs aged 41-50 years gave less importance to pain-free dental treatment (Wondimu \& Dahllöf, 2005). Studies in the United States have also evaluated pain management strategies. One reported that about one-third of dentists did not always use LA when performing fillings or extraction 
(Murtomaa et al., 1996). A Dutch study reported that SPDs used LA more often than GDPs during dental fillings in children up to 9 years of age (Schorer-Jensma \& Veerkamp, 2010).

Figure 4a-f. Different types of pain assessment scales often used in a paediatric context.

a. FPS- $R$

Faces Pain

Scale -

Revised

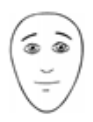

0

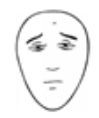

2

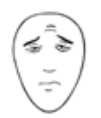

4

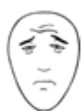

6

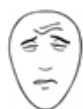

8

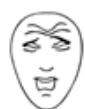

10

b. Wong-Baker FACES ${ }^{\circ}$

Pain Rating Scale
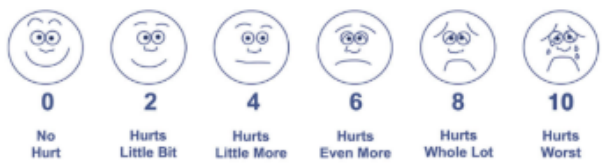

c. $\quad N R S$

(Numeric

Pain Rating

Scale)

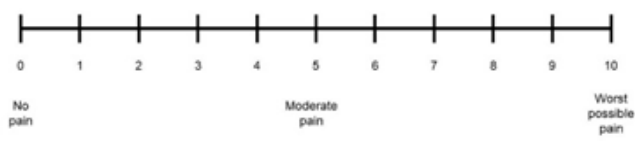

d. $V A S$

(Visual Analogue Scale)

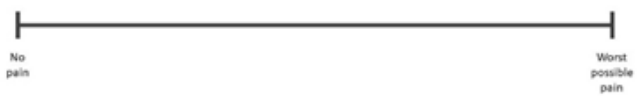

e. $C A S$

Color Analogue Scale)

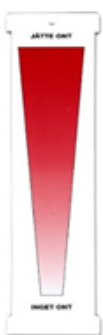

f. FLACC -

Face, Legs, Activity, Cry,

\begin{tabular}{|c|c|c|c|}
\hline Behaviour & 0 & 1 & 2 \\
\hline Face & $\begin{array}{l}\text { No particular } \\
\text { expression or smile }\end{array}$ & $\begin{array}{l}\text { Occasional grimace or } \\
\text { fown, withdrawn, } \\
\text { disinterested }\end{array}$ & $\begin{array}{l}\text { Frequent to constant quivering } \\
\text { chin, clenched jaw }\end{array}$ \\
\hline Legs & $\begin{array}{l}\text { Normal position or } \\
\text { relaxed }\end{array}$ & Uneasy, restless, tense & Kicking or legs drawn up \\
\hline Activity & $\begin{array}{l}\text { Lying quietly, nomal } \\
\text { position, moves easily }\end{array}$ & $\begin{array}{l}\text { Squiming, shifting back } \\
\text { and forth, tense }\end{array}$ & Arched, rigid or jerking \\
\hline Cry & $\begin{array}{l}\text { No cry (awake or } \\
\text { asleep) }\end{array}$ & $\begin{array}{l}\text { Moans or whimpers, } \\
\text { occasional complaing }\end{array}$ & $\begin{array}{l}\text { Crying steadily, screams, sobs, } \\
\text { fequent complaints }\end{array}$ \\
\hline Consolability & Content, relaxed & $\begin{array}{l}\text { Reassured by touching } \\
\text { hugging or being tatked } \\
\text { to, distractable }\end{array}$ & Dificuitt to console or coenfort \\
\hline
\end{tabular}


Dentists' attitudes towards children's pain perception have been investigated in an unpublished thesis by Krekmanova et al. (2017). Other than this study, the topic has not been explored in the field of dentistry. To explore this area further, Kremanov et al. (2017) used earlier research on nurses' attitudes toward and knowledge of pain management in children (Salanterä, 1999; Enskär et al., 2007) as a source to develop an instrument to be used in the dental care context. Their results led to the conclusion that this is a topic that requires further research and a questionnaire specific to dental settings that has been tested for validity and reliability, and preferable shortened without dropping crucial information.

\section{Prevention of procedural pain and postoperative pain in dental settings}

There is a risk of pain in conjunction with dental treatment, especially when LA is not used or when it does not give the expected full effect. Pain during treatment is problematic, as it increases the risk of developing dental anxiety (Klingberg \& Broberg, 2007). However, there does not seem to be any one specific pharmacological agent or injection technique that is superior to other alternatives and is therefore to be recommended (Klingberg et al., 2017).

A Cochrane review from 2012 (updated 2016) found that the scientific evidence for preoperative administration of analgesics to children and adolescents before dental treatment is insufficient to modulate postoperative pain. The review identified five original articles and concluded that there was no evidence that preoperative analgesics prior to tooth extraction or dental fillings reduce pain (Ashley et al., 2016).

The Swedish Agency for Technology Assessment and Assessment of Social Services (SBU) has stated that there is insufficient scientific evidence to determine the effect of analgesics administered before, during and after oral surgery in children and adolescents (SBU, 2012a; SBU, $2012 b$ ) and has highlighted this as an evidence gap. The definition of an evidence gap is if (i) systematic literature reviews find there is no conclusive evidence of benefits and harms, and (ii) no systematic literature reviews can be identified (SBU, 2020a; SBU, 2020b).

A review of the preoperative administration of analgesics in nondental procedures concluded that findings regarding the control of post- 
operative pain were contradictory (Campiglia et al., 2010). Some studies failed to show any beneficial effect of preoperative analgesia in controlling postoperative pain, while others reported benefits from preoperative analgesia on both postoperative pain control and the consumption of postoperative analgesics.

Another interesting way to reduce pain is preoperative administration of analgesics as an adjunct to local anaesthesia, a technique that has the potential to reduce both intraoperative and postoperative pain (Ashley et al., 2016). Theoretically, preoperative administration of analgesics could be a measure in order to prevent pain in several different ways. The rationale for using preoperative analgesics is to inhibit nociceptive mechanisms before they are triggered. There are three goals in the preoperative administration of analgesics: (i) reduce pain caused by inflammation related to the surgical incision, (ii) block the CNS's pain memory response (i.e., a central sensitization that may outlast the stimuli that triggered the alterations in the first place), and (iii) control postoperative pain so that chronic pain can be avoided (Campiglia et al., 2010). Both paracetamol and ibuprofen (the latter being an example of an NSAID (Non-steroidal anti-inflammatory drug)) have an effect on the central nervous system (Werner, 2019).

When a cell wall is disturbed - for example, by inflammation or trauma - arachidonic acid is released from the cell membrane. Arachidonic acid, prostaglandins and thromboxanes are produced through the cyclooxygenase pathway (COX). These products are involved in causing the redness, swelling and pain associated with inflammation. The mechanism of NSAIDs inhibits the biosynthesis of prostaglandin via COX. There have been two different COX isoenzymes identified: COX1 and COX-2. Following trauma or inflammation, the amount of COX-2 increases (Litalien \& Jacqz-Aigrain, 2001; Maunuksele \& Olkkola, 2003). Paracetamol's mechanism of action is similar to that of NSAIDs, although it is a weaker analgesic than NSAIDs. Paracetamol appears to have COX-2 selectivity (Graham et al., 2013).

However, pharmacological intervention is only one aspect of pain management, since pain, as mentioned before, consists of both a physiological component and a psychological component (IASP, 2017). It is important for dentists to follow a child-centred or individual approach in their assessment and management of pain and painful procedures (Royal 
Australasian College of Physicians, 2006). This encourages children to be fully involved in the procedure and for them to have choices, make associations and communicate. Different cognitive interventions can be used to handle procedure-related pain depending on the age of the child receiving treatment. The child can be asked to think about something enjoyable or to repeat a set of positive thoughts, or they can be given age-appropriate information to prepare them for the procedure itself and the feelings associated with it. Such information equips the child with a better understanding of the procedure and why it is being performed (Royal Australasian College of Physicians, 2006).

Pain in paediatric dental care can be controlled efficiently by using LA. The success rate, however, depends on both the LA technique and the practitioner performing it. Practitioners' attitudes toward and confidence in administering LA also vary, affecting the success rate. Some dentists find it stressful to administer a mandibular block to preschool children (Rasmussen et al., 2005; Wondimu \& Dahllöf, 2005; Rønneberg et al., 2015). For some individuals receiving LA, the injection itself can be difficult to handle, which is why, for example, a topical anaesthetic is recommended prior to insertion of the needle (Taneja et al., 2020). Topical anaesthesia is extremely important in order to reduce pain during intraoral injections, and thus it should be used routinely (Haukli et al., 2017). Sometimes these measures, including providing information and using topical anaesthesia, are not sufficient for children to cope with an injection of LA. In those cases, nitrous oxide can be used as a complement, since it offers both analgesic and anxiolytic effects (Clark \& Brunick, 2015). However, its analgesic effect is poor, and it should be combined with LA for invasive procedures (Hallonsten et al., 2006; Haukali et al., 2017).

\section{Questionnaires as a sampling method}

Surveys are created and used on a daily basis by many organizations to obtain a broader understanding of specific topics. They can be used not only to broaden but also to get a deeper understanding of topics such as attitudes in a cohort. Surveys may be conducted in different formats - in person, online, by telephone or by mail, for example. Surveys can also be conducted using multiple modes for answering questions. Sometimes 
the respondents are asked to respond on a single occasion, while other surveys may ask a single individual to answer questions on repeated occasions over months or years. Although there are a wide range of methods for designing surveys, they all have much in common. They all strive to collect information on a particular question or solve a specific problem. During the last two decades, rapid technological development has changed the way respondents are contacted. Online and cellular telephone communication has undergone rapid maturation as means of collecting survey responses, resulting in new ways of answering questions (e.g., voice recognition, pre-recorded phone surveys that ask for numerical or voice-recorded responses, fillable PDFs, smartphone or tablet apps, etc.). Despite these technological developments, traditional phone and mail contacts have not disappeared and are often used in combination to maximize the potential of reaching people (Dillman et al., 2014).

With the development of new communication devices, there has been a tendency among researchers to abandon mail as a survey mode, with the explanation that people clearly prefer electronic communication in other parts of their life and are therefore unwilling to complete a paper survey and return it by mail. This has been proven to be wrong (Dillman, et al., 2014). A number of studies have shown that mail surveys can still achieve reasonable response rates of well above 50\% (Smyth et al., 2010; Olson et al., 2012; Edwards et al., 2013a; Edwards et al., 2013b). Some of these studies offered incentives, and others did not.

Healthcare professionals, in particular doctors, are considered to be a problematic population from which to collect survey data (Asch et al., 1997). Cook et al. (2009) concluded that response rates to postal surveys of healthcare professionals are low and appear to be declining. Reminders are known to improve response rates, yet only half of the studies used reminders. Although an assessment of the potential for nonresponse bias is crucial to the interpretation of study findings, such nonresponse analysis is seldom conducted. Journal readers should be very cautious about the results of any survey that does not report its response rate and discuss the possibility of non-response bias. If the scientific community wishes to have reliable and valid information from postal surveys of healthcare professionals, then a number of steps are required. Researchers should routinely conduct non-response analyses and, and if necessary, improve the analytical methods available. Research funders 
should allocate the additional resources required to conduct nonresponse analysis. Finally, journal editors should consider not publishing studies that have low response rates, especially if the studies make no attempt to understand the implications of this (Cook et al., 2009).

\section{Systematic review and health technology assessment}

The purpose of a systematic review (SR) is, according to Cochrane Handbook (Chandler et al., 2019), to 'collate evidence that fits prespecific eligibility criteria in order to answer a specific research question'. SR strives to reduce bias to a minimum by using systematic methods documented on beforehand in a protocol'. The increase in the volume of medical literature published every year has been almost avalanche-like. Therefore, SRs have become increasingly critical, and because they summarize results from all original articles within a given topic, SRs are often regarded as high-quality evidence (see Figure 5).

Patient treatment practices are often based on clinical research. Systematic reviews are a core type of such clinical research. When several similar studies (i.e. studies investigating the same research question using similar methods) have been conducted, they can be identified and analysed in a systematic review. Systematic reviews summarize existing studies and provide an overview of a specific research field. Thus, systematic reviews may have a major influence on decisions about patient care, and it is essential that such reviews be trustworthy (Hansen et al., 2019).

A Health Technology Assessment (HTA) is a multidisciplinary process that, like an SR, uses explicit methods to determine the value of a given health technology at different points in its lifecycle. The purpose of an HTA is to inform decision-making in order to promote equitableness, efficiencies and quality in healthcare systems (HTA Glossary). In contrast to SRs, HTAs consider not only scientific evidence but also the medical, social, ethical and economic implications of the development, use, and diffusion of health technologies (Rotstein \& Laupacis, 2004; INAHTA, 2019). HTAs have been described as 'the bridge between the world of research and the world of decision making' (Battista \& Hodge, 1999). 


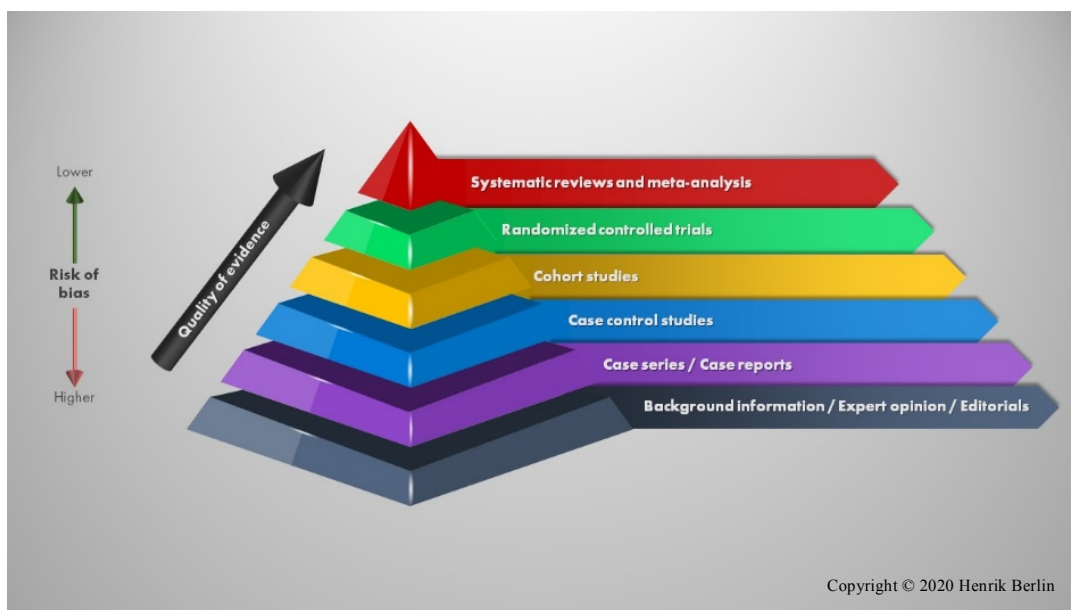

Figure 5. The evidence pyramid.

\section{Quantitative and qualitative research methods}

Medical research has been predominantly quantitative, with randomized controlled trials (RCTs) being the gold standard of medical research, and systematic reviews of RCTs considered the highest level of evidence (Ebell et al., 2004; Finkelstein, 2005) - see Figure 5. However, in the past decade there appears to have been increasing recognition that qualitative research is well suited for the field of medicine, as it can be used to develop concepts and enhance our understanding of clinicians' and patients' behaviour in their 'natural environment' (i.e., naturalism). Thus, qualitative research may be used for assessing practitioners' and patients' attitudes, beliefs, preferences and behaviours and how these change over time (Mays \& Pope, 1995). Qualitative research can be used to determine 'how' and 'why' evidence is translated into clinical practice, in comparison to 'what' evidence is translated into practice as derived from quantitative research (Green \& Britten, 1998; Kuper et al., 2008). Qualitative research is especially useful for the discovery and explanation of phenomena, compared to the usefulness of randomized controlled trials for evaluating the efficacy of an intervention, for example (Greenhalgh \& Taylor, 1997). Qualitative research may also be used in conjunction with quantitative studies to enhance the validity of findings through triangulation (Lewin et al., 2009; Creswell, 2008). 
Traditionally, quantitative methods with positivistic underpinnings dominate public health research. Ontologically, the positivistic paradigm assumes that a 'real' reality 'exists out there' and that, epistemologically, it is possible to approach this reality objectively in order to assess the 'truth'. Quantitative analyses use surveys and statistical sampling methods with high reliability to answer questions such as 'How many unhealthy, disabled years of life are lost due to premature death?' It is important that qualitative research methods be used to find the meaning behind the numbers produced in quantitative research and to improve our understanding of health concerns. Qualitative methods can be used to answer research questions that investigate the how, what and why of a given phenomenon. They are most often based on interviews or participant observation, and offer a high level of validity when answering questions such as, 'What is health and how does it vary with circumstances?' Qualitative research means different things to different people (Karlberg et al., 2002). However, Strauss and Corbin (1998) defined it as 'any type of research that produces findings not arrived at by statistical procedures or other means of quantification'. Qualitative methods rest on alternative paradigms of inquiry and basic beliefs, such as postpositivism, constructivism and participatory/cooperative paradigms (Karlberg et al., 2002).

\section{Grounded theory}

One commonly performed type of qualitative research method is grounded theory (GT). It was first presented in 1967 by the sociologists Glaser and Strauss when they published their book 'The Discover of Grounded Theory'. The book is what shifted the route of the social sciences (Charmaz, 2006), and it also became a contributor to the acceptance and legitimacy of qualitative research in applied social research (Thomas \& James, 2006). The classical original version of grounded theory (Glaser \& Strauss, 1967) describes the phenomenon under study as a main concern for the informants that has to be solved. Its ontological position is close to positivism due to its adoption that a 'real reality' that is objective and external can be discovered and described without any influence from the 'objective' researcher (Hallberg, 2006). 
In this study, the constant comparative method for grounded theory, described by Glaser \& Strauss (1967), and advanced by Strauss \& Corbin (1998), and Charmaz (2000), was used in data collection and analysis. Constant comparative method is where data already collected and categorized, is compared with new data, new codes, new theories that emerges along the process of analysing the data. The researcher reading data, codes and theories constantly redesign and reintegrate his notions as he/she reviews his material (Glaser, 1965).

The modified version of grounded theory (i.e. the development by Strauss \& Corbin, 1998), used in this study, argues that reality cannot be fully known but can always be interpreted. Strauss \& Corbin's version of grounded theory (Strauss \& Corbin, 1998) takes a more postpositivistic position, focusing on social processes (Hallberg, 2006), meaning that the observer cannot stay totally neutral and therefore imposes some shape and sense to the data. This version of GT accepts this and realizes that there is some form of interpretation by the researcher. In classical grounded theory, to be able to solve the main concern, informants use different strategies that are described in different categories. In the various versions of grounded theory, the aim is to make meaning explicit by generating concepts, models, or theories that are grounded in empirical data. The basic principles of grounded theory include theoretical sampling and hierarchical analysis, constant comparisons, theoretical sensitivity, and saturation. Theoretical sampling is the process of data collection in order to generate a theory where the analyst jointly collects, codes, and analyses the data and decides what data to collect next and where to find them, all in order to develop the theory as it emerges (Glaser \& Strauss, 1967). This is in contrast to initial sampling where sampling criteria for people, cases, situations, and/or settings before you enter the field. This initial sampling is needed to find suitable and relevant material (in our case informants) for the study. Once this is done, theoretical sampling directs were to go next in the analysis (Charmaz, 2006). Theoretical sampling is used to reach saturation and is guided by the emerging categories (Strauss \& Corbin, 1998). Saturation, although somewhat 'elastic', is reached when new interviews do not bring additional information to the emerging categories, i.e. when new data fit into the categories already devised (Strauss \& Corbin, 1998). Theoretical sensitivity refers to the researcher's reflexive 
way of developing research questions and doing analysis. Grounded theory is rooted in symbolic interactionism and includes that meaning is constructed and changed through interactions between people (Charmaz, 2000). Accordingly, perceptions of the world are individual and constantly changed by individuals' interaction with it (Blumer, 1969).

\section{Ethical considerations}

Since 1 January 2020, the United Nations' Convention on the Rights of the Child (Convention on the Rights of the Child, 20 November 1989) has been the law in Sweden (2018:1197). This law supports and protects the interest of children. The first article defines a child as an individual under the age of 18. The following 53 articles focus on children and their opportunity to develop mentally and physically (www.barnombudsmannen.se). The $24^{\text {th }}$ article deals with children's right to healthcare. All children have the right to receive care when they are sick. One aspect of this is pain. Pain should always be treated, primarily due to humanitarian reasons. Pain relief should be a basic human right, regardless of age, sex, socioeconomic status, religion or ethnic origin (IASP, 2010).

From an ethical standpoint, it is important to include children and adolescents in research concerning this age group. However, it is also important to avoid research involving children whenever possible. This is due to their inability to fully grasp the meaning of the research question and to give informed consent. Research involving children requires the highest level of ethical standards and analysis, and insight into children's mental capability, in order to adjust the information according to their age.

There has been very little research on how children experience dental care. One part of this thesis is exploring children's experience of pain in conjunction with tooth extraction. Tooth extraction is used as a model to study pain. An ethical analysis can be made from three perspectives: the patient's, the dentist's and society's. From the patient's perspective, there is a slight risk of experiencing pain and violating the child's right to privacy in conjunction with treatment. The extractions are performed in line with contemporary treatment strategies, as it is stressful to treat patients with pain and DFA. It is therefore of great importance to try to 
find new treatment strategies that seek to reduce pain and DFA for patients and ultimately reduce stress for dentists. Dental care for children and adolescents with DFA is currently very costly for society: specialist referrals may be needed, procedures may need to be performed under general anaesthesia and children and their parents must attend several follow-up visits, leading to a loss of productivity and income. To summarize: if treatment methods that might reduce the risk of developing pain exist, from an ethical point of view it is important to evaluate those treatment modalities. Should those methods be cost-effective, there is a rationale for them to be implemented; otherwise, they should not be introduced into dental care standards.

Regarding ethical aspects, the first choice should be to answer research questions by performing clinical trials in adults. However, it may be unethical to not involve children in research studies evaluating drugs. If children were excluded from all drug research, medication used in children would be limited to extrapolation from adult studies and might even exclude children from the possibility of receiving existing and new drugs that could benefit them. Thus, the research community has a significant responsibility to design, approve, and conduct high-quality studies in children so that this population can have access to important medications and receive optimal therapies (Shaddy and Denne, 2010). 


\section{AIMS AND HYPOTHESES}

\section{AIMS}

The overall aims of this thesis were to deepen the knowledge of procedural and postoperative pain and pain management in paediatric dentistry, from the perspectives of patients, dental staff and the research community.

The specific aims were:

- to investigate the handling of children's pain and pain management strategies when treating children and adolescents by both Swedish general dental practitioners (GDPs) and specialists in paediatric dentistry (SPDs) (Paper I),

- to measure pain intensity in 10-15-year-olds during and after uncomplicated standard maxillary bilateral premolars extractions on orthodontic indications in order to understand the natural course of pain and to make comparisons between the first and second extractions (Paper II),

- to perform a systematic review and health technology assessment of the effects, adverse events, and cost-effectiveness of prescriptionfree/over-the-counter oral analgesics given immediately after dental treatment to prevent or reduce postoperative pain in children and adolescents ages $3-19$, and also to assess the ethical aspects of the intervention (Paper III),

- to explore and describe children's experiences with and thoughts about pain in conjunction with orthodontically indicated tooth extraction and the subsequent postoperative period, using grounded theory (Paper IV). 


\section{HYPOTHESES}

The following hypotheses were formulated for each paper, respectively:

- The null-hypotheses were that there would be no difference (i) in the use of pre- and postoperative analgesics when treating primary vs permanent teeth, (ii) in the use of LA when treating primary vs permanent teeth, and (iii) between GDPs and SPDs regarding (i) and (ii) (Paper I).

- Children and adolescents experience pain (defined as $\mathrm{VAS}_{\mathrm{PI}} \geq 40$ ) after tooth extraction (Paper II).

- The first extraction is as painful as the second (Paper II).

For Paper III and Paper IV, no hypotheses were formulated due to the choice of research methods, which generate hypotheses rather than test them. 


\section{MATERIAL AND METHODS}

Four different methods were used in this thesis, one for each paper. The common denominator for all papers was the investigation of procedural and postoperative pain in child and adolescent dentistry. Paper I investigated dentists' attitudes towards pain management when treating children and adolescents. Paper II studied the natural course of pain after tooth extraction, and Paper III consists of a systematic review (SR) and a health technology assessment (HTA) on the postoperative administration of oral analgesics to children and adolescents after dental treatment. Paper IV is a qualitative study using grounded theory (GT) that examines the consequences of pain during and after dental treatment. A more detailed description of materials and methods can be read in each separate Paper.

\section{Study population}

\section{Pain management in clinical practice (Paper I)}

A total of 929 active dentists in Sweden were invited to participate in a postal survey. Of these, 807 were general dental practitioners (GDPs) working in the Skåne Regional Council (Region Skåne). The remaining 122 dentists were specialists in paediatric dentistry (SPDs) (one of nine recognized dental specialities in Sweden) working throughout the country. Those who were aged 65 years or younger at the time of the survey were invited to participate. 


\section{The natural course of pain (Paper II)}

Participants in Paper II's study of the natural course of pain were children between the ages of 10 and 15 years who required extraction of both maxillary premolars prior to orthodontic treatment. Participants also had to be of good general health. Patients who were deemed to require conscious sedation to handle the tooth extractions were excluded, as were those who themselves or their legal guardian were unable to understand Swedish. A total of 34 children were identified during one of their initial visits to their orthodontist, when orthodontic therapy was decided, and enrolled to participate. Participants were then sent to the specialist clinic at Malmö University, where the extractions were performed.

\section{Postoperative pain management - systematic review and health technology assessment (Paper III)}

For the systematic review and health technology assessment, study population was defined in the PICO (participants, intervention, control, outcome). Healthy children and adolescents aged 3-19 years receiving dental treatment without support of any sedation or general anaesthesia, were included.

\section{Children's perceptions of pain (Paper IV)}

Eleven healthy $(\mathrm{n}=11)$ individuals, aged 10 to 16 years, who had undergone dental extraction in the maxilla due to planned orthodontic treatment, were included in this qualitative study, using grounded theory. In the strategic sampling it was ensured to mirror sex, age, residence (type of housing to mirror socioeconomic background), experience of both one and two extractions, and also recently initiated orthodontic treatment.

\section{Methods}

\section{Pain management in clinical practice (Paper I)}

Paper I is a study of praxis based on a postal survey. The participants were sent a questionnaire along with written information about the study and a consent form; the questionnaire and consent form were returned in 
an included prepaid envelope. Two reminders were also sent during the study period, spaced two weeks apart.

The questionnaire used in Paper I (Appendix 1) is based on a previous questionnaire used by Wondimu \& Dahllöf (2005) in a Swedish setting. In addition to demographic questions such as age, sex, years in practice and experience treating children, participants were asked about following four different clinical scenarios and how often they used different types of pain management strategies:

- Filling therapy on maxillary primary molars in a preschool child,

- Filling therapy on a maxillary permanent first molar in a schoolaged child,

- Extraction of a maxillary primary incisor in a preschool child, and

- Extraction of a maxillary permanent premolar in a school-aged child.

Respondents indicated how often they used each of the following pain managing strategies in each scenario:

- Topical anaesthetics

- Local anaesthetics

- Sedation

- Recommendations for preoperative analgesics

- Recommendations for postoperative analgesics

The frequency of each alternative was indicated using a 5-point Likert scale with the options always, often, sometimes, seldom, and never. The questionnaire also contained three open-ended questions about the type of pharmaceutical agents the respondents recommended for pre- and postoperative pain-relief and their recommendations regarding the timing of administration.

In the subsequent analyses, the Likert scale responses for the scenarios were dichotomized into always/often and sometimes/seldom/never.

\section{The natural course of pain (Paper II)}

\section{Clinical procedure}

The participants for Paper II were identified and then enrolled during their first visit to an orthodontic clinic in Malmö, Sweden. Inclusion and 
exclusion criteria are listed in Table 2. Patients and their legal guardians received verbal and written information, and if they agreed to participate the legal guardian signed a consent form. All children received ageappropriate information and assented to participate. At their first visit to the clinic where the tooth extractions were to be performed, they once again received information about the study. The extractions were performed according to a treatment protocol (see Table 3), so all participants got equivalent standardized treatment. The same treatment protocol was followed at both the first and the second extractions. The same provider (HB) performed all extractions except for four teeth. One of the co-authors for Paper II (KR) extracted the other four. Before the tooth extractions began the providers' technique was calibrated against the treatment protocol.

Table 2. Inclusion and exclusion criteria for participation in Paper II.

\begin{tabular}{ll}
\hline Inclusion criteria & Exclusion criteria \\
\hline 10 to 15 years of age & $\begin{array}{l}\text { Patient needs of conscious sedation to manage the } \\
\text { extractions }\end{array}$ \\
$\begin{array}{l}\text { Patiant oral extraction of maxillary premolars prior } \\
\text { orthodontic treatment }\end{array}$ & $\begin{array}{l}\text { Swedish } \\
\text { Uncomplicated root anatomy (based on radio- } \\
\text { graphs) }\end{array}$ \\
Good general health & \\
\hline
\end{tabular}

\section{Questionnaires before and after treatment}

Before the first visit to the dental clinic where the extractions were to be performed, the participants received a questionnaire containing the Children's Fear Survey Schedule - Dental Subscale (CFSS-DS) (Appendix 2). They were given this questionnaire to ensure that anxiety would not influence their perception of pain intensity. The children were instructed to fill out the questionnaire themselves and bring it with them to their first appointment. The CFSS-DS is the most commonly used instrument to measure dental fear and anxiety in children (Klingberg \& Broberg, 2007) and consists of 15 questions, each scored on a Likerttype scale ranging from 1 to 5 , where 1 represents not afraid at all and 5 represents very afraid. The total score ranges between 15 and 75 . A score of $\geq 38$ is considered to represent DFA (Klingberg, 1994). 
Table 3. Treatment protocol for tooth extractions.

\begin{tabular}{|c|c|}
\hline Step & Measure \\
\hline \multirow[t]{2}{*}{1} & Brief information about the treatment procedure. \\
\hline & Presenting the Visual Analogue Scale, with its endpoints. \\
\hline 2 & Flip coin to choose which tooth to begin with (upper right or upper left). \\
\hline 3 & $\begin{array}{l}\text { Apply topical anaesthesic (Lidocaine gel } 5 \% \text {, APL, Sweden) for } 2 \text { minutes, both buccal and palatal, } \\
\text { to the tooth to be extracted. Amount should be equivalent to the size of a pea. Check time with } \\
\text { stopwatch. }\end{array}$ \\
\hline 4 & Check with a dental probe if the mucosa is numb. \\
\hline 5 & $\begin{array}{l}\text { Injection with } 1 \text { cartridge }(=1.8 \mathrm{ml}) \text { of room-temperature local anaesthetic (Xylocain Dental } \\
\text { Adrenalin (lidocaine hydrochloride } 20 \mathrm{mg} / \mathrm{ml} \text {, adrenaline } 12.5 \mu \mathrm{g} / \mathrm{ml} \text {; Dentsply Pharmaceutical, } \\
\text { Weybridge, Surrey, UK), using a } 30 \text {-gauge }(21 \text { - } \mathrm{mm} \text { long) needle. Use a stopwatch to standardize } \\
\text { the length of injection to } 2 \text { minutes. }\end{array}$ \\
\hline 6 & $\begin{array}{l}\text { Check level of anaesthesia using an explorer, penetrating the gingiva around the tooth to be ex- } \\
\text { tracted. }\end{array}$ \\
\hline 7 & If not adequately anesthetized, perform additional injection of local anaesthetics. \\
\hline 8 & When properly anesthetized - use elevator and forceps in a gentle, standardized technique. \\
\hline 9 & After extraction - place a dental gauze on the extraction site \\
\hline 10 & Give standardized postoperative information, verbally and written. \\
\hline 11 & $\begin{array}{l}\text { Do not suggestion or prescribe postoperative analgesics; Simply provide information that if they } \\
\text { use one, to note when, how often, and the pharmaceutical agent used. }\end{array}$ \\
\hline
\end{tabular}

At various time points during and after treatment, patients were instructed to rate their pain intensity on a $100 \mathrm{~mm}$ VAS (for examples of VAS forms, see Appendix 3). The endpoints on the VAS were no pain at all and worst possible pain, respectively. The VAS is a unidimensional scale to measure patients' perception of pain intensity (Huskisson, 1974). The participants were instructed to place a mark on the VAS at the point that represented their perceived pain intensity at that time point $\left(\mathrm{VAS}_{\mathrm{PI}}\right)$. Before analysing the data, a ruler was used to convert these marks to numerical values. In this study we chose a $\mathrm{VAS}_{\mathrm{PI}} \geq 40$ to define clinically relevant pain. A second threshold was defined as $\mathrm{VAS}_{\mathrm{PI}} \geq$ 30, reflecting lower levels of moderate pain (Jensen et al., 2003; van Dijk et al. 2002). Table 4 shows the different time points at which pain intensity was rated. In the evening after the first extraction, the dentist telephoned the family to remind the patient to fill out the VAS.

After the second appointment patients and their parents or legal guardians received a questionnaire (Appendix 4) about the time they had missed from school or work due to the two treatment appointments. They were also asked if they had had any additional contact with any dental clinic due to complications after the two extractions, or if the patients' schoolwork had been affected due to the treatments. If they had 
made any expenditures linked to the treatments, they were asked to report this as well on the form they received. The form could be returned using a prepaid return envelope or, if additional extractions were to be performed, they could bring it with them to their next appointment. This questionnaire was then used to analyse health economic data. Any additional extractions (performed in the mandible) needed for orthodontic treatment were not included in this study.

Table 4. Time points when patients rated pain intensity.

\begin{tabular}{lll}
\hline & Time of measurement & Location \\
\hline 1 & During injection of LA ${ }^{\mathrm{a}}$ & Dental clinic \\
2 & Immediately after injection of LA & Dental clinic \\
3 & During tooth extraction & Dental clinic \\
4 & $0 \mathrm{~h}$; immediately after tooth extraction & Dental clinic \\
5 & $2 \mathrm{~h}$ after tooth extraction & Home (or school) \\
6 & $4 \mathrm{~h}$ after tooth extraction & Home (or school) \\
7 & $1^{\text {st }}$ evening after tooth extraction & Home \\
8 & $1^{\text {st }}$ morning after tooth extraction & Home \\
9 & $2^{\text {nd }}$ evening after tooth extraction & Home \\
10 & $3^{\text {rd }}$ evening after tooth extraction & Home \\
11 & $4^{\text {th }}$ evening after tooth extraction & Home \\
12 & $5^{\text {th }}$ evening after tooth extraction & Home \\
13 & $6^{\text {th }}$ evening after tooth extraction & Home \\
14 & $7^{\text {th }}$ evening after tooth extraction & Home \\
\hline${ }^{\mathrm{a}}$ Recorded at the same time as Immediately after injection of LA & \\
${ }^{\mathrm{b}}$ Recorded at the same time as 0 h; immediately after tooth extraction &
\end{tabular}

\section{Sample size calculation}

No previous data on sample size calculation suitable for Paper II could be found. Two earlier studies included 221 (Acs et al., 1986) and 84 (Ashkenazi et al., 2007) participants, respectively. However, these studies were difficult to use as a basis for sample size calculation due to methodological issues. A split-mouth study that analysed pain after the use of different types of forceps included 27 patients (Hariharan et al., 2014). The 31 patients recruited for this study therefore seems satisfactory. 


\section{Postoperative pain management - systematic review and health technology assessment (Paper III)}

Paper III contains a systematic review (SR) and health technology assessment (HTA). A Population, Intervention, Comparison, Outcome (PICO) framework was constructed (see Table 5) to define population, interventions, control, and outcome measures, as well as inclusion and exclusion criteria (see Table 6). The study protocol was registered on PROSPERO (CRD42017075589) on September 1, 2017, and is available at:

http://www.crd.york.ac.uk/PROSPERO/display_record.php?ID=CRD42 017075589. The literature search was performed in

Table 5. PICO-strategy for the systematic review and health technology assessment.

\begin{tabular}{|c|c|c|}
\hline $\mathbf{P}$ & Population & - $\quad$ Children and adolescents aged 3-19 years. \\
\hline | & Intervention & $\begin{array}{l}\text { Administration of oral analgesics after dental treatment } \\
\text { Pharmacological substances: prescription-free/over-the- } \\
\text { counter oral analgesics containing paracetamol (acetamino- } \\
\text { phen), ibuprofen, diclofenac or naproxen } \\
\text { Administration of drug: oral administration as a single dose } \\
\text { or multiple doses following an administration regimen } \\
\text { Dental treatments: primary or permanent teeth treated by fill- } \\
\text { ing, pulp therapy/capping, tooth extraction or minor oral sur- } \\
\text { gery }\end{array}$ \\
\hline C & Control/Comparison & $\begin{array}{l}\text { Postoperative administration of other oral analgesics or placebo after } \\
\text { same dental treatment } \\
\text { - } \quad \text { Pharmacological substances: other prescription-free/over-the- } \\
\text { counter oral analgesics containing paracetamol (acetamino- } \\
\text { phen), ibuprofen, diclofenac, or naproxen, or placebo or no } \\
\text { control } \\
\text { Administration of drug: oral administration as a single dose } \\
\text { or multiple doses following an administration regimen } \\
\text { Dental treatments: primary or permanent teeth treated by fill- } \\
\text { ing, pulp therapy/capping, tooth extraction, minor oral sur- } \\
\text { gery }\end{array}$ \\
\hline O & Outcome & $\begin{array}{l}\text { Pain after dental treatment assessed by the paediatric patient } \\
\text { using the Visual Analog Scale (VAS), Faces Pain Scale - } \\
\text { Revised, Wong-Baker FACES, Numerical Rating Scale, } \\
\text { Eland Colour Scale, or other facial scales } \\
\text { - } \quad \text { Adverse effects, side effects } \\
\text { - Costs, cost-effectiveness }\end{array}$ \\
\hline
\end{tabular}


November 2017 by two librarians specialized in informatics, and an updated search was conducted in November 2018. Five databases were used: PubMed via NML, Cochrane via Wiley, Scopus via Elsevier, CINAHL via EBSCO, and Embase via Elsevier. After checking for duplicates and articles not meeting our requirements for language or date for publication, the included studies were evaluated according to the PRISMA statement (Moher et al., 2009). The reviewing authors, reading in pairs, screened the article titles and abstracts independently, and if at least one reviewer found the abstract relevant, the full text was retrieved and read for assessment of relevance. This full-text assessment was also done independently by the same pair of authors. The researchers planned to grade relevant articles in terms of quality (the Grading of Recommendations Assessment, Development and Evaluation (GRADE) system) (Balshem et al., 2011), to assess the risk of bias and relevance using the checklist from Swedish Agency for Health Technology Assessment and Assessment of Social Services (SBU, 2018), and to conduct an assessment of systematic reviews using AMSTAR (A MeaSurement Tool to Assess systematic Reviews) (Shea et al., 2017).

Table 6. Inclusion and exclusion criteria for the systematic review and health technology assessment.

\begin{tabular}{ll}
\hline Inclusion criteria & Exclusion criteria \\
\hline Randomized control trials (RCT) & Participants 20 years or older; studies where date \\
& could not be extracted for 3-19-year-olds \\
Systematic reviews & Narrative reviews \\
Observational studies & Disability or medical conditions leading to cognitive \\
& impairment or neuropsychiatric diagnosis \\
Qualitative studies & Oral analgesics other than paracetamol (acetamino- \\
& phen), ibuprofen, diclofenac, or naproxen, or routes \\
& of administration other than per os \\
Studies published 1980 or later & Treatment under hypnosis, sedation, or general an- \\
& aesthesia \\
& Pain assessment by proxy \\
& Languages other than English, Swedish, Danish, or \\
& Norwegian \\
\hline
\end{tabular}




\section{Children's perceptions of pain (Paper IV)}

Paper IV used grounded theory (GT) as its method. The participants were identified and enrolled during their meeting with an orthodontist at which the orthodontic therapy plan, including tooth extractions, was presented. Verbal and written information was given both to the parents/guardians and the participants, and if the child assented to participate, the signed consent form was sent to the principal investigator (HB). The child received age-appropriate written information.

An interview was conducted one to two weeks after participants had their teeth extracted, using an interview guide that included themes such as experiences with tooth extraction, pain, coping strategies, and overall reflections on the treatment. These open-ended interviews lasted 30 to 45 minutes and were conducted in a conversational style. The same researcher (HB) conducted all the interviews. Depending on the answers, the interviewer followed up with relevant probing questions. The focus of the interviews was the participants' thoughts and feelings on a variety of themes, such as their earlier experiences with dental treatment, their thoughts about treatment, any problems they had experienced related to dental treatment (such as procedural and postoperative pain experiences). The interview subjects were also given the opportunity to raise relevant issues besides the themes mentioned here. The initial protocol was not followed dogmatically; rather, participates were given wide latitude to control the direction of the interview.

The interviews were transcribed verbatim and analysed shortly after the interview was completed. Data collection and analysis used the constant comparative method for GT (Glaser \& Strauss, 1967). This method was further refined by Strauss \& Corbin (1998). Data collection and analysis took place in parallel, with an open mind towards data. The interviews were initially read as a whole, and then each section was read while querying the text in an open coding process. Such queries sought to elucidate questions such as 'what is expressed in this section?' Concepts were identified and labelled, either with using the participants' own words (in-vivo codes) or set terms (in-vitro codes). These codes were then clustered into preliminary categories that were then named. In the axial coding process, each category was further elaborated by identifying subcategories (dimensions and characteristics). The reviewers sought patterns and relationships between categories and data in order to 
present a new whole. In the selective coding process, categories were saturated with information by collecting new data in subsequent interviews or recoding previously analysed data. The selective coding process was guided by the question 'what is all this about?' leading to the identification of core categories that were, in turn, central and related to other categories and subcategories. Throughout the analytical process, ideas and assumptions about conceptual relationships (hypotheses) and theoretical reflections were written down as memos.

The interviews were analysed separately by $\mathrm{HB}$, GK, and $\mathrm{UH}$, who continuously discussed their work throughout the whole process.

\section{Sample size calculation}

Qualitative studies do not require a sample size calculation due to the nature of such studies. Data is collected until saturation is achieved: i.e., when no new information can be found. The number of informants is of less importance than the content and quality of the data they provide.

\section{Ethical considerations}

Ethical approval for Papers I and II was obtained from the Regional Ethics Review Board in Lund, Sweden (\#2014/527). Ethical approval for Paper IV was given by the Swedish Ethical Review Authority, Sweden (\#2019-00121, (2018/1029)).

After receiving written information, the participating dentists in Study I signed a consent form. In studies II and IV, legal guardians gave their consent to allow their children to participate after receiving written and verbal information. All children were given age-appropriate information and assented to participate.

Paper III was registered in PROSPERO (CRD42017075589) and is available at

http://www.crd.york.ac.uk/PROSPERO/display_record.php?ID=CRD 42017075589.

Paper IV was registered at https://clinicaltrials.gov/ under identifier: NCT04064853. 


\section{Statistical analyses}

The statistical analyses were performed using IBM SPSS Statistics, version 22.0 (Statistical Package for the Social Sciences, SPSS Inc., Chicago, IL, USA), and IBM SPSS Statistics for Windows version 24.0 (IBM Corp., Armonk, NY, USA).

The chi-square test, McNemar's test, and logistic regression analysis was used in Paper I for statistical analysis. The first two were used to compare general GDPs and SPDs regarding the use of different painreducing strategies in four different clinical scenarios. McNemar's test was also used to compare different strategies for treating primary vs permanent teeth within the two groups of dentists (GDPs and SPDs). In the backward logistic regression analysis, sex, age, dentists' having children of their own, years of professional experience and numbers of hours treating children per week were used as independent variables.

In Paper II, independent samples $t$ test was used to analyse differences among groups such as age, sex, and treatment time of day. Paired samples $t$ test was used to compare treatment time between the first and second extractions. The $t$ tests were used because the analysed data were deemed to be parametric. Differences in pain ratings between the first and second extraction were analysed using Wilcoxon signed-rank test, while the Mann-Whitney $U$ test was used to analyse pain ratings between groups at the first and second extractions.

A $p$-value of less than $5 \%(p<0.05)$ was considered statistically significant. 


\section{RESULTS}

\section{Pain management in clinical practice}

Of the 929 invited practitioners, $562(60.5 \%)$ completed the questionnaire and returned it with their signed consent form (461 GDPs and 101 SPDs). The SPDs had a much higher response rate $(82.8 \%)$ than the GDPs $(57.1 \%)$. This difference was statistically significant $(p=0.001)$. No statistically significant differences in response rate by gender were found between female and male dentists, nor was there a difference in gender distribution between respondents and non-respondents. Nonrespondents' gender was extrapolated based on the given names of the dentists contacted.

Responses that used a 5-point Likert scale were dichotomized as always/often vs. sometimes/seldom/never before conducting statistical analyses on questions where it was considered clinically important to consider a high intention to use pain management strategies versus lower levels of intention.

All the scenarios investigated revealed a difference between GPDs and SPDs regarding pain management when treating children, with the exception of the administration of LA for extraction of a permanent premolar. In this scenario, GDPs and SPDs were equally and highly likely to recommend the practice. In all other cases, SPDs used pain management strategies more frequently than GDPs. Another difference found within GDPs concerned the use of LA for dental fillings to restore primary teeth versus permanent teeth. The most significant results can be seen in Table 7 . 
When both classes of dentists did recommend pre- or postoperative oral analgesics, they preferred paracetamol (acetaminophen) over other types of oral analgesics (Table 7). On a preoperative basis, the majority of both GDPs and SPDs recommended that patients take this drug at least one hour before treatment ( $84.8 \%$ and $94.0 \%$, respectively; $p=0.000)$. GDPs also seemed more likely to recommend the use of pain management strategies when treating permanent teeth than when treating primary teeth.

Table 7. Recommendations and/or use of oral analgesics and local anaesthetics.

\begin{tabular}{|c|c|c|c|c|c|c|c|c|c|}
\hline & \multicolumn{3}{|c|}{$\begin{array}{l}\text { Oral analgesics }^{\mathrm{a}} \\
\text { before extraction }\end{array}$} & \multicolumn{3}{|c|}{$\begin{array}{l}\text { Oral analgesics } \\
\text { after extraction }\end{array}$} & \multicolumn{3}{|c|}{$\begin{array}{l}\text { Local anaesthetics } \\
\text { for filling therapy }\end{array}$} \\
\hline & $\begin{array}{c}\text { GDPs } \\
(\%)\end{array}$ & $\begin{array}{l}\text { SPDs } \\
(\%)\end{array}$ & $p$ & $\begin{array}{c}\text { GDPs } \\
(\%)\end{array}$ & $\begin{array}{l}\text { SPDs } \\
(\%)\end{array}$ & $p$ & $\begin{array}{l}\text { GDPs } \\
(\%)\end{array}$ & $\begin{array}{l}\text { SPDs } \\
(\%)\end{array}$ & $p$ \\
\hline Primary tooth & 13.2 & 63.4 & 0.01 & 41.5 & 73.0 & 0.01 & 79.8 & 100.0 & 0.01 \\
\hline \multirow{2}{*}{$\begin{array}{l}\text { Permanent } \\
\text { tooth }\end{array}$} & 9.8 & 63.4 & 0.01 & 49.2 & 75.8 & 0.01 & 87.9 & 100.0 & 0.01 \\
\hline & & & & $\begin{array}{l}p< \\
0.05\end{array}$ & & & $\begin{array}{l}p< \\
0.01\end{array}$ & & \\
\hline
\end{tabular}

For many of the scenarios in the questionnaire, female GDPs were more likely to respond always or often compared to male GPDs (see Table 8).

For the purpose of analysis, years of experience as GDP were dichotomized into $\leq 5$ years and $\geq 6$ years. This did not seem to have any effect on the likelihood to recommend the use of local anaesthesia prior to dental fillings in either primary or permanent teeth, or with regard to the preoperative use of analgesics. However, there was a difference in the likelihood of recommending postoperative analgesics after tooth extraction, which dentists with less experience were more likely to recommend, a difference that held for both primary and permanent teeth scenarios (see Table 9). 
Table 8. Differences between female and male GDPs regarding different dental treatment scenarios. Percentages represents those answering Always or Often.

\begin{tabular}{lccc}
\hline & \multicolumn{3}{c}{ GDPs } \\
\cline { 2 - 4 } & $\begin{array}{c}\text { Female } \\
(\%)\end{array}$ & $\begin{array}{c}\text { Male } \\
(\%)\end{array}$ & 83.4 \\
\hline $\begin{array}{l}\text { Local anaesthetics prior to fillings on } \\
\text { permanent teeth }\end{array}$ & 91.0 & 35.4 & 0.024 \\
$\begin{array}{l}\text { Postoperative oral analgesics recom- } \\
\text { mended after extraction of primary mo- }\end{array}$ & 45.7 & & 0.041 \\
lar & & 39.5 & \\
$\begin{array}{l}\text { Postoperative oral analgesics recom- } \\
\text { mended after extraction of permanent } \\
\text { molar }\end{array}$ & 55.8 & & 0.001 \\
$\begin{array}{l}\text { Preoperative oral analgesics recom- } \\
\text { mended prior to extraction of permanent } \\
\text { tooth }\end{array}$ & 12.6 & 5.6 & 0.026 \\
\hline
\end{tabular}

For the purpose of analysis, years of experience as GDP were dichotomized into $\leq 5$ years and $\geq 6$ years. This did not seem to have any effect on the likelihood to recommend the use of local anaesthesia prior to dental fillings in either primary or permanent teeth, or with regard to the preoperative use of analgesics. However, there was a difference in the likelihood of recommending postoperative analgesics after tooth extraction, which dentists with less experience were more likely to recommend, a difference that held for both primary and permanent teeth scenarios (see Table 9).

Table 9. Differences in pain management strategies for different clinical scenarios, depending on years of experience. Percentages represent those answering Always or Often.

\begin{tabular}{lccc}
\hline & \multicolumn{3}{c}{ GDPs } \\
\cline { 2 - 4 } & \multicolumn{4}{c}{$\begin{array}{c}\text { years' experience } \\
(\%)\end{array}$} & $\geq 6$ years' experience & $p$ \\
\hline Extraction of primary teeth & 57.8 & 37.6 & 0.001 \\
Extraction of permanent teeth & 63.5 & 47.5 & 0.005 \\
\hline
\end{tabular}


The researchers conducted a backward logistic regression analysis that assessed whether various factors affected GDPs' likelihood of recommending various pain-reducing strategies in different scenarios: gender, age, having children of their own, years of experience, and number of hours treating children per week. Gender turned out to be a predictor: female GDPs were twice as likely to use LA during dental fillings on permanent molars, and they were more likely to recommend postoperative analgesics after extractions of permanent premolars compared with male GDPs ( $p=0.025$ and $p=0.002$, respectively), with the other variables kept constant. GDPs who had children of their own were $58 \%$ less likely to always/often recommend preoperative analgesics for patients undergoing extraction of a primary incisor $(p=0.016)$ compared to GDPs who did not have children of their own. Years of experience as a GDP turned out to be a predictor for recommending the use of preoperative analgesics when extracting primary incisors. GDPs with 6 or more years of experience were three times more likely to recommend this compared to GDPs with 5 years of experience or less $(p=0.041)$.

\section{The natural course of pain}

\section{Analysing pain intensity ratings}

Thirty-four individuals were recruited, but three of them were excluded from the study: one had an appointment the day after the first extraction for placement of orthodontic brackets, one already had orthodontic brackets, and one did not understand the concept of the VAS. Therefore, 31 patients underwent both extractions. As the study progressed, data was not successfully collected for all 62 extractions over the entire seven-day postoperative period because not all the VASs were filled out properly or because the patient had self-administered oral analgesics. In the latter case, only the pain intensity data points until the patient took the oral analgesics were included in the analyses. All VAS data-points recorded after any ingestion of oral analgesics were excluded from further analysis. One patient's postoperative pain reports could not be included because the patient failed to return them.

The gender distribution was equal (15 boys and 16 girls), and the mean age did not differ by gender (13.5 yrs. vs. 13.3 yrs., respectively, 
$p=0.591)$. When subdivided into age groups (10-13 years vs. 14-15 years) the gender distribution of the younger age group was 10 girls vs. 6 boys, and for the older age group it was 6 girls vs. 9 boys. This difference was not statistically significant, however ( $p=0.210$; Chi-square test).

Previous experience with local anaesthesia did not seem to have any impact on pain intensity during and after tooth extraction. There were no differences between those who had received LA previously and those who had not. There was also no difference in pain intensity reports between those who required an additional injection of LA compared to those who did not require additional LA prior to extraction.

In this cohort, DFA did not seem to be an issue. Before the first extraction, only one individual had a CFSS-DS score above 38, which is the cut-off for DFA (Klingberg, 1994). One other important finding was the lack of any statistically significant differences in CFSS-DS scores before the first and before the second extraction or between genders or age groups. The initial analysis found no relationship between VAS and CFSS-DS scores, and thus this relationship was not analysed further, since DFA did not have any influence on pain intensity.

\section{Procedural pain}

In general, patients seemed to find the LA injection more painful than the extraction procedure (Figure 6), as mean pain intensity ratings were higher for during LA than for during extraction. For the six first measurement points, there were no differences in pain intensity ratings between the first and second extractions (Figure 6).

\section{Postoperative pain}

Although pain intensity did differ between the patients, pain levels all followed the same course of progress postoperatively. There were also no differences between the first and second extractions (Figure 6). The highest mean pain intensity occurred at 2 hours after extraction. Pain subsided dramatically thereafter, however, as reported at the next time point 4 hours after extraction (Figure 6). 


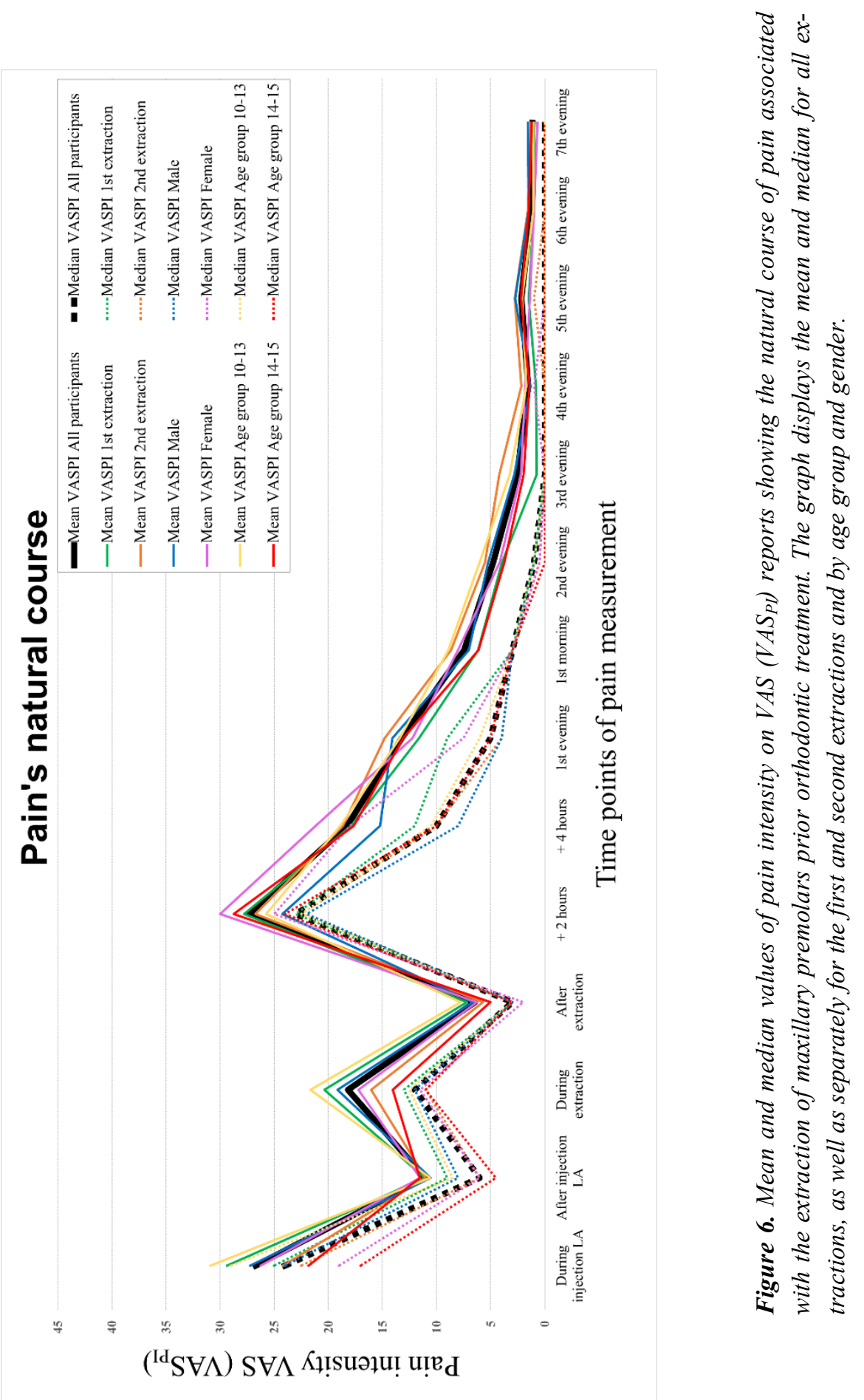


Eight patients self-administered oral analgesics after the first extraction, and six patients did so after the second extraction. Table 10 shows the last valid pain intensity records prior to ingesting oral analgesics.

Table 10. Pain intensity recordings preceding ingestion of analgesics.

\begin{tabular}{|c|c|c|c|c|c|}
\hline $\begin{array}{l}\text { Subject } \\
\text { no. }\end{array}$ & $\mathrm{VAS}_{\mathrm{PI}^{0}}{ }^{\mathrm{hir}}$ & $\mathrm{VAS}_{\mathrm{PI}}{ }^{2 \mathrm{hr}}$ & $\mathrm{VAS}_{\mathrm{PI}}{ }^{4 \mathrm{hr}}$ & $\mathrm{VAS}_{\mathrm{PI}}^{\text {evI }}$ & $\mathrm{VAS}_{\mathrm{PI}}{ }^{\mathrm{mol}}$ \\
\hline $1 \mathrm{~A}$ & 0 & 13 & 4 & $4 *$ & \\
\hline $1 \mathrm{~B}$ & $5 *$ & & & & \\
\hline $2 \mathrm{~A}$ & 0 & $58 *$ & & & \\
\hline $2 \mathrm{~B}$ & 0 & $34 *$ & & & \\
\hline $3 \mathrm{~A}$ & 8 & 44 & $64 *$ & & \\
\hline $3 \mathrm{~B}$ & 8 & $3 *$ & & & \\
\hline $4 \mathrm{~A}$ & 8 & 63 & $37 *$ & & \\
\hline $4 \mathrm{~B}$ & 23 & 65 & $15 *$ & & \\
\hline $5 \mathrm{~A}$ & 2 & 29 & $34 *$ & & \\
\hline $6 \mathrm{~A}$ & 4 & 11 & $18 *$ & & \\
\hline $7 \mathrm{~A}$ & 1 & 2 & $1 *$ & & \\
\hline $7 \mathrm{~B}$ & 0 & 0 & $0 *$ & & \\
\hline $8 \mathrm{~A}$ & 0 & 18 & 39 & 15 & $26 *$ \\
\hline $8 \mathrm{~B}$ & 8 & 26 & 49 & 35 & $40 *$ \\
\hline
\end{tabular}

Visual analogue scale pain intensity $\left(\mathrm{VAS}_{\mathrm{PI}}\right)$ scores for eight patients who self-administered oral analgesics (8 after the first extraction, 6 after the second). Time points are hours after extraction. * = last valid VAS measurement before ingestion of oral analgesics. All measurements after ingestion of oral analgesics were excluded from the analyses.

$\mathrm{A}=$ measurements from first extraction; $\mathrm{B}=$ measurements from second extraction.

\section{Health and economic analysis}

No patient had to seek additional dental care as a result of the tooth extractions performed as part of this study. The extractions prompted seven of the children to miss school after treatment. The mean amount of missed school for all children was 6 hours.

\section{Postoperative pain management - systematic review and health technology assessment}

The search strategies were performed using five databases and yielded a total of 8,003 studies. However, after removing duplicates and studies published before 1980, 3,963 articles were left for evaluation according to the PRISMA statement (Moher et al., 2009). Of them, 3,647 articles 
were identified in the initial search and an additional 316 articles were identified between November 2017 and November 2018. However, none of the new articles could be included in the subsequent analysis since they did not meet the inclusion criteria. The whole selection process is illustrated in Figure 7.

The major reasons for exclusion was a lack of data on children ages 0 to 19 that could be retrieved from the articles. Articles addressing treatment performed under general anaesthesia or using narcotic analgesics were also excluded. This does not necessarily mean that no children participated in the studies, but if they did so, they could not be singled out as a cohort.

Since no studies were eligible for inclusion in this systematic review and health technology assessment, we could not go ahead with the quality assessment, which had been planned to use the Grading of Recommendations Assessment, Development and Evaluation (GRADE) system (Balshem et al., 2011). Neither could we make an assessment of the risk of bias and relevance using the checklist from Swedish Agency for Health Technology Assessment and Assessment of Social Services (SBU, 2018) or an assessment of systematic review using AMSTAR (A MeaSurement Tool to Assess systematic Reviews) (Shea et al., 2017). Thus, our study turned out to yield an empty systematic review.

During every stage of the data extraction process (reading titles/abstracts and reading full texts), the researchers looked for and evaluated information about complications and side effects. No serious side effects or adverse effects were reported in the assessed abstracts and full-text articles.

Since Paper III also is not only a systematic review but also a health technology assessment, an ethical analysis is mandatory. This type of ethical evaluation, based on a framework by Heintz et al. (2015), addresses certain core main ethical issues such as effects on health, evidence gaps, compatibility with ethical norms, and autonomy. Since no studies could be included for quality assessment, the ethical aspects of our review and assessment can only be reflected upon at a general level. The central point is to defend children's rights and welfare in medical and dental treatment, which, of course, also applies to all research involving young people. 
Figure 7. Flowchart showing the literature review process for the SR/HTA.
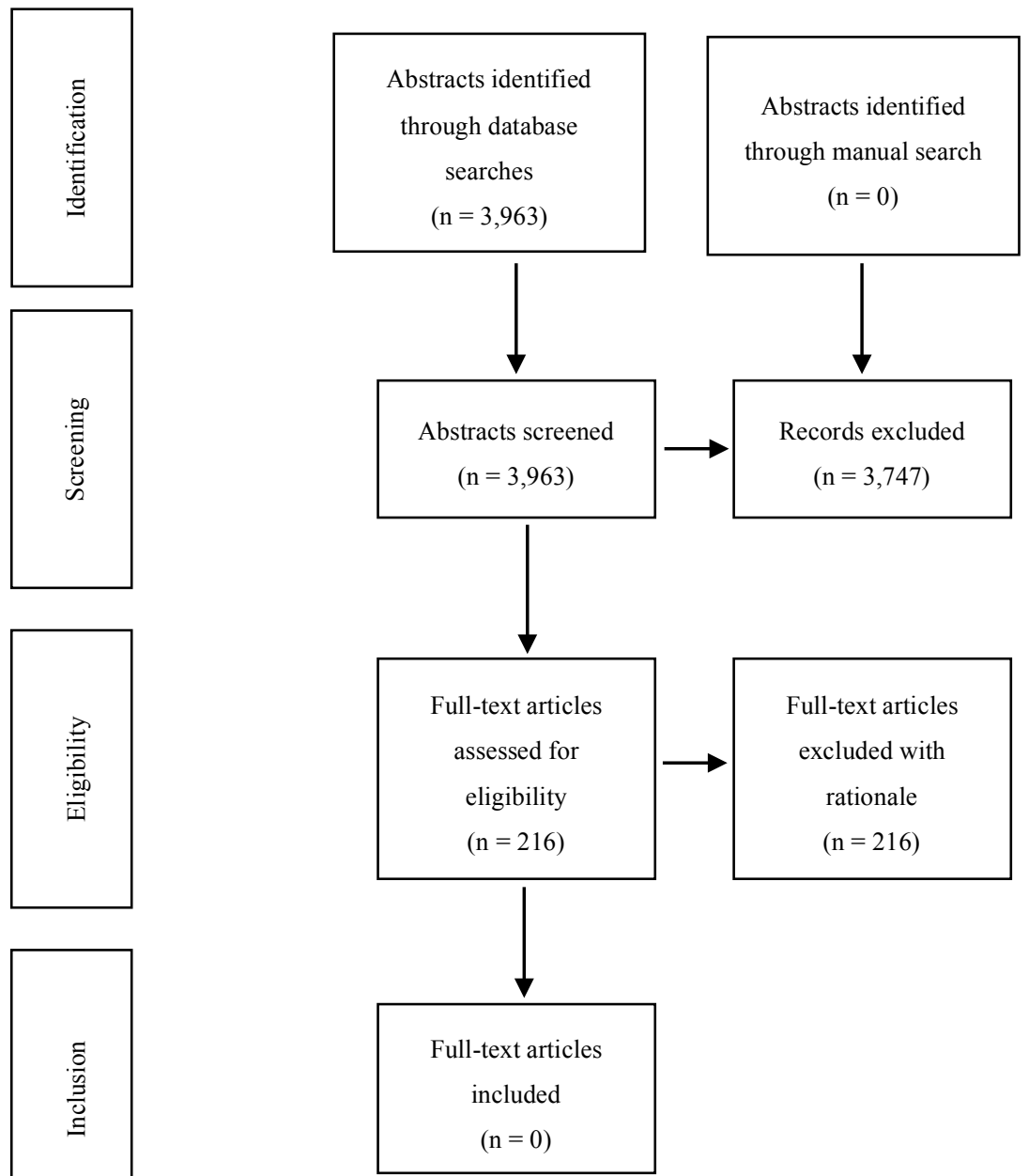

Paper III identified an evidence gap, which is a signal of the need for more studies. However, before including children in research on the effect of oral analgesics, it is crucial that well-designed studies in adults be identified and scrutinized. Paper III did not undertake this step. Welldesigned studies in adults can only serve as a model for studies in chil- 
dren and adolescents. It is still important that the perspective of children and adolescents be acknowledged. They must not be excluded from research that could be beneficial for them.

\section{Children's perceptions of pain}

Most of the participants had experienced only minor interventions at the dentist's office such as regular dental check-ups. They otherwise had limited previous experiences with treatments such as local anaesthesia, fillings and extractions. Nevertheless, all the participants expressed some level of worry prior to their first dental extraction as part of their forthcoming orthodontic treatment. However, no one hesitated to go through with the planned treatment; rather, they used a variety of coping strategies to deal with the procedure.

In the analysis, one main concern (i.e., core category) was identified: handling the unavoidable unknown. The participants reported uncertainty about the treatment procedure and what to expect during and after the tooth extraction. Despite this, they 'jumped into the unknown' and went through with the treatment. While doing so, they used different coping strategies that emerged as conceptual categories (see Figure 8).

\section{Core category}

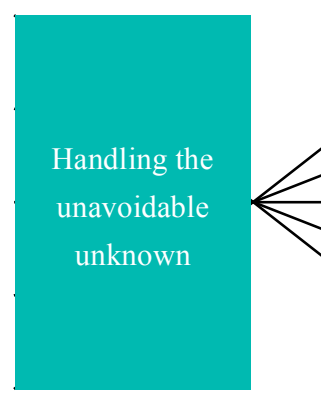

\section{Conceptual categories (coping strategies)}

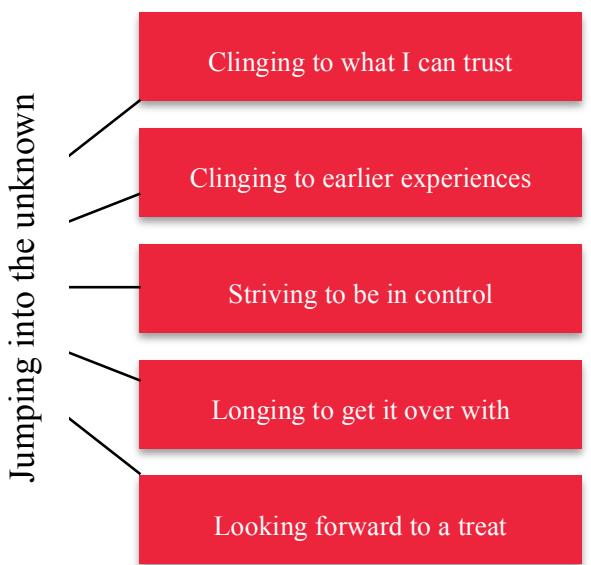

Figure 8. Coping strategies (conceptual categories) used to handle the core category. 
These coping strategies were all used initially to handle the anxiety they all felt at different time points prior to treatment, as well as during and after the tooth extraction. The five categories representing coping strategies were as follows: clinging to what I can trust, clinging to earlier experiences, striving to be in control, longing to get it over with, and looking forward to a treat.

\section{Clinging to what I can trust}

This category emerged from participants who repeatedly reported that they clung to and trusted the dentist's information about the whole procedure - before, during, and after the tooth extraction - in terms of the course of action, the pain and discomfort they would experience, and other sensations they would feel. The dentist's information was valuable, since the child might have heard others talk about dental extractions in more emotionally charged terms. One participant said they thought it was going to hurt.

'[...] 'cause mom and dad said it would hurt, so yeah...' (ID3)

\section{Clinging to earlier experiences}

Children's earlier experiences with the extractions were also important sources for coping with dental extractions. This could be either positive or negative: those with more psychologically challenging previous dental visits required more soothing and calming information to handle the treatment, while those with more positive experiences felt more at ease and could use those positive experiences as a source of reassurance regarding the upcoming extractions. One example of this was a participant who had had two teeth extracted. Before the first extraction, he had been more nervous than he was before the second extraction.

'[...] but the second time I knew, sort of, how it was supposed to feel, and that made it easier.' (ID2)

For some informants, however, their earlier experiences were not always positive. One stated that he dreaded the postoperative period, due to the blood, and stated that it would have an unpleasant taste. He was more worried. 
'Yes, because then I knew what was waiting.' (ID3)

\section{Striving to be in control}

Another central coping strategy was seeking some form of control over the dental situation. The ability to use this strategy was heavily dependent on the dentist performing the treatment, who could, for example, instruct the patient to raise their hand as a 'stop sign' if they needed a momentary break during the procedure, for example. Children gained a feeling of being in control over their pain/discomfort in the postoperative period as well if they were given the option to take oral analgesics or not. This made them more capable of handling their pain and discomfort.

'I was laying down watching YouTube on the ceiling, on the screen. And then I tried to listen to what they said - on the TV, I mean. And then, if it hurt, then I just raised my hand to show them that it hurt. Then they took a short break before starting again.' (ID5)

\section{Longing to get it over with}

Since all the children were keen on getting orthodontic treatment and were also well aware that extractions were a prerequisite to that process, they were able to put up with the pain and discomfort because they knew they had to in order to get the desired orthodontic treatment. They did not want to prolong the treatment sessions, and therefore they sometimes told themselves to put up with the pain and discomfort in order to shorten the unpleasantness. For example, one participant experienced some pain and discomfort when the dentist started to extract the tooth. Despite that, the patient did not ask the dentist to stop.

'No, 'cause it did not... well, I didn't think that it... I just wanted to get it over with... I just thought that I wanted it done. Like, I didn't want to drag it out longer.' (ID1)

\section{Looking forward to a treat}

The children also motivated themselves to go through with the extractions simply because they knew there would be a positive outcome after the treatment. This knowledge helped them to cope better with the un- 
pleasantness of the procedure and postoperative period. The treats that the participants looked forward to included getting to choose what movie to watch that evening, getting some Netflix time, getting full attention from their mother afterwards or getting their braces. One informant described it as a positive experience to come to the dentist and have a tooth extracted.

'I was happy. Maybe because... Well, I took it very easy afterwards, and it was fun to get to choose a movie.' (ID6)

Another informant used watching a film as a distraction.

'Like, when it began to hurt, then I felt it, and then you think about the pain, but I watched movies both times after I had it done, and you are getting... if you're getting caught up in the film, then you don't think about the pain so much.' (ID2). 


\section{DISCUSSION}

This thesis has its starting point in two evidence gaps that the Swedish Agency for Health Technology Assessment and Assessment of Social Services identified and listed in their database in 2012 (SBU). The SBU stated that the scientific evidence is insufficient to determine the effect of preoperatively administered analgesics during and after oral surgery in children and adolescents (SBU, 2012a). They also noted the same lack of rigorous evidence for or against postoperative analgesics used to reduce or prevent postoperative pain after oral therapies.

The initial plan for this thesis was to conduct a randomized controlled trial (RCT) on the effect of preoperatively administered oral analgesics on postoperative pain after tooth extraction for orthodontic indications. Initially, it was thought that such an RCT would serve as a basis for clinical guidelines on pain management, since no such existing study could be found specifically for dental procedures in children. In order to formulate guidelines, it was crucial to (i) have an understanding of how dentists (both GDPs and SPDs) use pain management strategies in Sweden today (Paper I), and (ii) have an understanding about pain perception in patients after tooth extraction (Paper IV). This was important in order to be able to plan the RCT in terms of calculating the sample size. But because pain intensity after tooth extraction turned out to be only mild to moderate (Paper II), we had to rethink our overall aims. Would it be ethically acceptable to go through with a pharmacological trial when the level of pain was not very severe? In Paper II it was noticed that the mean pain intensity differed from the median, indicating that the majority of participants felt only mild pain at the most painful measurement point, but a minority experienced a moderate to severe pain inten- 
sity per their VAS scores. Therefore, it was decided to delve into what had been written about the postoperative administration of oral analgesics to children as a means to reduce or prevent postoperative pain after dental treatment. We concluded this was an evidence gap, and by that, an important part of the puzzle of how to alleviate children's pain after dental treatment. The systematic review that was performed (Paper III) came out as an empty review. The fact that there is very little research on pain and children, in relation to dental treatments, where children themselves serve as informants encouraged us to pursue a qualitative study that highlighted the voices of the population in question (Paper IV).

Earlier studies have shown that dentists underuse LA when treating children (Klingberg, 1994; Wondimu \& Dahllöf, 2005). Studies have also shown that dentists do not think that children feel pain and that children's reporting of pain is not trustworthy (Murtomaa et al., 1996). Together, this is a signal that the development of guidelines is essential. However, in order to create such guidelines, it must be elucidated how dentists use pain-reducing strategies today to serve as a baseline for new guidelines. And more importantly, it is crucial to know how children perceive pain and discomfort during and after dental treatment in order to be able to optimise pain-relieving strategies.

\section{Main findings}

This thesis has uncovered several important findings. First, the importance of pain-free dental care is still a very central goal that needs to be highlighted and pursued by dentists. This insight emerged while analysing the results of Paper I, the postal survey. Second, despite today's level of knowledge, there is not enough evidence to design any guidelines for the pharmaceutical pain-reduction/prevention strategies. There is therefore a need for well-designed randomized controlled trials (RCTs). The final main finding is that children need information from their dentist in order to cope with dental treatment that potentially might entail pain or discomfort.

The methodology used in Paper II proved to be a good model for future RCTs that seek to determine whether oral analgesics should be prescribed or recommended, and if so, how. The SR and HTA (Paper III) 
found no scientific evidence that would support or discourage the use of oral analgesics after dental treatment to prevent or reduce postoperative pain. Therefore, no guidelines can be designed based on existing research. More well-designed, high-quality studies are sorely needed in order to identify traits that can help dentists tailor their pain management strategies for each patient in order to reduce pain and anxiety associated with dental treatment. This became clear after analysing the data in Paper IV.

The order in which such studies should be performed could be a matter of debate. However, when dealing with a research area characterised by evidence gaps, it is crucial to map out the state of current practices in the present. Therefore, a study of pain management practices among dentists served as starting point for this thesis. This is also important to be able to follow up on the implementation of any guidelines through future studies of practices designed to map changes over time. Before any pharmacological research projects could be planned, a better understanding of pain intensity following tooth extraction is needed as a baseline value and to be able to evaluate bilateral extraction of teeth as a model for future pain research. Since tooth extraction did not lead to any greater pain intensity, it was questionable whether an RCT studying oral analgesics was defensible. Therefore, it was decided to further elucidate children's perceptions of dental treatment. This path was chosen because it was found that although the majority of the participants did not experience a high level of pain during and after tooth extraction, some individuals did. What could be the reason? To address this question, a qualitative study design, using grounded theory, was adopted. In parallel, this thesis' ST/HTA on postoperatively administered oral analgesics used to reduce/prevent postoperative pain in paediatric dental care, was performed. This was another evidence gap identified by the SBU in 2012 and updated in 2020 (SBU, 2012b), which formed the basis of Paper III (Berlin et al., 2019a).

\section{Methodological aspects of the four papers}

One methodological shortcoming of the two first studies is that neither was registered on https://clinicaltrial.gov. This was an oversight on our part. However, it would not have been fair to back register these two 
studies. It is important to register studies prospectively in order to enhance transparency and make it possible for others to review the whole research process. This is a central measure for enhancing the quality of research. In today's research community we are expected to generate knowledge within a knowledge-based system; this is an important quality indicator.

\section{Pain management in clinical practice}

The merits of postal versus digital questionnaires are a matter of debate. In this first Paper, only a mailed paper questionnaire was chosen as method for data collection. In today's society, we are all presented with numerous questionnaires and forms to fill out every time a web browser is opened or our in-box is checked. It is easy to just click away or delete such requests to participate in surveys. In light of this, it was thought that a mail questionnaire would be more attention-grabbing. Another reason for choosing a postal survey was that digital surveys would not have reached out to the wished target group, since the company that maintains the database of dentists' addresses (Cegedim AB) could not provide email addresses. Thus, such a digital survey would not have been a comprehensive study that reached all GDPs in the Skåne county and all SPDs in Sweden.

Along with the questionnaire itself, the participants also received an informational letter and an informed consent form to fill out. Paper mail delivery was also chosen for practical reasons, in order to minimize participants' time and other burdens by not requiring them to print out and sign a digitally delivered consent form. In a systematic review on methodologies for improving response rates in surveys of physicians, VanGeest et al. (2007) concluded that postal surveys have generally been more successful compared to online approaches. They also concluded that first-class stamps on return envelopes and questionnaires designed to be brief, personalised and authorised by professional associations were also more likely to be successful. For present study, pre-paid return envelopes, a rather brief questionnaire, printed sheets, and forms bearing the logo of Malmö University was delivered.

The strength of the postal survey is that it was a comprehensive study that contacted all eligible general dental practitioners in Skåne county and all specialists in paediatric dentistry in Sweden. 
Two reminders were sent, along with duplicate copies of the initial information and questionnaire. Sending two reminders can effectively and economically increase the response rate of a postal survey (Roberts et al., 1993). The response rate could possibly have been improved by making a telephone call to each non-respondent after the second mailed reminder (Salim Silva et al., 2002). However, this was not possible since that information was not available from the company that provided the mailing addresses (Cegedim AB). Therefore, the response rate of $60.5 \%$ (for GDPs and SPDs as a whole) was considered acceptable. This response rate is also in line with an earlier Swedish survey (Wondimu \& Dahllöf, 2005) that had a response rate of $61 \%$. Both these figures $(60.5$ and $61 \%$, respectively) are on the lower end of acceptable response rates (Bowling, 2014). Less than $60 \%$ is considered low, and $75 \%$ or more is considered good (Bowling, 2014). Compared to the results of a review conducted among healthcare professionals that achieved a mean response rate of $56 \%$, our $60.5 \%$ is within the expected range.

One reason for the modest response rate might be the length of the survey. The questionnaire consisted of 19 items in total, some requiring a single answer and others requiring multiple answers. Sending reminders more frequently seems to have led to a higher response rate (Blumenberg et al., 2019). However, this comes at the expense of increasing the financial cost of the survey. The importance of questionnaire length to response rates is also a matter of debate. It is, therefore, crucial that questionnaires consist of validated questions. In our case, a 19-item questionnaire must be regarded as a rather short questionnaire. In a study by Bolt et al. (2014), the researchers concluded that reducing the length of surveys sent to physicians did not necessarily improve the response rate. Instead, they suggest that a drastically shortened version of the questionnaire be sent to non-respondents.

\section{The natural course of pain}

Due to ethical considerations when performing pain studies in children, we were eager not to inflict any extra and/or unnecessary pain. Therefore, a standard procedure that is easy to reproduce and that is performed almost daily in a normal general dental clinic was preferred.

It was important that we had a washout period of two weeks between the treatments to avoid any carryover effect that would have acted as a con- 
founder. A carryover effect is defined as the effect of a treatment from a previous time period on the response at the current time period. In other words, if a patient receives treatment $\mathrm{A}$ during the first period and treatment $\mathrm{B}$ during the second period, then measurements taken during the second period could be a result of the direct effect of treatment B administered during the second period and/or the carryover or residual effect of treatment A administered during the first period. These carryover effects create statistical bias (PennState Eberly College of Science, 2018). To overcome this, it is crucial to allow for a washout period (Pandis et al., 2017). The incorporation of lengthy washout periods in experimental designs can diminish the impact of carryover effects. A washout period is defined as the time between treatment periods. Instead of immediately stopping and then starting the new treatment, there is a period of time during which the treatment from the first period (a drug, for example) is washed out of the patient's system (PennState Eberly College of Science, 2018).

In Paper II potential carryover effects was looked for by measuring DFA before the second extraction/treatment session. Since the CFSS-DS scores did not differ between the first and second extraction, it could be determined that there was no carryover effect and that the washout period had been sufficient.

One strength of the study of the natural course of pain was that we first created a treatment protocol that was followed strictly. Two dentists performed all the extractions in the study, and their procedural techniques were calibrated by reading the protocol individually and then discussing anything that was unclear so that they were both absolutely clear as to how to perform the different steps in the protocol. The use of standardized protocols is important to research reliability. Data collection was also standardized and written down in a protocol. There is always uncertainty regarding respondents' compliance with the study requirements. To address this, all participants were called the first evening after the first treatment to remind them to fill out the pain intensity forms they had taken with them when they left the clinic.

One possible limitation of the study of the natural course of pain was the number of participants. At the time this study was planned, we only had a few studies to base our own sample size calculation on (Acs et al., 1986; Ashkenazi et al., 2007). These studies were not completely com- 
parable to the study that was under planning due their wider range of participant characteristics (age and reason for extraction, to mention a few). One study was found similar to the one that was being designed (Hariharan et al., 2014), which used 27 participants. Based on this, and after thorough discussions with a statistician, we set our goal at 25 to 30 participants. During the course of data collection, some participants were unable to return their filled-out VAS forms. In order to not lose statistical power, more children were enrolled than originally was planned for at the beginning.

\section{Postoperative pain management - systematic review and health technology assessment}

One strength with the SR and HTA was that the search strategies were created in collaboration with informatics specialists at the Malmö University Library, based on the previously determined PICO. The databases searches were also performed by the informatics specialists. These specialists had previous experience with this type of database search because they had participated in several other SRs and HTAs produced by the various departments of the Faculty of Odontology at Malmö University.

One of the most important advantages of using informatics specialists in SRs and HTAs is that they can create accurate search blocks in the various databases. Without their specialist knowledge, there is a great risk of not retrieving all data that should be included. We therefore recommend that the inclusion of informatics specialists in the research group should be a gold standard, since these specialists have a deeper knowledge of search methodology for systematic reviews and health technology assessments.

One criticism that could be raised is that our PICO might have been too narrow, resulting in an empty review. However, the number of titles, abstracts and full-text articles screened (almost 4,000) shows that it was not the PICO itself that was the problem, but rather the lack of welldesigned, relevant studies.

A scientific evidence gap is identified when a systematic review shows that more practical research is needed: for example, when we do not know the effectiveness of a measure or the accuracy of a diagnostic method. An evidence gap is also found when there is a lack of good- 
quality systematic reviews (SBU, 2020a). The purpose of a systematic review is to review and conduct research for the purpose of identifying scientifically supported measures and methods, as well as to identify scientific evidence gaps. This makes systematic reviews an obvious part of a research project or thesis (SBU, 2020b). A good-quality SR includes a predetermined PICO that enhances transparency. An evidence gap occurs when existing studies on a specific topic are too few, too small-scale, of insufficient quality or yield contradictory results. It these cases, additional practical research is needed to improve knowledge about the pros and cons of a given measure or method. It is also important to stress that even if a systematic review cannot identify any primary studies within a specific topic, it is of uttermost importance to publish this finding, since this shows the need for additional research (SBU, 2020b). It is important to identify such evidence gaps for many reasons. The field of knowledge becomes clearer for patients, care providers, and everyone associated with these two groups. From a researcher's perspective it is important to know about the existence of evidence gaps in order to identify what practical research is needed or what SRs need to be performed (SBU, 2020b).

The study was designed so that this SR could be expanded into a health technology assessment (HTA), a study that also evaluates both ethical aspects and health economics. HTAs are an important tool for reviewing scientific evidence in order to appraise how scientifically based knowledge can be implemented in healthcare systems and society more broadly (Rotstein and Laupacis, 2004; INAHTA, 2019).

This SR and HTA followed a PRISMA statement (Moher et al., 2009) to evaluate which studies to include after the primary search and elimination of duplicates and outdated articles. The plan was also to conduct an assessment of relevance and risk of bias using the standardized checklist from the Swedish Agency for Health Technology Assessment and Assessment of Social Services (SBU, 2018), which is similar to the Cochrane checklist (http://www.cochrane.org/) but includes some extra items (Guyatt et al., 2011; SBU, 2018). A quality grading using the GRADE system (Grading of Recommendations Assessment, Development and Evaluation) (Balshem et al., 2011) was also intended to be performed. Finally, the plan was to to assess existing systematic reviews using AMSTAR - A MeaSurement Tool to Assess systematic Reviews 
(Shea et al., 2017). However, due to the fact that no studies remained for further analysis after the first assessment (PRISMA), the other three steps could not be conducted.

This SR and HTA was planned based on an evidence gap identified by the SBU. When our SR and HTA (Berlin et al., 2019a ) was published, we reported it to the SBU, who changed the status of their evidence gap in the database to reflect the fact that it was no longer a result of the absence of a systematic review (SBU, 2012b). Instead, this evidence gap is now identified as only resolvable through new primary studies.

\section{Children's perceptions of pain}

One strength of using a qualitative method (grounded theory - GT) is that it uses an insider perspective. To date, qualitative methods are rarely used when studying children in the field of odontology. GT is a suitable method for generating emerging conceptual categories that explore important aspects of dental treatment. Grounded theory can be used when taking a new approach to a well-known area of research (Stern, 1980).

Another strength of this study is the research group's expertise. One of the co-authors ( $\mathrm{UH})$ has worked extensively with qualitative research that uses GT. When a researcher enters a totally new field of study, it is important to have an experienced person on hand with whom to triangulate.

This study has been inspired by the modified version of GT (Strauss $\&$ Corbin, 1998) since it is humble to the fact that present study is one way of looking at the 'reality'. However, the classical version (Glaser \& Strauss, 1967) did also inspire the work with this GT study since we have started with the problem and how the informant is handling this. The third version of GT, introduced by Charmaz (2000) in which repeated interviews with the same informant are requested, and that the results should be presented as a stories.

The number of informants can be seen as a weakness of this study, although saturation was considered to have been reached after nine interviews. In an ideal world, it would have been preferable to have one or two more participants. However, the Covid-19 outbreak prevented the 
inclusion of new participants and brought an immediate halt to data collection.

Using an interview guide that covered the various themes in an open interview format conducting a conversational style gave participants the opportunity to express themselves freely regarding the topics that were given to them. It also gave the interviewer a great degree of freedom to follow up on the informant's answers, which guided the interviews based on the informant's thoughts and experiences. Using an interview guide is a good idea when interviewing children, because children sometimes provide fairly short answers, and at this point the guide can ensure that no central theme is forgotten. In the present study, this was not a problem, since all the interviews were rather lengthy (30 to 45 minutes) and rich in information.

A recently published article (Aldiabat \& Le Navenc, 2018) discusses different types of data saturation, based on previous studies. They give a short background about where the concept of data saturation in grounded theory derives from. The concept of data saturation applies to the analytic phase of qualitative research and means that the researcher continues sampling and analysing data until there is no new data that emerges, indicating that all concepts within the theory have been welldeveloped and their linkages to other concepts are clearly described. In other words, it is assumed that when no new similarities or differences in the data can be identified, data collection does not have to continue. However, in 2006 Charmaz pointed out disagreement on the definition of data saturation. Charmaz (2006) emphasize that data saturation does not mean that gathering new data should be aborted prematurely when stories and incidents begin a pattern of repetition across interviews; rather, researchers should continue on to the 'conceptualization of comparisons of these incidents' in order to identify new properties in the pattern, until no new properties in the pattern emerge. In our study, we had planned to conduct an additional four or five interviews, but the Covid19 outbreak abruptly prevented the enrolment of new informants. This could possibly be perceived as a shortcoming of this study, but since we reached saturation already after nine interviews, the results has to be judged as valid.

With that said, there is no specific sample size required for qualitative research. In general, the number of informants is smaller in qualitative 
research than in quantitative research. This is because qualitative research methods often involve gathering data for an in-depth understanding of a phenomenon or are focused on meaning (and heterogeneities in meaning), questioning the how and why of a particular issue, process or situation. Therefore, sample size calculation per se is not the main goal; rather, the most important thing is the concept of saturation (Dworkin, 2012).

There is/has been a criticism of grounded theory as methodology, since GT uses interpretive and constructionist tools even if it originates from a positivist/objectivist school of thought. Because of this, it suffers from internal misalignment (Jones \& Alony, 2011). In designing qualitative studies, it is important to include quality control at all stages. In addition, they must obey an internal logic: that is, there must be harmony between the research question, the research approach, the nature of the phenomena, the collection of data and its analysis (Dellve et al., 2002).

\section{Discussion of results}

\section{Pain management in clinical practice}

The difference seen between GDPs and SPDs can be discussed. It can be argued that the results from these two groups are not comparable, since specialists might be aware of problems that general dental practitioners were not aware of at the beginning of treatment. Having this prior knowledge as a specialist might have a conditioning effect, making the use of pain-reducing strategies when treating children more frequent. On the other hand, the questionnaire presented both groups with the same conditions, and thus the patient group in question was the same. Of course, the experience of working as a specialist might have an influence on treatment decisions. A Dutch study (Schorer-Jensma \& Veerkamp, 2010) found the same pattern as the one seen as in Paper I of this study. The Dutch researchers concluded, however, that it needs to be further elucidated whether the difference is due to differing patient needs or supervised neglect by general dentists.

From a developmental perspective, it is crucial that dental personnel always strive to provide pain-free dental care. One aspect of this is to always use LA when there is a risk of pain during treatment. SPDs re- 
ported that they always use LA when performing tooth extractions and doing dental fillings. GDPs also generally used LA for such procedures, but not always, as SPDs did. Why is there a difference? Do GDPs fear that the LA injection itself will be painful? Are they hesitant to give injections to children based on inexperience? The postal survey cannot reveal answers to these questions, but they are important to ask and a starting point for further research in this area.

It is important to manage pain correctly when treating children, since this shapes an individual's future response to painful stimuli. By giving the child enough time to shape their behaviour and by introducing the procedure by telling/showing/doing, it is possible to educate children and de-sensitize them to injections. The question is whether GDPs have the opportunity to give their paediatric patients sufficient time to follow these recommendations.

In addition, we might also problematize whether SPDs' frequent use/recommendation of preoperative and postoperative analgesics is correct, especially since the scientific evidence for their effectiveness is quite limited. The most commonly recommended drug was paracetamol (acetaminophen), which is considered a potentially harmful drug. There have also been reports of side effects, which cannot be overlooked (Matok et al., 2016; Norman et al., 2014). More studies are needed on the effectiveness of pre- and postoperative analgesics administered to reduce or prevent pain during and after dental treatment. If preoperative analgesics are used, it is also important to elucidate the optimal timing for administering the drug to achieve maximum plasma concentration and time of effect. According to FASS, maximum plasma concentration for paracetamol is reached within 30 to 60 minutes, with a half-life of 120 minutes (FASS, 2018). For ibuprofen, the corresponding figures are 120 minutes to maximum plasma concentration and a 120-minute halflife (FASS, 2019). Thus, if oral analgesics are recommended preoperatively, it is important to be aware of the targeted outcome: for example, pain reduction during the LA injection versus management of postoperative pain. In this context, it is also important to be aware of what type of pain patients experience at different points in the procedure and the effectiveness of oral analgesics against those types of pain. The injection of local anaesthetics primarily involves nociceptive pain, for example, while postoperative pain derives from inflammation of the affected tis- 
sue. Therefore, it is not likely that oral analgesics - which target inflammatory processes - will have any beneficial effect on nociceptive pain (Allegaert, 2020). If not used correctly, the desired effect will not be achieved and any benefit to the patient will be merely a result of the placebo effect. If this is the case - and again, the placebo effect should not be disregarded -should a pharmacological substance be used for this reason?

On the other hand, if the differences in frequency of using/recommending different pain management strategies are a question of attitudes, how can this be tackled in dental education? How do teachers at dental schools talk about this topic? What happens when young dentists start to work as general dental practitioners? This is an area that merits research.

Murtomaa et al. (1996) found that neither the American nor the Finnish dentists (general practitioners) routinely asked children about pain, Instead, they encouraged children to report if they felt pain during treatment. Finnish dentists were more likely to not use LA during restorative treatment in both primary and permanent teeth compared to American dentists. Neither of the two groups routinely prescribed preor postoperative pain medication. Finally, neither of the two groups rated dental treatment as particularly painful or unpleasant. A notinsignificant proportion of dentists thought that children were not credible in their pain reporting. The same trend was seen in a Danish study from 2005 (Rasmussen et al.). The findings of Murtomaa et al. (1996) are hugely problematic, because when children's pain is underestimated or their self-reports not seen as credible, there is a considerable risk of failure to deliver needed dental care (Versloot \& Craig, 2009). It is also problematic to find that LA is still underused during filling procedures (Berlin et al., 2018) - a finding was reported as far back as 1994 by Klingberg et al. In that study, $67.7 \%$ of those receiving dental fillings were not given LA. The same trend was found in a study by Wondimu \& Dahllöf (2005), who concluded that LA was underutilised when treating children.

The major question is why we have not seen a change in this troubling trend of underuse of local anaesthesia. One explanation could be that dentists feel stressed by giving administering LA to children via injection. A survey performed in Norway in 2015 (Rønneberg et al.) 
GDPs reported less frequently use of LA in children younger than 10 years when performing restorative treatment. In a Danish study of 317 GDPs, just over one-third said that they felt stress when administering a mandibular block to preschool children (Rasmussen et al., 2005). Despite this, in a Swedish study by Wondimu \& Dahllöf (2005) dentists deemed themselves to have a low need for continuing education in LA and pain control in children.

\section{The natural course of pain}

The results show that pain intensity is not evenly distributed on the VAS. The mean and median values differ, with the mean value being a bit higher than the median value. This indicates that the majority of respondents experienced low to moderate levels of pain, but certain outliers reveal that a portion of children who experience more intense pain. These are an important group to identify and target so that care for such children can be tailored so as to lower the intensity of the pain they experience, with both psychological and pharmacological measures. This has to be further researched and developed. In a systematic review from 2015 (Racine et al.) different factors that can predict anticipatory distress to painful medical procedures in children was evaluated. They concluded that factors such as, for example, child psychopathology, difficult child temperament, parent distress promoting behaviours, parent situational distress, and previous pain events, seems to increase children's anticipatory distress to medical procedures. More studies, longitudinal and experimental, are needed to further analyse these factors (Racine et al., 2015). This is an area the dental research community also has to conduct research within.

There is always room for discussion of the cut-off points for different pain levels. Studies use different types of scales (VAS, NRS, etc.), and may involve rating of different types of pain, but most often chronic pain or pain associated with diagnoses such as multiple sclerosis (Alschuler et al., 2012). Alschuler et al. (2012) suggest that the optimal classification scheme for moderate pain on a 10-point scale is $0-2=$ mild, 3-5 = moderate, and 6-10 = severe. The scheme for worst pain was $0-4=$ mild, $5-7=$ moderate, and $8-10=$ severe. A cut-off value of VAS $\mathrm{PI}_{\mathrm{P}}$ $\geq 40$ was chosen to define clinically relevant pain in the present study. A 
second threshold was defined as $\mathrm{VAS}_{\mathrm{PI}} \geq 30$, reflecting lower levels of moderate pain (van Dijk et al., 2002; Jensen et al., 2003).

The results of this study of the natural course of pain also reveal that bilateral premolar extractions are a good model for future pain studies, since there does not seem to be a conditioning effect from the first to the second treatment. This is, therefore, a good model for pharmaceutical clinical trials, with no carryover effect provided there is an adequate washout period.

A cross-sectional study (Mathias et al., 2019) on factors associated with children's perception of pain following dental treatment concluded that pain may be influenced by preoperative pain and the use of LA and is furthermore associated with uncooperative behaviour during treatment. With reference to a postal survey among dentists in Sweden (Berlin et al., 2018) it is problematic that GDPs report an underuse of LA. The study by Mathias et al. (2019) also underpins the importance of carefully planning care before the procedure, including the use of topical anaesthetics and proper psychological preparation, both of which require the allocation of sufficient time for the procedure.

There are not many studies that have examined the natural course of pain in the field of dentistry. To date, the only study identified on this topic is Berlin et al. (2019b). The natural course of pain following after tonsillectomy has been elucidated in a study by Kim et al. (2018), finding that the pain profile over time was basically the same as in the Berlin et al. study. However, mean pain intensity after tonsillectomy was higher compared with after tooth extraction, with a VAS 64 the first postoperative day (being calculated by taking the mean of three measurement points during day $1-$ morning, lunchtime, and evening). The pain also lasted longer after tonsillectomy. It could be interesting to compare tooth extraction and tonsillectomy further since these treatments are all often performed on children. Making further comparisons between tooth extraction and tonsillectomy is however, in my opinion, not meaningful since these are two very different surgical interventions. Despite having the same profile on postoperative pain course, the pain is present as a total, much longer after tonsillectomy. This procedure also requires general anaesthesia. With this comes also other problems such as nausea and vomiting (Karlsson et al., 1990). Aydin et al. (2016) studied pain intensity during the procedure of phlebotomy (draw blood from 
a vein) in 7-12-year-olds. Three intervention groups were exposed to different coping techniques and a fourth group served as control group. All groups consisted of 30 participants. Pain ratings were done using Wong-Baker FACES Pain Rating Scale, and the control group scored 2.86 (corresponding to VAS 28.6), in pain intensity. This is the same similar to the participants in Paper II, both regarding number of participants and pain intensity levels. In the light of this, our model presented in Paper II (tooth extraction) has to be regarded as a highly suitable model for future pain research on children since it does not require additional care than the one already planned prior orthodontic treatment and it can be, and often is, repeated.

Kim et al. (2018) found that children perceived less postoperative pain compared to adults after tonsillectomy. One reason for this was thought to be that adults were more likely to have inflammation as an indication for their tonsillectomies, whereas the indication for children was most often obstructive symptoms. Therefore, postoperative pain was thought to be correlated to neutrophil infiltration, accounting for the more severe pain in the adult group compared to the child group. This is why the study by Berlin et al. (2019b) is methodologically sounder, since earlier studies looked at tooth extraction for a variety of reasons (caries, pulpal involvement, etc.) all of which include some degree of existing inflammation.

\section{Postoperative pain management - systematic review and health technology assessment}

The SR and HTA came out empty. There has been and is still a discussion as to whether empty reviews should be published. First of all, it is important that the methodology be well described and determined beforehand. If these requirements are met and the review still turns out empty, it is important to look at whether the inclusion and exclusion criteria are too strict or too narrow.

This SR was registered in the PROSPERO database, which increases transparency (Stewart et al., 2012). SRs are promoted as providing the best evidence to inform decision-making. With this comes the responsibility to promote and encourage the use of the best methods and practices to ensure that the reviews are as transparent, robust and bias-free as possible. One key element to high-quality SRs is the protocol that marks 
out the main objectives, key design features and analyses planned for the review (Centre for Reviews and Dissemination, 2009; Higgins et al., 2020; Institute of Medicine, 2011). Having a prior written protocol for the review ensures that the review methods are transparent, reproducible and adhere to the predetermined plan. This should help avoid bias (Stewart et al., 2012). Prospective registration of SRs is an important development that will play a role in promoting transparency and avoiding bias. This will lead to improved methodological standards. It is also important in order to avoid unintentional duplication. Avoiding duplication ensures that, globally, research funding can be invested wisely and more effectively (Stewart et al., 2012).

The outcome of the SR and HTA is troubling, since we still do not know whether administration of oral analgesics in the immediate postoperative period has any effect on reducing or preventing postoperative pain after dental treatment, and yet according to Berlin et al. (2018) it is still recommended. It is important to emphasise that although there is no scientific evidence for its effectiveness, there is also no scientific evidence against its effectiveness. What is much needed is more welldesigned primary studies.

Although over-the-counter oral analgesics are safe medications, there have been reports of side-effects from paracetamol (acetaminophen) (Roberts et al., 2015), which is the most widely used analgesic worldwide (Goldman, 2013; Blieden et al., 2014). Roberts et al. (2015) studied paracetamol used over the long term and found its risks were related to dose-response. Thus, in that aspect it is not possible to extrapolate their results to the present study. It is also important to state that the research community has different views on the potential harmful sideeffects of paracetamol. With this said, it is still important to have a strong indication before giving pharmaceutical products to patients and not recommend them on the sole basis of a better-safe-than-sorry stance; the precautionary principle should prevail (Axelsson, 2014).

\section{Children's perceptions of pain}

It turned out that pain and discomfort themselves were not the main concern for the informants. Instead, we found they could handle those aspects of the procedure quite well, depending mainly on the information they got from their dentist. Their own motivation to undergo or- 
thodontic treatment for the outcome of straight teeth was also an important coping strategy. These two components helped them tolerate the pain and discomfort of tooth extraction. Giving the child a feeling of control is also a key to supporting their coping abilities.

The informants reported that they were satisfied with the information they were given when they met with the dental team performing the tooth extractions. All the children in this study seemed to have a positive feeling towards the dentist that performed their extractions. This seems to be an important aspect in helping children cope with dental treatments. Abrahamson et al. (2002) found, in a qualitative study, that DFA seems to be related to individual vulnerability, but in many cases was also related to traumatic dental care experiences, where perceived negative dentist behaviour seems to be significant. Thus, one part of preventing DFA is to ensure that a good relationship is created between the patient and the care provider (Abrahamson et al., 2002). Otherwise, there is a risk that fearful patients might get caught up in a 'vicious circle' that is hard to break, with negative expectations about treatment leading to increased fear and anxiety (Kent, 1989). The study by Abrahamson et al. (2002) was conducted with adults; however, it is reasonable to believe that the same line of thinking can be applied to children.

Still, the participants did report some anxiety, especially prior to the first extraction. How can we reduce this anxiety? Should the dentist performing the extractions plan for an initial meeting to give information about the extraction procedure? Would such a protocol be defensible from a health economics perspective? Should orthodontist provide more information about the dental extraction itself?

Why not beginning by asking the children about their perceptions regarding dental care, with a focus on tooth extractions? Before doing so, it was necessary to square off the topic of pain in paediatric dental care from different angles, which was believed to be done with the postal survey on pain management in paediatric dental care and the study on the natural course of pain. This was important from an ethical perspective. It is necessary to narrow a research area that is initially broad in order not to overwhelm participating children with unnecessary questions. In addition, it is important to include children in research if they can benefit from it. They are the only ones who can provide insight into their perceptions regarding dental treatment. 


\section{Ethical consideration in research involving children}

Involving children in research is ethically problematic. All research that includes human subjects is grounded on the informed consent procedure, which requires competent participants who are able to decide for themselves. To that end, participants have to be able to fully understand the consequences of the research, its possible risks and benefits, and also the features of integrity. Children cannot be assumed to fulfil those prerequisites, and therefore their inability to fully grasp the meaning of the research question and give informed consent is limited. This is also valid for other groups with impaired autonomy, such as people with severe illness, learning disabilities or communication problems, or persons who are unconscious. Therefore, in terms of ethical aspects, research on human subjects should primarily be conducted on individuals who are competent to understand the scope of the research and are able to give their consent. It is important to avoid research involving children whenever possible.

However, it may also be unethical to not involve children in research studies evaluating drugs. If children were excluded from all drug research, medication used in children would be limited to extrapolation from adult studies or might even exclude children from the possibility of receiving existing and new drugs that they could benefit from. Therefore, it is important to include children and adolescents in research concerning this age group. The research community has a significant responsibility to design, approve and conduct high-quality studies in children so that they can have access to important medications and receive optimal therapies (Shaddy \& Denne, 2010). Research involving children requires high ethical standards and analysis and an understanding of children's mental capabilities so that the information given to them can be tailored to their age.

There has been very little research on how children experience dental care. The present study analysed the experience of pain in association with tooth extractions. Tooth extraction was used as a model to study pain. The ethical analysis can be made from three perspectives: the patient, the dentist and society.

For the patient, we deemed that there was a slight risk of experiencing pain or violating the children's privacy in conjunction with the treatment. In the study on the natural course of pain, the extractions were 
performed in alignment with current treatment protocols. It was also extremely central that children's participation be voluntary, based on adequate age-appropriate information, and that they have the possibility of discontinuing their participation at any stage. We received signatures on informed consent forms from the participants' legal guardians and obtained verbal assent from the children. According to the Swedish Ethical Review Authority (https:/etikprovningsmyndigheten.se/), all children aged 15 or older should give their consent to participation in research. Despite the consent of the legal guardians, research may not be carried out if an individual under the age of 15 understands what it means for them and opposes it. Adolescents between the ages of 15 and 18 may give their own consent if they realize what the research means for them.

Dentists find it stressful to treat patients who are experiencing pain or suffer from DFA. It is therefore of great importance to find new treatment strategies that can reduce pain and DFA among their patients and thus ultimately reduce stress for the dentist. However, in studies such as this where a questionnaire was sent out asking about pain management strategies in paediatric dental care, there is a risk that dental providers might feel critically judged. This could lead to them feeling that their integrity had been violated. It is of the uttermost importance to inform participants about the routines to ensure that answers will be unidentifiable and that all raw data will be, by obligation, handled with great care so that no unauthorized persons can access it.

Currently, dental care for children and adolescents with DFA is very costly for society due to the need for specialist dental care, increased need to perform treatments under general anaesthesia, and the need for children and their guardians to attend several follow-up visits, leading to loss of productivity and income. In summary, if there is a possible treatment that could reduce the risk of experiencing pain, it is ethically important to evaluate that treatment modality. Should this method be found to be cost-effective, there is a rationale for it to be implemented; otherwise, it should not be introduced to dental care. 


\section{CONCLUSIONS}

There are some central conclusions that can be drawn from this thesis. First, the importance of pain-free dental care is still a very central goal that needs to be highlighted and pursued by dentists. Second, since pain consists of both a physiological and a psychological component, it is just as important to consider both pharmaceutical agents and psychological techniques. In addition, the following conclusions can be made.

- Pain management strategies differ between general dental practitioners (GDPs) and specialists in paediatric dentistry (SPDs).

- There is a difference in the use of local anaesthetics (LA) and recommendations for oral analgesics in paediatric dental care between GDPs and SPDs, which points to uncertainty regarding pain management strategies when treating children and adolescents.

- In general dentistry, LA is used less often for fillings procedures compared to specialist dentistry.

- GDPs use LA less often for restorative treatment of primary teeth compared to treatment of permanent teeth.

- SPDs recommend oral analgesics pre- and postoperatively to a much greater extent than GDPs.

- Uncomplicated extractions of maxillary premolars result in moderate postoperative pain that peaks 2 hours after treatment, coinciding with the time when the effect of LA wears off.

- Tooth extraction is a painful experience. In approximately 3 out of 10 extractions, pain is perceived as moderate or worse. 
- There is no difference in pain intensity between a patient's first and second extraction. These types of extractions can serve as a good model for future pain research.

- The empty systematic review/health technology assessment points to an evidence gap, since no studies could be included for further quality assessment. The lack of data leading to this evidence gap makes it impossible to formulate guidelines on pain management in paediatric dentistry.

- There is an urgent need for high-quality primary studies of this topic among children and adolescents in order to be able to formulate such guidelines.

- Well-designed studies among children, preferably with a RCT design that measures patient-centred outcomes, must be planned for.

- Children describe pain in conjunction with orthodontically indicated tooth extractions.

- Children are rather resilient and able to cope with tooth extractions that initially cause anxiousness if they are well-informed about the treatment procedure and are given some tools that allow them to feel a sense of control.

- Dental care providers should try to alter their strategies in terms of how and what they share with the child prior to, during, and after tooth extractions.

- The timing of when to give this information is also crucial. If these prerequisites are met, children report that they can cope with the discomfort and pain they experience during and after dental extractions. 


\section{CLINICAL IMPLICATIONS AND OUTLOOK FOR THE FUTURE}

This thesis has shown that we need to develop our methods further in order to prevent children from feeling pain during dental treatment.

Dental care providers must be better at using the methods that are already available, including both psychological and procedural measures.

Oral analgesics for dental care require further evaluation.

Overall, this thesis points towards an urgent need for more welldesigned studies that can be used to support the formulation of guidelines for pain management strategies in paediatric dental care. Since pain consists of both a psychological and a physiological component, both aspects must be researched to find the best way to minimise periand postoperative pain in dentistry. Future studies has to focus on psychological and behavioural measures, use of different pharmacological substances, and pain-sensitive children.

It is important to target certain specific areas. One is to try to identify personal traits of children that would allow dental providers to better identify which patients need additional or special attention, which ones would benefit from more time to get comfortable with the dental situation and/or receive help in shaping their behaviour, as well as those who might benefit from pre- or postoperative oral analgesics.

It is important to be aware of the pharmacokinetics of oral analgesics in order to use them correctly and with the proper indications. Paracetamol and NSAID, target the inflammation process and will therefore not have any beneficial effect on nociceptive pain. When used incorrectly, they will not achieve the desired effect except possibly through a placebo effect. Although the placebo effect should not be disregarded, 
we must ask ourselves whether a pharmacological substance should be used for this reason alone.

It is also important to gain knowledge why there is resistance to giving LA to children, particularly among general dentists. Identifying the reason for this belief will help target extra resources to increase awareness of the importance of using LA more generously with paediatric patients and enhancing its acceptance.

Dental curricula should also be studied to learn more about what dental students' education on and attitudes towards LA. The responsibility for the perpetration of such knowledge and attitudes falls not only on universities providing undergraduate education but also on institutions responsible for continuing education. It is important that students graduate from dental schools well acquainted with these techniques.

It is also important to evaluate what children and parents think about the treatment they receive and what else they need, in terms of treatment and handling at the dental office, in order to achieve and maintain good oral health. Using focus groups and GT could provide answers to these questions.

The dental research society also has to find indicators in children that can be used to predict if a child is more sensitive to pain, and therefore more likely to develop DFA/DBMP. This is to be able to optimize the care.

It is also important to perform an RCT that examines pre- or postoperative analgesics administered with the goal of minimising pain in order to determine whether, and how, they should be used in clinical practice for those who are at risk of scoring high in pain intensity.

Research has to direct its focus on dental personnel's attitudes towards administration of local anaesthetics on children, preferably with a qualitative study design as a complement to the postal survey recently conducted.

It is important that future studies also include other age groups, preferably children younger than the ones studied in this thesis.

In this thesis, procedural pain was studied through the specific case of tooth extraction performed as part of orthodontic treatment. This is, in most cases, a rather atraumatic treatment with few complications. Therefore, studies - preferable randomized controlled trials - should be conducted using other specific pain conditions as a model. 


\section{ACKNOWLEDGEMENTS}

This thesis you are holding in your hand is a milestone on a long journey that started 2013. This journey would not have been possible without a number of persons around me. Your encouragement and neverfailing support are what has made this thesis possible. For this I will always be deeply grateful!

I am grateful to all the children who participated in studies II and IV and made it possible to perform this research.

Professor Gunilla Klingberg, my main supervisor and co-author, I will be forever thankful that you have been such an amazing guide on my journey when I have been entering the wonderful and exciting-but sometimes confusing and stressful-world of science and research! Your positive and supportive words have always lifted me up when I have had moments of self-doubt. You have shared your vast knowledge and wisdom very generously, regardless of the topic, from dead serious science to very vital life hacks in general.

Professor Thomas List, my co-supervisor and co-author, thank you for always being encouraging and giving me valuable advice on how to navigate in the complex jungle of research and writing, and for putting things in a different perspective.

Odont Dr Karin Ridell, my co-supervisor and co-author, thank you for always being present no matter what large or small thoughts were on my mind, and for always popping in to see me with encouraging words. 
Associate professor Thomas Davidson, my co-author - I am very thankful for you introducing me to the world of health economics and for so generously inviting me to Linköping for fruitful discussions!

Dr Danijela Toft, my co-author - thank you for always being positive when came to you with research propositions. Thank you as well for your sharp eyes during the writing process.

Odont Dr Susanne Brogårdh-Roth, my co-author - your never-ending enthusiasm and supportive words have always inspired me and invigorated me.

Dr Elisabeth Lager, co-author and roommate - thank you for being such a great roommate and always making me smile and laugh, and for always cheering me on.

Associate professor Ulrika Hallberg, co-author and mentor - thank you for opening the door to the world of qualitative research in an exemplary manner! I am forever grateful for that.

Dr Anna Alm and Dr. Rikard Roxner - thank you for always very willingly rolling up your sleeves when I needed help with clinical work for my research and for sharing your linguistic skills in teenage language!

Librarians Elisabeth Bergenäs and Martina Vall, co-authors - thank you for your immensely valuable work building huge search blocks and for putting up with me when I asked you to run it twice!

My colleagues across the corridor, associate professors Liselotte Paulsson, Sofia Petrén, and Mikael Sonesson - thank you for all your help recruiting participants for my research projects, and also for all the happy encouragement that gave me energy during my $\mathrm{PhD}$ studies.

Associate professor Aron Naimi-Akbar - thank you for interesting and rewarding discussions and for having patience with me when an 'acute research issue' pops up in my head. 
Senior consultants Dr Michael Blitz, and associate professor Thor Henrikson - thank you for invaluable help identifying suitable participants for my clinical studies.

All former and present colleagues and coworkers at the Department of Paediatric Dentistry and the Department of Orthodontics in the Faculty of Odontology at Malmö University - thank you for always being supportive and encouraging. No one mentioned, no one forgotten!

Colosseum Smile Dental Group, Malmö, Sweden - thank you for your willing attitude when I contacted you regarding collaboration in this project.

Dental nurse Pia Björklund - thank you for keeping track of me and my patients at times when my head may have been elsewhere.

My fellow research colleagues at the National Dental Research School: it was a pleasure to have gotten to know all of you, and you all have contributed to an enjoyable and stimulating environment during my $\mathrm{PhD}$ student life when we met in locations throughout Sweden.

Gail Conrod provided excellent revision of the English text in Papers I and II.

Per-Erik Isberg provided statistical guidance in Paper I and II.

Dr Pernilla Holmberg, my long-term and forever best friend, thank you for always being there by my side and cheered me on. Who would have guessed, when we were undergraduates, that I would end up with my own name tag on a door at the faculty?

To my parents, Birgitta and Sven-Olle, who always have supported me and been there for me, and to my sister EIna and her family, for your constant support and encouragement. Special thanks to Ida, who is the artist who created the painting on the cover of this thesis, as well as special thanks to Filip, who freely (somewhat) volunteered as a model for my 'The research process for this thesis (Thesis at a glance)' pictures. 
And most of all - a HUGE thank you to my husband Göran! You have seen my highs and lows! You served me coffee when I was nesting in front of my computer. You dragged me out on the golf course when I most needed it. You put up with my mood swings (and not only my bad golf swing). And still you love me! We are an amazing team! I love you!

I would also like to send a thought to our late beloved dog Okkie, who always kept me company in my home office. It's a shame you cannot be with me today, but I know that you are busy chasing rabbits on the other side of the rainbow! Happy hunting!

These studies would not have been possible without the financial support from the Faculty of Odontology at Malmö University, Oral Health Research by Region Skåne (Odontologisk Forskning i Region Skåne, OFRS), the American Dental Society of Sweden, the Swedish Dental Society, and the Swedish Society of Paediatric Dentistry. 


\section{REFERENCES}

Aartman, I.H., van Everdingen, T., Hoogstraten, J. \& Schuurs, A.H. (1998) 'Selfreport measurements of dental anxiety and fear in children: a critical assessment', ASDC journal of dentistry for children, 65(4), pp. 252-258, 229-230. PMID: 9740944.

Abrahamsson, K.H., Berggren, U., Hallberg, L. \& Carlsson, S.G. (2002) 'Dental phobic patients' view of dental anxiety and experiences in dental care: a qualitative study', Scandinavian Journal of Caring Sciences, 16(2), pp.188-96. PMID: 12000673. doi:10.1046/j.1471-6712.2002.00083.x.

Acs, G., Moore, P.A., Needleman, H.L. \& Shusterman, S. (1986) 'The incidence of post-extraction pain and analgesic usage in children', Anesthesia Progress, 33(3), pp. 147-151.

Aldiabat, K.M. \& Le Navenec, C. (2018) 'Data Saturation: The Mysterious Step In Grounded Theory Method', The Qualitative Report, 23(1), pp. 45-61. Available from: https://nsuworks.nova.edu/tqr/vol23/iss1/18.

Al-Khateeb, T.H. \& Alnahar, A. (2008) 'Pain experience after simple tooth extraction', Journal of Oral Maxillofac Surgery, 66, pp. 911-917. PMID: 18423280. doi: 10.1016/j.joms.2007.12.008.

Allegaert, K. (2020) 'A Critical Review on the Relevance of Paracetamol for Procedural Pain Management in Neonates', Frontiers in Pediatrics, 8(89), pp. 1-11. PMID: 32257982; PMCID: PMC7093493. doi: 10.3389/fped.2020.00089.

Alschuler, K.N., Jensen, M.P. and Ehde, D.M. (2012) 'Defining mild, moderate, and severe pain in persons with multiple sclerosis', Pain Medicine, 13(10), pp. 13581365. PMID: 22925457; PMCID: PMC3473137. doi:10.1111/j.15264637.2012.01471.x.

Ambuel, B., Hamlett. K.W., Marx, C.M. \& Blumer, J.L. (1992) 'Assessing distress in pediatric intensive care environments: the COMFORT scale', Journal of Pediatric Psychology, 17(1), pp. 95-109. PMID: 1545324. doi: 10.1093/jpepsy/17.1.95. 
Anand, K.J. \& Hickey, P.R. (1987) 'Pain and its effects in the human neonate and fetus', The New England Journal of Medicine, 317(21), pp. 1321-1329. PMID: 3317037. doi: 10.1056/NEJM198711193172105.

Arnrup, K., Broberg, A.G., Berggren, U. \& Bodin L. (2002) 'Lack of cooperation in pediatric dentistry--the role of child personality characteristics', Pediatric Dentistry Journal, 24(2), pp. 119-28. PMID: 11991314

Arnrup, K., Broberg, A.G., Berggren, U. \& Bodin L. (2007) 'Temperamental reactivity and negative emotionality in uncooperative children referred to specialized paediatric dentistry compared to children in ordinary dental care', International Journal of Paediatric Dentistry, 17(6), pp. 419-429. doi:10.1111/j.1365263X.2007.00868.x

Asch, D.A., Jedrziewski, M.K. \& Christakis, N.A. (1997) 'Response rates to mail surveys published in medical journals', Journal of Clinical Epidemiology, 50(10), pp.1129-1136. PMID: 9368521. doi: 10.1016/s0895-4356(97)00126-1.

Ashkenazi, M., Blumer, S. \& Eli, I. (2007) 'Post-operative pain and use of analgesic agents in children following intrasulcular anaesthesia and various operative procedures', British Dental Journal, 202(5), E13; discussion pp. 276-7. PMID: 17273178. doi: 10.1038/bdj.2007.81.

Ashley, P.F., Parekh, S., Moles, D.R., Anand, P. \& MacDonald, L.C. (2016) 'Preoperative analgesics for additional pain relief in children and adolescents having dental treatment', Cochrane Database of Systematic Reviews, 8(8), CD008392. PMID: 27501304. doi: 10.1002/14651858.CD008392.pub3.

Axelsson, I. (2014) 'Paracetamol till barn och gravida - försiktighetsprincipen bör råda', Läkartidningen, pp. 32-33. [In Swedish].

Aydin, D., Şahiner, N.C. \& Çiftçi, E.K. (2016) 'Comparison of the effectiveness of three different methods in decreasing pain during venipuncture in children: ball squeezing, balloon inflating and distraction cards', Journal of Clinical Nursing, 25(15-16), pp. 2328-2335. PMID: 27112434. doi: 10.1111/jocn.13321.

Bailey, B., Gravel, J. \& Daoust, R. (2012) 'Reliability of the visual analog scale in children with acute pain in the emergency department', Pain, 153(4), pp. 839842. PMID: 22305630. doi: 10.1016/j.pain.2012.01.006.

Balshem, H., Helfand, M., Schünemann, H.J., Oxman, A.D., Kunz, R., Brozek, J., Vist, G.E., Falck-Ytter, Y., Meerpohl, J., Norris, S. \& Guyatt, G.H. (2011) 'GRADE guidelines: 3. Rating the quality of evidence', Journal of Clinical Epidemiology, 64(4), pp. 401-406. PMID: 21208779. doi: 10.1016/j.jclinepi.2010.07.015.

Bandstra, N.F., Johnson, S.A., Filliter, J.H. \& Chambers, C.T. (2012) 'Self-reported and parent-reported pain for common painful events in high-functioning children and adolescents with autism spectrum disorder', The Clinical Journal of Pain, 28(8), pp. 715-721. PMID: 22699139. doi: 10.1097/AJP.0b013e318243ecf6. 
Barnombudsmannen. (2015) A booklet on the UN Convention on the Rights of the Child. Available at: https://www.barnombudsmannen.se/globalassets/dokumentfor-nedladdning/publikationer/barnkonventionen-pa-engelska.pdf (Accessed: 8 July 2020).

Battista, R.N. \& Hodge, M.J. (1999) 'The evolving paradigm of health technology assessment: Reflections for the millennium', Canadian Medical Association Journal, 160(10), pp. 1464-1467. PMID: 10352637; PMCID: PMC1232608.

Bee, H. \& Boyd, D. (2014) The Developing Child. $13^{\text {th }}$ edn. Essex: Pearson Education Limited.

Beltramini, A., Milojevic, K. \& Pateron, D. (2017) 'Pain Assessment in Newborns, Infants, and Children', Pediatric Annals, 46(10), e387-e395. PMID: 29019634. doi:10.3928/19382359-20170921-03.

Berggren, U. \& Meynert, G. (1984) 'Dental fear and avoidance: causes, symptoms, and consequences', The Journal of the American Dental Association, 109(2), pp. 247-251. PMID: 6590605. doi: 10.14219/jada.archive.1984.0328.

Berlin, H., List, T., Ridell, K. \& Klingberg, G. (2018) 'Dentists' attitudes towards acute pharmacological pain management in children and adolescents', International Journal of Paediatric Dentistry, 28(2), pp. 152-160. PMID: 28691744. doi: 10.1111/ipd.12316.

Berlin, H., Vall, M., Bergenäs, E., Ridell, K., Brogårdh-Roth, S., Lager, E., List, T., Davidson, T. \& Klingberg, G. (2019a) 'Effects and cost-effectiveness of postoperative oral analgesics for additional postoperative pain relief in children and adolescents undergoing dental treatment: Health technology assessment including a systematic review', PLoS One, 14(12), e0227027. PMID: 31891621; PMCID: PMC6938383.doi:10.1371/journal.pone.0227027.

Berlin, H., List, T., Ridell, K., Davidson, T., Toft, D. \& Klingberg, G. (2019b) 'Postoperative pain profile in 10-15-year-olds after bilateral extraction of maxillary premolars', European Archives of Paediatric Dentistry, 20(6), pp. 545-555. PMID: 30963511. doi: 10.1007/s40368-019-00425-9.

Beyer, J.E. \& Aradine, C.R. (1986) 'Content validity of an instrument to measure young children's perceptions of the intensity of their pain', Journal of Pediatric Nursing, 1(6), pp. 386-395. PMID: 3641907.

Blieden, M., Paramore, L.C., Shah, D. \& Ben-Joseph, R. (2014) 'A perspective on the epidemiology of acetaminophen exposure and toxicity in the United States', Expert Review of Clinical Pharmacology, 7(3), pp. 341-348. PMID: 24678654. doi: 10.1586/17512433.2014.904744.

Blumenberg, C., Menezes, A.M.B., Gonçalves, H., Assunção, M.C.F., Wehrmeister, F.C., Barros, F.C. \& Barros, A.J.D. (2019) 'The Role of Questionnaire Length and Reminders Frequency on Response Rates to a Web-Based Epidemiologic Study: A Randomised Trial', International Journal of Social Research Methodology, 22(6), pp. 625-635. Available at: 
https://search.ebscohost.com/login.aspx?direct=true\&db=eric\&AN=EJ1230628\& lang $=$ sv\&site $=$ eds-live (Accessed: 4 September 2020).

Blumer, H. (1969) Symbolic interactionism: perspective and method. Englewood Cliffs, N.J.: Prentice Hall.

Bolt, E.E., van der Heide, A. \& Onwuteaka-Philipsen, B.D. (2014) 'Reducing questionnaire length did not improve physician response rate: a randomized trial', Journal of Clinical Epidemiology, 67(4), pp. 477-481. Available at: https://search-ebscohost-

com.proxy.mau.se/login.aspx?direct=true $\& \mathrm{db}=$ edselp\&AN $=\mathrm{S} 089543561300390$ 9\&lang $=$ sv\&site=eds-live (Accessed: 4 September 2020).

Bowling, A. (2014) Research Methods in Health Investigating Health and Health Services. Maidenhead, Berkshire, UK: Open University Press.

Broberg, A., Almqvist, K. \& Tjus, T. (eds). (2003) Klinisk barnpsykologi. Utveckling på avvägar. Stockholm: Natur och Kultur. [In Swedish].

Broberg, A.G. \& Klingberg, G. (2017) 'Child and Adolescent Psychological Development', in Koch, G., Poulsen, S., Espelid, I. \& Haubek, D. (eds). Pediatric Dentistry - A Clinical Approach. $3^{\text {rd }}$ edn. West Sussex, UK: Wiley Blackwell, pp. 1527.

Bäckryd, E. \& Werner, M. (2019) 'En introduktion till smärtmedicinen', in Werner, M. \& Bäckrud, E. (eds.) Akut och cancerrelaterad smärta. Smärtmedicin vol 1. Stockholm: Liber AB, pp. 21-34. [In Swedish].

Campiglia, L., Consales, G. \& De Gaudio, A.R. (2010) 'Pre-emptive analgesia for postoperative pain control: a review', Clinical Drug Investigation, 30 Suppl 2, pp. 15-26. PMID: 20670045. doi: 10.2165/1158411-S0-000000000-00000.

Castarlenas, E., Miró, J. \& Sánchez-Rodríguez, E. (2013) 'Is the verbal numerical rating scale a valid tool for assessing pain intensity in children below 8 years of age?', The Journal of Pain, 14(3), pp. 297-304. PMID: 23380267. doi: 10.1016/j.jpain.2012.12.004.

Centre for Reviews and Dissemination (CRD), University of York. (2009) Systematic Reviews: CRD's Guidance for Undertaking Reviews in Health Care York. UK: Centre for Reviews and Dissemination, University of York. Available at: http://www.york.ac.uk/inst/crd/pdf/Systematic Reviews.pdf (Accessed 4 July 2020).

Chandler, J., Cumpston, M., Thomas, J., Higgins, J.P.T., Deeks, J.J. \& Clarke, M.J. (2020) 'Chapter I: Introduction', in Higgins, J.P.T. , Thomas, J., Chandler, J., Cumpston, M., Li, T., Page, M.J. \& Welch VA. (eds.) Cochrane Handbook for Systematic Reviews of Interventions version 6.0 (updated September 2020). Cochrane. Available at: www.training.cochrane.org/handbook (Accessed $27 \mathrm{Au}-$ gust 2020). 
Charmaz, K. (2000) 'Grounded Theory. Objectivist and constructivist methods', in Denzin, N.K. and Lincoln, Y.S. (eds.) Handbook of qualitative research. $2^{\text {nd }}$ edn. Thousand Oaks, CA: Sage, pp. 509-535.

Charmaz, K. (2006) Constructing Grounded Theory. A practical Guide Through Qualitative Analysis. London: Sage Publications.

Chess, S. \& Thomas, A. (1999) Goodness of fit: Clinical applications for infancy through adult life. Philadelphia, PA: Bruner/Mazel.

Clark, M.S. and Brunick, A.L. (2015) Handbook of Nitrous Oxide and Oxygen Sedation. $4^{\text {th }}$ edn. St. Louis, Missouri: Elsevier.

Cook, J.V., Dickinson, H.O. \& Eccles, M.P. (2009) 'Response rates in postal surveys of healthcare professionals between 1996 and 2005: an observational study', BMC Health Services Research, 9, p. 160. PMID: 19751504; PMCID: PMC2758861. doi: 10.1186/1472-6963-9-160.

Creswell, J.W. (2008) Research Design: Qualitative, quantitative, and mixed methods approaches. Thousand Oaks, CA: Sage Publication.

Cuthbert, M.I. \& Melamed, B.G. (1982) 'A screening device: children at risk for dental fears and management problems', ASDC Journal of Dentistry for Children, 49(6), pp. 432-436. PMID: 6960031.

Davey, G.C. (1989) 'Dental phobias and anxieties: evidence for conditioning processes in the acquisition and modulation of a learned fear', Behavior Research and Therapy, 27(1), pp. 51-58. PMID: 2914005. doi: 10.1016/00057967(89)90119-8.

de Tovar, C., von Baeyer, C.L., Wood, C., Alibeu, J.P., Houfani, M. \& Arvieux, C. (2010) 'Postoperative self-report of pain in children: interscale agreement, response to analgesic, and preference for a faces scale and a visual analogue scale', Pain Research and Management, 15(3), pp. 163-168. PMID: 20577659. PMCID: PMC2912614. doi: 10.1155/2010/475907.

Dellve, L., Abrahamsson, K.H., Trulsson, U. \& Hallberg, L.R.M. (2002) 'Grounded theory in public health research', in Hallberg, L.R.M. (ed.). Qualitative Methods in Public Health Research - Theoretical Foundations and Practical Examples. Lund: Studentlitteratur AB, pp. 137-173.

Dillman, D.A., Smyth, J.D. \& Christian, L.M. (2014) Internet, Phone, Mail, and Mixed-Mode Surveys - The Tailored Design Method. $4^{\text {th }}$ ed. Hoboken, NJ: John Wiley \& Sons, Inc.

Dorland. (2020) Dorland's illustrated medical dictionary. $33^{\text {rd }}$ ed. Philadelphia: Saunders.

Dworkin, S.L. (2012) 'Sample size policy for qualitative studies using in-depth interviews', Archives of Sexual Behavior, 41(6), pp. 1319-1320. PMID: 22968493. doi: 10.1007/s10508-012-0016-6. 
Ebell, M.H., Siwek, J., Weiss, B.D., Woolf, S.H., Susman, J., Ewigman, B. \& Bowman, M. (2004) 'Strength of recommendation taxonomy (SORT): a patientcentered approach to grading evidence in the medical literature', The Journal of the American Board of Family Practice, 17(1), pp. 59-67. PMID: 15014055. doi: 10.3122/jabfm.17.1.59.

Edwards, M.L., Dillman, D.A. \& Smyth, J.D. (2013a) Attitudes of Nebraska residents on Nebraska water management (Technical Report No. 13-020). Pullman: Washington State University, Social and Economic Sciences Research Center.

Edwards, M.L., Dillman, D.A. \& Smyth, J.D. (2013b) Attitudes of Washington residents on Washington water management (Technical Report No. 13-019). Pullman: Washington State University, Social and Economic Sciences Research Center.

Enskär, K., Ljusegren, G., Berglund, G., Eaton, N., Harding, R., Mokoena, J., Chauke, M. \& Moleki, M. (2007) 'Attitudes to and knowledge about pain and pain management, of nurses working with children with cancer: A comparative study between UK, South Africa and Sweden', Journal of Research in Nursing, 12(5), pp. 501-515. doi:10.1177/1744987107080455

FASS. (2019) Paracetamol [Online]. Available at: https://www.fass.se/LIF/product?userType $=0 \& n p l I d=19581215000033$ cessed 13 October 2020).

FASS. (2020) Ibuprofen [Online]. Available at: https://www.fass.se/LIF/product?userType=0\&nplId=20080117000043 （Accessed: 13 October 2020).

Finkelstein, A. (2005) 'Levels of evidence: how they help in applying study findings to clinical practice', The Journal of Family Practice, 54(12), p. 1032. PMID: 16321339 .

Freund, D. \& Bolick, B.N. (2019) 'CE: Assessing a Child's Pain', The American Journal of Nursing', 119(5), pp. 34-41. PMID: 30985327. doi: 10.1097/01.NAJ.0000557888.65961.c6.

Ghai, B., Makkar, J.K. \& Wig, J. (2008) 'Postoperative pain assessment in preverbal children and children with cognitive impairment', Pediatric Anesthesia, 18(6), pp. 462-477Epub 2008 Mar 18. Erratum in: Pediatric Anesthesia. 2008 Dec;18(12):1283. PMID: 18363630 . doi: 10.1111/j.1460-9592.2008.02433.x.

Ghanei, M., Arnrup, K. \& Robertson, A. (2018) 'Procedural pain in routine dental care for children: a part of the Swedish BITA study', European archives of Paediatric Dentistry, 19(5), pp. 365-372. PMID: 30194611; PMCID: PMC6208776. doi: 10.1007/s40368-018-0368-2.

Glaser, B.G. \& Strauss, A.L. (1967) The discovery of grounded theory: strategies for qualitative research. New York: Aldine de Gruyter. 
Glaser, B.G. (1965) 'The Constant Comparative Method of Qualitative Analysis', Social Problems, 12, pp. 436-445.

Goldman, R.D. (2013) 'Acetaminophen in children: an old drug with new warnings', Canadian Family Physician, 59(10), pp. 1065-1066, e449-50. PMID: 24130280; PMCID: PMC3796971.

Graham, G.G., Davies, M.J., Day, R.O., Mohamudally, A. \& Scott, K.F. (2013) 'The modern pharmacology of paracetamol: therapeutic actions, mechanism of action, metabolism, toxicity and recent pharmacological findings', Inflammopharmacology, 21(3), pp. 201-232. PMID: 23719833. doi: 10.1007/s10787-0130172-x.

Green, J. \& Britten, N. (1998) 'Qualitative research and evidence based medicine', The BMJ, 316(7139), pp. 1230-1232. PMID: 9583929; PMCID: PMC1112988. doi: 10.1136/bmj.316.7139.1230.

Greenhalgh, T. \& Taylor, R. (1997) 'Papers that go beyond numbers (qualitative research)', The BMJ, 315(7110), pp. 740-743. PMID: 9314762; PMCID: PMC2127518. doi: 10.1136/bmj.315.7110.740.

Gustafsson, A., Arnrup, K., Broberg, A.G., Bodin, L. \& Berggren, U. (2007) 'Psychosocial concomitants to dental fear and behaviour management problems', International Journal of Paediatric Dentistry, 17(6), pp. 449-459. PMID: 17935598. doi: 10.1111/j.1365-263X.2007.00883.x.

Guyatt, G., Oxman, A.D., Akl, E.A., Kunz, R., Vist, G., Brozek, J., Norris, S., Falck-Ytter, Y., Glasziou, P., DeBeer, H., Jaeschke, R., Rind, D., Meerpohl, J., Dahm, P. \& Schünemann, H.J. 'GRADE guidelines: 1. Introduction-GRADE evidence profiles and summary of findings tables', Journal of Clinical Epidemiology, 64(4), $\quad$ pp. 383-394. 21195583. doi.org/10.1016/j.jclinepi.2010.04.026.

Hallberg, L.R.M. (2006) 'The "core category” of grounded theory: Making constant comparisons', International Journal of Qualitative Studies on Health and Wellbeing, 3, pp. 141-148. DOI: 10.1080/17482620600858399.

Hallonsten, A.L., Jensen, B., Raadal, M., Veerkamp, J., Hosey, M.T. \& Poulsen, S. (2006) 'EAPD Guidelines on Sedation in Paediatric Dentistry', European Academy of Paediatric Densitry, Available at: https://www.eapd.eu/uploads/5CF03741 file.pdf. (Accessed 15 September 2020).

Hansen, C., Lundh, A., Rasmussen, K. \& Hróbjartsson, A. (2019) 'Financial conflicts of interest in systematic reviews: associations with results, conclusions, and methodological quality', Cochrane Database of Systematic Reviews, Issue 8. Art. No.: MR000047. DOI: 10.1002/14651858.MR000047.pub2

Harbeck, C. \& Peterson, L. (1992) 'Elephants dancing in my head: a developmental approach to children's concepts of specific pains', Child Development, 63(1), pp. 138-149. PMID: 1551322. 
Hariharan, S., Narayanan, V. \& Soh, C.L. (2014) 'Split-mouth comparison of physics forceps and extraction forceps in orthodontic extraction of upper premolars', British Journal of Oral and Maxillofacial Surgery, 52(10), e137-40. PMID: 25015020. doi: 10.1016/j.bjoms.2014.06.013.

Haukali, G., Lundeberg, S., Høgsbro Østergaard, B. \& Haubek, D. (2017) 'Pain, Pain Control, and Sedation', in Koch, G., Poulsen, S., Espelid, I. \& Haubek, D. (eds.). Pediatric Dentistry - A clinical Approach. $3^{\text {rd }}$ ed. West Sussex, UK: Wiley Blackwell, pp. 87-101.

Heintz, E., Lintamo, L., Hultcrantz, M., Jacobson, S., Levi, R., Munthe, C., Tranæus, S., Östlund, P. \& Sandman L. (2015) 'Framework for systematic identification of ethical aspects of healthcare technologies: the SBU approach', International Journal of Technology Assessment in Health Care, 31(3), pp. 124-130. PMID: 26134927. doi.org/10.1017/S0266462315000264.

Hester. N.K. (1979) 'The preoperational child's reaction to immunization', Nursing Research, 28(4), pp. 250-255. PMID: 255924.

Hicks, C.L., von Baeyer, C.L., Spafford, P.A., van Korlaar, I. \& Goodenough, B. (2001) 'The faces pain scale-revised: toward a common metric in paediatric pain measurement', Pain, 93(2), pp. 173-183. PMID: 11427329. doi.org/10.1016/s0304-3959(01)00314-1.

Higgins, J.P.T., Thomas, J., Chandler, J., Cumpston, M., Li, T., Page, M.J. \& Welch, V.A. (eds.). (2020) Cochrane Handbook for Systematic Reviews of Interventions version 6.1 [Online]. Cochrane. Available at: www.training.cochrane.org/handbook. (Updated September 2020; Accessed 2 October 2020).

Hirschfeld, G. \& Zernikow, B. (2013) 'Cut points for mild, moderate, and severe pain on the VAS for children and adolescents: what can be learned from 10 million ANOVAs?', Pain, 154(12), pp. 2626-32. PMID: 23742796. doi: 10.1016/j.pain.2013.05.048.

Holst, A. \& Crossner, C.G. (1987) 'Direct ratings of acceptance of dental treatment in Swedish children', Community Dentistry and Oral Epidemiology, 15(5), pp. 258-263. PMID: 3477357. doi:10.1111/j.1600-0528.1987.tb00533.x

Hosey, M.T., Lourenço-Matharu, L. \& Roberts, G.J. (2012) 'Management of pain and anxiety', in Welbury, R., Duggal, M. \& Hosey, M. (eds.). Paediatric Dentistry. $4^{\text {th }}$ edn. Oxford: Oxford University Press, pp. 54-71.

HTA Glossary.net. (2020) Health technology assessment. Adelaide: INAHTA. Available at: http://htaglossary.net/health+technology+assessment (Accessed 28 August 2020).

Huguet, A., Stinson, J.N. \& McGrath, P.J. (2010) 'Measurement of self-reported pain intensity in children and adolescents', Journal of Psychosomatic Research, 68(4), 329-336. PMID: 20307699. doi: 10.1016/j.jpsychores.2009.06.003. 
Huskisson, E.C. (1974) 'Measurement of pain', Lancet, 2(7889), pp. 1127-1131. PMID: 4139420. doi: 10.1016/s0140-6736(74)90884-8.

Hwang, P. \& Frisén, A. (2005) 'Utvecklingspsykologi. Individens utveckling i ett livsperspektiv', in Hwang, P., Lundberg, I., Rönnberg, J. \& Smedler, A.C. (eds.). Vår tids psykologi. Stockholm: Natur och Kultur, pp. 169-220. [In Swedish].

IASP Subcommittee on Taxonomy. (1979) 'Pain terms: a list with definitions and notes on usage. Recommended by the IASP Subcommittee on Taxonomy', PAIN 6, pp. 249-252.

IASP. International Association for the Study of Pain. (2017) 'IASP Terminology' [Online]. Available at: https://www.iasp-pain.org/terminology (Accessed 30 September 2020).

IASP. International Association for the Study of Pain. (2010) 'Declaration of Montréal' [Online] Available at: https://www.iasp-pain.org/DeclarationofMontreal (Accessed 8 July 2020).

IASP. International Association for the Study of Pain. (2018) 'Download the FPS-R' [Online]. Available at: https://www.iasppain.org/Education/Content.aspx?ItemNumber=1823\&navItemNumber=1119 (Accessed 31 August 2020).

INAHTA (International Network of Agencies for Health Technology Assessment). (2020) 'HTA Tools \& Resources. Definitions' [Online]. Available at: http://www.inahta.org/hta-tools-resources/ (Accessed 24 January 2020).

Institute of Medicine (US) Committee on Standards for Systematic Reviews of Comparative Effectiveness Research. (2011) 'Finding What Works in Health Care: Standards for Systematic Reviews', Eden, J., Levit, L., Berg, A. \& Morton, S. (eds.). Washington (DC): National Academies Press (US). PMID: 24983062.

Jacob, E. (2013) 'Pain Assessment and Management in Children', in Hockenberry, M. \& Wilson, D. (eds.). Wong's essentials of pediatric nursing. $9^{\text {th }}$ edn. St. Louis, Missouri: Elsevier Mosby, pp. 144-180.

Jain, A.A., Yeluri, R. \& Munshi, A.K. (2012) 'Measurement and assessment of pain in children--a review', Journal of Clinical Pediatric Dentistry, 37(2), pp. 125136. PMID: 23534317. doi: 10.17796/jcpd.37.2.k84341490806t770.

Jensen, M.P., Chen, C. \& Brugger, A.M. (2003) 'Interpretation of visual analog scale ratings and change scores: a reanalysis of two clinical trials of postoperative pain', The Journal of Pain, 4(7), pp. 407-414. PMID: 14622683. doi: 10.1016/s1526-5900(03)00716-8.

Jensen, M.P., Karoly, P. \& Braver, S. (1986) 'The measurement of clinical pain intensity: A comparison of six methods', Pain, 27(1), pp. 117-126. PMID: 3785962. doi.org/10.1016/0304-3959(86)90228-9.

Johnston, C.C., Stevens, B.J., Boyer, K. \& Lang Porter, F. (2003) 'Development of Psychologic Responses to Pain and Assessment of Pain in Infants and Toddlers', 
in Schechter, N.L., Berde, C.B. \& Yaster, M. (eds.). Pain in Infants, Children, and Adolescents. $2^{\text {nd }}$ edn. Philadelphia: Lippincott, Williams and Wilkins, pp. 105-127.

Jones, M. \& Alony, I. (2011) 'Guiding the use of Grounded Theory in Doctoral studies - an example from the Australian film industry', International Journal of Doctoral Studies 6, pp. 95-114.

Karlberg, I., Hallberg, L.R.M. \& Sarvimäki, A. (2002) 'Introduction and aims of the book - Health, Public Health and Research on Public Health', in Hallberg, L.R.M. (ed.). Qualitative Methods in Public Health Research - Theoretical Foundations and Practical Examples. Lund: Studentlitteratur, pp. 13-38.

Karlsson, E., Larsson, L.E. \& Nilsson, K. (1990) 'Postanaesthetic nausea in children', Acta Anaesthesiologica Scandinavica, 34(7), pp. 515-158. PMID: 1978765. doi: 10.1111/j.1399-6576.1990.tb03136.x.

Kendall, P.C. (ed.) (2006) Child and Adolescent Therapy: Cognitive-Behavioral Procedures. $3^{\text {rd }}$ edn. New York: The Guilford Press.

Kent, G. (1989) 'Cognitive aspects of the maintenance and treatment of dental anxiety: a review', Journal of Cognitive Psychotherapy, 3, pp. 201-221.

Kim, M.S., Choi, H.G., Park, E.K., Kim, S.Y., Kim, J.H. \& Park B. (2018) 'Natural course of tonsillectomy pain: A prospective patient cohort study', Auris Nasus Larynx, 45(3), pp. 508-513. PMID: 28890114. doi:10.1016/j.anl.2017.07.018.

Klingberg, G. \& Arnrup, K. (2017) 'Dental fear and behavior management problems', in Koch, G., Poulsen, S., Espelid, I. \& Haubeck, D. (eds.). Pediactric dentistry-a clinical approach. $3^{\text {rd }}$ ed. West Sussex, UK: Wiley Blackwell, pp. 5565 .

Klingberg, G. \& Broberg, A.G. (2007) 'Dental fear/anxiety and dental behaviour management problems in children and adolescents: a review of prevalence and concomitant psychological factors', International Journal of Paediatric Dentistry, 17(6), pp. 391-406. PMID: 17935593. doi: 10.1111/j.1365263X.2007.00872.x.

Klingberg, G. (1994) 'Reliability and validity of the Swedish version of the Dental Subscale of the Children's Fear Survey Schedule, CFSS-DS', Acta Odontologica Scandinavica, 52(4), pp. 255-6. PMID: 7985512. doi: $10.3109 / 00016359409029055$.

Klingberg, G. (1995) Dental fear and behavior management problems in children. A study of measurement, prevalence, concomitant factors, and clinical effects. Doctoral Thesis. Gothenburg: Faculty of Odontology, Göteborg University, Swed Dent J Suppl, 103, pp. 1-78.

Klingberg, G., Andersson-Wenckert, I., Grindefjord, M., Lundin, S.Å., Ridell, K., Tsilingaridis, G. \& Ullbro, C. (2010) 'Specialist paediatric dentistry in Sweden 
2008 - a 25-year perspective', International Journal of Paediatric Dentistry, 20(5), pp. 313-321. PMID: 20545788. doi: 10.1111/j.1365-263X.2010.01057.x.

Klingberg, G., Berggren, U., Carlsson, S.G. \& Noren, J.G. (1995) 'Child dental fear: cause-related factors and clinical effects', European Journal of Oral Sciences, 103(6), 405-412. doi:10.1111/j.1600-0722.1995.tb01865.x

Klingberg, G., Ridell, K., Brogårdh-Roth, S., Vall, M. \& Berlin, H. (2017) 'Local analgesia in paediatric dentistry: a systematic review of techniques and pharmacologic agents', European Archives of Paediatric Dentistry, 18(5), pp. 323-329. PMID: 28913645; PMCID: PMC5651714. doi: 10.1007/s40368-017-0302-z.

Klingberg, G., Vannas Löfqvist, L., Bjarnason, S. \& Norén, J.G. (1994) 'Dental behavior management problems in Swedish children', Community Dentistry and Oral epidemiology, 22(3), pp. 201-205. PMID: 8070250. doi:10.1111/j.16000528.1994.tb01841.x.

Krekmanova, L., Bergius, M., Robertson, A., Sabel, N., Hafström, C., Klingberg, G. \& Berggren, U. (2009) 'Everyday- and dental-pain experiences in healthy Swedish 8-19 year olds: an epidemiological study', International Journal of Paediatric Dentistry, 19(6), pp. 438-47. PMID: 19732190. doi: 10.1111/j.1365263X.2009.01016.x.

Krekmanova, L., Hakeberg, M., Robertson, A. \& Klingberg, G. (2017) 'Dentists' Knowledge and Attitudes toward Child Pain Perception (DKA-CPP) - A novel measurement to understand pain management in dental care for children and adolescents' [In manuscript], in Krekmanova, L. Pain in Pediatric Dentistry. Experiences, attitudes and knowledge from the perspective of the child, the adolescent and the dentist (Doctoral Thesis). Sahlgrenska Academy, Institute of Odontology, Göteborg, Sweden. Available from: http://hdl.handle.net/2077/48661.

Kuper, A., Reeves, S. \& Levinson, W. (2008) 'An introduction to reading and appraising qualitative research', The $B M J$, p. 337: a288. PMID: 18687727. doi: 10.1136/bmj.a288.

Lewin, S., Glenton, C. \& Oxman, A.D. (2009) 'Use of qualitative methods alongside randomised controlled trials of complex healthcare interventions: methodological study', The BMJ, 339, b3496. PMID: 19744976; PMCID: PMC2741564. doi: 10.1136/bmj.b3496.

Litalien, C. \& Jacqz-Aigrain, E. (2001) 'Risks and benefits of nonsteroidal antiinflammatory drugs in children: a comparison with paracetamol', Paediatric Drugs, 3(11), pp. 817-858. PMID: 11735667. doi: 10.2165/00128072200103110-00004.

London, M., Ladewig, P., Davidson, M., Ball, J.W., Bindler, R.C. \& Cowen, K.J. (2014) Maternal and child nursing care. Boston, Massachusetts: Pearson.

Manworren, R.C. \& Stinson, J. (2016) 'Pediatric Pain Measurement, Assessment, and Evaluation', Seminars in Pediatric Neurology, 23(3), pp. 189-200. PMID: 27989326; PMCID: PMC5261830. doi: 10.1016/j.spen.2016.10.001. 
Mathias, F.B., Cademartori, M.G. \& Goettems, M.L. (2020) 'Factors associated with children's perception of pain following dental treatment', European Archives of Paediatric Dentistry, 21(1), pp. 137-143. PMID: 31236833. doi: 10.1007/s40368019-00456-2.

Matok, I., Elizur, A., Perlman, A., Ganor, S., Levine, H. \& Kozer, E. (2017) 'Association of Acetaminophen and Ibuprofen Use With Wheezing in Children With Acute Febrile Illness', Annals of Pharmacotherapy, 51(3), pp. 239-244. PMID: 27794128. doi: 10.1177/1060028016678006.

Maunuksele, E.L. \& Olkkola, K.T. (2003) 'Nonsteroidal Anti-inflammatory Drygs in Pediatric Pain Management', in Schechter, N.L., Berde, C.B. \& Yaster, M. (eds.). Pain in infants, children and adolescents. $2^{\text {nd }}$ edn. Philadelphia, Pa.: Lippincott Williams \& Wilkins, pp. 171-180.

Mays, N. \& Pope, C. (1995) 'Rigour and qualitative research', The BMJ, 311(6997), pp. 109-12. PMID: 7613363; PMCID: PMC2550154. doi: 10.1136/bmj.311.6997.109.

McGrath, P.A. \& DeVeber, L.L. (1986) 'Helping children cope with painful procedures', AJN The American Journal of Nursing, 86(11), pp. 1278-1279. PMID: 3535513.

McGrath, P.A. (1990) Pain in Children - Nature, Assessment, \& Treatment. New York: The Guilford Press.

McGrath, P.A. (2005) 'Children - Not Simply "Little Adults"' [Online], in Merskey, H., Loeser, J.D. \& Dubner, R. (eds.). Seattle, WA: IASP Press. Available at: http://www.iasp-

pain.org/files/Content/ContentFolders/GlobalYearAgainstPain2/20052006Painin Children/childrennotsimplylittleadults.pdf. (Accessed 20 February 2018).

McGrath, P.A., Seifert, C.E., Speechley, K.N., Booth, J.C., Stitt, L. \& Gibson, M.C. (1996) 'A new analogue scale for assessing children's pain: an initial validation study', Pain, 64(3), pp. 435-43. PMID: 8783307. doi:10.1016/03043959(95)00171-9.

McGrath, P.J., Johnson, G., Goodman, J.T., Dunn, J. \& Chapman J. (1985) 'CHEOPS: A behavioral scale for rating postoperative pain in children', in Fields, H.L., Dubner, R. \& Cervero, F. (eds.) Advances in pain research and therapy. New York: Raven Press, pp. 395-402.

Merkel, S.I., Voepel-Lewis, T., Shayevitz, J.R. \& Malviya, S. (1997) 'The FLACC: a behavioral scale for scoring postoperative pain in young children', Journal of Pediatric Nursing, 23(3), pp. 293-297. PMID: 9220806.

Milgrom, P., Weinstein, P., Golletz, D., Leroux, B. \& Domoto, P. (1994) 'Pain management in school-aged children by private and public clinic practice dentists', Pediatric Dentistry Journal, 16(4), pp. 294-300. PMID: 7937263. 
Moher, D., Liberati, A., Tetzlaff, J. \& Altman, DG., PRISMA Group. (2009) 'Preferred reporting items for systematic reviews and meta-analyses: the PRISMA statement', Journal of Clinical Epidemiology, 62(10), pp. 1006-1012. PMID: 19631508. doi: 10.1016/j.jclinepi.2009.06.005.

Murtomaa, H., Milgrom, P., Weinstein, P. \& Vuopio, T. (1996) 'Dentists' perceptions and management of pain experienced by children during treatment: a survey of groups of dentists in the USA and Finland', International Journal of Paediatric Dentistry, 6(1), pp. 25-30. PMID: 8695586. doi: 10.1111/j.1365263x.1996.tb00204.x.

Nilsson, S. (2014) 'Att bedöma smärta hos barn', Information från Läkemedelsverket, 25(3), pp. 32-35. [In Swedish].

Norman, H., Elfineh, M., Beijer, E., Casswall, T. \& Németh, A. (2014) 'Även ibuprofen, inte bara paracetamol, kan ge barn allvarlig leverskada. NSAID bör användas med försiktighet hos barn, visar fall med letal utgång' ['Also ibuprofen, not just paracetamol, can cause serious liver damage in children. NSAIDs should be used with caution in children, as shown in case with fatal outcome'], Läkartidningen, 111(40), pp. 1709-1711. [In Swedish]. PMID: 25759881.

Norrbrink, C. \& Lundeberg, T. (eds.). (2012) Om smärta - ett fysiologiskt perspektiv. Lund: Studentlitteratur.

Nutter, D.P. (2010) 'Good, clinical pain practice for pediatric procedure pain: metric considerations', The Journal of the California Dental Association, 38(12), pp. 857-863. PMID: 21261188.

Oakes, L. (2011) Compact clinical guide to infant and child pain management: an evidence-based approach for nurses. New York: Springer Publishing Company.

Olson, K., Smyth, J.D. \& Wood, H.M. (2012) 'Does giving people their preferred survey mode actually increase survey participation rates? An experimental examination', Public Opinion Quarterly, 76(4), pp. 611-635. doi: 10.1093/poq/nfs024.

Olsson, G.L., Lundeberg, S. (2019) 'Akut smärta hos barn', in Werner, M.U. \& Bäckryd, E. (eds.). Akut och cancerrelaterad smärta. Smärtmedicin vol. 1. Stockholm: Liber, pp. 463-77. [In Swedish].

Osterweis, M., Kleinman, A. \& Mechanic, D. (eds.). (1987) 'Chapter 7: The Anatomy and Physiology of Pain. Clinical, Behavioral, and Public Policy Perspectives' [Online]. Institute of Medicine (US) Committee on Pain, Disability, and Chronic Illness Behavior; Pain and Disability. Washington (DC): National Academies Press (US). Available at: https://www.ncbi.nlm.nih.gov/books/NBK219252/.

Pagé, M.G., Katz, J., Stinson, J., Isaac, L., Martin-Pichora, A.L. \& Campbell, F. (2012) 'Validation of the numerical rating scale for pain intensity and unpleasantness in pediatric acute postoperative pain: sensitivity to change over time', The Journal of Pain, 13(4), pp. 359-69. PMID: 22424915. doi: 10.1016/j.jpain.2011.12.010. 
Pandis, N., Chung, B., Scherer, R.W., Elbourne, D. \& Altman, D.G. (2017) 'CONSORT 2010 statement: extension checklist for reporting within person randomised trials', The BMJ, 357, j2835. PMID: 28667088; PMCID: PMC5492474. doi: 10.1136/bmj.j2835.

PennState Eberly College of Science. (2018) 'STAT 509' [Online]. Available at: https://online.stat.psu.edu/stat509/node/125/. (Accessed 13 October 2020).

Persson, J. (2016) 'Smärtfysiologi, smärtsinnets utveckling och kognitiva utveckling', in Lundeberg, S. \& Olsson, G.L. (eds). Smärta och smärtbehandling hos barn och ungdomar. Lund: Studentlitteratur, pp. 15-35. [In Swedish].

Piaget, J. \& Inhelder, B. (1969) The psychology of the child. New York: Basic Books.

Purves, D., Augustine, G.J., Fitzpatrick, D., Hall, W.C., LaMantia, A.S., Mooney, R.D., Platt, M.L. \& White, L.E. (eds.). (2018) Neuroscience. $6^{\text {th }}$ edition. Sunderland, MA: Oxford University Press.

Raadal, M., Strand, G.V., Amarante, E.C. \& Kvale, G. (2002) 'Relationship between caries prevalence at 5 years of age and dental anxiety at 10', European Journal of Paediatric Dentistry, 3(1), pp. 22-26. PMID: 12871013.

Racine, N.M., Riddell, R.R., Khan, M., Calic, M., Taddio, A. \& Tablon, P. (2016) 'Systematic Review: Predisposing, Precipitating, Perpetuating, and Present Factors Predicting Anticipatory Distress to Painful Medical Procedures in Children', Journal of Pediatric Psychology, 41(2), pp. 159-181. PMID: 26338981; PMCID: PMC4884904. doi: 10.1093/jpepsy/jsv076.

RACP (Royal Australasian college of physicians). (2006) 'Management of procedure related pain in children and adolescents. Guideline statement: management of procedure-related pain in children and adolescents', Journal of Paediatrics and Child Health, 42 Suppl 1, S1-29. PMID: 16626312. doi: 10.1111/j.14401754.2006.00798_1.x.

Raja, S.N., Carr, D.B., Cohen, M., Finnerup, N.B., Flor, H., Gibson, S., Keefe, F.J., Mogil, J.S., Ringkamp, M., Sluka, K.A., Song, X.J., Stevens, B., Sullivan, M.D., Tutelman, P.R., Ushida, T. \& Vader, K. (2020) 'The revised International Association for the Study of Pain definition of pain: concepts, challenges, and compromises', Pain, Epub ahead of print. PMID: 32694387. doi: 10.1097/j.pain.0000000000001939.

Rasmussen, J.K., Frederiksen, J.A., Hallonsten, A.L. \& Poulsen, S. (2005) 'Danish dentists' knowledge, attitudes and management of procedural dental pain in children: association with demographic characteristics, structural factors, perceived stress during the administration of local analgesia and their tolerance towards pain', International Journal of Paediatric Dentistry, 15(3), pp. 159-168. PMID: 15854111. doi: 10.1111/j.1365-263X.2005.00635.x.

Rey, R. (1993) The history of pain. Cambridge, Massachusetts: Harvard University Press. 
Roberts, E., Delgado Nunes, V., Buckner, S., Latchem, S., Constanti, M., Miller, P., Doherty, M., Zhang, W., Birrell, F., Porcheret, M., Dziedzic, K., Bernstein, I., Wise, E. \& Conaghan, P.G. (2016) 'Paracetamol: not as safe as we thought? A systematic literature review of observational studies', Annals of the Rheumatic Diseases, 75(3), pp. 552-559. PMID: 25732175; PMCID: PMC4789700. doi: 10.1136/annrheumdis-2014-206914.

Roberts, H., Pearson, JC. \& Dengler, R. (1993) 'Impact of a postcard versus a questionnaire as a first reminder in a postal lifestyle survey', Journal of Epidemiology and Community Health, 47(4), pp. 334-335. PMID: 8228774; PMCID: PMC1059805. doi: 10.1136/jech.47.4.334.

Rocha, E.M., Marche, T.A., von Baeyer, C.L. (2009) 'Anxiety influences children's memory for procedural pain', Pain Research and Management, 14(3), pp. 233237. PMID: 19547763; PMCID: PMC2706554. doi: 10.1155/2009/535941.

Rønneberg, A., Strøm, K., Skaare, A.B., Willumsen, T. \& Espelid, I. (2015) 'Dentists' self-perceived stress and difficulties when performing restorative treatment in children', European Archives of Paediatric Dentistry, 16(4), pp. 341-317. PMID: 25628090. doi: 10.1007/s40368-014-0168-2.

Rotstein, D. \& Laupacis, A. (2004) 'Differences between systematic reviews and health technology assessments: a trade-off between the ideals of scientific rigor and the realities of policy making', International Journal of Technology Assessment in Health Care, 20(2), pp. 177-183. PMID: 15209177. doi.org/10.1017/s0266462304000959.

Salanterä, S. (1999) 'Finnish nurses' attitudes to pain in children', Journal of Advanced Nursing, 29(3), pp. 727-736. PMID: 10210472. doi: 10.1046/j.13652648.1999.00944.x.

Salim Silva, M., Smith, W.T. \& Bammer, G. (2002) 'Telephone reminders are a cost effective way to improve responses in postal health surveys', Journal of Epidemiology and Community Health, 56(2), pp. 115-118. PMID: 11812810; PMCID: PMC1732073. doi: 10.1136/jech.56.2.115.

SBU. (2018) Assessment of methods in health care-A handbook [Online]. Stockholm: Swedish Agency for health technology assessment and assessment of social services (SBU). Available at: https://www.sbu.se/contentassets/76adf07e270c48efaf67e3b560b7c59c/eng meto dboken.pdf. (Accessed 7 September 2020).

SBU. (2012a) 'Preoperativ smärtlindring vid oralkirurgiskt ingrepp på barn och ungdom' [Online]. Swedish Agency for health technology assessment and assessment of social services (SBU), Available at: https://www.sbu.se/sv/publikationer/kunskapsluckor/preoperativ-smartlindringvid-oralkirurgiskt-ingrepp-pa-barn-och-ungdom/ (Updated 28 February 2020; accessed 2 October 2020). [In Swedish]. 
SBU. (2012b) 'Postoperativ smärtlindring vid oralkirurgiskt ingrepp på barn och ungdom' [Online]. Swedish Agency for health technology assessment and assessment of social services (SBU), Available at: https://www.sbu.se/sv/publikationer/kunskapsluckor/postoperativ-smartlindringvid-oralkirurgiskt-ingrepp-pa-barn-och-ungdom/ (Updated 27 February 2020; Accessed 2 October 2020). [In Swedish].

SBU. (2020) 'Evidence gaps' [Online]. The Swedish agency for health technology assessment and assessment of social services (SBU), Available from: https://www.sbu.se/en/publications/evidence-gaps/. (Updated 20 January 2020; accessed 7 September 2020).

SBU. (2020) 'Vetenskapliga kunskapsluckor - otillräckligt utvärderade åtgärder och metoder' [Online]. Swedish Agency for health technology assessment and assessment of social services (SBU). Available at: https://www.sbu.se/sv/publikationer/kunskapsluckor/. (Updated 22 June 2020; accessed 21 August 2020). [In Swedish].

SCB. (2020) 'Befolkningsstatistik', Statistiska centralbyrån (SCB). Available at: https:/www.scb.se/hitta-statistik/statistik-efter-amne/befolkning/befolkningenssammansattning/befolkningsstatistik/. (Updated 19 August 2020; accessed 11 September 2020).

Schorer-Jensma, M.A. \& Veerkamp, J.S. (2010) 'A comparison of paediatric dentists' and general dental practitioners' care patterns in paediatric dental care', $E u$ ropean Archives of Paediatric Dentistry, 11(2), pp. 93-6. PMID: 20403304. doi:10.1007/BF03262719

Scott, J., Huskisson, E.C. (1976) 'Graphic representation of pain', Pain, 2(2), pp. 175-184. PMID: 1026800.

Seymour, R.A., Simpson, J.M., Charlton, J.E. \& Phillips, M.E. (1985) 'An evaluation of length and end-phrase of visual analogue scales in dental pain', Pain, 21(2), pp. 177-185. PMID: 3982841. doi: 10.1016/0304-3959(85)90287-8.

Shaddy, R.E. \& Denne, S.C.; Committee on Drugs and Committee on Pediatric Research. (2010) 'Clinical report--guidelines for the ethical conduct of studies to evaluate drugs in pediatric populations', Pediatrics, 125(4), pp. 850-860. PMID: 20351010. doi: 10.1542/peds.2010-0082.

Shea, B.J., Reeves, B.C., Wells, G., Thuku, M., Hamel, C., Moran, J., Moher, D., Tugwell, P., Welch, V., Kristjansson, E. \& Henry, D.A. (2017) 'AMSTAR 2: a critical appraisal tool for systematic reviews that include randomised or nonrandomised studies of healthcare interventions, or both', The BMJ, 358: j4008. PMID: 28935701; PMCID: PMC5833365. doi: 10.1136/bmj.j4008.

Smyth, J.D., Dillman, D.A., Christian, L.M. \& O’Neill, A.C. (2010) 'Using the Internet to Survey Small Towns and Communities: Limitations and Possibilities in the Early 21st Century', American Behavioral Scientist, 53(9), pp. 1423-1448. https://doi.org/10.1177/0002764210361695. 
Stenebrand, A., Wide Boman, U. \& Hakeberg, M. (2013) 'Dental anxiety and symptoms of general anxiety and depression in 15-year-olds', International Journal of Dental Hygiene, 11(2), pp. 99-104. PMID: 22498171. doi: 10.1111/j.16015037.2012.00551.x.

Stern, P.N. (1980) 'Grounded theory methodology: its uses and processes', Image (IN), 12(1), pp. 20-23. PMID: 6898518. doi: 10.1111/j.15475069.1980.tb01455.x.

Stewart, L., Moher, D. \& Shekelle, P. (2012) 'Why prospective registration of systematic reviews makes sense', Systematic Reviews, 1, p. 7. PMID: 22588008; PMCID: PMC3369816. doi: 10.1186/2046-4053-1-7.

Stinson, J.N., Kavanagh, T., Yamada, J., Gill, N. \& Stevens, B. (2006) 'Systematic review of the psychometric properties, interpretability and feasibility of selfreport pain intensity measures for use in clinical trials in children and adolescents', Pain, 125(1-2), 143-157. doi:10.1016/j.pain.2006.05.006. PMID: 16777328.

Strauss, A. \& Corbin, J. (1990) Basics of qualitative research. Grounded Theory procedures and techniques. California: Sage Publications.

Strauss, A.L. \& Corbin, J. (1998) Basics of qualitative research. Techniques and procedures for developing grounded theory. Thousand Oaks, CA: Sage.

Taddio, A., Katz, J., Ilersich, A.L. \& Koren, G. (1997) 'Effect of neonatal circumcision on pain response during subsequent routine vaccination', Lancet, 349(9052), pp. 599-603. PMID: 9057731. doi: 10.1016/S0140-6736(96)10316-0.

Taneja, S., Singh, A. \& Jain, A. (2020) 'Anesthetic Effectiveness of Articaine and Lidocaine in Pediatric Patients During Dental Procedures: A Systematic Review and Meta-Analysis', Pediatric Dentistry Journal, 42(4), pp. 273-281. PMID: 32847666 .

Ten Berge, M., Veerkamp, J.S. \& Hoogstraten, J. (2002) 'The etiology of childhood dental fear: the role of dental and conditioning experiences', Journal of Anxiety Disorders, 16(3), pp. 321-329. PMID: 12214817. doi: 10.1016/s08876185(02)00103-2.

The Swedish Ethical Review Agency [Online]. (2020). Available at: https://etikprovningsmyndigheten.se/ (Accessed 8 September 2020).

Thomas, A., Chess, S., Birch, H.G., Hertzig, M.E. \& Korn, S. (1963) Behavioral individuality in early childhood. New York, NY: New York University Press.

Thomas, G. \& James, D. (2006) 'Reinventing grounded theory: some questions about theory, ground and discovery', British Educational Research Journal. 32(6), pp. 767-795. doi.org/10.1080/01411920600989412.

Tsze, D.S., von Baeyer, C.L., Bulloch, B. \& Dayan, PS. (2013) 'Validation of selfreport pain scales in children', Pediatrics, 132(4), e971-979. PMID: 23999954; PMCID: PMC3784298. doi: 10.1542/peds.2013-1509. 
Twycross, A. \& Williams, A. (2013) 'Establishing the validity and reliability of a pediatric pain knowledge and attitudes questionnaire', Pain Management Nursing, 14(3), e47-53. PMID: 23972870. doi: 10.1016/j.pmn.2011.03.001.

Twycross, A. (2017) 'Guidelines, strategies and tools for pain assessment in children' [Online]. Nursing Times, 113(5), pp. 18-21.

Twycross, A., Dowden, S. \& Stinson, J. (eds.). (2013) Managing Pain in Children: A Clinical Guide for Nurses and Healthcare Professionals. Hoboken: John Wiley \& Sons, Incorporated.

Uhl, K., Litvinova, A., Sriswasdi, P., Zurakowski, D., Logan, D. \& Cravero, J.P. (2019) 'The effect of pediatric patient temperament on postoperative outcomes', Pediatric Anesthesia, 29(7), pp. 721-729. PMID: 31001859. doi:10.1111/pan.13646

UN Commission on Human Rights. (1990) 'Convention on the Rights of the Child', E/CN.4/RES/1990/74. Available at: https://www.refworld.org/docid/3b00f03d30.html. (Accessed 8 July 2020).

van Dijk, M., Koot, H.M., Saad, H.H., Tibboel, D. \& Passchier, J. (2002) 'Observational visual analog scale in pediatric pain assessment: useful tool or good riddance?' The Clinical Journal of Pain, 18(5), 310-316. PMID: 12218502. doi: 10.1097/00002508-200209000-00006.

VanGeest, J.B., Johnson, T.P. \& Welch, V.L. (2007) 'Methodologies for improving response rates in surveys of physicians: a systematic review', Evaluation \& the Health Professions, 30(4), pp. 303-321. PMID: 17986667. doi: 10.1177/0163278707307899.

Versloot, J. \& Craig, K.D. (2009) 'The communication of pain in paediatric dentistry', European Archives of Paediatric Dentistry, 10(2), pp. 61-66. PMID: 19627668. doi: 10.1007/BF03321601.

Versloot, J., Veerkamp, J.S. \& Hoogstraten, J. (2008) 'Children's self-reported pain at the dentist', Pain, 137(2), pp. 389-394. PMID: 18035498. doi: 10.1016/j.pain.2007.09.025.

von Baeyer, C.L., Marche, T.A., Rocha, E.M. \& Salmon, K. (2004) 'Children's memory for pain: overview and implications for practice', The Journal of Pain, 5(5), 241-249. PMID: 15219255. doi: 10.1016/j.jpain.2004.05.001.

Werner, M. (2019) 'Farmakologi', in Werner, M. \& Bäckryd, E. (eds.). Akut och cancerrelaterad smärta. Smärtmedicin vol. 1. Stockholm: Liber AB. [In Swedish].

Wilson-Pauwels, L. (2010) Cranial Nerves : Function and Dysfunction. $3^{\text {rd }}$ ed. People's Medical Pub. House.

Wondimu, B. \& Dahllöf, G. (2005) 'Attitudes of Swedish dentists to pain and pain management during dental treatment of children and adolescents', European Journal of Paediatric Dentistry, 6(2), pp. 66-72. PMID: 16004534. 
Wong-Baker FACES Foundation. (2018) 'Wong-Baker FACES ${ }^{\circledR}$ Pain Rating Scale' [Online]. Available at: http://www.WongBakerFACES.org. (Accessed 5 March 2019).

Woolf, C.J. \& Salter, M.W. (2000) 'Neuronal plasticity: increasing the gain in pain', Science, 288(5472), pp. 1765-769. PMID: 10846153. doi:10.1126/science.288.5472.1765.

Yaster, M., Krane, E.H., Kaplan, R.F., Cote, C.H. \& Lappe, D.G. (1997) Pediatric pain management and sedation handbook. St. Louis: Mosby Year Book.

Young, K.D. (2005) 'Pediatric procedural pain', Annals of Emergency Medicine, 45(2), pp. 160-171. PMID: 15671974. doi: 10.1016/j.annemergmed.2004.09.019.

Zeltzer, L.K., Jay, S.M. \& Fisher, D.M. (1989) 'The management of pain associated with pediatric procedures', Pediatric Clinics of North America, 36(4), pp. 941-64. PMID: 2569184. doi: 10.1016/s0031-3955(16)36730-x. 


\section{Appendix 1}

Malmö högskola

Kodnr:

Odontologiska fakulteten

\section{Enkät till tandläkare om: Smärta och smärtkontroll i samband med tandbehandling av barn och ungdom}

Markera ditt svar med $\mathbf{X}$ i rutan som representerar ditt svar. Endast ett svar per fråga om inte annat anges. Några frågor besvaras genom att du fyller i t ex ett årtal efter frågan. Försök att besvara samtliga frågor.

1. Kön:

$\square$ Man

$\square$ Kvinna

2. Födelseår (ange endast år)

19.

3. Utbildningsort grundutbildning tandläkare
$\square$ Umeå
$\square$ Stockholm
$\square$ Göteborg
$\square$ Malmö
$\square$ Annan ort:

4. Examensår tandläkare.

5. Om utländsk tandläkarexamen:

När erhölls svensk tandläkarlegitimation?

6. Om du är specialist, ange disciplin:

7. Examensår specialisttandläkare:

8. Har du själv barn (egna, adoptivbarn eller bonusbarn)?
$\square$ ja

$\square$ nej

9. Var är din nuvarande arbetsplats?(Sätt mer än ett X om du arbetar på mer än ett ställe)

$\square$ Anställd inom Folktandvården

$\square$ Anställd på privatklinik

$\square$ Egen privatklinik (i egen regi eller PTJ och eget kostnadsställe)

$\square$ Lärosäte/fakultet

10. Hur många timmar per vecka arbetar du i genomsnitt?
$\square \leq 10$ timmar
$\square$ 11-20 timmar
$\square$ 21-30 timmar
$\square$ 31-40 eller fler timmar 
11. Hur många timmar per vecka ägnar du åt barn- och ungdomstandvård?
$\square 0$ timmar
$\square$ 1-10 timmar
$\square$ 11-20 timmar
$\square$ 21-30 timmar
$\square$ 31-40 timmar

12. Hur många barn och ungdomar (0-19 år) har du haft behandlingsansvar för år 2013?
$\square<100$
$\square 101-200$
$\square$ 201-500
$\square$ 501-1000
$\square>1001$

13. Vid lagning av en primär tand $\mathrm{i}$ överkäken $(55 \mathrm{mo})$ på en femårig patient: Hur ofta använder du dig av följande metoder?

\begin{tabular}{|c|c|c|c|c|c|}
\hline & Alltid & Ofta & $\begin{array}{l}\text { Från } \\
\text { och till }\end{array}$ & Sällan & Aldrig \\
\hline Ytanestesi före injektion & $\square$ & $\square$ & $\square$ & $\square$ & $\square$ \\
\hline Lokalanestesi & $\square$ & $\square$ & $\square$ & $\square$ & $\square$ \\
\hline Sedering (lustgas eller bensodiazepiner) & $\square$ & $\square$ & $\square$ & $\square$ & $\square$ \\
\hline $\begin{array}{l}\text { Rekommenderar vanliga smärtstillande läkemedel } \\
\text { efter behandling }\end{array}$ & $\square$ & $\square$ & $\square$ & $\square$ & $\square$ \\
\hline $\begin{array}{l}\text { Rekommenderar vanliga smärtstillande läkemedel } \\
\text { före behandling }\end{array}$ & $\square$ & $\square$ & $\square$ & $\square$ & $\square$ \\
\hline
\end{tabular}

14. Vid lagning av en permanent tand i överkäken (16 o) på en tioårig patient: Hur ofta använder du dig av följande metoder?

\begin{tabular}{|c|c|c|c|c|c|}
\hline & Alltid & Ofta & $\begin{array}{l}\text { Från } \\
\text { och till }\end{array}$ & Sällan & Aldrig \\
\hline Ytanestesi före injektion & $\square$ & $\square$ & $\square$ & $\square$ & $\square$ \\
\hline Lokalanestesi & $\bar{\square}$ & $\square$ & $\square$ & $\square$ & $\square$ \\
\hline Sedering (lustgas eller bensodiazepiner) & $\square$ & $\square$ & $\square$ & $\square$ & $\square$ \\
\hline $\begin{array}{l}\text { Rekommenderar vanliga smärtstillande läkemedel } \\
\text { efter behandling }\end{array}$ & $\square$ & $\square$ & $\square$ & $\square$ & $\square$ \\
\hline $\begin{array}{l}\text { Rekommenderar vanliga smärtstillande läkemedel } \\
\text { före behandling }\end{array}$ & $\square$ & $\square$ & $\square$ & $\square$ & $\square$ \\
\hline
\end{tabular}

15. Vid extraktion av en primär tand i överkäken (51) på en fyraårig patient: Hur ofta använder du dig av följande metoder?

\begin{tabular}{l|c|c|c|c|c} 
& \multicolumn{3}{c}{ Alltid } & \multicolumn{3}{c}{ Ofta } & Från Sällan & Aldrig \\
Ytanestesi före injektion & $\square$ & $\square$ & $\square$ & $\square$ & $\square$ \\
\hline Lokalanestesi & $\square$ & $\square$ & $\square$ & $\square$ & $\square$ \\
\hline Sedering (lustgas eller benzodiazepiner) & $\square$ & $\square$ & $\square$ & $\square$ & $\square$ \\
\hline $\begin{array}{l}\text { Rekommenderar vanliga smärtstillande läkemedel } \\
\text { efter behandling }\end{array}$ & $\square$ & $\square$ & $\square$ & $\square$ & $\square$ \\
\hline $\begin{array}{l}\text { Rekommenderar vanliga smärtstillande läkemedel } \\
\text { före behandling }\end{array}$ & $\square$ & $\square$ & $\square$ & $\square$ & $\square$
\end{tabular}


16. Vid extraktion av en permanent tand i överkäken (14) på en tolvårig patient: Hur ofta använder du dig av följande metoder?

\begin{tabular}{|c|c|c|c|c|c|}
\hline & Alltid & Ofta & $\begin{array}{l}\text { Från } \\
\text { och till }\end{array}$ & Sällan & Aldrig \\
\hline Ytanestesi före injektion & $\square$ & $\square$ & $\square$ & $\square$ & $\square$ \\
\hline Lokalanestesi & $\square$ & $\square$ & $\square$ & $\square$ & $\square$ \\
\hline Sedering (lustgas eller bensodiazepiner) & $\square$ & $\square$ & $\square$ & $\square$ & $\square$ \\
\hline $\begin{array}{l}\text { Rekommenderar vanliga smärtstillande läkemedel } \\
\text { efter behandling }\end{array}$ & $\square$ & $\square$ & $\square$ & $\square$ & $\square$ \\
\hline $\begin{array}{l}\text { Rekommenderar vanliga smärtstillande läkemedel } \\
\text { före behandling }\end{array}$ & $\square$ & $\square$ & $\square$ & $\square$ & $\square$ \\
\hline
\end{tabular}

17. Om du rekommenderar patienten att ta smärtstillande läkemedel efter tandbehandling, vad brukar du ordinera? (Exempelvis paracetamol, ibuprofen etc.)

18. Om du rekommenderar patienten att ta smärtstillande läkemedel före tandbehandling, vad brukar du ordinera? (Exempelvis paracetamol, ibuprofen etc.)

19. Om du rekommenderar patienten att ta smärtstillande läkemedel före tandbehandling, hur lång tid innan behandlingsstart ordinerar du att patienten ska ta det smärtstillande? (Ange i timmar)

\title{
Tack för din medverkan!
}

Besvarad enkät skickas tillsammans med samtyckesformuläret i det frankerade svarskuvertet till:

\author{
Henrik Olsson \\ Malmö högskola \\ Odontologiska fakulteten \\ 20506 Malmö
}




\section{Appendix 2}

而

Kodnr:

MALMÖ HÖGSKOLA

Odontologiska fakulteten

\section{The Children's Fear Survey Schedule - Dental Subscale (CFSS-DS)}

Försök uppskatta hur rädd du är i följande situationer.

Markera ditt svar med X. Endast ett svar per fråga. Försök att besvara alla frågorna.

\section{Hur rädd är du......}

\begin{tabular}{|c|c|c|c|c|c|c|}
\hline & & $\begin{array}{l}\text { Inte } \\
\text { alls } \\
\text { rädd }\end{array}$ & $\begin{array}{l}\text { Bara } \\
\text { lite } \\
\text { rädd }\end{array}$ & $\begin{array}{l}\text { Ganska } \\
\text { rädd }\end{array}$ & $\begin{array}{l}\text { Mycket } \\
\text { rädd }\end{array}$ & Livrädd \\
\hline 1 & ... för tandläkaren & & & & & \\
\hline 2 & ... för doktorn & & & & & \\
\hline 3 & ... för att få spruta eller bedövning & & & & & \\
\hline 4 & ... när någon undersöker dina tänder eller mun & & & & & \\
\hline 5 & ... när du gapar hos tandläkaren & & & & & \\
\hline 6 & ... när någon du inte känner rör eller tar i dig & & & & & \\
\hline 7 & ... när någon du inte känner tittar på dig & & & & & \\
\hline 8 & ... när tandläkaren borrar i din tand & & & & & \\
\hline 9 & ... för att se tandläkaren borra i någon annans tand & & & & & \\
\hline 10 & ... för att höra tandläkarborren & & & & & \\
\hline 11 & ... när någon har/håller instrument i din mun & & & & & \\
\hline 12 & ... för att sätta i halsen & & & & & \\
\hline 13 & ... för att behöva åka till sjukhus & & & & & \\
\hline 14 & ... för personer i vita sjukhus- eller tandläkarkläder & & & & & \\
\hline 15 & ... när någon gör rent eller fluorlackar dina tänder & & & & & \\
\hline
\end{tabular}


Appendix 3
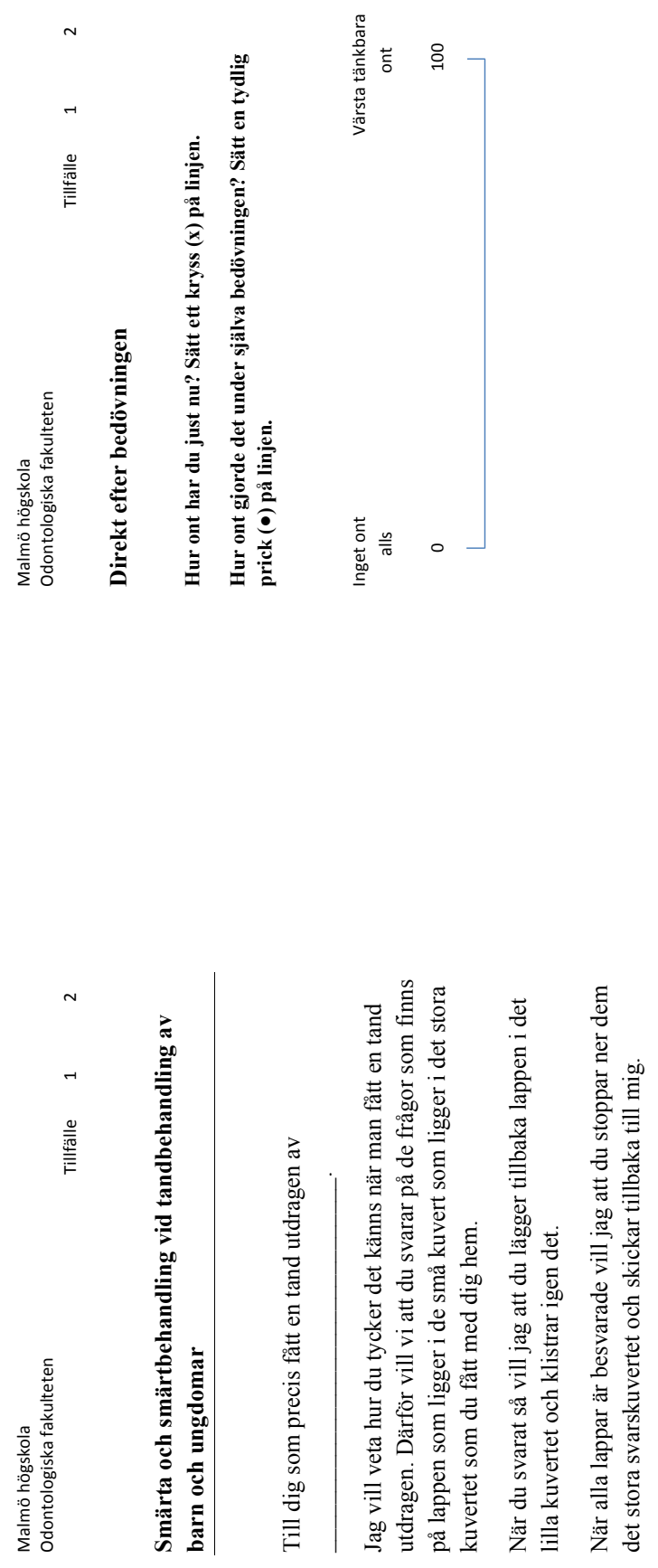
H."H.

H. 
ill.thn.

H."HW. 


$$
\text { illwh. }
$$




\section{Appendix 4}

Malmö högskola

Kodnr:

Odontologiska fakulteten

\section{Till vårdnadshavare för barn som deltar i studien: Smärta och smärtkontroll $i$ samband med tandbehandling av barn och ungdomar}

I samband med att ditt barn varit hos tandläkaren och deltagit i forskningsprojektet har du troligen fått ta ledigt från jobb för att kunna följa med ditt barn. Dessutom har ditt barn troligen varit borta från skolan för att kunna komma till kliniken och få sin behandling. Det är därför av intresse att veta hur mycket tid som du varit borta från arbetet för att kunna följa med, samt hur mycket tid som ditt barn har missat i skolan för denna behandling. Frågorna rör enbart de besök för tandutdragning som skett på Tandvårdshögskolan eller Colosseumkliniken.

Tacksam om du svarar på nedanstående frågor!

1. Hur mycket tid har du/ni tagit ledigt från arbetet/studier för att kunna följa med ert barn till tandläkarkliniken för tandutdragningarna?

Om båda vårdnadshavarna har varit med vid något tillfälle, vänligen räkna samman den totala tiden.

alla timmar totalt (ange hela timmar)

Därav hur många timmar från arbete respektive studier?

.timmar från arbete (ange hela timmar)

.timmar från egna studier (ange hela timmar)

2. Hur många timmar har ditt barn varit borta från skolan i samband med tandbehandlingarna i denna studie? Ange totaltid för alla behandlingstillfällena.

.timmar (ange hela timmar)

3. Har ditt barn behövt vara hemma från skolan på grund av eventuella komplikationer efter tandbehandlingarna? Ange i så fall sammanlagd tid.

Nej $\square$

Ja $\quad$ Om ja - hur många timmar? .timmar (ange hela timmar)

4. Om du svarat "ja" på fråga 3: har vårdnadshavare varit hemma med barnet under tiden?

Ja

Nej $\quad$ Om nej-hur många timmar? .timmar (ange hela timmar) 
5. Hur har ni transporterat er till kliniken? (flera svar är möjliga)

Bil

Buss

$\square$

Tåg

$\square$

Till fots

$\square$

Cykel

Annat färdsätt.

6. Hur lång tid har transporterna till och från kliniken tagit totalt? ..timmar

7. Har ni behövt uppsöka tandläkare efter tandbehandlingen som utförts i denna studie på grund av besvär som uppstått vid tandutdragningarna?

Nej $\square$

Ja

Om ja - hur många gånger?

.gånger

8. Hur lång tid har dessa besök (från fråga 7) tagit i genomsnitt?

timmar

\title{
Tack för din medverkan!
}

\author{
Henrik Olsson \\ Malmö högskola \\ Odontologiska fakulteten \\ 20506 Malmö
}


I 



\title{
Dentists' attitudes towards acute pharmacological pain management in children and adolescents
}

\author{
HENRIK BERLIN $\mathbb{D i D}^{1}$, THOMAS LIST ${ }^{2}$, KARIN RIDELL ${ }^{1}$ \& GUNILLA KLINGBERG ${ }^{1}$ \\ ${ }^{1}$ Department of Paediatric Dentistry, Faculty of Odontology, Malmö University, Malmö, Sweden, and ${ }^{2}$ Department of \\ Orofacial Pain and Jaw Function, Faculty of Odontology, Malmö University, Malmö, Sweden
}

International Journal of Paediatric Dentistry 2018; 28: $152-160$

\begin{abstract}
Aim. This study aimed to investigate Swedish dentists' attitudes regarding pain management strategies for treating children and adolescents. It assessed recommendations for pre- and postoperative analgesics, and use of local anaesthesia, and whether application of these strategies differs between general dental practitioners (GDPs) and specialists in paediatric dentistry (SPDs).

Design. We invited all GDPs $(n=807)$ in southern Sweden (Region Skåne), and all registered SPDs $(n=122)$ working in Sweden (929 actively practising dentists under age 65 years) to participate in a postal survey on pain management in paediatric dental care.
\end{abstract}

Results. The SPDs reported using all types of painreducing strategies more frequently than GDPs except local anaesthesia when extracting a permanent premolar, which SPDs and GDPs used equally often. Preoperative analgesic use was greater among SPDs than GDPs. GDPs used local anaesthesia less frequently for filling therapy in primary teeth than in permanent teeth.

Conclusions. SPDs recommend preoperative analgesics more often than GDPs do. GDPs seem to underuse local anaesthetics when treating children and adolescents. SPDs also use pain management strategies more frequently than GDPs. Among GDPs, pain management is less frequent when treating primary teeth than permanent teeth.

Few studies have investigated how and to what extent dentists use procedural and postoperative pain-reducing strategies ${ }^{5-7}$. Wondimu and Dahllöf ${ }^{5}$ queried 700 Swedish GDPs about their views on pain and various painreducing regimes. Rasmussen et al. ${ }^{6}$ performed a similar study in Denmark. Both studies found that a considerable number of GDPs did not think that children could report pain with any degree of certainty. A rather large portion of the Swedish and Danish GDPs also reported that pain-free dental treatment was simply an ideal, but not achievable. Wondimu and Dahllöf concluded that there was a general underuse of local anaesthetics, analgesics, and sedatives when treating children and adolescents. Local anaesthetic use was even lower among Danish GDPs. Rasmussen et al. ${ }^{6}$ suggested that female caregivers were more empathetic, which is debatable since the Swedish study found that female GDPs, aged 41-50 years, gave less importance to pain-free dental treatment ${ }^{5}$. Studies in the United States have also evaluated pain management strategies. One
Henrik Berlin, Department of Paediatric Dentistry, Faculty of Odontology, Malmö University, SE-205 06 Malmö, Sweden. E-mail: henrik.berlin@mah.se 
reported that about a third of dentists did not always use local anaesthesia in conjunction with filling therapy or extraction ${ }^{8}$. Another study reported that SPDs used local anaesthesia more often than GDPs during filling therapy in children up to 9 years of age .

The aim of this study was to investigate Swedish dentists' attitudes about pain management when treating children and adolescents by assessing (i) dentists' recommendations for the use of pre- and postoperative analgesics, (ii) use of local anaesthesia during treatment of primary and permanent teeth, and (iii) if the use of these strategies differs between GDPs and SPDs.

The null-hypotheses were that there are no differences (i) in the use of pre- and postoperative analgesics when treating primary $v s$ permanent teeth, (ii) in the use of local anaesthesia when treating primary vs permanent teeth, and (iii) between GDPs and SPDs regarding (i) and (ii).

\section{Materials and methods}

\section{Participants}

In Sweden, comprehensive dental care, including specialist dental treatment, is free of charge for children and adolescents (age 0-19 years). Caregivers (GDPs) in the Public Dental Services or in the private sector provide regular dental care. This study was conducted in the Skåne Regional Council (Region Skåne), in southern Sweden. According to official statistics, Region Skåne has 1.3 million inhabitants, of which 296,000 are aged 19 years or younger. The study solicited all general practitioners working with children and adolescents (807 GDPs) in Region Skåne, and all registered specialists in paediatric dentistry working in Sweden (122 SPDs). Thus, we invited a total of 929 dentists to take a postal survey on pain management in paediatric dental care (Table 1). Our search included only those aged 65 years or younger and still active as dentist.

\section{Questionnaire}

The dentists received a questionnaire about pain management adapted from Wondimu and Dahllö ${ }^{5}$ that had been used in Sweden previously. It contained demographic questions such as age, sex, years in practice, type of practice/employment, hours treating patients per week, hours treating child patients per week, and number of child patients treated per year. Additionally, the dentists responded to questions about four clinical scenarios:

(i) When performing filling therapy on a maxillary second primary molar (tooth 55) in a 5 year-old patient: how often would you use the following procedure?

(ii) When performing filling therapy on a maxillary first permanent molar (tooth 16) in a 10-year-old patient: how often would you use the following procedure?

(iii) When extracting a maxillary primary incisor (tooth 51) in a 4-year-old patient: how often would you use the following procedure? and

(iv) When extracting a maxillary first permanent premolar (tooth 14) in a 12-year-old patient: how often would you use the following procedure?

Each clinical scenario (i-iv) asked questions concerning local anaesthesia and recommendations for pre- and postoperative analgesics. The dentists responded on a 5-point Likert scale with the options Always, Often, Sometimes, Seldom, and Never. Finally, after the scenarios, there were three open-ended questions regarding the type of pharmaceutical agent used if dentists recommended preor postoperative analgesics for tooth extractions, and the timing of administration if used preoperatively.

\section{Procedure and statistical methods}

We mailed the questionnaires to the dentists together with written information about the study and a consent form with the return postage for the surveys and forms prepaid. We also sent two reminders. The Regional Ethics Review Board in Lund, Sweden, approved the study in August 2014 (\# 2014/527).

Data compilation and analysis used SPSS version 22.0 (Statistical Package for the Social Sciences; SPSS Inc., Chicago, IL, USA), applying the chi-square test, McNemar's test, and logistic regression analysis. We dichotomized 
Table 1. Participant characteristics.

\begin{tabular}{|c|c|c|c|c|c|c|c|c|}
\hline & \multicolumn{3}{|c|}{ GDPs } & \multicolumn{3}{|c|}{ SPDs } & \multirow[b]{2}{*}{ Total } & \\
\hline & $\begin{array}{l}\text { Total } \\
N\end{array}$ & $\begin{array}{l}\mathrm{F} \\
N(\%)\end{array}$ & $\begin{array}{l}M \\
N(\%)\end{array}$ & Total N & $\begin{array}{l}\mathrm{F} \\
N(\%)\end{array}$ & $\begin{array}{l}\mathrm{M} \\
\mathrm{N}(\%)\end{array}$ & & \\
\hline Invited & $807 *$ & $450(56)$ & $355(44)$ & 122 & $100(82)$ & $22(18)$ & 929 & \\
\hline Participating & 461 * & $270(59)$ & $189(41)$ & 101 & $86(85)$ & 15 (15) & 562 & \\
\hline Mean age (SD) & $46.5(12.1)$ & $44.5(12.0)$ & $49.3(11.7)$ & $48.4(10.4)$ & $48.4(10.4)$ & $48.6(10.9)$ & & $P=0.098$ \\
\hline
\end{tabular}

GDPs, general dental practitioners; SPDs, specialists in paediatric dentistry; $F$, females; $M$, males.

*2 missing values.

the Likert-scale responses for the four scenarios into Always-Often and Sometimes-SeldomNever. The corrected $P$-value and logistic regression analysis used the following independent variables: sex, age, dentists having children of their own, years of experience as a dentist and numbers of hours treating children per week. The corrected $P$-value in Table 3 used these same variables together with the additional variable $S P D$. The significance level was set at $P<0.05$.

\section{Results}

A total of 562 dentists $(60.5 \%)$ answered the questionnaire, with a significantly higher response rate for SPDs than GDPs $(82.8 \%$ vs. $57.1 \%, P=0.001$; Table 1). For the 314 nonrespondents (293 GDPs and 21 SPDs), no information on age was available. Response rates between female and male dentists did not differ significantly (Table 1); non-responders' sex was assessed based on the names in the lists of eligible dentists.

Table 2 shows the distribution of dentists' response to the Likert scale. Dichotomized responses were, however, chosen for the statistical analyses as high intention to use the different pain management strategies (Always-Often) was considered important from a clinical point of view.

Table 3 shows the dentists' recommendations for pre- and postoperatively administered analgesics. The type of general analgesic most frequently recommended by both GDPs and SPDs was paracetamol (in the USA often referred to as acetaminophen); as preoperative analgesic, $70.5 \%$ and $78.0 \%$, respectively, $P=0.181$; as postoperative analgesic, $57.0 \%$ and $60.0 \%$, respectively, $P=0.665$. Of those who recommended preoperative analgesics, only $12.4 \%$ of GDPs and $1.0 \%$ of SPDs advocated administration $<1 \mathrm{~h}$ before dental treatment $(P=0.000)$. The majority of both GDPs and SPDs advocated preoperative administration of analgesics $1 \mathrm{~h}$ or more before dental treatment $(84.8 \%$ and $94.0 \%$, respectively; $P=0.000)$.

SPDs used all types of pain-reducing strategies more frequently than GDP, apart from local anaesthesia, when extracting a permanent premolar, which each group used equally often. Between-group differences remained after adjusting for the independent variables, as the corrected $P$-values in Table 3 show. SPDs and GDPs also differed in their application of pain management strategies for treating primary vs permanent teeth. Whereas SPDs used the same strategies in both dentitions, GDPs used local anaesthesia less frequently for filling therapy in primary teeth than for filling therapy in permanent teeth (Table 4).

In the GDP group, females answered Always or Often more frequently than males for several scenarios. Thus, women used local anaesthesia prior to filling therapy in permanent teeth more often than men $(91.0 \%$ vs. $83.4 \%, P=0.024)$, as well as postoperative analgesics after extraction for primary molars (45.7\% vs. $35.4 \%, P=0.041)$ and permanent molars $(55.8 \%$ vs. $39.5 \%, P=0.001)$. We also found this effect for preoperative analgesics prior to extraction of a permanent tooth, although the overall frequency was low $(12.6 \%$ vs. $5.6 \%, P=0.026)$. We found no significant differences between the sexes 


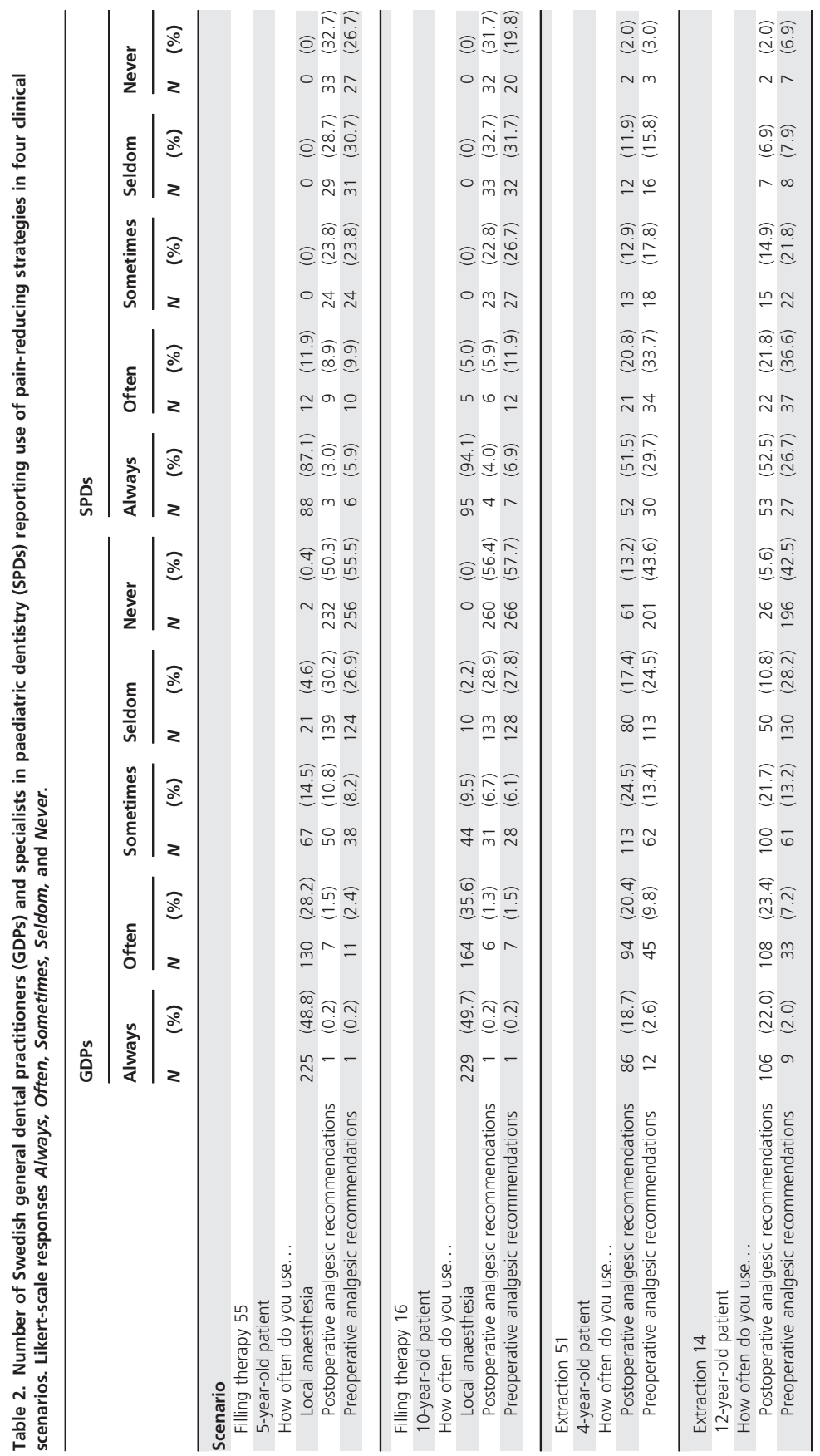


Table 3. Number of Swedish general dental practitioners (GDPs) and specialists in paediatric dentistry (SPDs) reporting use of pain-reducing strategies in four clinical scenarios. Likert-scale responses dichotomized to Always-Often and SometimesSeldom-Never. Chi-square and Fisher's exact test.

\begin{tabular}{|c|c|c|c|c|c|c|c|c|c|c|}
\hline & \multicolumn{4}{|c|}{ GDPs } & \multicolumn{4}{|c|}{ SPDs } & \multirow[b]{3}{*}{$P$-value } & \multirow{3}{*}{$\begin{array}{l}\text { Corrected } \\
P \text {-value }\end{array}$} \\
\hline & \multicolumn{2}{|c|}{ Always-Often } & \multicolumn{2}{|c|}{$\begin{array}{l}\text { Sometimes- } \\
\text { Seldom-Never }\end{array}$} & \multicolumn{2}{|c|}{ Always-Often } & \multicolumn{2}{|c|}{$\begin{array}{l}\text { Sometimes- } \\
\text { Seldom-Never }\end{array}$} & & \\
\hline & $N$ & $(\%)$ & $N$ & $(\%)$ & $N$ & $(\%)$ & $N$ & $(\%)$ & & \\
\hline \multicolumn{11}{|l|}{ Scenario } \\
\hline \multicolumn{11}{|l|}{ Filling therapy 55} \\
\hline \multicolumn{11}{|l|}{ 5-year-old patient. } \\
\hline \multicolumn{11}{|l|}{ How often do you use... } \\
\hline Local anaesthesia & 355 & $(79.8)$ & 90 & $(20.3)$ & 100 & $(100)$ & 0 & $(0)$ & 0.000 & 0.000 \\
\hline $\begin{array}{l}\text { Postoperative analgesic } \\
\text { recommendations }\end{array}$ & 8 & $(1.9)$ & 421 & $(98.1)$ & 12 & $(12.2)$ & 86 & (87.8) & 0.000 & 0.009 \\
\hline $\begin{array}{l}\text { Preoperative analgesic } \\
\text { recommendations }\end{array}$ & 12 & $(2.8)$ & 418 & $(97.2)$ & 16 & (16.3) & 82 & $(83.7)$ & 0.000 & 0.028 \\
\hline \multicolumn{11}{|l|}{ Filling therapy 16} \\
\hline \multicolumn{11}{|l|}{ 10-year-old patient. } \\
\hline \multicolumn{11}{|l|}{ How often do you use... } \\
\hline Local anaesthesia & 393 & $(87.9)$ & 54 & $(12.1)$ & 100 & $(100)$ & 0 & $(0)$ & 0.000 & 0.007 \\
\hline $\begin{array}{l}\text { Postoperative analgesic } \\
\text { recommendations }\end{array}$ & 7 & $(1.6)$ & 424 & $(98.4)$ & 10 & $(10.2)$ & 88 & (89.8) & 0.000 & 0.016 \\
\hline $\begin{array}{l}\text { Preoperative analgesic } \\
\text { recommendations }\end{array}$ & 8 & $(1.9)$ & 422 & $(98.1)$ & 19 & (19.4) & 79 & (80.6) & 0.000 & 0.011 \\
\hline \multicolumn{11}{|l|}{ Extraction 51} \\
\hline \multicolumn{11}{|l|}{ 4-year-old patient. } \\
\hline \multicolumn{11}{|l|}{ How often do you use... } \\
\hline $\begin{array}{l}\text { Postoperative analgesic } \\
\text { recommendations }\end{array}$ & 180 & $(41.5)$ & 254 & $(58.5)$ & 73 & $(73.0)$ & 27 & $(27.0)$ & 0.000 & 0.009 \\
\hline $\begin{array}{l}\text { Preoperative analgesic } \\
\text { recommendations }\end{array}$ & 57 & $(13.2)$ & 376 & $(86.8)$ & 64 & $(63.4)$ & 37 & $(36.6)$ & 0.000 & 0.028 \\
\hline \multicolumn{11}{|l|}{ Extraction 14} \\
\hline \multicolumn{11}{|l|}{ 12-year-old patient. } \\
\hline \multicolumn{11}{|l|}{ How often do you use... } \\
\hline $\begin{array}{l}\text { Postoperative analgesic } \\
\text { recommendations }\end{array}$ & 214 & $(49.2)$ & 221 & $(50.8)$ & 75 & (75.8) & 24 & $(24.2)$ & 0.000 & 0.001 \\
\hline $\begin{array}{l}\text { Preoperative analgesic } \\
\text { recommendations }\end{array}$ & 42 & $(9.8)$ & 387 & $(90.2)$ & 64 & (63.4) & 37 & (36.6) & 0.000 & 0.000 \\
\hline
\end{tabular}

regarding local anaesthesia before filling therapy of primary molars or preoperative analgesics before extraction of primary teeth.

There was no relationship between years of experience as a GDP (dichotomized to $\leq 5$ years and $\geq 6$ years) and use of local anaesthesia for filling therapy in either primary or permanent teeth or with regard to use of preoperative analgesics. Dentists with $\leq 5$ years of working experience, however, recommended postoperative analgesics when extracting teeth more frequently than those with more experience (primary teeth $57.8 \%$ vs. $37.6 \%$, $P=0.001$; permanent teeth $63.5 \%$ vs. $45.7 \%$, $P=0.005)$.

A backward logistic regression analysis assessed whether various factors affected the pain-reducing strategies of GDPs using the following variables: sex, age, having children of their own, years of experience as a dentist, and numbers of hours treating children per week. Sex was identified as a predictor for the use of local anaesthesia during filling therapy of permanent molars $(P=0.025)$ 
Table 4. Number of Swedish general dental practitioners (GDPs) and specialists in paediatric dentistry (SPDs) reporting use of pain-reducing strategies Always or Often when treating primary and permanent teeth. McNemar's test.

\begin{tabular}{|c|c|c|c|c|c|c|c|c|c|c|}
\hline & \multicolumn{5}{|c|}{ GDPs } & \multicolumn{5}{|c|}{ SPDs } \\
\hline & \multicolumn{2}{|c|}{ Primary teeth } & \multicolumn{2}{|c|}{ Permanent teeth } & \multirow[b]{2}{*}{ ( $P$-value) } & \multicolumn{2}{|c|}{ Primary teeth } & \multicolumn{2}{|c|}{ Permanent teeth } & \multirow[b]{2}{*}{ ( $P$-value) } \\
\hline & $N$ & $(\%)$ & $N$ & $(\%)$ & & $N$ & $(\%)$ & $N$ & $(\%)$ & \\
\hline \multicolumn{11}{|l|}{ Scenario } \\
\hline \multicolumn{11}{|l|}{ Filling therapy } \\
\hline Local anaesthesia & 355 & $(80.0)$ & 390 & $(87.7)$ & 0.000 & 100 & $(100)$ & 100 & $(100)$ & n.s \\
\hline $\begin{array}{l}\text { Preoperative analgesics } \\
\text { recommendation }\end{array}$ & 12 & $(2.8)$ & 8 & $(1.9)$ & 0.289 & 16 & $(16.3)$ & 19 & (19.4) & 0.453 \\
\hline $\begin{array}{l}\text { Postoperative analgesics } \\
\text { recommendation }\end{array}$ & 8 & (1.9) & 7 & $(1.6)$ & 1.000 & 12 & $(12.2)$ & 10 & $(10.2)$ & 0.687 \\
\hline \multicolumn{11}{|l|}{ Extraction } \\
\hline $\begin{array}{l}\text { Preoperative analgesics } \\
\text { recommendation }\end{array}$ & 54 & $(12.7)$ & 42 & (9.9) & 0.065 & 64 & $(63.4)$ & 64 & $(63.4)$ & 1.000 \\
\hline $\begin{array}{l}\text { Postoperative analgesics } \\
\text { recommendation }\end{array}$ & 178 & $(41.4)$ & 212 & (49.3) & 0.000 & 73 & $(73.7)$ & 75 & $(75.8)$ & 0.687 \\
\hline
\end{tabular}

with female GDPs twice as likely to use it compared to males, whereas the other variables were constant. Women were also twice as likely to recommend analgesics after extraction of a permanent premolar $(P=0.002)$. Having children of their own reduced the odds of GDPs recommending preoperative analgesics by $58.3 \% \quad(P=0.016)$ when extracting a primary incisor, compared to those without children of their own. Those who had worked $\geq 6$ years as a GDP had an almost three-times-greater probability of recommending preoperative analgesics when extracting a primary incisor than those with $\leq 5$ years of experience $(P=0.041)$. For the other tested scenarios, the logistic regression analyses identified no other variables as significant predictors.

\section{Discussion}

The main findings of this study were differences in acute pharmacological pain management between GDPs and SPDs, and also among GDPs when treating primary vs permanent teeth; SPDs were more likely to use/ recommend a variety of pain-reducing strategies compared to GDPs, and GDPs were more likely to use pain management strategies when treating permanent teeth than primary teeth. We also found that analgesic use was less frequent preoperatively than postoperatively, more common in conjunction with tooth extractions, and more often recommended by SPDs than GDPs. Additionally, female GDPs were more likely to use/recommend pain-reducing strategies than male GDPs.

This was a comprehensive study of practice among GDPs in Region Skåne, and SPDs in Sweden. In December 2013, there were a total of 893 GDPs (of which 807 treated child patients) in Region Skåne. They accounted for $13.0 \%$ of all GDPs in Sweden. A wellplanned and well-implemented postal survey can easily achieve $50 \%$ or more in response rate 9 . A review from $2009^{10}$ concluded that the response rate for postal surveys among healthcare professionals between 1996 and 2005 was low (mean response rate 56\%). Even though there is no definite lower limit for an acceptable response rate, figures below $60 \%$ are often considered low. A response rate of $75 \%$ or more is graded as good ${ }^{10}$. The response rate for the present study, $60.5 \%$, is thus acceptable and also in line with a similar Swedish survey ${ }^{5}$. Analysis of non-responders did not indicate any differences between male or female dentists. The proportions of male and female respondents were in accordance with national statistics in Sweden. Therefore, we consider this material representative for Sweden.

The results raise the question of whether there is an explanation for the higher likelihood of SPDs to recommend preoperative 
analgesics than GDPs. The scientific evidence supporting use of preoperative analgesics in paediatric dentistry is scarce. Preoperative analgesics for children having dental treatment are still a knowledge gap ${ }^{3,11}$. A review from 2010 on preoperative analgesics for postoperative pain control in outpatient surgeries (such as dental, abdominal, and orthopaedic procedures) concluded that the data from scientific studies are contradictory as to whether preoperative analgesics have any positive effect. Instead, they state that, to achieve good postoperative pain control, pain control must focus on all phases of the perioperative period ${ }^{12}$. A later study also concluded that preoperative analgesics have not clearly improved immediate postoperative pain relief or reduced the need for supplemental analgesics, and that further research is needed. They also reported, based on reviewing other articles, that NSAID use as a preoperative analgesic seems to have a better effect than paracetamol ${ }^{13}$. Thus, Swedish dentists' use of preoperative analgesics is based on concerns for their young patients rather than on scientific evidence. It may be argued that a single dose of paracetamol is rather harmless. Still, there are reports of adverse effects, and it is an open question whether perfunctory use of analgesics in dentistry should be acceptable ${ }^{14,15}$.

Interestingly, the timing for administering preoperative analgesics also differs widely among those using this regime. The pharmacokinetic properties of paracetamol and ibuprofen should also be taken into consideration when choosing and administering analgesics. Maximum plasma concentration for paracetamol is achieved within $0.5-1 \mathrm{~h}$, and the half-life is $2 \mathrm{~h}^{16}$. For ibuprofen, the figures are $2 \mathrm{~h}$ to reach maximum plasma concentration and a 2-h half-life ${ }^{17}$. Depending on the desired outcome, it is therefore important to administer preoperative analgesics correctly according to whether the indication is pain reduction during treatment or postoperative pain reduction. If incorrectly used, the desired pharmacological effects may not be achieved. The effect may instead be solely placebo. The placebo effect, however, should not be underrated, but perhaps an active substance should not be used for this purpose. Whereas both paracetamol and ibuprofen are widely used for children and adolescents to fight fever and pain ${ }^{18}$, some studies have reported an increased risk of exacerbation of asthma symptoms in children taking paracetamol or ibuprofen ${ }^{14}$. Both pharmaceutical substances also seem to enhance the risk of liver damage in children ${ }^{15}$. Based on current scientific knowledge, there is no rationale for introducing or using preoperative administration of analgesics as a routine procedure before dental treatment.

Bivariate analyses revealed that SPDs used all types of pain-reducing strategies more frequently than GDPs in the present study. This finding is supported by a Dutch study, showing that SPDs used local anaesthetics more frequently when performing fillings compared to GDPs (however, only in children up to 9 years of age $)^{7}$. A possible reason for this could be enhanced knowledge that comes with specialist training and the fact that SPDs often treat child patients who have been referred for problems related to anxiety or behaviour ${ }^{4}$.

SPDs used local anaesthetics equally often when treating primary and permanent teeth. This was in contrast to GDPs, who used it less frequently for primary teeth than permanent. This finding agrees with reports from Finnish and American dentists ${ }^{19}$. The lower use of local anaesthesia among GDPs when treating primary teeth, that is, in younger children, is problematic as there is no evidence of less pain from the treatment of primary teeth or of young children not perceiving pain to the same extent as older children or adolescents. On the contrary, young children may have more difficulties understanding pain as it is an abstract phenomenon, which may increase their risk of developing DFA and BMP. A plausible explanation for the underuse of local anaesthesia by GDPs could be feelings of stress related to treating child patients, especially due to injections and children's reactions to injections and pain. This was previously suggested by both Wondimu and Dahllöf $\mathrm{f}^{5}$ and Rasmussen et al. ${ }^{6}$. Thus, there seems to be uncertainty among GDPs of how to manage pain prevention, including 
injections of local anaesthetics, in paediatric dental patients. This uncertainty calls for further investigation and creation of guidelines/ strategies that are easy to follow in the dental office. The results of the present study support and stress the need for strengthening undergraduate curricula, continuing education and discussion about pain management in child dental care, which other researchers have also advocated ${ }^{5}$.

Pain management includes pain prevention as well as pain reduction. Both are equally important and include pharmacological methods, such as use of topical and local anaesthesia, but also good psychological care. To provide professional pain management, the dentist should always ensure that the local anaesthetic has taken full effect and be prepared to supplement it if not, as well as know how to administer pain-free local anaesthesia and communicate with the child patient to ensure that he or she is as comfortable as possible and pain-free.

To conclude, this study raises questions about dentists' use of pain-reducing strategies during dental treatments in children and adolescents. There is an underuse of local anaesthetics when treating children and adolescents in general dentistry. SPDs use general analgesics more frequently, despite only scarce scientific evidence supporting their use, especially for preoperative analgesics. There is also a knowledge gap concerning the effectiveness of pre- and postoperative use of analgesics in paediatric dentistry that needs to be bridged.

Why this paper is important to paediatric dentists

- The effect of preoperative analgesics should be explored further before being introduced as a recommended pain-reducing regime.

- The importance of painless dental treatment should be further stressed, regardless of whether treating primary or permanent teeth.

\section{Acknowledgements}

This study was supported by grants from the Swedish Dental Society; the Swedish Society of Paediatric Dentistry; the Faculty of
Odontology, Malmö University; Skåne Regional Council, Sweden; and the American Dental Society of Sweden.

We thank Per-Erik Isberg, Department of Statistics, Lund University, for statistical assistance.

\section{Conflict of interest}

The authors declare no conflict of interest.

\section{Author contributions}

H.B. and G.K. conceived the ideas; H.B. collected the data; H.B., G.K., T.L., and K.R analysed the data; and H.B. and G.K. led the writing.

\section{References}

1 Klingberg G, Broberg AG. Dental fear/anxiety and dental behaviour management problems in children and adolescents: a review of prevalence and concomitant psychological factors. Int $J$ Paediatr Dent 2007; 17: 391-406.

2 Raadal M, Strand GV, Amarante EC, Kvale G. Relationship between caries prevalence at 5 years of age and dental anxiety at 10. Eur J Paediatr Dent 2002; 3: 22-26.

3 Ashley PF, Parekh S, Moles DR, Anand P, Behbehani A. Preoperative analgesics for additional pain relief in children and adolescents having dental treatment. Cochrane Database Syst Rev 2012; 9: CD008392.

4 Klingberg G, Andersson-Wenckert I, Grindefjord M et al. Specialist paediatric dentistry in Sweden 2008 - a 25-year perspective. Int J Paediatr Dent 2010; 20: 313-321.

5 Wondimu B, Dahllof G. Attitudes of Swedish dentists to pain and pain management during dental treatment of children and adolescents. Eur J Paediatr Dent 2005; 6: 66-72.

6 Rasmussen JK, Frederiksen JA, Hallonsten AL, Poulsen S. Danish dentists' knowledge, attitudes and management of procedural dental pain in children: association with demographic characteristics, structural factors, perceived stress during the administration of local analgesia and their tolerance towards pain. Int $J$ Paediatr Dent 2005; 15: 159-168.

7 Schorer-Jensma MA, Veerkamp JS. A comparison of paediatric dentists' and general dental practitioners' care patterns in paediatric dental care. Eur Arch Paediatr Dent 2010; 11: 93-96.

8 Milgrom P, Weinstein P, Golletz D, Leroux B, Domoto P. Pain management in school-aged 
children by private and public clinic practice dentists. Pediatr Dent 1994; 16: 294-300.

9 Dillman D, Smyth J, Christian L. Chapter 10: Mail questionnaires and implementation. In: Dillman D, Smyth J, Christian L, (eds.). Internet, Phone, Mail, and Mixed-Mode Surveys. The Tailored Design Method. Hoboken, NJ: John Wiley \& Sons, Inc., 2014: 351-397.

10 Bowling A. Research Methods in Health Investigating Health and Health Services. Maidenhead, Berkshire, UK: Open University Press 2014.

11 Mejare IA, Klingberg G, Mowafi FK, StecksenBlicks C, Twetman SH, Tranaeus SH. A systematic map of systematic reviews in pediatric dentistrywhat do we really know? PLOS ONE 2015; 10: e0117537.

12 Campiglia L, Consales G, De Gaudio AR. Pre-emptive analgesia for postoperative pain control: a review. Clin Drug Investig 2010; 30(Suppl 2): 15-26.

13 Dahl JB, Moiniche S. Pre-emptive analgesia. $\mathrm{Br} \mathrm{Med}$ Bull 2004; 71: 13-27.

14 Matok I, Elizur A, Perlman A, Ganor S, Levine H, Kozer E. Association of acetaminophen and ibuprofen use with wheezing in children with acute febrile illness. Ann Pharmacother 2016; 51: 239-244.
15 Norman $\mathrm{H}$, Elfineh $\mathrm{M}$, Beijer $\mathrm{E}$, Casswall $\mathrm{T}$, Nemeth A. Also ibuprofen, not just paracetamol, can cause serious liver damage in children. NSAIDs should be used with caution in children, as shown in case with fatal outcome. Läkartidningen 2014; 111: 1709-1711.

16 FASS. Paracetamol. (The Swedish medical products list). 2016; https://www.fass.se/LIF/product?use rType $=08$ nplId=19581215000033 [updated December 13, 2016].

17 FASS. Ibuprofen. (The Swedish medical products list). 2016; https://www.fass.se/LIF/product?use rType $=08 n p l I d=20080117000043$ [updated December 13, 2016].

18 Southey ER, Soares-Weiser K, Kleijnen J. Systematic review and meta-analysis of the clinical safety and tolerability of ibuprofen compared with paracetamol in paediatric pain and fever. Curr Med Res Opin 2009; 25: 2207-2222.

19 Murtomaa H, Milgrom P, Weinstein P, Vuopio T. Dentists' perceptions and management of pain experienced by children during treatment: a survey of groups of dentists in the USA and Finland. Int J Paediatr Dent 1996; 6: 25-30. 

II 



\title{
Postoperative pain profile in 10-15-year-olds after bilateral extraction of maxillary premolars
}

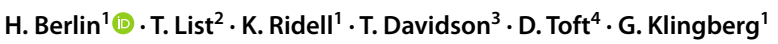 \\ Received: 13 December 2018 / Accepted: 25 February 2019 / Published online: 8 April 2019 \\ (C) The Author(s) 2019
}

\begin{abstract}
Purpose To study pain perception in 10-15-year-olds, during and after uncomplicated extractions of bilateral maxillary premolars. The study investigated pain's natural course and made comparisons between the first and second extractions.

Methods 31 Swedish children in need of orthodontic treatment were identified and consecutively enrolled. Tooth extractions followed a standardised protocol and the two teeth were extracted with at least 10 days between. The participants rated pain intensity using visual analogue scale (VAS) at 14 different time points from treatment and 7 days forward.

Results The pain intensity profile followed the same pattern for all patients. Pain intensity peaked $2 \mathrm{~h}$ after extractions (mean $\mathrm{VAS}_{\mathrm{PI}}$ 27.3, SD 20.8; median 23.0) when moderate pain intensity (VAS $\left.\mathrm{PI}_{2} \geq 40\right)$ was registered for 16 (28\%) of 57 cases. After that, there was a rapid decrease in pain intensity notable already at $4 \mathrm{~h}$ after extractions. There were no statistically significant differences in any $\mathrm{VAS}_{\mathrm{PI}}$ measurements between the first and second extractions, sexes, or different age groups. Conclusions The majority of the participants who undergo uncomplicated bilateral extraction of maxillary premolars experience mild to moderate levels of postoperative pain during a short period of time, with no differences between the first and second extractions. Bilateral tooth extractions is a suitable model for further studies on pain management.
\end{abstract}

Keywords Pain $\cdot$ Child $\cdot$ Adolescent $\cdot$ Visual analogue scale $\cdot$ Self-assessment $\cdot$ Tooth extraction $\cdot$ Postoperative

\section{Introduction}

Although extraction is one of the most frequently performed oral surgical therapies (Al-Khateeb and Alnahar 2008; Ghanei et al. 2018), knowledge about natural course of pain perception during and after tooth extraction in children and adolescents is sparse. Post-extraction pain was investigated in an observational study on 221 children, 2-7 years of age (Acs et al. 1986). Of these, $38 \%$ reported pain experience via a questionnaire that the parents filled out (proxy assessment) at home and returned to the dentist. Pain level was recorded

\section{H. Berlin}

henrik.berlin@mau.se

1 Department of Pediatric Dentistry, Faculty of Odontology, Malmö University, 20506 Malmö, Sweden

2 Department of Orofacial Pain and Jaw Function, Faculty of Odontology, Malmö University, Malmö, Sweden

3 Department of Medical and Health Sciences (IMH), Linköping University, Linköping, Sweden

4 Colosseum Smile Dental Group, Malmö, Sweden as mild, moderate, or severe. The study did not report the actual time of pain measurement, number of pain recordings, type of tooth extracted, or reasons for extraction. Another study (Ashkenazi et al. 2007), on 2-15-year-old children, described pain after extraction in $43 \%$ of the 84 participants. In a telephone interview, usually with the parents, one question to assess pain between 8 and $24 \mathrm{~h}$ after extractions was asked. No other details of any pain assessments were reported; the children had received various pharmacological as well as behaviour management approaches, including sedation with midazolam and inhalation of nitrous-oxide/ oxygen during treatment.

Both of the above studies have several methodological issues. First, the patient material spanned a wide age range, both primary and permanent teeth were included, and diagnoses and reasons for extractions or number of extractions were not described. However, it is reasonable to believe that one common reason for extraction would be teeth with some form of pathology related to it. Second, pain-measuring methods were insufficiently described; the criteria were not defined, and parental reports were the main source of information. Parental and other proxy reports are problematic: 
pain is a subjective experience (IASP 2014) and basing measurements on the patient's understanding and perception of pain is preferable.

Pain not only harms the patient, but is also an important concomitant factor in the development of dental fear and anxiety (DFA) and behaviour management problems in children and adolescents (Klingberg and Broberg 2007); thus, prevention of pain is important. Today, use of local anaesthetics is well established and regarded as a safe and effective way to minimize pain during treatment (Klingberg et al. 2017). In addition, use of general analgesics, such as oral administration of paracetamol (acetaminophen) to minimize the risk of pain in conjunction with dental treatments such as tooth extractions has been proposed. An updated Cochrane-review from 2016 on preoperative administration of analgesics concluded that there was not enough scientific evidence to determine whether analgesics taken before treatment were effective for reducing pain after dental treatment under local anaesthetic in children and adolescents. They also concluded that more well-designed studies are needed (Ashley et al. 2016). No systematic review on postoperative administration of analgesics for preventing/reducing postoperative pain has been identified. Despite the lack of scientific support, there are reports of dentists using oral analgesics to reduce pain in conjunction with extractions and filling therapy (Berlin et al. 2018). Thus, there is a need for well-designed clinical studies to evaluate the effect of oral analgesics to prevent pain, and based on this to formulate clinical guidelines. Before doing these studies there are still some methodologic issues to consider. Two questions need answers: (1) what does pain's natural course, using standardised measures made by children, look like after tooth extractions and, (2) if repeated extractions-will this affect the perceived pain intensity? The latter question is important as future studies probably would be randomized controlled trials using two arms with either two different pharmacologic agents or dosages, or two arms where one is an active drug and the other placebo. It cannot be disregarded that repeated experiences of tooth extraction may affect pain perception: that the child understands and accepts pain differently if the treatment is replicated.

Health economics is important for the development of clinical guidelines. As decisions may be guided by interventions' cost-effectiveness, it is important to know not only the effects but also the societal cost related to all interventions. Because simple or uncomplicated tooth extractions, especially extractions for orthodontic reasons, can be standardised, this treatment may serve as a model for studying pain and pain intensity.

The present study aims to investigate pain intensity in 10-15-year-olds during and after uncomplicated tooth extractions-orthodontically indicated and standardised bilateral extractions of maxillary premolars - to understand the natural course of pain and to make comparisons between the first and second extractions.

The null hypotheses were:

- Children and adolescents experience pain (defined as $\mathrm{VAS}_{\mathrm{PI}} \geq 40$ ) after tooth extraction.

- The first extraction is as painful as the second.

\section{Materials and methods}

Eligible participants were identified and consecutively enrolled in the study during their first visit for orthodontic treatment in Malmö, Sweden. Inclusion criteria were good general health, age 10 to 15 years, and requiring extraction of two permanent maxillary premolars (bilateral) before orthodontic treatment. Based on the radiographs, the extractions were expected to be uncomplicated. If the patients needed extractions of mandibular premolars, these were done after the study. Extractions in the maxilla were chosen as they are easier to standardise because of both root anatomy and buccal and palatal infiltration for local anaesthetics. In the mandible, infiltration technique is not always sufficient and if inferior alveolar nerve block is required, the additional numbness of the tongue and lower lip may be interpreted as uncomfortable and could affect the $\mathrm{VAS}_{\mathrm{PI}}$ measurement.

Exclusion criteria were the patient needing conscious sedation to manage the extractions, and the patient or legal guardian being unable to understand Swedish.

After verbal and written information, the legal guardian signed an informed consent form. All children received age-appropriate information and assented to participate. The Regional Ethics Review Board in Lund, Sweden (\#2014/527) approved the study.

\section{Clinical procedures}

At the first visit, patients received brief information about the treatment procedure. Which tooth to extract first (on the left or right side) was randomly chosen in a coin toss.

A detailed treatment protocol describing all parts of the treatment including amount of and timing of topical and local anaesthetics was constructed and followed for all extractions. Topical local anaesthetic (lidocaine gel 5\%, APL, Sweden) was placed for 2 min both buccal and palatal to the tooth to be extracted (Bhalla et al. 2009). The total amount of topical anaesthetic used was equivalent to the size of a pea (approx. $0.4 \mathrm{~g}$ ). After that, buccal and palatal injection with 1 cartridge $(=1.8 \mathrm{ml})$ of room-tempered local anaesthetics (LA), Xylocain Dental Adrenalin (lidocaine hydrochloride $20 \mathrm{mg} / \mathrm{ml}$, adrenaline $12.5 \mu \mathrm{g} / \mathrm{ml}$; Dentsply Pharmaceutical, Weybridge, Surrey, UK) was administered using a 30 -gauge (21-mm long) needle. A stopwatch was 
used to standardise the length of the injections to $2 \mathrm{~min}$ (Maragakis and Musselman 1996). 2 min after injection, the level of anaesthesia was controlled using an explorer, penetrating the gingiva around the tooth to be extracted. When anaesthesia was inadequate, additional LA was injected. The clinician extracted the tooth using an elevator and forceps and a gentle, standardised technique. No suggestions or prescriptions were given regarding postoperative analgesics. The second visit followed the same treatment procedure as the first visit. All patients, except for two, were treated by the same operator (HB). The other two were treated by one of the other authors (KR). The operators were calibrated by information and discussions about the treatment protocol before performing the tooth extractions.

\section{Pain measurements}

At various time points during and after treatment, the patient recorded pain intensity on a $100-\mathrm{mm}$ visual analogue scale (VAS) with the endpoints no pain at all and worst possible pain (Table 1). VAS is a unidimensional scale for estimating patients' perceptions of pain intensity (Huskisson 1974). Patients would place a mark on the VAS at the point representing their perceived pain intensity $\left(\mathrm{VAS}_{\mathrm{PI}}\right)$. Later, measurements with a ruler converted the marks to numerical values.

We chose $\mathrm{VAS}_{\mathrm{PI}} \geq 40$ to define clinically relevant pain in the present study. A second threshold was defined as $\mathrm{VAS}_{\mathrm{PI}}$ $\geq 30$ - to mirror lower levels of moderate pain (Jensen et al. 2003; van Dijk et al. 2002).

Table 1 Time and location of visual analogue scale pain intensity measurements $\left(\mathrm{VAS}_{\mathrm{PI}}\right)$

\begin{tabular}{|c|c|c|}
\hline VAS $_{\text {PI }}$ variable & Time of measurement & Location \\
\hline VAS $_{\mathrm{PI}}{ }^{\text {inj1 } 1}$ & During injection of LA & Dental clinic \\
\hline $\mathrm{VAS}_{\mathrm{PI}}{ }_{\mathrm{inj}}$ & $\begin{array}{l}\text { Immediately after injection of } \\
\text { LA }\end{array}$ & Dental clinic \\
\hline $\mathrm{VAS}_{\mathrm{PI}}{ }^{\text {extr }}$ & During tooth extraction & Dental clinic \\
\hline $\mathrm{VAS}_{\mathrm{PI}}{ }^{0 \mathrm{hr}}$ & $\begin{array}{l}0 \mathrm{~h} \text {; immediately after tooth } \\
\text { extraction }\end{array}$ & Dental clinic \\
\hline $\mathrm{VAS}_{\mathrm{PI}}^{2 \mathrm{hr}}$ & $2 \mathrm{~h}$ after tooth extraction & Home (or school) \\
\hline $\mathrm{VAS}_{\mathrm{PI}}^{4 \mathrm{hr}}$ & $4 \mathrm{~h}$ after tooth extraction & Home (or school) \\
\hline $\mathrm{VAS}_{\mathrm{PI}}$ ev1 & 1st evening after tooth extraction & Home \\
\hline $\mathrm{VAS}_{\mathrm{PI}}^{\mathrm{mol}}$ & 1st morning after tooth extraction & Home \\
\hline $\mathrm{VAS}_{\mathrm{PI}}^{\mathrm{ev} 2}$ & $\begin{array}{l}\text { 2nd evening after tooth extrac- } \\
\text { tion }\end{array}$ & Home \\
\hline $\mathrm{VAS}_{\mathrm{PI}}^{\mathrm{ev} 3}$ & 3rd evening after tooth extraction & Home \\
\hline $\mathrm{VAS}_{\mathrm{PI}}^{\mathrm{ev} 4}$ & 4th evening after tooth extraction & Home \\
\hline $\mathrm{VAS}_{\mathrm{PI}}^{\mathrm{ev} 5}$ & 5 th evening after tooth extraction & Home \\
\hline $\mathrm{VAS}_{\mathrm{PI}}{ }^{\mathrm{ev} 6}$ & 6th evening after tooth extraction & Home \\
\hline $\mathrm{VAS}_{\mathrm{PI}}^{\mathrm{ev} 7}$ & 7 th evening after tooth extraction & Home \\
\hline
\end{tabular}

$L A$ local anesthetic
Before treatment, patients were given instruction on how to use the VAS. After treatment, they received an envelope with a number of blank VAS and were instructed to fill them out at specific points of time. The time points are presented in Table 1. The evening after treatment, the dentist telephoned the patients to remind them about the VAS.

\section{Dental fear and anxiety}

Before each visit, participants received a questionnaire with the Children's Fear Survey Schedule-Dental Subscale (CFSS-DS) (Cuthbert and Melamed 1982) to measure dental fear and anxiety (DFA). This was addressed to ensure that anxiety would not influence the perceived pain intensity. The CFSS-DS is the most frequently used measure of DFA in children and adolescents (Klingberg and Broberg 2007) and comprises 15 items scored on a Likert-type scale ranging from 1 (not afraid at all) to 5 (very afraid). The total score ranges between 15 and 75; 38 and above is considered to represent DFA (Klingberg 1994). The children were instructed to fill out the CFSS-DS by themselves and bring it to the dental appointments.

\section{Costs outside the clinic}

The patients and their parents or legal guardians were also asked about the time at school or work that had been missed due to the procedure and the related pain, expenditures linked to the dental appointments, and whether the patient's schoolwork had been affected. Treatment length and numbers of follow-up visits and contacts with the dental clinic in the 7 days after extractions were also queried. All costs were calculated in Swedish Crowns (SEK) and then converted into Euros $(€)$. Mean exchange rate in 2016 was $€ 1.00=9.63$ SEK [Sveriges Riksbank (Sweden's central bank)].

\section{Statistical methods}

Data were compiled and analysed using SPSS version 24.0 (IBM Corp. Released 2016. IBM SPSS Statistics for Windows, version 24.0. Armonk, NY: IBM Corp). The independent samples $t$ test analysed differences between groups such as age, sexes, and time of day of the treatment. Paired samples $t$ test was used for comparing treatment time between the first and second extractions. The $t$ tests was used since the data being analysed were judged to be parametric data. The Wilcoxon signed-rank test was used to analyse differences between $\mathrm{VAS}_{\mathrm{PI}}$ at the first and second extractions, and the Mann-Whitney $U$ test for differences in $\mathrm{VAS}_{\mathrm{PI}}$ between groups at the first and second extractions. A significance level of $p<0.05$ was chosen. 


\section{Results}

\section{Patient characteristics}

34 children were initially invited. Three were excluded: one because placement of orthodontic brackets was planned for the day after the first extraction; one, because orthodontic treatment had already begun; and one, who did not understand the VAS. Thus, 31 patients were included and divided into two age groups: 10-13-year-olds, and 14-15-year-olds (Table 2). Thus, 62 extractions were performed, but the number of valid $\mathrm{VAS}_{\mathrm{PI}}$ registrations made at home or at school, were lower owing to patients failing to return registrations, VAS not correctly filled out, or excluded when patients had self-administered oral analgesics.

Only one individual reported a CFSS-DS score $\geq 38$ (40, representing DFA) before the first extraction, and none before the second. There were no statistically significant differences in mean CFSS-DS scores before the first and second extractions, between sexes or age groups, and there was no relationship between CFSS-DS scores and $\mathrm{VAS}_{\mathrm{PI}}$. No additional analyses were made regarding the CFSS-DS scores since DFA did not have any impact on pain intensity.

\section{Clinical procedures}

Extraction began on the right side in 20 cases (64.5\%); 44 of the 62 extracted teeth were permanent maxillary first premolars; the remaining were permanent maxillary second premolars. The mean time between the first and second extractions was 15 days (range 11-33 days). Mean treatment time, from application of topical anaesthetic to finished extraction of the tooth, was $13.2 \mathrm{~min}$ (range $8-22$ ) for the first extraction, and 12.6 min (range 8-19) for the second extraction ( $p=0.327$, paired-samples $t$ test). 36 of the extractions were done in the morning. $2 \mathrm{~h}$ after

Table 2 Characteristics of the 31 participants by sex and age

\begin{tabular}{lllll}
\hline & Boys & Girls & Total & $\begin{array}{l}\text { Signifi- } \\
\text { cance } p \\
\text { value }\end{array}$ \\
\hline No. (\%) & $15(48.4)$ & $16(51.6)$ & $31(100)$ & \\
$\begin{array}{l}\text { Mean age in years } \\
\quad(S D)\end{array}$ & $13.5(1.1)$ & $13.3(1.1)$ & $13.4(1.1)$ & $0.591^{\#}$ \\
Age group (no.) & & & & \\
10-13 years & 6 & 10 & 16 & \\
$14-15$ years & 9 & 6 & 15 & \\
\hline
\end{tabular}

${ }^{\#}$ Independent samples $t$ test treatment, $\mathrm{VAS}_{\mathrm{PI}}{ }^{2 \mathrm{hr}}$ did not differ statistically significantly between extractions performed before or after noon.

13 of 29 participants ( $44.8 \%$; 6 boys and 7 girls) reported previous experience of LA before entering the present study. No statistically significant differences in pain intensity during injection, extraction, or $2 \mathrm{~h}$ after treatment occurred between patients with and without previous experience of LA.

At the first extraction, nine patients reported insufficient anaesthesia after the injection of one capsule LA, and at the second extraction, seven patients. These patients (12 in all) received another 0.5 to 1.5 capsules of LA before extraction. $\mathrm{VAS}_{\mathrm{PI}}$ scores at $2 \mathrm{~h}$ after treatment did not differ statistically significantly between patients receiving one capsule of LA and those who received more (Table 3).

Patients reported higher $\mathrm{VAS}_{\mathrm{PI}}$ scores during injection $\left(\mathrm{VAS}_{\mathrm{PI}}{ }^{\text {inj1 }}\right.$ ) than during extractions $\left(\mathrm{VAS}_{\mathrm{PI}}{ }^{\text {extr }}\right)$ (Fig. 1). There were no differences in VAS scores between the first and second appointments $\operatorname{VAS}_{\mathrm{PI}}{ }^{\text {inj1 }}, \mathrm{VAS}_{\mathrm{PI}}{ }^{\text {inj2 }}, \mathrm{VAS}_{\mathrm{PI}}{ }^{\text {extr }}, \mathrm{VAS}_{\mathrm{PI}}{ }^{\mathrm{ohr}}$, $\operatorname{VAS}_{\mathrm{PI}}{ }^{2 \mathrm{hr}}$ and $\mathrm{VAS}_{\mathrm{PI}}{ }^{4 h r}$ ) (Table 4).

\section{Postoperative pain}

Postoperative pain ratings followed the same course for all patients (Figs. 1, 2a-c), with no statistically significant differences between the first and second extractions, between boys and girls, or between age groups (Tables 3, 4). Pain intensity peaked $2 \mathrm{~h}$ after treatment at a mean $\mathrm{VAS}_{\mathrm{PI}}$ for all extractions of 27.3 (SD 20.8; median 23.0) and then decreased to a mean of 18.3 (SD 17.9; median 10.0) at $4 \mathrm{~h}$ after treatment. At $\mathrm{VAS}_{\mathrm{PI}}{ }^{2 \mathrm{hr}}, 16$ of 57 extractions resulted in pain $\left(\mathrm{VAS}_{\mathrm{PI}} \geq 40\right)$. This level of pain intensity remained in 6 of 53 cases at $\operatorname{VAS}_{\mathrm{PI}}{ }^{4 \mathrm{hr}}$. The corresponding numbers for $\mathrm{VAS}_{\mathrm{PI}} \geq 30$ were 24 of 57 extractions at $\mathrm{VAS}_{\mathrm{PI}}{ }^{2 \mathrm{hr}}$ and 13 of 53 at $\operatorname{VAS}_{\mathrm{PI}}^{4 \mathrm{hr}}$.

Eight patients took oral analgesics after the first extraction and six of these did so after the second on their own initiative. Table 5 shows the VAS $_{\mathrm{PI}}$ scores of these patients made before their intake of oral analgesics. Any scores made after medication were excluded from the statistical analyses. Pain intensity did not differ at any time between patients who took oral analgesics and those who did not.

\section{Costs outside the clinic}

Time spent for both extractions showed that parents (and/or legal guardians) spent a mean time of $3.6 \mathrm{~h}$ (SD 1.4; median 4.0) for accompanying their children to the two dental treatments. The majority of the participants came to the dental clinic by car, but since all treatments within this study, were performed at the university clinic, (a clinic different from their normal dental clinic), the expenditures for their travel was difficult to calculate. Children missed a mean time of 
Table 3 Visual analogue scale pain intensity $\left(\mathrm{VAS}_{\mathrm{PI}}\right)$ measurements after first and second extraction by sex, age and volume of local anesthetics, $2 \mathrm{~h}$ after extraction

\begin{tabular}{|c|c|c|c|c|c|c|c|c|c|c|}
\hline & \multicolumn{3}{|c|}{ All extractions } & \multicolumn{3}{|c|}{ Extraction 1} & \multicolumn{3}{|c|}{ Extraction 2} & \multirow[t]{3}{*}{$p$ value } \\
\hline & No. & $\mathrm{VAS}_{\mathrm{PI}}$ & $p$ value & No. & $\mathrm{VAS}_{\mathrm{PI}}$ & $p$ value & No. & $\mathrm{VAS}_{\mathrm{PI}}$ & $p$ value & \\
\hline & & Median/mean (SD) & & & Median/mean (SD) & & & Median/mean (SD) & & \\
\hline \multicolumn{11}{|l|}{ Extractions } \\
\hline All & 57 & 23.0/27.3 (20.8) & & 29 & 23.0/27.9 (19.8) & & 28 & $\mathbf{2 2 . 5} / 26.8(22.1)$ & & $0.629^{\mathrm{a}}$ \\
\hline Boys & 27 & 22.0/24.3 (17.1) & $0.497^{\mathrm{b}}$ & 14 & $\mathbf{2 2 . 5} / 24.1(16.1)$ & $0.458^{\mathrm{b}}$ & 13 & 21.0/24.5 (18.7) & $0.890^{\mathrm{b}}$ & $0.656^{\mathrm{a}}$ \\
\hline Girls & 30 & $\mathbf{2 5 . 0 / 3 0 . 0 ( 2 3 . 6 )}$ & & 15 & 29.0/31.3 (22.8) & & 15 & $\mathbf{2 4 . 0 / 2 8 . 7}(25.1)$ & & $0.255^{\mathrm{a}}$ \\
\hline \multicolumn{11}{|l|}{ Age (year) } \\
\hline $11-13$ & 28 & $\mathbf{2 2 . 5} / 25.8(20.7)$ & $0.621^{\mathrm{b}}$ & 15 & 23.0/27.0 (16.8) & $0.948^{\mathrm{b}}$ & 13 & 14.0/24.3 (25.2) & $0.357^{\mathrm{b}}$ & $0.328^{\mathrm{a}}$ \\
\hline $14-15$ & 29 & $\mathbf{2 4 . 0 / 2 8 . 8}(21.1)$ & & 14 & $\mathbf{2 3 . 5} / 28.6(23.3)$ & & 15 & 24.0/28.9 (19.6) & & $0.700^{\mathrm{a}}$ \\
\hline \multicolumn{11}{|l|}{ LA } \\
\hline 1 capsule & & & & 20 & $\mathbf{2 3 . 5} / 25.3(18.2)$ & $0.069^{\mathrm{b}}$ & 21 & 14.0/20.1 (19.7) & $0.396^{\mathrm{b}}$ & $0.195^{\mathrm{a}}$ \\
\hline$>1$ capsule & & & & 9 & 33.0/37.1 (21.9) & & 7 & 21.0/42.0 (22.5) & & $0.813^{\mathrm{a}}$ \\
\hline
\end{tabular}

no. number of teeth extracted, $L A$ local anesthetics

${ }^{a}$ Comparisons between the first and second extraction (Wilcoxon signed-ranks test)

${ }^{\mathrm{b}}$ Comparisons within groups (sexes, age groups, and amount of LA) (Mann-Whitney $U$ test)

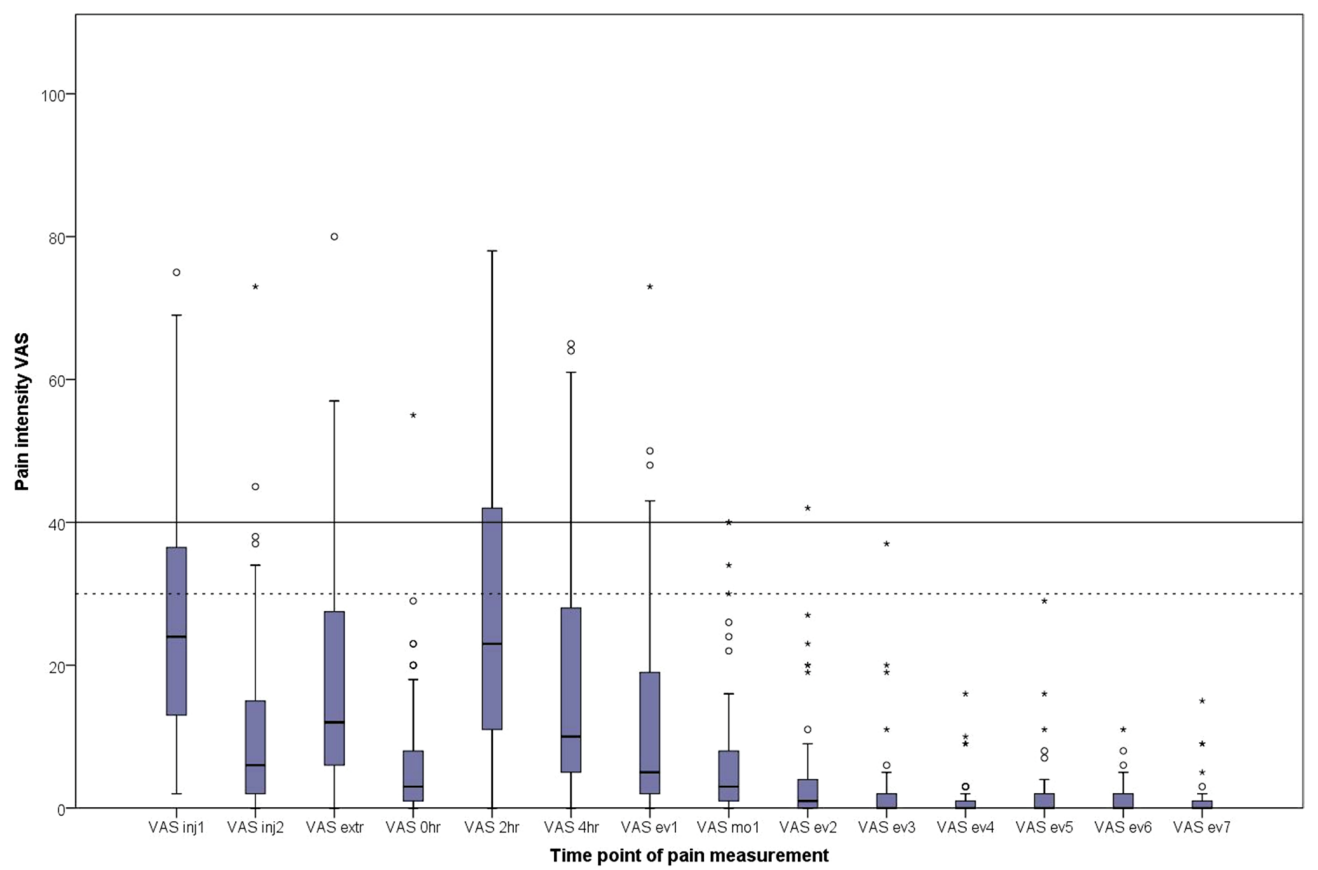

Fig. 1 Box plot of pain intensity measurements (visual analogue scale, $\mathrm{VAS}_{\mathrm{PI}}$ ) from injection of local anaesthesia to the evening of the 7 th day post-treatment. Combined measurements from first and second extractions. Horizontal bars indicate $\mathrm{VAS}_{\mathrm{PI}} 40$ (threshold for moderate pain) and 30 (threshold for mild pain). Measurements after intake of analgesics are excluded 
Table 4 Comparisons of first and second extraction, visual analogue scale pain intensity $\left(\mathrm{VAS}_{\mathrm{PI}}\right)$ scores (median/mean, [SD]), and numbers of participants reporting $\mathrm{VAS}_{\mathrm{PI}} \geq 40$ and 30 , respectively, at the various time points

\begin{tabular}{|c|c|c|c|c|c|c|c|}
\hline & \multicolumn{3}{|l|}{ Extraction 1} & \multicolumn{3}{|l|}{ Extraction 2} & \multirow[t]{3}{*}{$p$ value } \\
\hline & $\mathrm{VAS}_{\mathrm{PI}}$ & $\mathrm{VAS}_{\mathrm{PI}} \geq 30$ & $\mathrm{VAS}_{\mathrm{PI}} \geq 40$ & $\mathrm{VAS}_{\mathrm{PI}}$ & $\mathrm{VAS}_{\mathrm{PI}} \geq 30$ & $\mathrm{VAS}_{\mathrm{PI}} \geq 40$ & \\
\hline & Median/mean (SD) & & & Median/mean (SD) & & & \\
\hline \multirow[t]{3}{*}{ During injection } & 25.0/29.3 (17.5) & & & $\mathbf{2 2 . 5} / 24.2(17.2)$ & & & $0.114^{\mathrm{a}}$ \\
\hline & & 12 of 29 & & & 11 of 30 & & $1.000^{\mathrm{b}}$ \\
\hline & & & 8 of 29 & & & 5 of 30 & $0.508^{b}$ \\
\hline \multirow[t]{3}{*}{ During extraction } & 13.0/20.4 (18.6) & & & 11.0/16.0 (13.9) & & & $0.153^{\mathrm{a}}$ \\
\hline & & 8 of 29 & & & 5 of 30 & & $0.375^{b}$ \\
\hline & & & 4 of 29 & & & 2 of 30 & $0.625^{\mathrm{b}}$ \\
\hline \multirow[t]{3}{*}{$2 \mathrm{~h}$ after extraction } & 23.0/27.8 (20.3) & & & 22.5/26.8 (22.3) & & & $0.629^{\mathrm{a}}$ \\
\hline & & 12 of 29 & & & 12 of 28 & & $1.000^{\mathrm{b}}$ \\
\hline & & & 11 of 29 & & & 5 of 28 & $0.063^{\mathrm{b}}$ \\
\hline \multirow[t]{3}{*}{$4 \mathrm{~h}$ after extraction } & 12.0/17.9 (16.1) & & & 10.0/18.7 (19.9) & & & $0.493^{\mathrm{a}}$ \\
\hline & & 6 of $27^{c}$ & & & 7 of $26^{c}$ & & $1.000^{\mathrm{b}}$ \\
\hline & & & 2 of $27^{c}$ & & & 4 of $26^{c}$ & $0.625^{\mathrm{b}}$ \\
\hline
\end{tabular}

${ }^{a}$ Wilcoxon sign-ranks test

${ }^{\mathrm{b}} \mathrm{McNemar}$ 's test

${ }^{\mathrm{c}}$ Two recordings excluded from analyses due to intake of oral analgesics, affecting the $\mathrm{VAS}_{\mathrm{PI}}$

$6.1 \mathrm{~h}$ (SD 4.4; median 4.0) of school. None of the participants sought additional dental treatment for complications after the extractions. Seven children (4 girls and 3 boys) did not return to school after tooth extraction. No detailed data for reason or if they stayed at home after one or both treatments is available.

\section{Discussion}

In the present study, the majority of the patients who underwent uncomplicated bilateral extractions of maxillary premolars experienced mild to moderate levels of postoperative pain. Pain intensity peaked $2 \mathrm{~h}$ after tooth extraction, and had declined radically $4 \mathrm{~h}$ after extractions. Thus, pain was perceived for a short period of time. There were no differences in pain intensity profiles between the first and second extractions. Nor were there any differences between sexes, or between younger and older patients. Thus, postoperative pain after uncomplicated bilateral extractions of maxillary premolars due to orthodontic indications follows a steady pain intensity profile. As this treatment is relatively common, easy to standardise, and reproducible, we suggest this model as robust and suitable for studies on treatment of in young patients.

Pain studies on children and adolescents can raise ethical issues, why these studies should primarily be done on adult patients. In the present study, however, the natural course of pain during and after a standard procedure that general dental practitioners perform on a daily basis, was studied. We chose this treatment since it is potentially painful but, according to the literature, not associated with a high frequency of any other problems. The patients and their parents were informed verbally and in writing that they could withdraw from the study whenever they liked. They also had access to the research group throughout the study, if needed. Parents and guardians signed informed-consent forms before a participant was allowed to enter the study, and the children received age appropriate information and assented. This study also received ethical approval.

Pain intensity peaked $2 \mathrm{~h}$ after treatment in the present study which is concordant with a study from 2013 (Mustafa et al. 2013). It is plausible to speculate that this peak coincides with the time when the anaesthesia wears off. Duration of anaesthesia when using Lidocaine $2 \%$ (with 1:50,000 to $1: 100,000$ epinephrine) in the pulp is about $60 \mathrm{~min}$ after infiltration injection and in soft tissue, about $170 \mathrm{~min}$ (Becker and Reed 2006). The duration of Lidocaine 2\% differs from one individual to another; well illustrated in a study from 2016 (Elbay et al. 2016) who reported a variation in duration of LA after inferior alveolar blocks from 111 to $285 \mathrm{~min}$ (mean $149 \mathrm{~min}$ ). Thus, measurement of pain intensity after both 2 and $4 \mathrm{~h}$ appears adequate and crucial, especially when infiltration technique, and not inferior alveolar nerve block, is used.

The prevalence of postoperative pain after tooth extraction varies among studies. While $28 \%$ (16 of 57) of the extractions in the present study led to moderate postoperative 

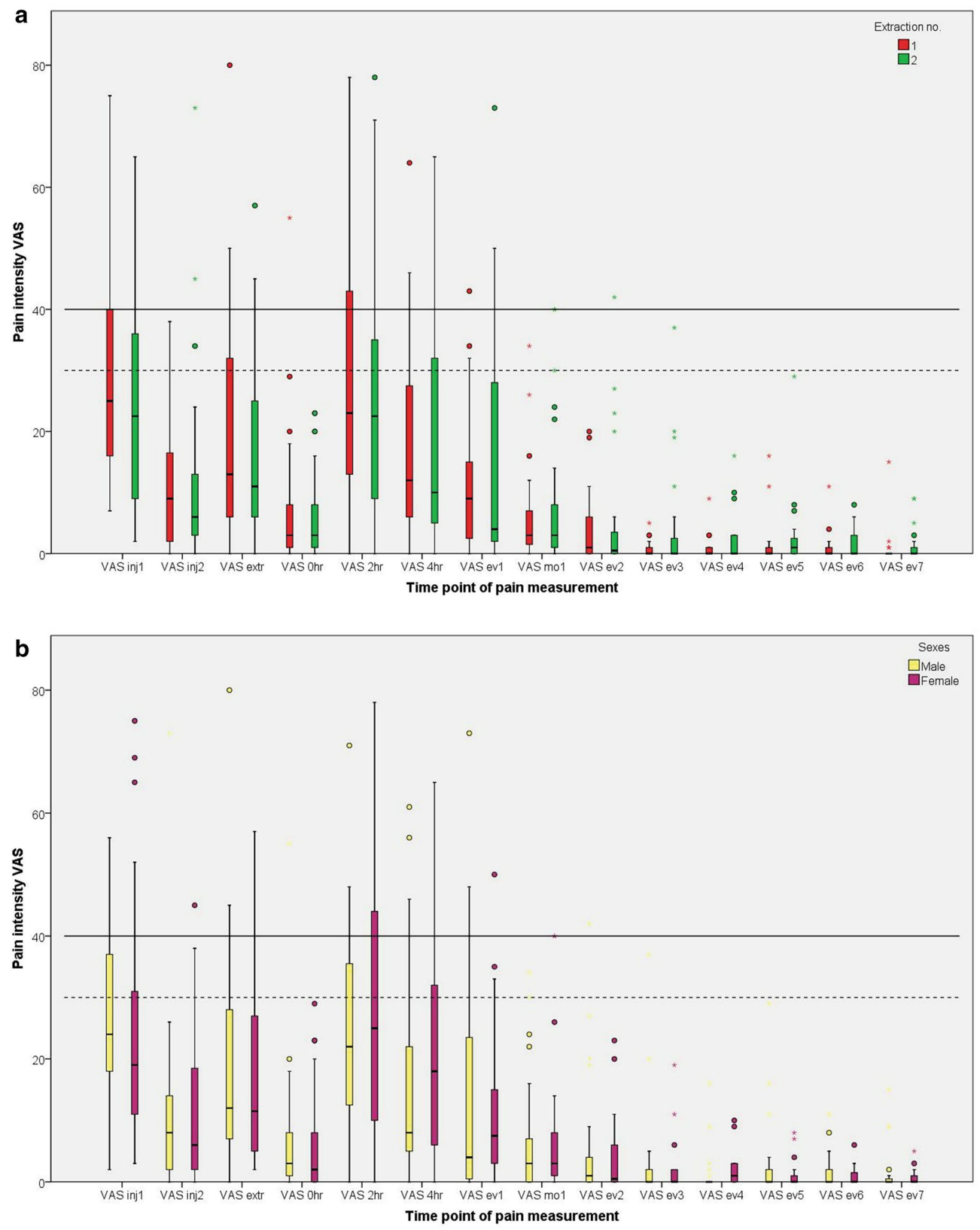

Fig. 2 Box plot of pain intensity measurements (visual analogue scale, $\mathrm{VAS}_{\mathrm{PI}}$ ) from injection of local anaesthesia to the evening of the 7 th day post-treatment. Horizontal bars indicate VAS $_{\mathrm{PI}} 40$ (threshold for moderate pain) and 30 (threshold for mild pain). Measurements after intake of analgesics are excluded. a Measurements are from the first and second extractions. b Measurements for boys and girls. c Measurements for younger (11-13 years) and older (14-15 years) age groups 


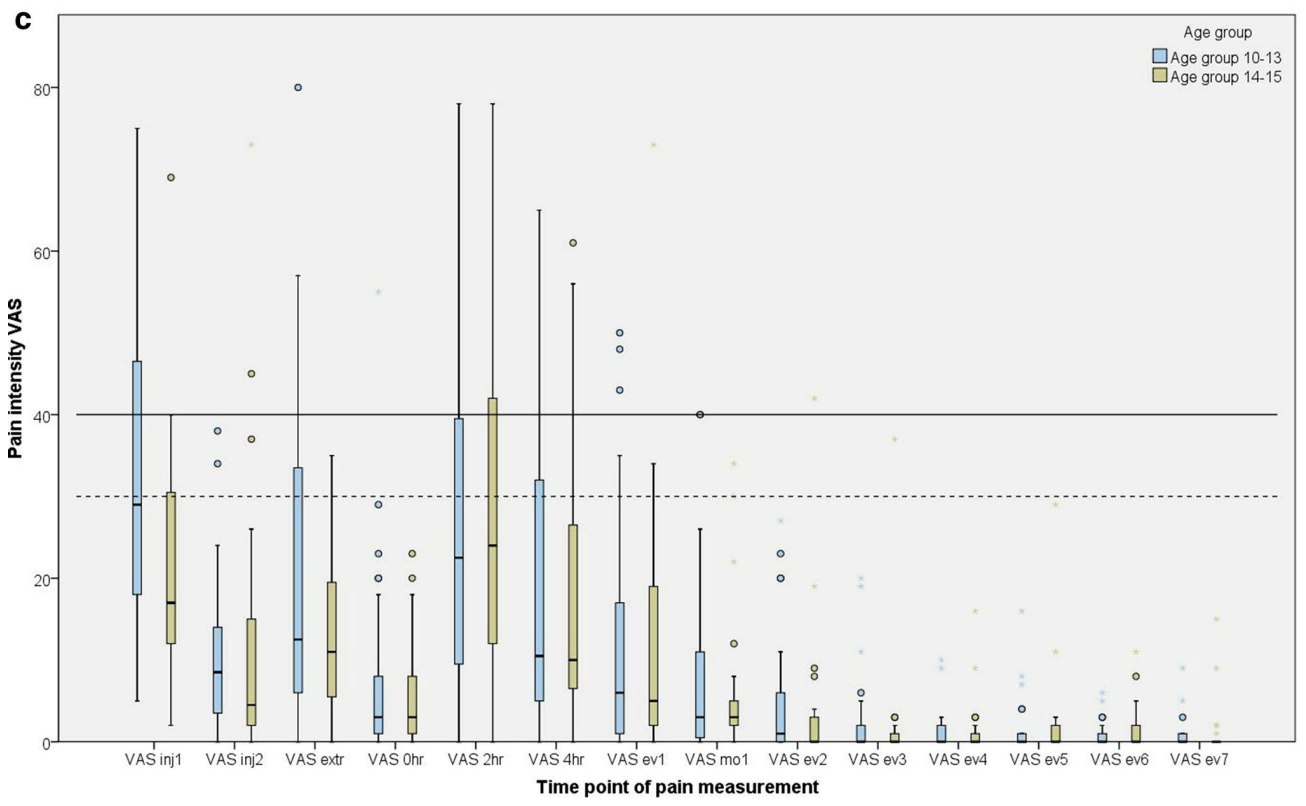

Fig. 2 (continued)

Table 5 Visual analogue scale pain intensity $\left(\mathrm{VAS}_{\mathrm{PI}}\right)$ scores of eight patients who self-administered oral analgesics ( 8 after the first extraction, 6 after the second)

\begin{tabular}{|c|c|c|c|c|c|}
\hline Subject no. & $\mathrm{VAS}_{\mathrm{PI}}{ }^{0 \mathrm{~h}}$ & $\mathrm{VAS}_{\mathrm{PI}}{ }^{2 \mathrm{~h}}$ & $\mathrm{VAS}_{\mathrm{PI}}^{4 \mathrm{~h}}$ & $\mathrm{VAS}_{\mathrm{PI}}^{\text {ev1 }}$ & $\overline{\mathrm{VAS}_{\mathrm{PI}}^{\mathrm{mol}}}$ \\
\hline $1 \mathrm{~A}$ & 0 & 13 & 4 & $4^{\mathrm{a}}$ & \\
\hline $1 \mathrm{~B}$ & $5^{\mathrm{a}}$ & & & & \\
\hline $2 \mathrm{~A}$ & 0 & $58^{\mathrm{a}}$ & & & \\
\hline $2 \mathrm{~B}$ & 0 & $34^{\mathrm{a}}$ & & & \\
\hline $3 \mathrm{~A}$ & 8 & 44 & $64^{\mathrm{a}}$ & & \\
\hline $3 \mathrm{~B}$ & 8 & $3^{\mathrm{a}}$ & & & \\
\hline $4 \mathrm{~A}$ & 8 & 63 & $37^{\mathrm{a}}$ & & \\
\hline $4 \mathrm{~B}$ & 23 & 65 & $15^{\mathrm{a}}$ & & \\
\hline $5 \mathrm{~A}$ & 2 & 29 & $34^{\mathrm{a}}$ & & \\
\hline $6 \mathrm{~A}$ & 4 & 11 & $18^{\mathrm{a}}$ & & \\
\hline $7 \mathrm{~A}$ & 1 & 2 & $1^{\mathrm{a}}$ & & \\
\hline $7 \mathrm{~B}$ & 0 & 0 & $0^{\mathrm{a}}$ & & \\
\hline $8 \mathrm{~A}$ & 0 & 18 & 39 & 15 & $26^{\mathrm{a}}$ \\
\hline $8 \mathrm{~B}$ & 8 & 26 & 49 & 35 & $40^{\mathrm{a}}$ \\
\hline
\end{tabular}

Time points are hours after extraction

$A$ measurements from first extraction, $B$ measurements from second extraction

${ }^{\mathrm{a}}$ Last valid VAS measurement before intake of oral analgesics. All measurement after intake of oral analgesics were excluded from the analyses pain $\left(\mathrm{VAS}_{\mathrm{PI}} \geq 40\right.$ ), other studies report from around $30 \%$ up to $85 \%$ postoperative pain (Acs et al. 1986; Ashkenazi et al. 2007; McGaw et al. 1987; Moore et al. 1985). Factors related to study design may explain the differences; for example, number of participants, age distribution, reasons for extraction, extraction technique, tooth extracted (in maxilla or mandible), and pain measurement method.

An important finding in the present study was that pain intensity did not differ between the first and second extractions, why there is no reason to assume any conditioning effect when repeating the treatment, i.e. the tooth extraction. This has not been studied before. This supports a future randomized controlled trial based on split mouth design using bilateral extractions of maxillary premolars as a model to investigate the effect of different pharmacologic agents, dosages or placebo in two arms. It is unlikely that there will be any conditioning effect provided a proper sample size calculation precedes the study.

The present study used a standardised protocol with uncomplicated bilateral extractions in the maxilla. This treatment is easy to reproduce, the anatomy of the roots are rather uncomplicated on upper premolars, easily accessible, and the trauma to the bone tissue is limited. Teeth extracted on orthodontic indications are in general healthy and free from inflammatory response in the pulp, which could affect 
the sensation of pain negatively. Administration of local anaesthetics in the maxilla is also less operator sensitive than administration of inferior alveolar nerve block. The present study included a homogeneous group of patients regarding age as well as reason for extractions, and one operator carried out the majority of all treatments. The study used a selfreported and patient-centred outcome, which is preferred due to the subjective nature of pain (American Academy of Pediatrics. Committee on Psychosocial Aspects of Child and Family Health, Task Force on Pain in Infants, Children, and Adolescents 2001). Further, pain intensity was measured several times over a 7-day period, enabling an understanding of the natural course of pain. These are strengths of the present study.

Previous data on sample size calculation applicable to this study could not be found. In two previous studies (Acs et al. 1986; Ashkenazi et al. 2007), they had 221 and 84 participants, respectively, who underwent dental extractions (tooth type and reason for extraction not explained). On the other hand, a study (Hariharan et al. 2014) included only 27 patients in a split-mouth designed evaluation of pain after use of two different forceps during extraction of upper premolars prior to orthodontic treatment. In the light of this, the number of participants in present study is adequate.

Use of the VAS as a pain rating scale for the age group in the present study could be discussed. At some ages, translating pain experiences to a rating tool can be difficult for children, even though they are capable of expressing their pain in words. When children are over the age of 7 , various types of scales for self-assessment can be used. Between 7 and 10 years, the literature has advocated face scales, and from the age of 10, numerical rating scales (NRS) and VAS (Norrbrink and Lundeberg 2012; Shields et al. 2003). To ensure comprehension of the VAS in the present study, the participants received thorough information and instruction about the instrument before each extraction.

Cut-off values are always troublesome, especially when dealing with something such as pain, which by definition is subjective (IASP 2014). A fixed cut-off point on the VAS is not relevant due to inter-individual variations in pain expression (van Dijk et al. 2002). A person who scores 45 on the VAS might still not think it is painful, while another might perceive a score of 24 as very painful. Still, there is a need for researchers and clinicians to have some kind of grid or ruler to develop methods for intervening in and preventing pain. To date, no cut-off for postoperative clinical pain requiring pain management in children has been defined. For postoperative pain, some studies have suggested, arbitrarily, VAS $_{\text {PI }} 30$ as cut-off for mild to moderate pain (Berde et al. 1991; Breivik et al. 2008; Mustafa et al. 2013; Taddio et al. 2009; van Dijk et al. 2002). VAS 40 and 44 have been used as thresholds for moderate pain or need for pain management (Jensen et al. 2003; van Dijk et al. 2002).
In this study, $\mathrm{VAS}_{\mathrm{PI}} \geq 40$ succeeded in identifying moderate pain $2 \mathrm{~h}$ postoperatively in 16 of 57 extractions. A $\mathrm{VAS}_{\mathrm{PI}} \geq 30$, however, would identify 26 of 57 scores $2 \mathrm{~h}$ after extraction as mild to moderately painful; this is a higher number, even though lower in intensity. More importantly, the same pattern of a short peak in pain intensity followed by a rapid decrease could be seen. This is important as it puts light on a short window of pain that has to be managed in some way. One strategy, possibly often overlooked, is information about expected level and the duration of pain and discomfort after the extraction. The finding of a pain profile in this study is thus important as it enables dental health professionals to provide patients with more accurate information about the expected course of pain after an extraction.

Use of pharmacological agents such as oral analgesics is another potential strategy. Still there are some questions. If analgesics were to be used, what would be the best way to administer them? A recently updated systematic review of the effect of preoperative analgesics for additional pain relief in dental treatment of children (Ashley et al. 2016) identified and evaluated five trials. The researchers concluded that it was not possible to determine whether preoperative analgesics were of benefit in paediatric dentistry for procedures under local anaesthesia, and the authors called for further randomized clinical trials. Based on the pain ratings in this study, and the pain profiles derived from the $\operatorname{VAS}_{\mathrm{PI}}$ ratings of the participants, would a single dose analgesics after treatment be a good alternative? The benefits with this model would be that the onset of the drug would be nearer the pain peak. However, this must be studied further. To our knowledge, no systematic review on postoperative administration of analgesics in paediatric dentistry has been published. Thus, there is hardly any evidence for analgesic use, pre- or postoperatively, to reduce pain after uncomplicated dental treatment in children; this remains a knowledge gap. Based on this, and the fact that all administration of pharmacologic agents comes with a risk (Matok et al. 2016; Norman et al. 2014), it can be questioned if there is any reason for clinical guidelines in this area. Analogously, there is no rationale for introducing or routinely using administration of analgesics in conjunction with routine dental treatments such as filling therapies or uncomplicated extractions (Berlin et al. 2018). When considering use of pharmacological agents with children, there must be a clear-cut reason for doing so. Otherwise, development of general guidelines would be unethical and contraindicated. Instead, the relatively mild pain intensity and short duration of pain indicates that medication should be individually tailored and not a general recommendation.

Another important aspect when making general recommendations is health economics. In this study, the cost of the dental treatment could be mirrored by the Swedish so-called reference price. For an uncomplicated tooth 
extraction, the reference price was $€ 104.3$ [Tandvårds- och läkemedelsförmånsverket (The Dental and Pharmaceutical Benefits Agency)] and this is assumed to mirror the total cost in the dental clinic. Other costs are related to travelling (which could not be calculated), and the indirect cost for productivity loss related to the parents' absence from work.

The average wage (year) for individuals aged 40-49, which may be assumed to be parents of children aged 10-15 years, is $€ 40,137$ [Statistiska centralbyrån (Statistics Sweden)] and when the social fees are added (35\%) the value is $€ 54,185$. Based on number of work hours for 2016 [Arbetstimmar per månad (work hours per month)], the hourly production value would be $€ 26.77$. Since the parents were away $3.6 \mathrm{~h}$ in mean, during the study period, the indirect cost for productivity loss would be $€ 96.4$. Adding the cost for the two extractions results in $€ 305.0$. This may be considered a low cost for this treatment, especially when comparing the cost for the orthodontic treatment, following (Petrén et al. 2011; Ganzer et al. 2018). In the present study, no side effects, requiring additional treatment were reported. Tooth extraction is a standard procedure and on the right indications, $€ 305.0$ has to be considered a reasonable cost and hence, this is a cost-effective procedure.

\section{Conclusion}

In conclusion, uncomplicated extractions of premolars caused moderate postoperative pain $\left(\mathrm{VAS}_{\mathrm{PI}} \geq 40\right)$ in 16 (28\%) of 57 extractions in young patients. There were no differences in the natural course of pain between first and second extractions, younger and older patients, or between sexes. The pain peaked $2 \mathrm{~h}$ after extraction, around the time where LA wears off. After that, there was a rapid decrease in pain intensity notable already at $4 \mathrm{~h}$ after extractions. As the pain intensity profiles for both extractions were similar to each other, it is suggested that bilateral extractions of maxillary premolars is a suitable model for studies on pain management.

Acknowledgements The study was supported by grants from the Swedish Dental Society, the Swedish Society of Paediatric Dentistry; the Faculty of Odontology, Malmö University; Skåne Regional Council, Sweden; and the American Dental Society of Sweden.

Author contributions $\mathrm{HB}$ and GK conceived the ideas; HB collected the data; HB, GK, TL, TD, KR, and DT analysed the data; HB and GK led the writing; and all authors participated in finalizing the manuscript.

\section{Compliance with ethical standards}

Conflict of interest The authors declare no conflict of interest.
Open Access This article is distributed under the terms of the Creative Commons Attribution 4.0 International License (http://creativeco mmons.org/licenses/by/4.0/), which permits unrestricted use, distribution, and reproduction in any medium, provided you give appropriate credit to the original author(s) and the source, provide a link to the Creative Commons license, and indicate if changes were made.

\section{References}

Acs G, Moore PA, Needleman HL, Shusterman S. The incidence of post-extraction pain and analgesic usage in children. Anesth Prog. 1986;33:147-51.

Al-Khateeb TH, Alnahar A. Pain experience after simple tooth extraction. J Oral Maxillofac Surg. 2008;66:911-7.

American Academy of Pediatrics. Committee on Psychosocial Aspects of Child and Family Health, Task Force on Pain in Infants, Children, and Adolescents. The assessment and management of acute pain in infants, children, and adolescents. Pediatrics. 2001;108:793-7.

Arbetstimmar per månad. [Work hours per month]. http://www.arbet stimmarpermanad.se/. Accessed September 2018.

Ashkenazi M, Blumer S, Eli I. Post-operative pain and use of analgesic agents in children following intrasulcular anaesthesia and various operative procedures. Br Dent J. 2007;202:7.

Ashley PF, Parekh S, Moles DR, et al. Preoperative analgesics for additional pain relief in children and adolescents having dental treatment. Cochrane Database Syst Rev. 2016;(8):CD008392.

Becker DE, Reed KL. Essentials of local anesthetic pharmacology. Anesth Prog. 2006;53:10.

Berde CB, Lehn BM, Yee JD, et al. Patient-controlled analgesia in children and adolescents: a randomized, prospective comparison with intramuscular administration of morphine for postoperative analgesia. J Pediatr. 1991;118:460-6.

Berlin H, List T, Ridell K, et al. Dentists' attitudes towards acute pharmacological pain management in children and adolescents. Int J Paediatr Dent. 2018;28:152-60.

Bhalla J, Meechan JG, Lawrence HP, et al. Effect of time on clinical efficacy of topical anesthesia. Anesth Prog. 2009;56:36-41.

Breivik H, Borchgrevink PC, Allen SM, et al. Assessment of pain. Br J Anaesth. 2008;101:17-24.

Cuthbert MI, Melamed BG. A screening device: children at risk for dental fears and management problems. ASDC J Dent Child. 1982;49:432-6.

Elbay US, Elbay M, Kaya E, et al. Effects of two different anesthetic solutions on injection pain, efficacy, and duration of soft-tissue anesthesia with inferior alveolar nerve block for primary molars. J Clin Pediatr Dent. 2016;40:456-63.

Ganzer N, Feldmann I, Petrén S, et al. A cost-effectiveness analysis of anchorage reinforcement with miniscrews and molar blocks in adolescents: a randomized controlled trial. Eur J Orthod. 2018:cjy041

Ghanei M, Arnrup K, Robertson A. Procedural pain in routine dental care for children: a part of the Swedish BITA study. Eur Arch Paediatr Dent. 2018. https://doi.org/10.1007/s4036 8-018-0368-2.

Hariharan S, Narayanan V, Soh CL. Split-mouth comparison of physics forceps and extraction forceps in orthodontic extraction of upper premolars. Br J Oral Maxillofac Surg. 2014;52:137.

Huskisson EC. Measurement of pain. Lancet. 1974;2:1127-31.

IASP. International Association for the Study of Pain. 2014. http:// www.iasp-pain.org/Taxonomy. Accessed September 2016.

Jensen MP, Chen C, Brugger AM. Interpretation of visual analog scale ratings and change scores: a reanalysis of two clinical trials of postoperative pain. J Pain. 2003;4:407-14. 
Klingberg G. Reliability and validity of the Swedish version of the Dental Subscale of the Children's Fear Survey Schedule, CFSSDS. Acta Odontol Scand. 1994;52:255-6.

Klingberg G, Broberg AG. Dental fear/anxiety and dental behaviour management problems in children and adolescents: a review of prevalence and concomitant psychological factors. Int J Paediatr Dent. 2007; 17:391-406.

Klingberg G, Ridell K, Brogardh-Roth S, et al. Local analgesia in paediatric dentistry: a systematic review of techniques and pharmacologic agents. Eur Arch Paediatr Dent. 2017;18:323-9.

Maragakis GM, Musselman RJ. The time used to administer local anesthesia to 5 and 6 year olds. J Clin Pediatr Dent. 1996;20:321-3.

Matok I, Elizur A, Perlman A, et al. Association of acetaminophen and ibuprofen use with wheezing in children with acute febrile illness. Ann Pharmacother. 2016;27.

McGaw T, Raborn W, Grace M. Analgesics in pediatric dental surgery: relative efficacy of aluminum ibuprofen suspension and acetaminophen elixir. ASDC J Dent Child. 1987;54:106-9.

Moore PA, Acs G, Hargreaves JA. Postextraction pain relief in children: a clinical trial of liquid analgesics. Int J Clin Pharmacol Ther Toxicol. 1985;23:573-7.

Mustafa O, Parekh S, Ashley P, et al. Post-operative pain and anxiety related to dental procedures in children. Eur J Paediatr Dent. 2013;14:289-94.

Norman H, Elfineh M, Beijer E, et al. Also ibuprofen, not just paracetamol, can cause serious liver damage in children. NSAIDs should be used with caution in children, as shown in case with fatal outcome. Läkartidningen. 2014;111:1709-11.
Norrbrink C, Lundeberg T, editors. Om smärta—ett fysiologiskt perspektiv. Lund: Studentlitteratur AB; 2012 (In Swedish).

Petrén S, Bjerklin K, Marké L, et al. Early correction of posterior crossbite-a cost-minimization analysis. Eur J Orthod. 2011;35:14-21.

Shields BJ, Cohen DM, Harbeck-Weber C, et al. Pediatric pain measurement using a visual analogue scale: a comparison of two teaching methods. Clin Pediatr (Phila). 2003;42:227-34.

Statistiska centralbyrån (SCB) [Statistics Sweden]. 2018. http://www. scb.se/. Accessed Sep 2018.

Sveriges Riksbank [Sweden's central bank]. 2018. https://www. riksbank.se/sv/statistik/sok-rantor--valut akurser/?g130SEKEURPMI =on \& from $=2018-08-21 \&$ to $=2018-09$ $21 \& \mathrm{f}=$ Year $\& \mathrm{c}=\mathrm{c}$ Average $\& \mathrm{~s}=$ Comma. Accessed Sep 2018.

Taddio A, O'Brien L, Ipp M, et al. Reliability and validity of observer ratings of pain using the visual analog scale (VAS) in infants undergoing immunization injections. Pain. 2009;147:141-6.

Tandvårds- och läkemedelsförmånsverket [The Dental and Pharmaceutical Benefits Agency]. 2018. https://www.tlv.se/tandvard/refer ensprislista.html. Accessed Sep 2018.

van Dijk M, Koot HM, Saad HH, et al. Observational visual analog scale in pediatric pain assessment: useful tool or good riddance? Clin J Pain. 2002;18:310-6.

Publisher's Note Springer Nature remains neutral with regard to jurisdictional claims in published maps and institutional affiliations. 

III 



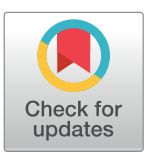

\section{Go openaccess}

Citation: Berlin H, Vall M, Bergenäs E, Ridell K, Brogårdh-Roth S, Lager E, et al. (2019) Effects and cost-effectiveness of postoperative oral analgesics for additional postoperative pain relief in children and adolescents undergoing dental treatment: Health technology assessment including a systematic review. PLoS ONE 14(12): e0227027. https://doi.org/10.1371/journal.pone.0227027

Editor: Federico Bilotta, University of Rome 'La Sapienza', ITALY

Received: July 3, 2019

Accepted: December 10, 2019

Published: December 31, 2019

Peer Review History: PLOS recognizes the benefits of transparency in the peer review process; therefore, we enable the publication of all of the content of peer review and author responses alongside final, published articles. The editorial history of this article is available here: https://doi.org/10.1371/journal.pone.0227027

Copyright: @ 2019 Berlin et al. This is an open access article distributed under the terms of the Creative Commons Attribution License, which permits unrestricted use, distribution, and reproduction in any medium, provided the original author and source are credited.
RESEARCH ARTICLE

\section{Effects and cost-effectiveness of postoperative oral analgesics for additional postoperative pain relief in children and adolescents undergoing dental treatment: Health technology assessment including a systematic review}

\author{
Henrik Berlin $\mathbb{D}^{1,2}{ }^{*}$, Martina Vall ${ }^{3}$, Elisabeth Bergenäs ${ }^{3}$, Karin Ridell ${ }^{1}$, Susanne Brogårdh- \\ Roth $^{1}$, Elisabeth Lager ${ }^{1}$, Thomas List ${ }^{4}$, Thomas Davidson ${ }^{2,5}$, Gunilla Klingberg ${ }^{1,2}$ \\ 1 Department of Pediatric Dentistry, Faculty of Odontology, Malmö University, Malmö, Sweden, 2 Health \\ Technology Assessment-Odontology (HTA-O), Faculty of Odontology, Malmö University, Malmö, Sweden, \\ 3 Malmö University Library, Malmö University, Malmö, Sweden, 4 Department of Orofacial Pain and Jaw \\ Function, Faculty of Odontology, Malmö University, Malmö, Sweden, $\mathbf{5}$ Department of Medical and Health \\ Sciences (IMH), Linköping University, Linköping, Sweden \\ * henrik.berlin@mau.se
}

\section{Abstract}

\section{Background}

There is an uncertainty regarding how to optimally prevent and/or reduce pain after dental treatment on children and adolescents.

\section{Aim}

To conduct a systematic review (SR) and health technology assessment (HTA) of oral analgesics administered after dental treatment to prevent postoperative pain in children and adolescents aged $3-19$ years.

\section{Design}

A PICO-protocol was constructed and registered in PROSPERO (CRD42017075589). Searches were conducted in PubMed, Cochrane, Scopus, Cinahl, and EMBASE, November 2018. The researchers (reading in pairs) assessed identified studies independently, according to the defined inclusion and exclusion criteria, following the PRISMA-statement.

\section{Results}

3,963 scientific papers were identified, whereof 216 read in full text. None met the inclusion criteria, leading to an empty SR. Ethical issues were identified related to the recognized knowledge gap in terms of challenges to conduct studies that are well-designed from methodological as well as ethical perspectives. 
Data Availability Statement: All relevant data are within the manuscript and its Supporting Information files.

Funding: This study was supported by research funds from Oral Health Related Research by Region Skåne (Odontologisk Forskning i Region Skåne, OFRS 569491), Sweden. The funders had no role in study design, data collection and analysis, decision to publish, or preparation of the manuscript The funders had no role in study design, data collection and analysis, decision to publish, or preparation of the manuscript.

Competing interests: The authors have declared that no competing interests exist.

\section{Conclusions}

There is no scientific support for the use or rejection of oral analgesics administered after dental treatment in order to prevent or reduce postoperative pain in children and adolescents. Thus, no guidelines can be formulated on this issue based solely on scientific evidence. Well-designed studies on how to prevent pain from developing after dental treatment in children and adolescents is urgently needed.

\section{Introduction}

Many patients associate dental treatment with pain. There are several reasons for this, and depending on the underlying diagnosis and type of treatment, the risk of pain is realistic and should be tackled. This is especially important in children and adolescents, as they may be more vulnerable to pain owing to their level of cognitive reasoning and understanding [1]. Painful medical/dental episodes, along with minor everyday pain experiences such as bumps, falls etc., are also likely to play a significant role in shaping the individual's pain perception in future medical and/or dental events [2]. Furthermore, painful dental treatment experiences have been identified as essential components in the development of dental fear and anxiety [3, 4], which affects approximately $9 \%$ of the paediatric population [3]. Therefore, preventing and reducing pain are major responsibilities for the dental team.

Apart from using local anaesthetics, administration of oral analgesics might be one way to prevent dental treatment pain and probably even more so during the postoperative period: after tooth extractions, for example. However, there is an uncertainty regarding the use of oral analgesics in paediatric dentistry [5] and a need for more general strategies. Before constructing guidelines for this purpose, the effects and cost-effectiveness of oral analgesics as well as the ethical aspects of the intervention should be scientifically evaluated, implying a need for a health technology assessment (HTA) as well as a systematic review (SR) [6, 7].

A recent systematic review of preoperative administration of oral analgesics could not determine whether this administration is of any benefit for children and adolescents undergoing dental treatment under local anaesthetic [8]. There is, so far, no available systematic review of postoperative administration of oral analgesics in conjunction with dental treatment in children. PROSPERO (available at https://www.crd.york.ac.uk/prospero/) has no information on published or ongoing review registered on this topic other than the present study.

This HTA and SR aimed to assess the effects, adverse events, and cost-effectiveness of oral analgesics given immediately after dental treatment in order to prevent and/or reduce postoperative pain in children and adolescents aged 3-19 years. The review also sought to assess the ethical aspects of the intervention.

\section{Materials and methods}

\section{Inclusion criteria}

The following research questions were addressed:

- Which is the most effective (most pain-reducing as measured by a pain rating scale) oral analgesics, administered after dental treatment, in order to prevent or alleviate postoperative pain after dental treatment in children and adolescents aged 3-19 years? 
- Is any pharmacological substance superior regarding preventing/alleviating pain? Is a singledose sufficient or does a several dosage regimen have better effect?

- Are there any side effects or adverse reactions reported when oral analgesics are administered immediately after dental treatment in children and adolescents aged 3-19 years?

- Are oral analgesics given after dental treatment considered cost-effective in children and adolescents aged 3-19 years?

A PICO model was constructed (participants, interventions, control, and outcome): Participants

- Children and adolescents aged 3-19 years

Interventions

- Administration of oral analgesics after dental treatment

- Pharmacological substances: prescription-free/over-the-counter oral analgesics containing paracetamol (acetaminophen), ibuprofen, diclofenac or naproxen

- Administration of drug: oral administration as a single dose or multiple doses following an administration regimen

- Dental treatments: primary or permanent teeth treated by filling therapy, pulp therapy/ capping, tooth extraction, minor oral surgery

Control

- Postoperative administration of other oral analgesics or placebo after same dental treatment

- Pharmacological substances: other prescription-free/over-the-counter oral analgesics containing paracetamol (acetaminophen), ibuprofen, diclofenac, or naproxen, or placebo or no control

- Administration of drug: oral administration as a single dose or multiple doses following an administration regimen

- Dental treatments: primary or permanent teeth treated by filling therapy, pulp therapy/ capping, tooth extraction, minor oral surgery

Outcome measures

- Pain after dental treatment assessed by the child patient using Visual Analog Scale (VAS)

[9], Faces Pain Scale-Revised [10], Wong-Baker FACES $®$ [11], Numerical Rating Scale

[12], Eland Color Scale [13], or other facial scales

- Adverse effects, side effects

- Costs, cost-effectiveness

Types of studies

- Randomized control trials (RCT), systematic reviews (not narrative), observational studies, studies using qualitative methods 


\section{Exclusion criteria}

- Participants 20 years or older; studies where data could not be extracted for 3-19-year-olds

- Disability or medical conditions leading to cognitive impairment or neuropsychiatric diagnosis

- Oral analgesics other than paracetamol (acetaminophen), ibuprofen, diclofenac, or naproxen, or routes of administration other than per os

- Treatment under hypnosis, sedation, or general anaesthesia

- Pain assessment by proxy

- Languages other than English, Swedish, Danish, or Norwegian

\section{Literature search strategy}

The protocol for this systematic review (SR) and health technology assessment (HTA) was registered on PROSPERO (CRD42017075589), September 1, 2017, available at http://www.crd. york.ac.uk/PROSPERO/display_record.php?ID=CRD42017075589.

Studies were identified using PubMed via NML, Cochrane via Wiley, Scopus via Elsevier, CINAHL via EBSCO and Embase via Elsevier. The literature searches were conducted in November 2017 and updated on November 20-23, 2018. Search strategies are presented in S1 File. Limitations were set to randomized control studies, systematic reviews (not narrative), observational studies, studies using qualitative methods, and publication year 1980 or later. There were no language restrictions. The literature search was done together with librarians specialized in informatics at the Malmö University library. Table 1 presents the number of articles identified via each database. After duplication control and removing articles published earlier than 1980, a total of 3,963 studies were finally evaluated according to the framework of the PRISMA-statement [14]. The number of abstracts retrieved, included and excluded articles, and the stage of exclusion are shown in a flowchart (Fig 1). No search for grey literature was performed.

All abstracts were screened independently by the review authors reading in pairs, according to the defined inclusion and exclusion criteria. If at least one reviewer considered an abstract relevant, the paper was included and read in full text.

Table 1. Results from each database search.

\begin{tabular}{l|l|l}
\hline Database & Date & Number of articles \\
\hline PubMed via NLM & $20^{\text {th }}$ November & 1216 \\
\hline Cochrane via Wiley & $20^{\text {th }}$ November & 1760 \\
\hline Scopus via Elsevier & $21^{\text {st }}$ November & 1972 \\
\hline CINAHL via EBSCO & $23^{\text {rd }}$ November & 469 \\
\hline Embase via Elsevier & $23^{\text {rd }}$ November & 2586 \\
\hline \multicolumn{2}{r}{ Total } & 8003 \\
\hline \multicolumn{2}{r}{ Dumber of articles evaluated according to PRISMA-statement } & 3963 \\
\hline
\end{tabular}

Number of articles identified via each database after updated search November 2018.

https://doi.org/10.1371/journal.pone.0227027.t001 


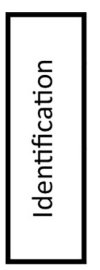

\begin{tabular}{|c|c|}
\hline $\begin{array}{c}\text { Abstracts identified through } \\
\text { database searching } \\
(n=3,963)\end{array}$ & $\begin{array}{c}\text { Abstracts identified through } \\
\text { hand search } \\
(n=0)\end{array}$ \\
\hline
\end{tabular}
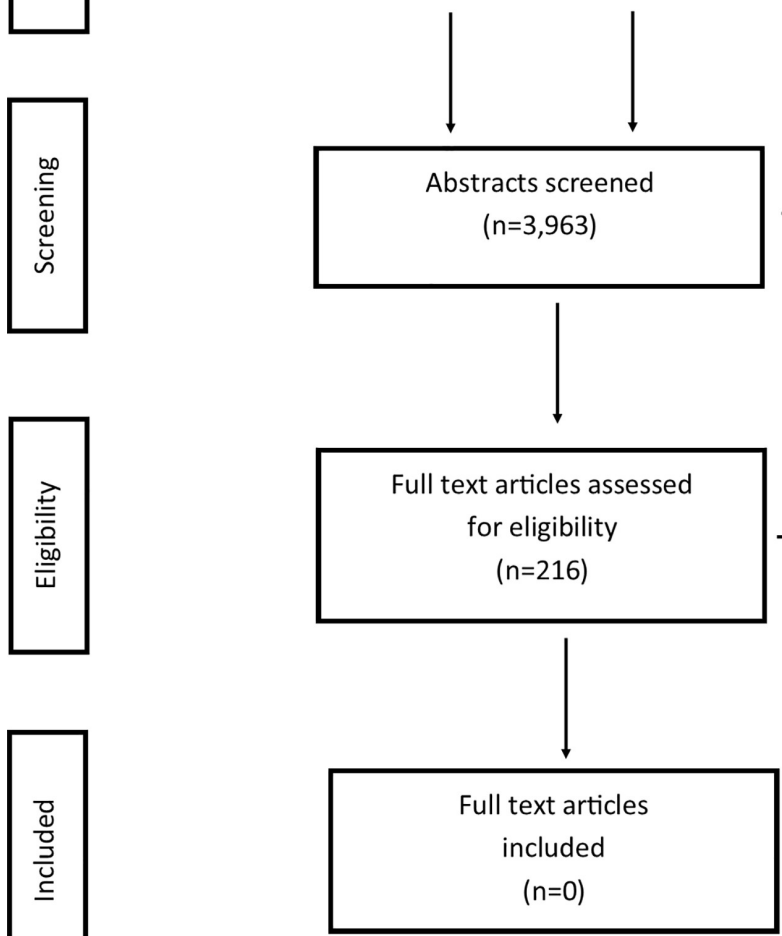

Full text articles excluded with reasons

$(n=216)$
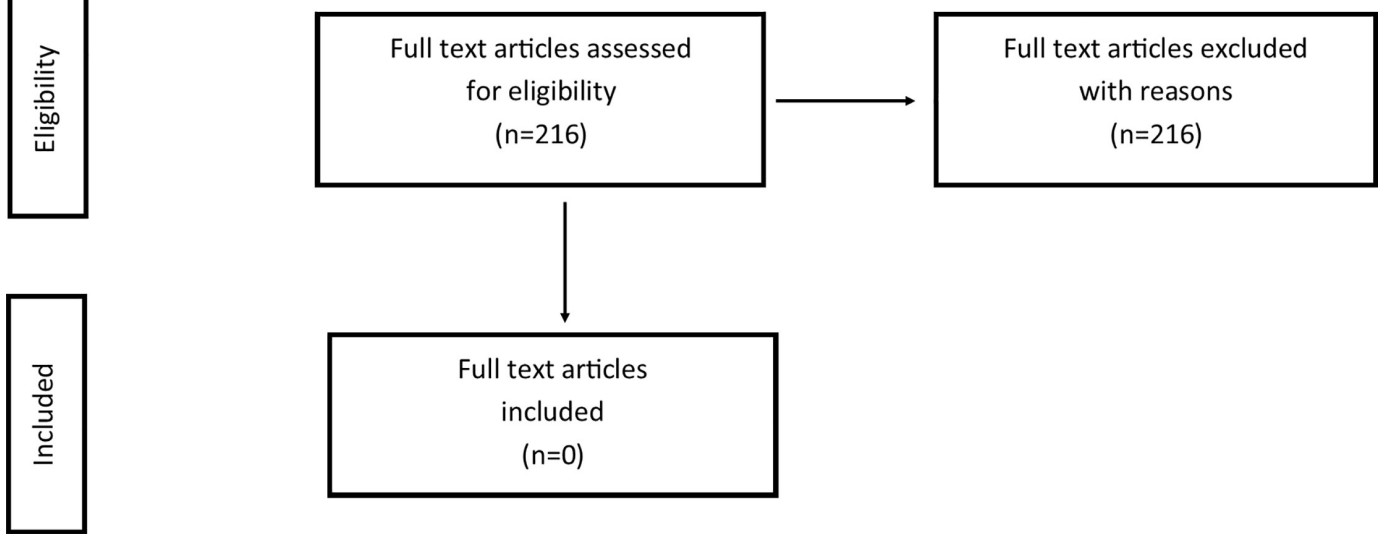

Fig 1. Flow diagram showing the literature review process.

\section{Data extraction and quality assessment}

The review authors, using the same pairs as when screening abstracts, assessed the relevance of the included full-text papers. The articles were assessed independently, and any differences were handled with discussion to arrive at a consensus within each review pair. Excluded fulltext papers are shown in S2 File. The following steps were also planned for risk of bias assessment, data extraction, and grading of quality.

- For assessment of relevance and risk of bias: the standardized checklist from Swedish Agency for Health Technology Assessment and Assessment of Social Services (SBU), which is similar to the Cochrane checklist (http://www.cochrane.org/) but has additional items [15, 16]. 
- For grading quality of evidence for studies with low or moderate risk of bias: the Grading of Recommendations Assessment, Development and Evaluation (GRADE) system [17].

- For assessment of systematic reviews: A MeaSurement Tool to Assess systematic Reviews (AMSTAR) [18]

\section{Results}

\section{Literature search}

The combined search from the five different databases resulted in 3,963 papers, of which 3,747 studies were excluded after reading titles and abstracts. The remaining 216 studies were retrieved and read in full text. No study was found to meet the criteria for inclusion (see Fig 1). Thus, no quality assessment or further analyses of the effects or cost-effectiveness of postoperative oral analgesics were made. S2 File, shows full references and reasons for exclusion of the 216 studies. Common reasons for exclusion were: no data for 3-19-year-olds, other pharmacologic substances (e.g. narcotic analgesics, agents not available over-the-counter), or patients treated under general anaesthesia or under sedation (e.g. benzodiazepine or nitrous oxide/oxygen sedation).

\section{Complications and side effects}

Complications and side effects were evaluated during all stages of data extraction: i.e. also based on abstracts for papers that were not read in full text. There were no serious side effects or adverse effects reported in the retrieved full-text papers or in any of the assessed abstracts.

\section{Ethics}

The present systematic review was unable to identify and include studies for quality assessment, and thus ethical aspects were considered on a general level, based on the framework by Heintz et al. [7]. The main ethical issues concerns the theme effects on health and the item knowledge gap (if there is insufficient scientific evidence for an intervention, are there any ethical or methodological issues for further research?) and the theme compatibility with ethical norms and the item autonomy (are the patients able to consent to the intervention?) [7]. Compliance with ethical standards was not evaluated in any of the identified studies, but some general thoughts can still be pinpointed. Explicit protections to safeguard children's rights and welfare are always necessary in medical and dental treatment, as they are in all research involving young individuals [19]. A knowledge gap as identified in the present study, signals a need for more studies. However, before including children in research on the effect of oral analgesics, well-designed studies in adults should be identified and scrutinized. The present study did not investigate this. Still, the perspective of children should be acknowledged, and children and adolescents must not be excluded from research that can be beneficial for them.

\section{Discussion}

This health technology assessment (HTA) and systematic review (SR) was performed to assess the effects, adverse or side effects, and cost-effectiveness of oral analgesics administered to children and adolescents after dental treatment to prevent postoperative pain. This is an intervention commonly used in clinical paediatric dentistry that has previously not been systematically evaluated. As no studies meeting the inclusion criteria could be identified, it was not possible to find scientific support for the effects of postoperatively administered oral analgesics for the 
prevention or reduction of pain after dental treatment in children and adolescents. Thus, this remains a knowledge gap. Based on the identified studies this HTA and SR could not identify any severe adverse events or side effects of over-the-counter oral analgesics. However, as the published literature does not provide support for the use or rejection of postoperative administration of oral analgesics in dental care for children and adolescents, it is not possible to formulate clinical guidelines on this issue solely based on scientific evidence.

In order to provide a basis for guidelines and to bridge research with decision-making, this SR was expanded to also be an HTA $[6,20,21]$. HTA includes evaluation of both ethical aspects and health economics and is an important tool when reviewing scientific evidence in order to appraise how the value of scientifically based knowledge can be implemented in health care systems and society more broadly $[6,20]$.

As no studies were found, we do not know the effects or the cost-effectiveness of oral analgesics given immediately after dental treatment in children and adolescents aged 3-19 years.

However, decisions on this issue are continuously being made every time a child or adolescent undergoes dental treatment, so in the absence of evidence, it is important to consider other types of knowledge [22]. It is therefore important to consider the most realistic consequences of the different alternatives. The direct cost of oral analgesics is considered low, so the costeffectiveness of the methods depends heavily on the effect side. In this situation, the decision to use oral analgesics, as well as the type of substance and whether to use a single dose or multiple dose regimen, should primarily depend on the clinical effects (including side effects) and not their cost-effectiveness. However, if it is proven that oral analgesics do not provide any additional effect, they should not be considered cost-effective. In future studies of treatment of dental pain in the child and adolescent population, it would be of value also to estimate their cost-effectiveness in order to guide decision makers in their prioritization process.

Regarding ethical aspects, the first choice should be to answer research questions by performing clinical trials in adults. However, it may be unethical to not involve children in research studies evaluating drugs. If children were excluded from all drug research, medication used in children would be limited to extrapolation from adult studies or even exclude children from the possibility of receiving existing and new drugs that they could benefit from. Thus, the research community has a significant responsibility to design, approve, and conduct highquality studies in children so that they can have access to important medications and receive optimal therapies [23].

The present SR did not identify any studies to be included and can therefore be considered an empty review. The definition of empty review is "having no eligible studies retrieved or located by the review authors" [24]. Different reasons for an empty review have been proposed. One is that a subject/research area might be new and therefore not researched. Another is that the topic is very specific and no studies can to be found. A third reason is the use of overly stringent inclusion criteria [25]. In addition, publication bias, i.e. more publications of studies with positive findings compared to studies with no or negative results, could contribute to empty reviews [26, 27].

Possible limitations of this SR could be that the outcome measure (pain after dental treatment assessed by the child patient) was too narrow. However, patient-reported and patientcentred outcomes are essential in clinical research and based on the definition of pain being a subjective experience, the used outcome measure is highly relevant $[28,29]$. This is in accordance with the COMET Handbook [30], which also states the importance of outcome measurement being appropriate and central for the key participants, including patients. Notably, no studies were excluded because of this inclusion criterion.

The definition of the population could also be discussed, as a limitation of this SR. As the review aimed to look at children and adolescents the age group, 3 to 19 years of age, was 
chosen in order to find as many publications as possible and to ensure that the whole teenage period was included. The literature search identified a considerable number of papers; 3,963 records of which 216 were read in full text. The majority of the excluded publications (S2) did not provide data for children or adolescents (i.e. the population intended for this review). Based on this, it is not likely that the inclusion criteria were too stringent. Instead, the problem comes down to the fact there are too few studies on postoperative pain management in children and adolescents. This is in accordance with the findings in the Cochrane review on preemptive administration of oral analgesics in young patients aged up to 17 years that identified 1,691 records and was able to include only two studies in a quantitative synthesis [8].

Empty systematic reviews are important to report as they highlight research gaps and indicate the state of research evidence at a particular point in time [19]; they may also serve as a guide for researchers and/or funders towards novel areas and future original research that needs to be undertaken $[25,31]$. There is also a risk of publication bias affecting decision-making in health care if not publishing empty systematic reviews. This problem is acknowledged by the WMA Declaration of Helsinki that raises the ethical obligation for researchers, authors, and editors etc. to publish and disseminate negative and inconclusive as well as positive results or research [32].

Within the field of paediatric dentistry, Mejàre et al. [33] identified and mapped a large number of knowledge gaps and concluded that there was an urgent need for good-quality primary clinical research in most clinically relevant domains. One domain pointed out was the "use of analgesics for the delivery of dental care" [33]. Also, the SBU database (Swedish Agency for Health Technology Assessment and Assessment of Social Services), serving as a repository for the UK Database of Uncertainties about the Effects of Treatments (DUETs) [34] has identified a need for a systematic review on postoperative pain relief for oral procedures in children and adolescents. The present SR meets this need [35] and thereby contributes to assembling the puzzle of research strategies related to pain reduction in conjunction with dental treatment in children and adolescents.

This HTA and SR points to a significant problem in that pharmacological substances are used in clinical practice without having been scrutinized. Also, the weighting of possible effects and side effects of the drugs or the intervention is lacking. Therefore, it is important to disseminate and discuss the results. Mainly two pharmacological substances, paracetamol (acetaminophen) and ibuprofen, have been suggested for treatment of pain resulting from dental treatment $[5,8]$. Paracetamol is considered a very safe drug and is used for the treatment of pain and fever. However, there is a risk of toxicity from overdose or from underlying patient conditions that might be affected by the drug: for instance, dehydration, malnutrition, or concomitant use of other medications [36]. It is known that NSAIDs can precipitate asthma in sensitive individuals, although this is uncommon (less than 10\%). Individuals sensitive to NSAIDs are often also sensitive to other unrelated COX inhibitors: for example, paracetamol [37]. This association between paracetamol and asthma is still under debate, since the evidence is inconclusive [38]. Ibuprofen, an NSAID, is also considered a safe pharmacological substance, and alongside paracetamol it is recommended as an antipyretic and analgesic from an early age [38]. However, there have been reported side effects in children from the use of ibuprofen, even though a clear association between ibuprofen and, for example, asthma or Reye's syndrome, has not been established [39, 40]. This calls for caution and highlights the importance of using only recommended standard doses of oral analgesics, based on weight and age [34]. Based on this knowledge, an empty systematic review is even more important. The lack of scientific evidence makes it impossible to construct any guidelines on the general administration of oral analgesics to prevent postoperative pain. Instead, all administration must be individually tailored and founded on a risk assessment that considers the type of dental 
treatment, the patient's medical status, previous pain experiences, and the patient's subjective point of views.

\section{Conclusions}

As no studies meeting the inclusion criteria were identified, it was not possible to find any scientific support for the effects, nor provide any support for rejection, of postoperatively administered oral analgesics for the prevention or reduction of pain after dental treatment in children and adolescents. Thus, it is not possible to formulate clinical guidelines on this issue solely based on scientific evidence. There is an urgent need for further well-designed studies on how to prevent pain after dental treatment. This empty systematic review serves as an important starting point for research in this area.

\section{Supporting information}

S1 PRISMA. PRISMA 2009 checklist.

(DOCX)

S1 File. Search strategies.

(DOCX)

S2 File. Characteristics of excluded studies. List of excluded full text papers.

(DOCX)

S1 Data.

(PDF)

\section{Author Contributions}

Conceptualization: Henrik Berlin, Gunilla Klingberg.

Formal analysis: Henrik Berlin, Karin Ridell, Susanne Brogårdh-Roth, Elisabeth Lager, Thomas List, Thomas Davidson, Gunilla Klingberg.

Funding acquisition: Gunilla Klingberg.

Investigation: Henrik Berlin, Martina Vall, Elisabeth Bergenäs, Karin Ridell, Susanne Brogårdh-Roth, Elisabeth Lager, Thomas List, Thomas Davidson, Gunilla Klingberg.

Methodology: Henrik Berlin.

Project administration: Henrik Berlin.

Writing - original draft: Henrik Berlin.

Writing - review \& editing: Henrik Berlin, Martina Vall, Elisabeth Bergenäs, Karin Ridell, Susanne Brogårdh-Roth, Elisabeth Lager, Thomas List, Thomas Davidson, Gunilla Klingberg.

\section{References}

1. McGrath PJ, Unruh AM. Measurement assessment of paediatric pain. In: McMahon SB, Koltzenburg M, Tracey I \& Turk D (editors). Wall and Melzack's textbook of pain. 6th ed. [Kindle for iPad, version 6.14]. Philadephila: Elsevier Saunders; 2013.

2. Young KD. Pediatric procedural pain. Ann Emerg Med. 2005; 45(2):160-71. Review. https://doi.org/10. 1016/j.annemergmed.2004.09.019 PMID: 15671974 
3. Klingberg G, Broberg AG. Dental fear/anxiety and dental behaviour management problems in children and adolescents: a review of prevalence and concomitant psychological factors. Int J Paediatr Dent. 2007; 17(6):391-406. https://doi.org/10.1111/j.1365-263X.2007.00872.x PMID: 17935593

4. Raadal M, Strand GV, Amarante EC, Kvale G. Relationship between caries prevalence at 5 years of age and dental anxiety at 10. Eur J Paediatr Dent. 2002; 3(1):22-6. PMID: 12871013

5. Berlin H, List T, Ridell K, Klingberg G. Dentists' attitudes towards acute pharmacological pain management in children and adolescents. Int J Paediatr Dent. 2018; 28(2):152-60. https://doi.org/10.1111/ipd. 12316 PMID: 28691744

6. INAHTA [Internet]. HTA Tools \& Resources. Definitions. The International Network of Agencies for Health Technology Assessment (INAHTA). 2019. Available: http://www.inahta.org/hta-tools-resources/ . Accessed 2019 January 24.

7. Heintz E, Lintamo L, Hultcrantz $M$, Jacobson $S$, Levi $R$, Munthe $C$, et al. Framework for systematic identification of ethical aspects of healthcare technologies: the SBU approach. Int J Technol Assess Health Care. 2015; 31(3):124-30. https://doi.org/10.1017/S0266462315000264 PMID: 26134927.

8. Ashley PF, Parekh S, Moles DR, Anand P, MacDonald LC. Preoperative analgesics for additional pain relief in children and adolescents having dental treatment. Cochrane Database Syst Rev. 2016; 8(8): CD008392. https://doi.org/10.1002/14651858.CD008392.pub3 PMID: 27501304

9. Huskisson EC. Measurement of pain. Lancet. 1974; 2(7889):1127-31. https://doi.org/10.1016/s01406736(74)90884-8 PMID: 4139420

10. Hicks CL, von Baeyer CL, Spafford PA, van Korlaar I, Goodenough B. The faces pain scale-revised: toward a common metric in paediatric pain measurement. Pain. 2001; 93(2):173-83. https://doi.org/10. 1016/s0304-3959(01)00314-1 PMID: 11427329

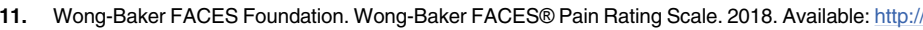
www.WongBakerFACES.org. Accessed 2019 March 5.

12. Jensen MP, Karoly $P$, Braver $S$. The measurement of clinical pain intensity: A comparison of six methods. Pain. 1986; 27(1):117-26. https://doi.org/10.1016/0304-3959(86)90228-9 PMID: 3785962

13. Eland JM. Minimizing pain associated with prekindergarten intramuscular injections. Issues Compr Pediatr Nurs. 1981; 5(5-6):361-72. https://doi.org/10.3109/01460868109106351 PMID: 6922129

14. Moher D, Liberati A, Tetzlaff J, Altman DG, The PG. Preferred reporting items for systematic reviews and meta-analyses: the PRISMA statement. PLoS Med. 2009; 6(7):e1000097. https://doi.org/10.1371/ journal.pmed.1000097 PMID: 19621072

15. Guyatt G, Oxman AD, Akl EA, Kunz R, Vist G, Brozek J, et al. GRADE guidelines: 1. IntroductionGRADE evidence profiles and summary of findings tables. J Clin Epidemiol. 2011; 64(4):383-94. https://doi.org/10.1016/j.jclinepi.2010.04.026 PMID: 21195583

16. Swedish Agency for Health Technology Assessment and Assessment of Social Services (SBU). Assessment of methods in health care-A handbook. Stockholm. 2018. Available: https://www.sbu.se/ contentassets/76adf07e270c48efaf67e3b560b7c59c/eng_metodboken.pdf.

17. Balshem $\mathrm{H}$, Helfand M, Schünemann HJ, Oxman AD, Kunz R, Brozek J, et al. GRADE guidelines: 3 . Rating the quality of evidence. J Clin Epidemiol. 2011; 64(4):401-6. https://doi.org/10.1016/j.jclinepi. 2010.07.015 PMID: 21208779

18. Shea BJ, Reeves BC, Wells G, Thuku M, Hamel C, Moran J, et al. AMSTAR 2: a critical appraisal tool for systematic reviews that include randomised or non-randomised studies of healthcare interventions, or both. BMJ. 2017; 358:j4008. https://doi.org/10.1136/bmj.j4008 PMID: 28935701

19. CIOMS (Council for International Organizations of Medical Sciences). Guideline 17: research involving children and adolescents. In: International Ethical Guidelines for Healthrelated Research Involving Humans [Internet] 2016. Available: https://cioms.ch/wp-content/uploads/2017/01/WEB-CIOMSEthicalGuidelines.pdf. Accessed 2019 January 18.

20. Rotstein $D$, Laupacis $A$. Differences between systematic reviews and health technology assessments: a trade-off between the ideals of scientific rigor and the realities of policy making. Int J Technol Assess Health Care. 2004; 20(2):177-83. https://doi.org/10.1017/s0266462304000959 PMID: 15209177

21. Battista RN, Hodge MJ. The evolving paradigm of health technology assessment: reflections for the millennium. CMAJ. 1999; 160(10):1464-7. PMID: 10352637

22. Drummond M, Sculpher M, Claxton C, Stoddart G, Torrance G. Methods for the economic evaluation of health care programmes. 4 ed: Oxford University Press. 2015.

23. Shaddy RE, Denne SC. Committee on Drugs and Committee on Pediatric Research. Clinical reportguidelines for the ethical conduct of studies to evaluate drugs in pediatric populations. Pediatrics. 2010 125(4):850-60. https://doi.org/10.1542/peds.2010-0082 PMID: 20351010

24. Lang A, Edwards N, Fleiszer A. Empty systematic reviews: hidden perils and lessons learned. J Clin Epidemiol. 2007; 60(6):595-7. https://doi.org/10.1016/j.jclinepi.2007.01.005 PMID: 17493517 
25. Yaffe J, Montgomery P, Hopewell S, Shepard LD. Empty reviews: a description and consideration of Cochrane systematic reviews with no included studies. PLoS One. 2012; 7(5):e36626. https://doi.org/ 10.1371/journal.pone.0036626 PMID: 22574201

26. Hopewell S, Loudon $\mathrm{K}$, Clarke MJ, Oxman $\mathrm{AD}$, Dickersin $\mathrm{K}$. Publication bias in clinical trials due to statistical significance or direction of trial results. Cochrane Database Syst Rev. 2009;(1);MR000006. https://doi.org/10.1002/14651858.MR000006.pub3 PMID: 19160345

27. Song F, Parekh S, Hooper L, Loke YK, Ryder J, Sutton AJ, et al. Dissemination and publication of research findings: an updated review of related biases. Health Technol Assess. 2010; 14(8):iii, ix-xi,1193. https://doi.org/10.3310/hta14080 PMID: 20181324

28. IASP. International Association for the Study of Pain. 2014. Available: http://www.iasp-pain.org/ Taxonomy. Accessed 2019 February 15.

29. McGrath PJ, Walco GA, Turk DC, Dworkin RH, Brown MT, Davidson K, et al Core outcome domains and measures for pediatric acute and chronic/recurrent pain clinical trials: PedIMMPACT recommendations. J Pain. 2008; 9(9):771-83. https://doi.org/10.1016/j.jpain.2008.04.007 PMID: 18562251

30. Williamson PR, Altman DG, Bagley H, Barnes KL, Blazeby JM, Brookes ST, et al. The COMET Handbook: version 1.0. Trials. 2017; 18(Suppl 3):280. https://doi.org/10.1186/s13063-017-1978-4 PMID: 28681707

31. Schlosser RW, Sigafoos J. Empty' reviews and evidence-based practice. Evid Based Commun Assess Interv. 2009; 3(1):1-3. https://doi.org/10.1080/17489530902801067

32. World Medical Association. Declaration of Helsinki. Ethical principles for medical research involving human subjects [Internet]. 2013. Available https://www.wma.net/policies-post/wma-declaration-ofhelsinki-ethical-principles-for-medical-research-involving-human-subjects/ Accessed 2019 March 7.

33. Mejàre IA, Klingberg G, Mowafi FK, Stecksén-Blicks C, Twetman SH, Tranæus SH, et al. A systematic map of systematic reviews in pediatric dentistry-what do we really know? PLoS One. 2015; 10(2): e0117537. https://doi.org/10.1371/journal.pone.0117537 PMID: 25706629

34. SBU. Databases with evidence gaps. Swedish Agency for Health Technology Assessment and Assessment of Social Services (SBU) [Internet]. 2018. [Updated 2018 Oct 4]. Available: https://www.sbu.se/ en/publications/evidence-gaps/databases-with-evidence-gaps/ Accessed 2019 March 22.

35. SBU. Postoperativ smärtlindring vid oralkirurgiskt ingrepp på barn och ungdom. Swedish Agency for Health Technology Assessment and Assessment of Social Services (SBU) [Internet]. 2014. [Published 2012 Dec 21; updated 2014 Sept 2]. Available: https://www.sbu.se/sv/publikationer/kunskapsluckor/ postoperativ-smartlindring-vid-oralkirurgiskt-ingrepp-pa-barn-och-ungdom-/ Accessed 2019 March 22

36. de Martino M, Chiarugi A. Recent Advances in Pediatric Use of Oral Paracetamol in Fever and Pain Management. Pain Ther. 2015; 4(2):149-68. https://doi.org/10.1007/s40122-015-0040-z PMID: 26518691

37. Rang HP, Ritter JM, Flower RJ, Henderson G, Dale MM. Rang and Dale's pharmacology. Edinburgh: Elsevier, Churchill Livingstone. 2016.

38. Lourido-Cebreiro T, Salgado FJ, Valdes L, Gonzalez-Barcala FJ. The association between paracetamo and asthma is still under debate. J Asthma. 2017; 54(1):32-8. https://doi.org/10.1080/02770903.2016. 1194431 PMID: 27575940

39. Barbagallo $M$, Sacerdote $P$. Ibuprofen in the treatment of children's inflammatory pain: a clinical and pharmacological overview. Minerva Pediatr. 2019; 71(1):82-99. https://doi.org/10.23736/S0026-4946. 18.05453-1 PMID: 30574736

40. Norman $\mathrm{H}$, Elfineh M, Beijer E, Casswall T, Nemeth A. Also ibuprofen, not just paracetamol, can cause serious liver damage in children. NSAIDs should be used with caution in children, as shown in case with fatal outcome [In Swedish]. Läkartidningen. 2014; 111(40):1709-11. PMID: 25759881 
Copyright of PLoS ONE is the property of Public Library of Science and its content may not be copied or emailed to multiple sites or posted to a listserv without the copyright holder's express written permission. However, users may print, download, or email articles for individual use. 


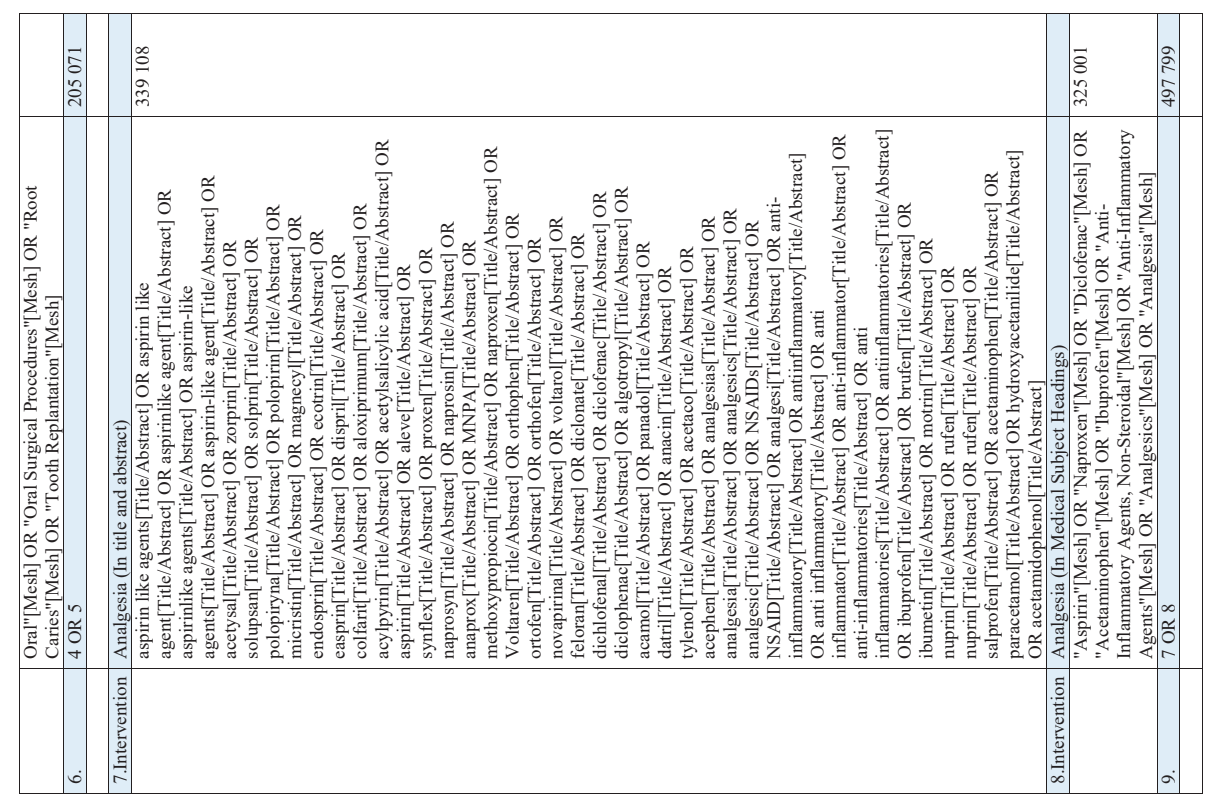

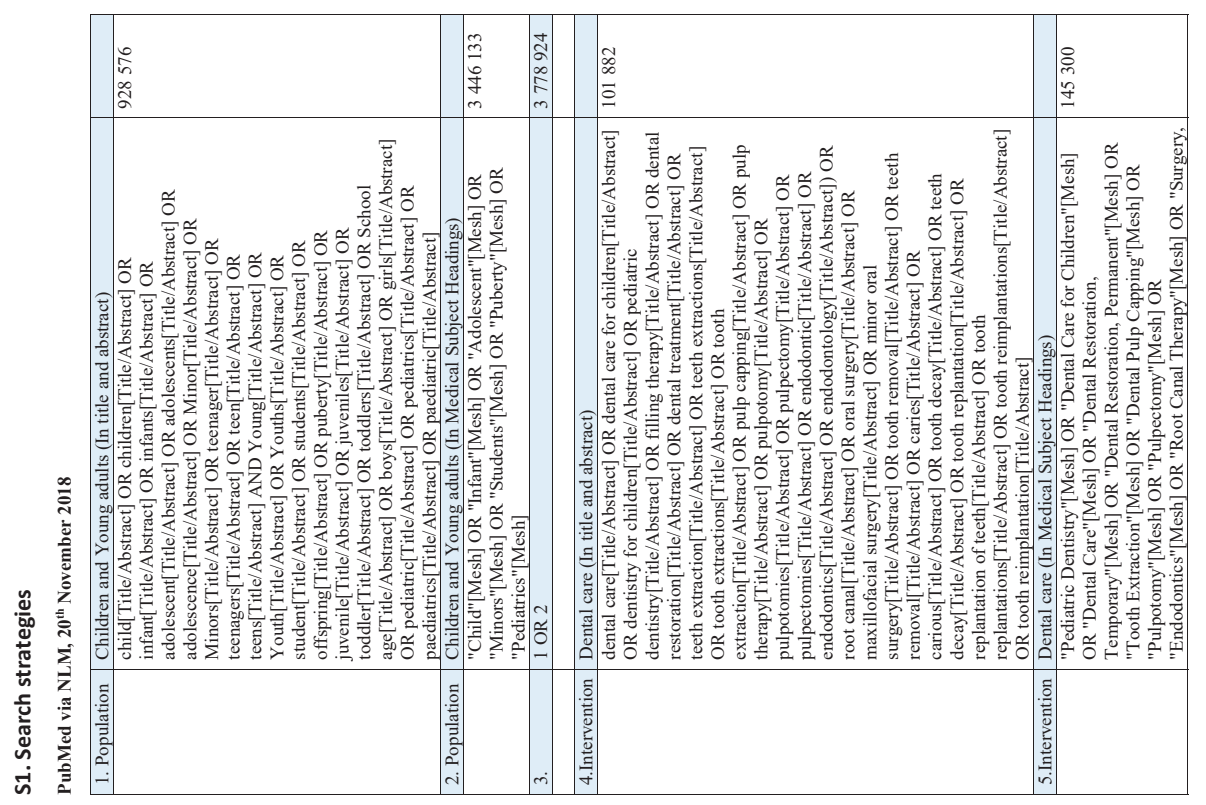



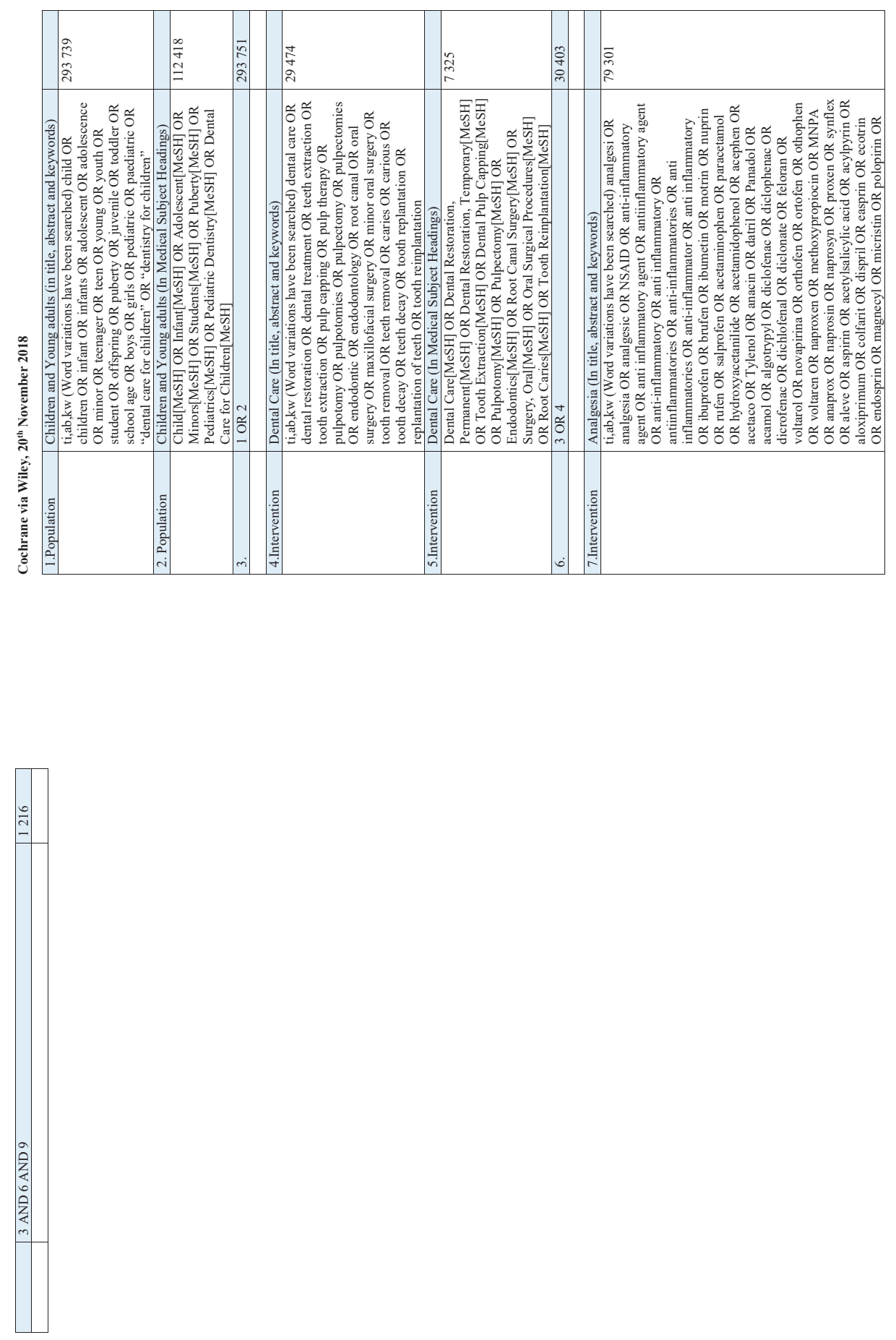

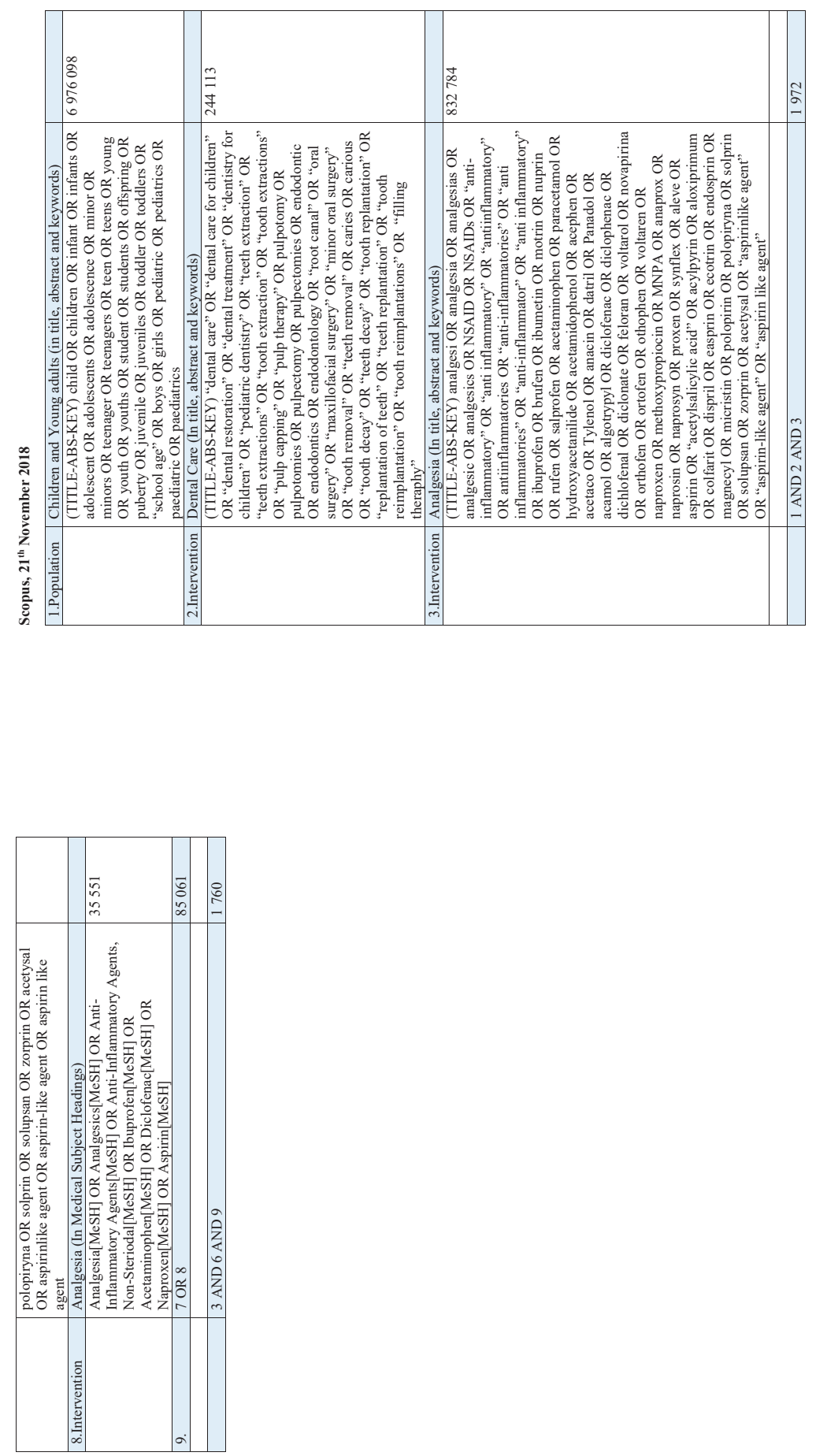

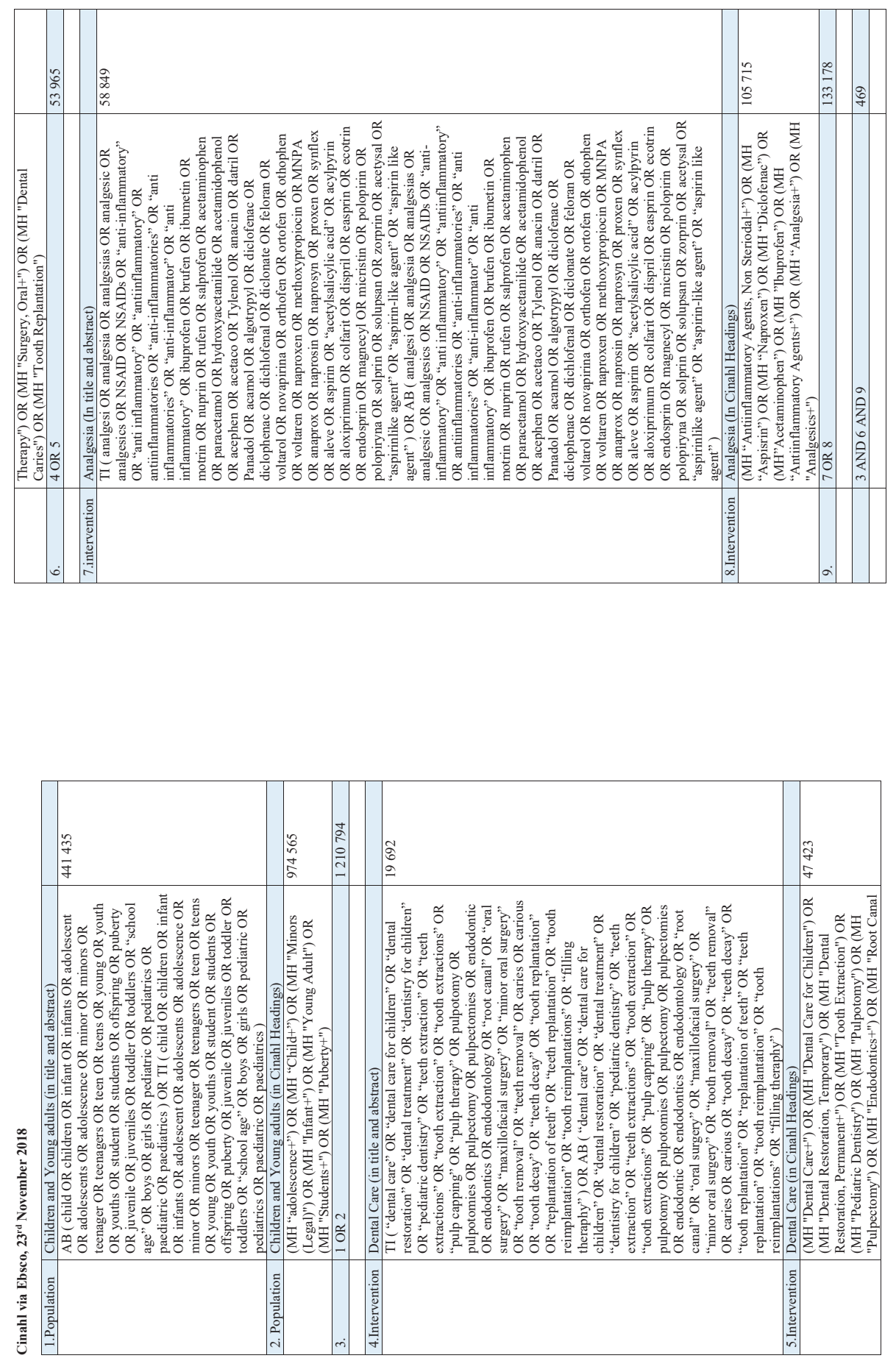

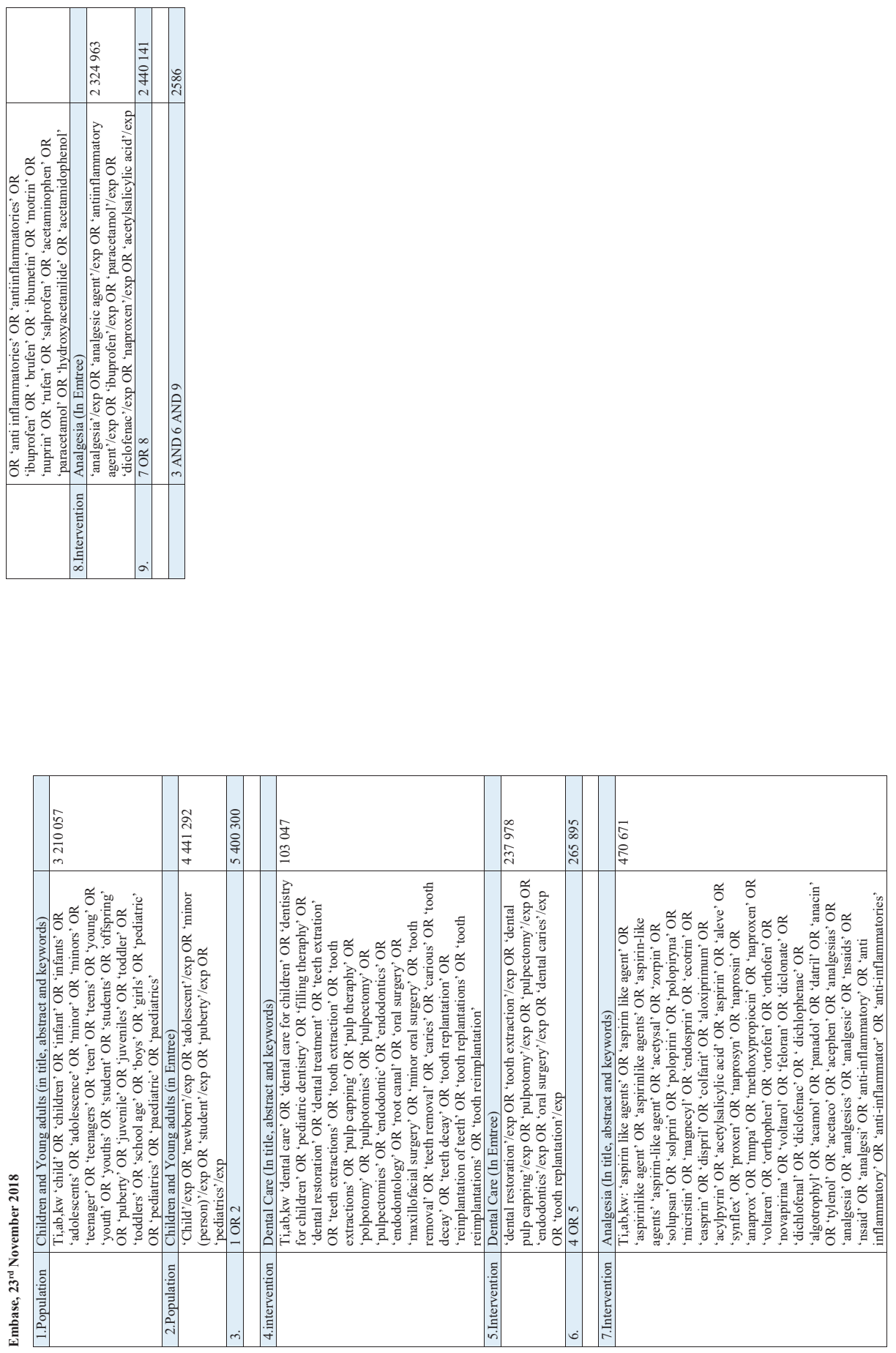

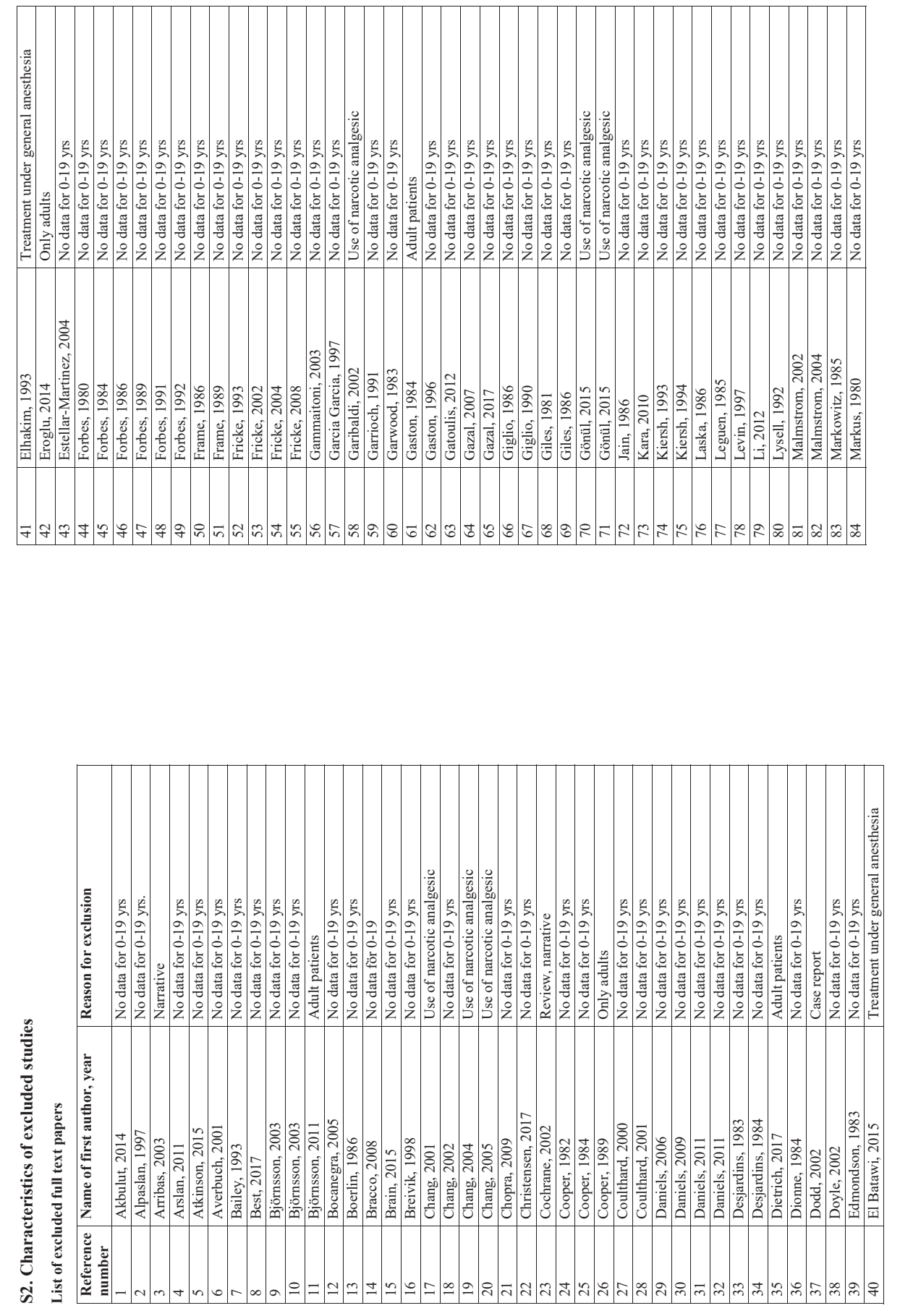

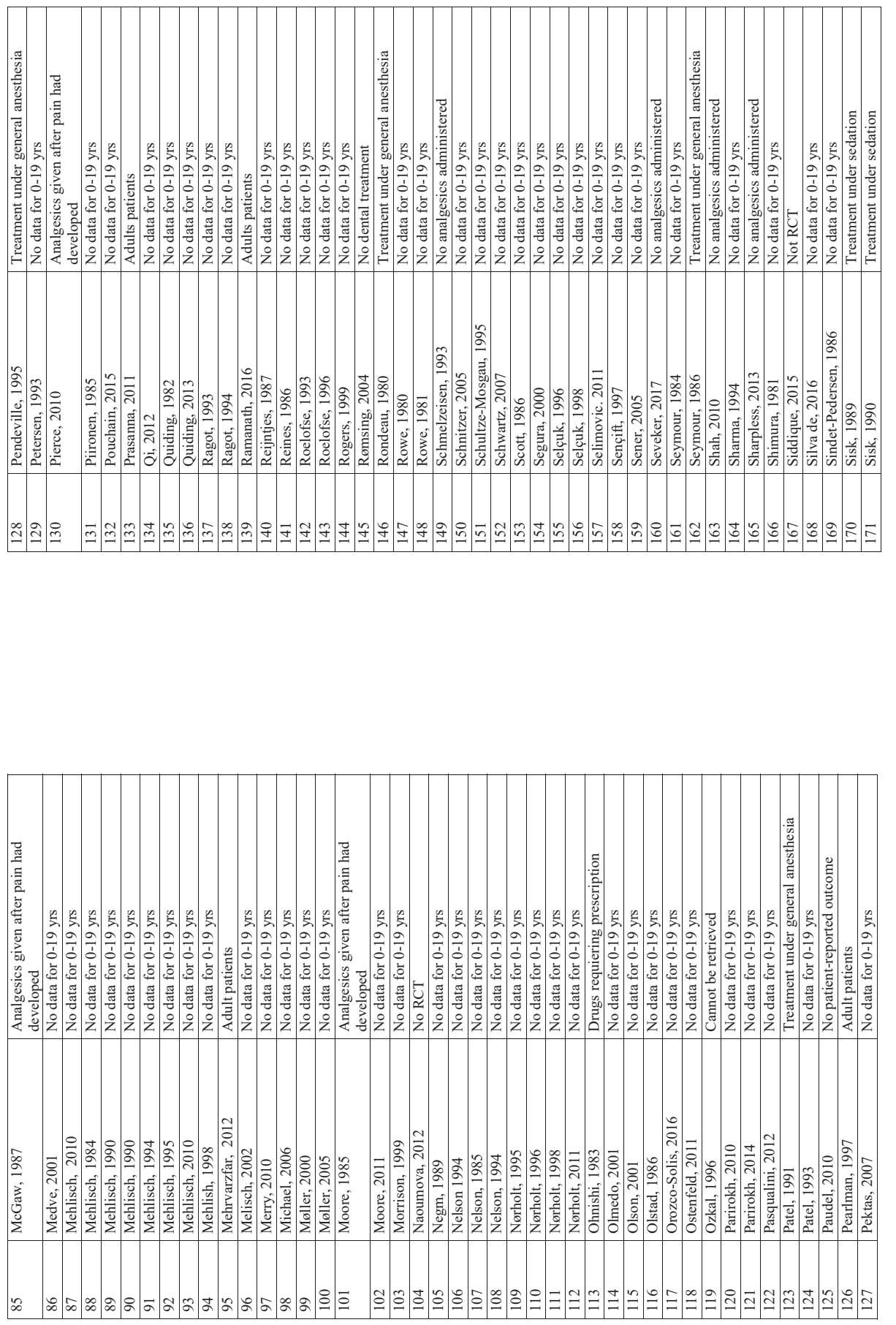

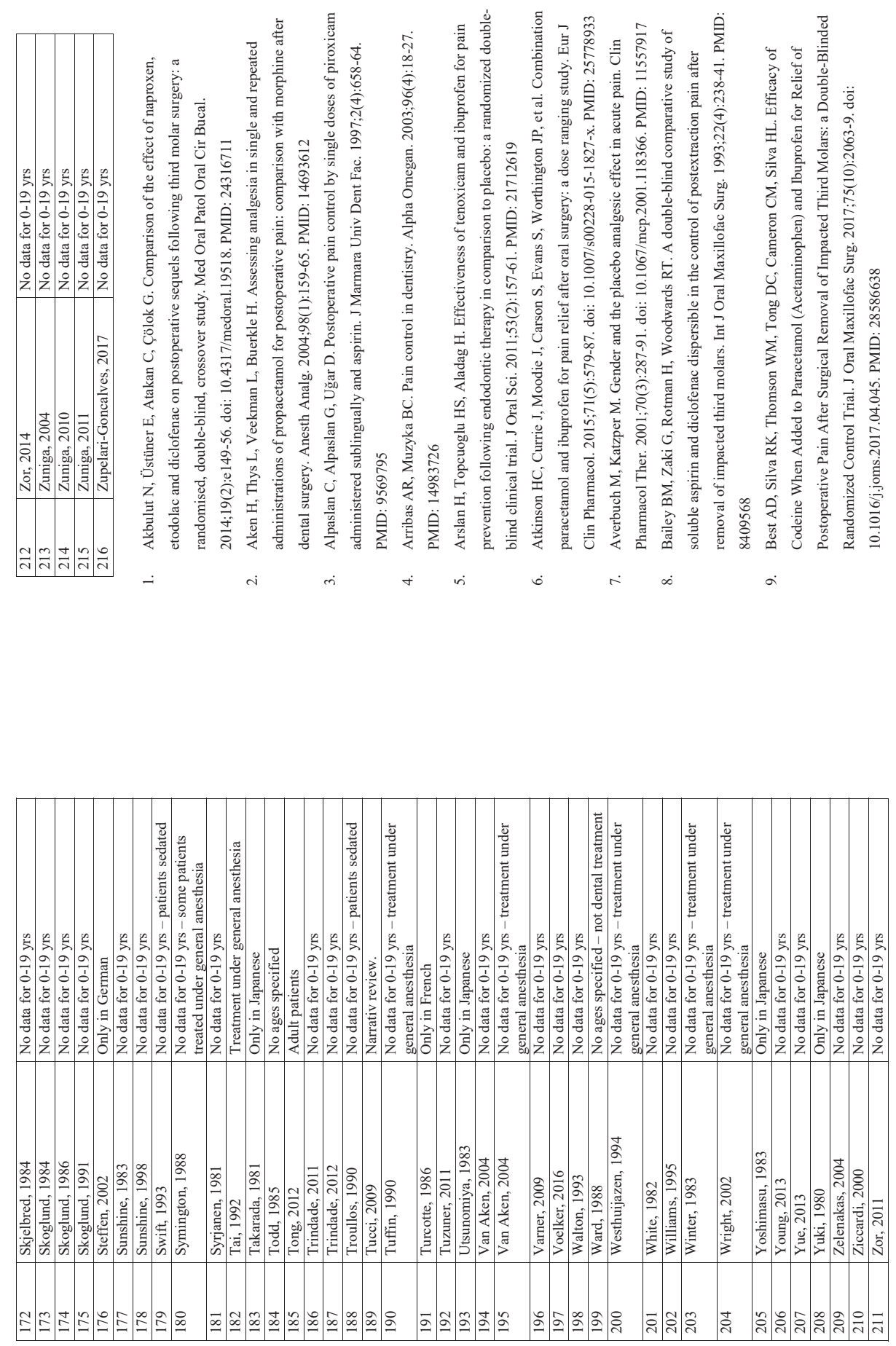

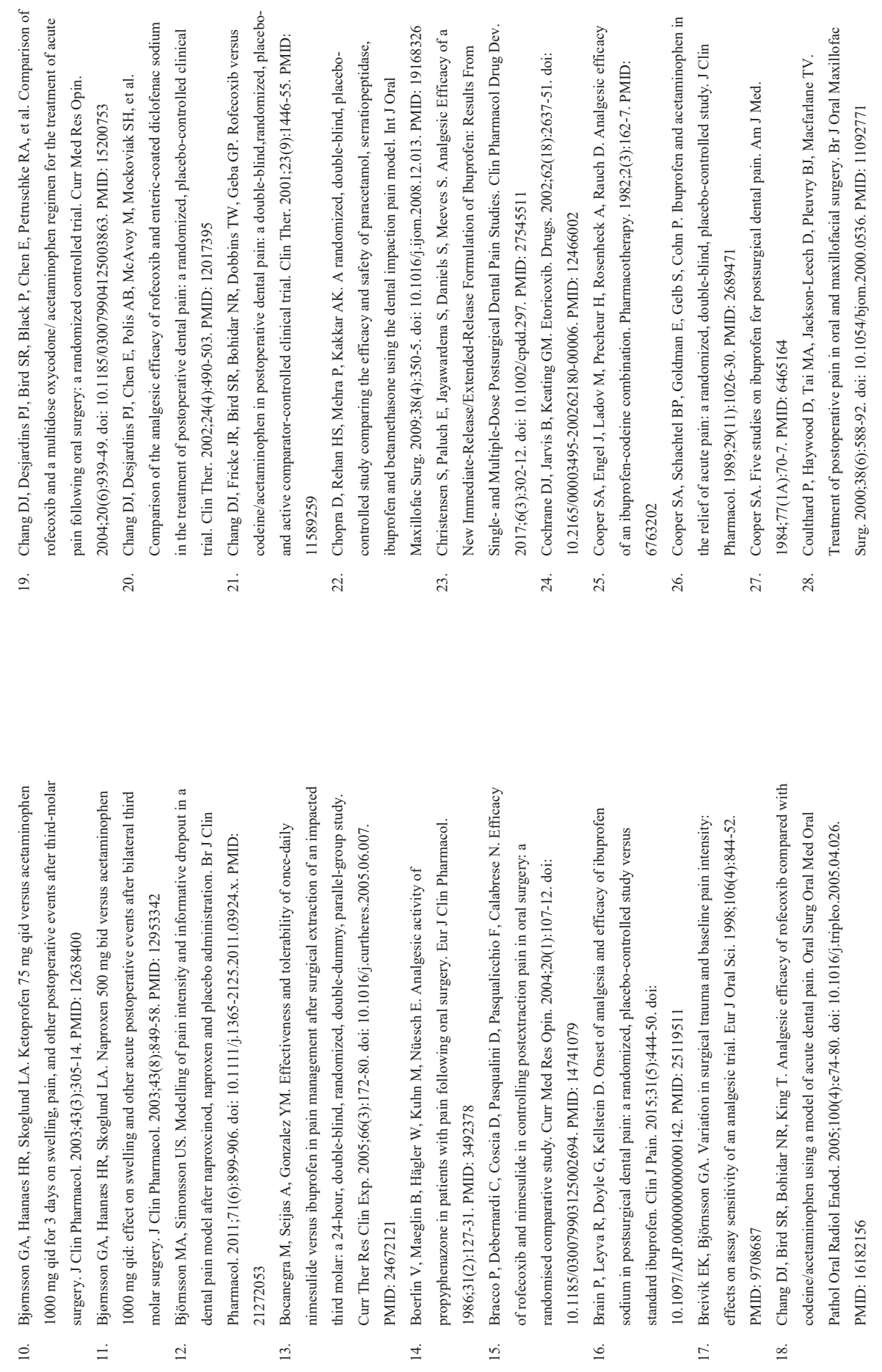

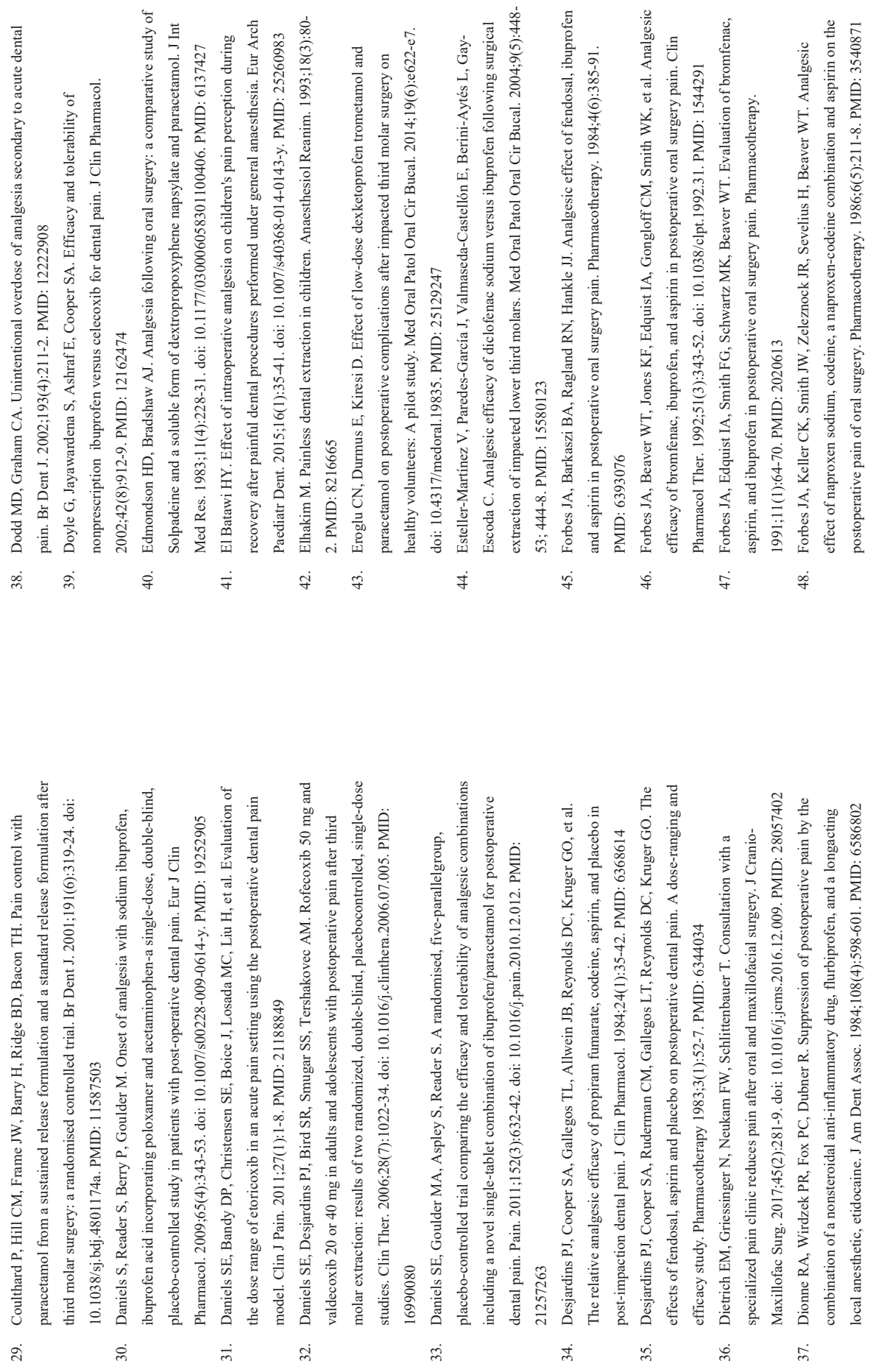

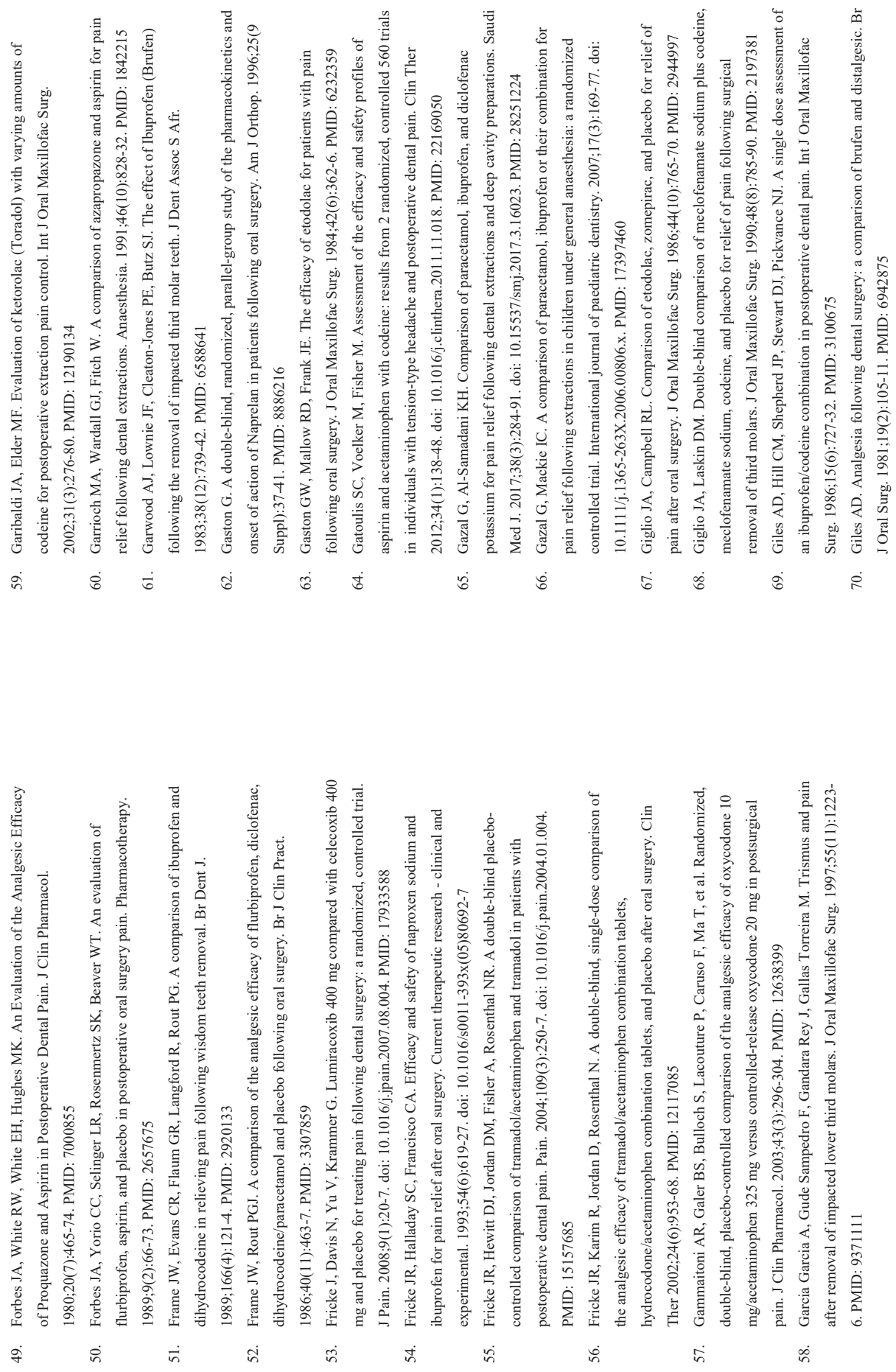

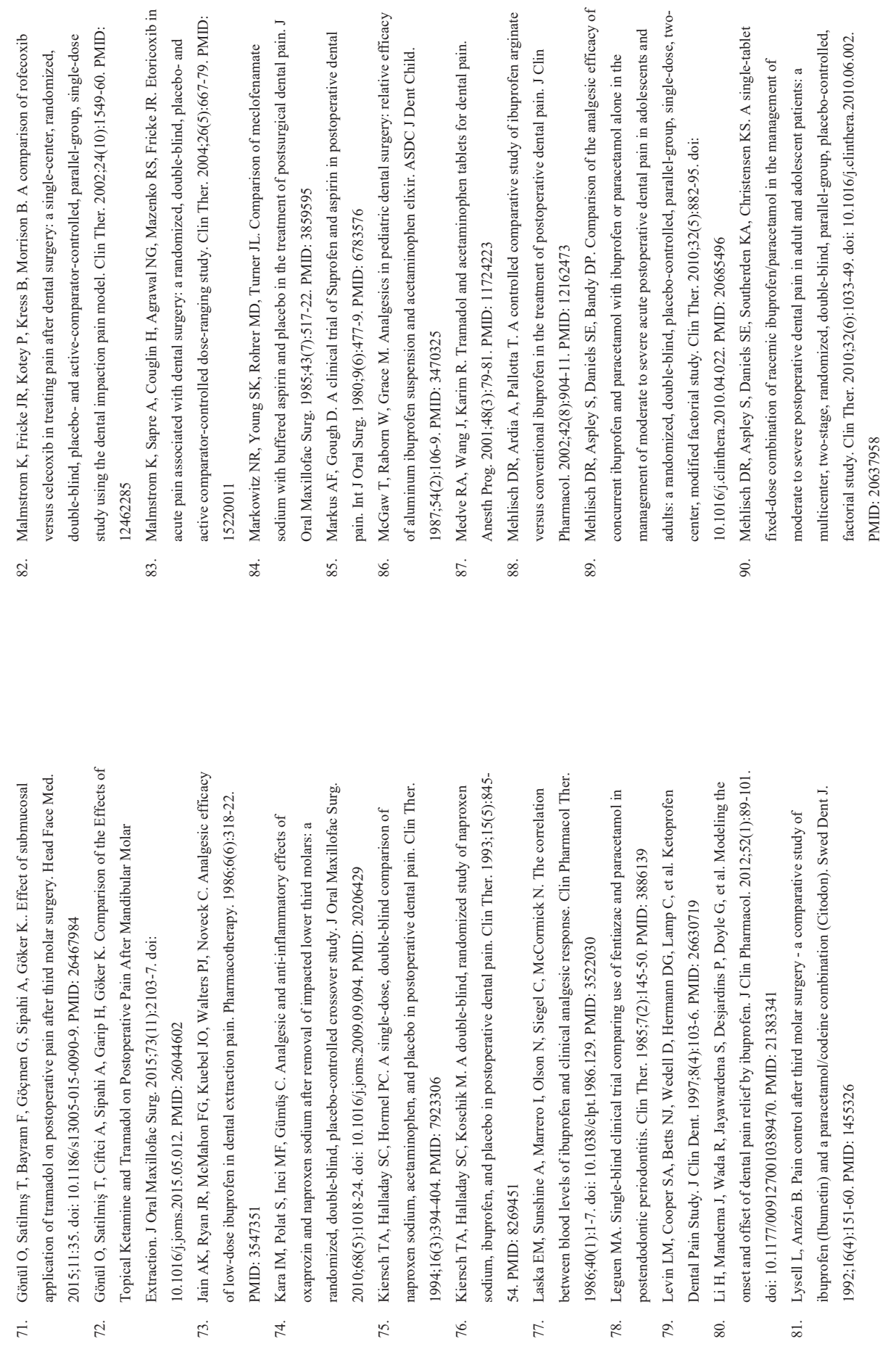

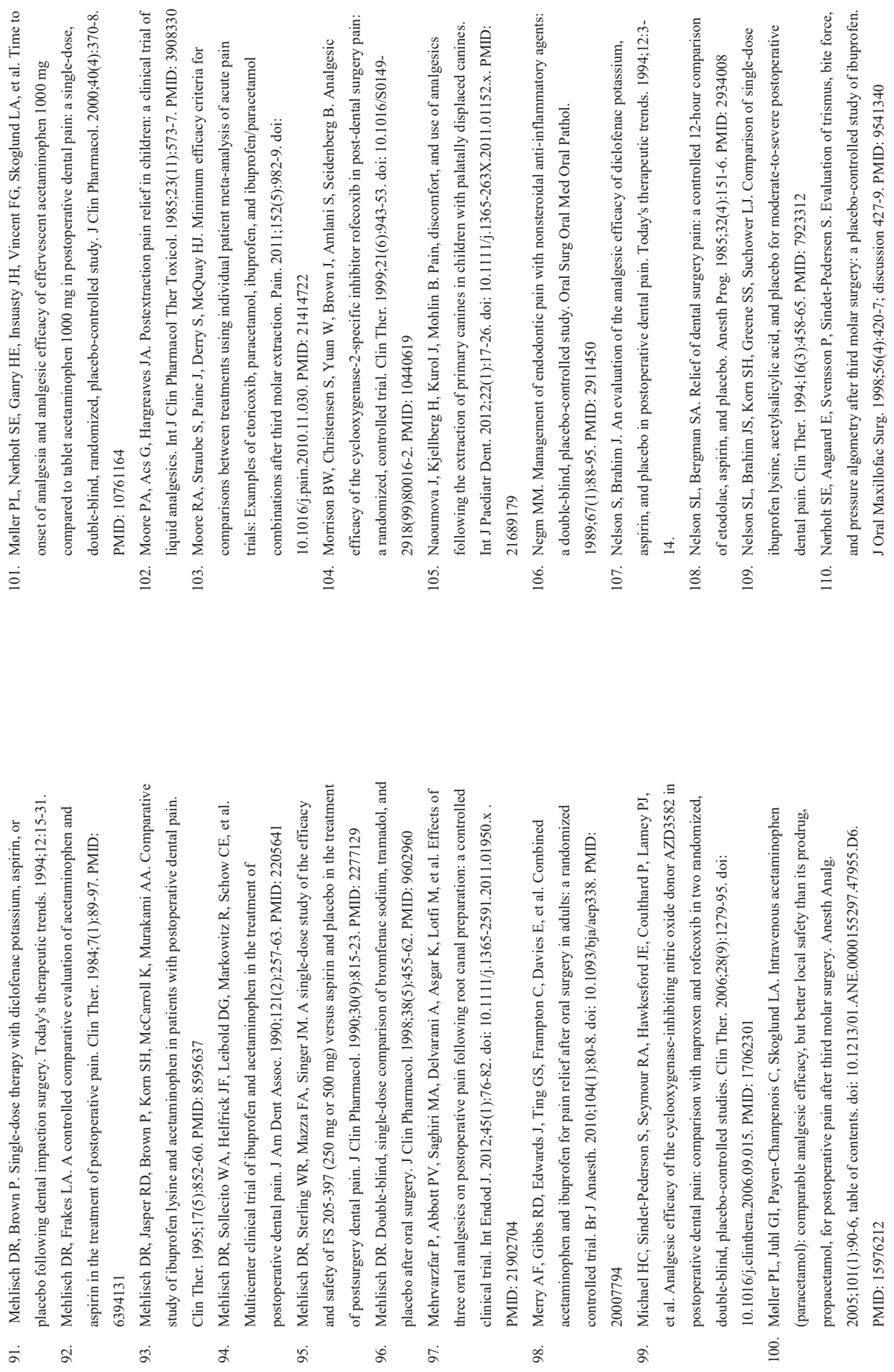

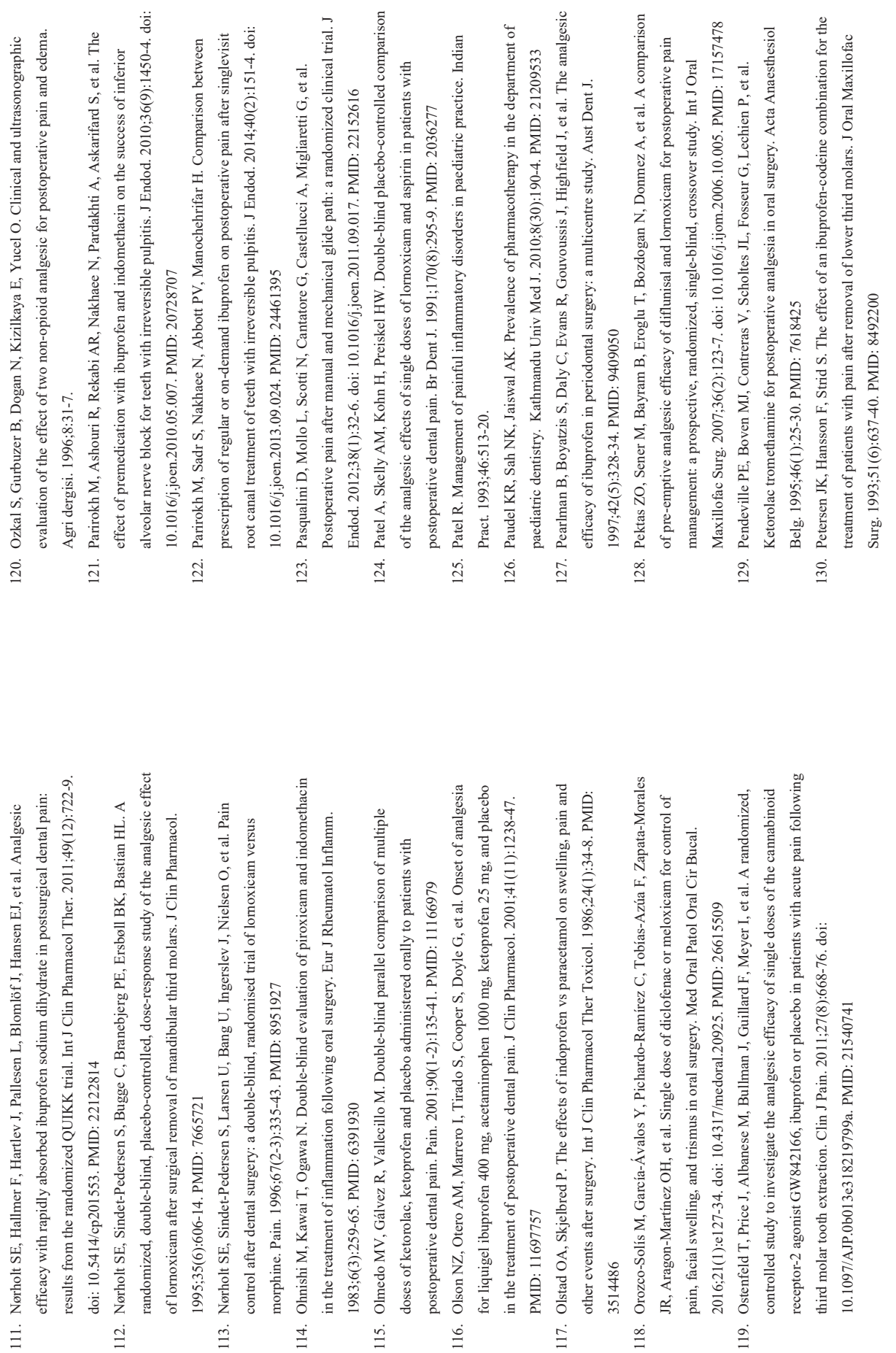

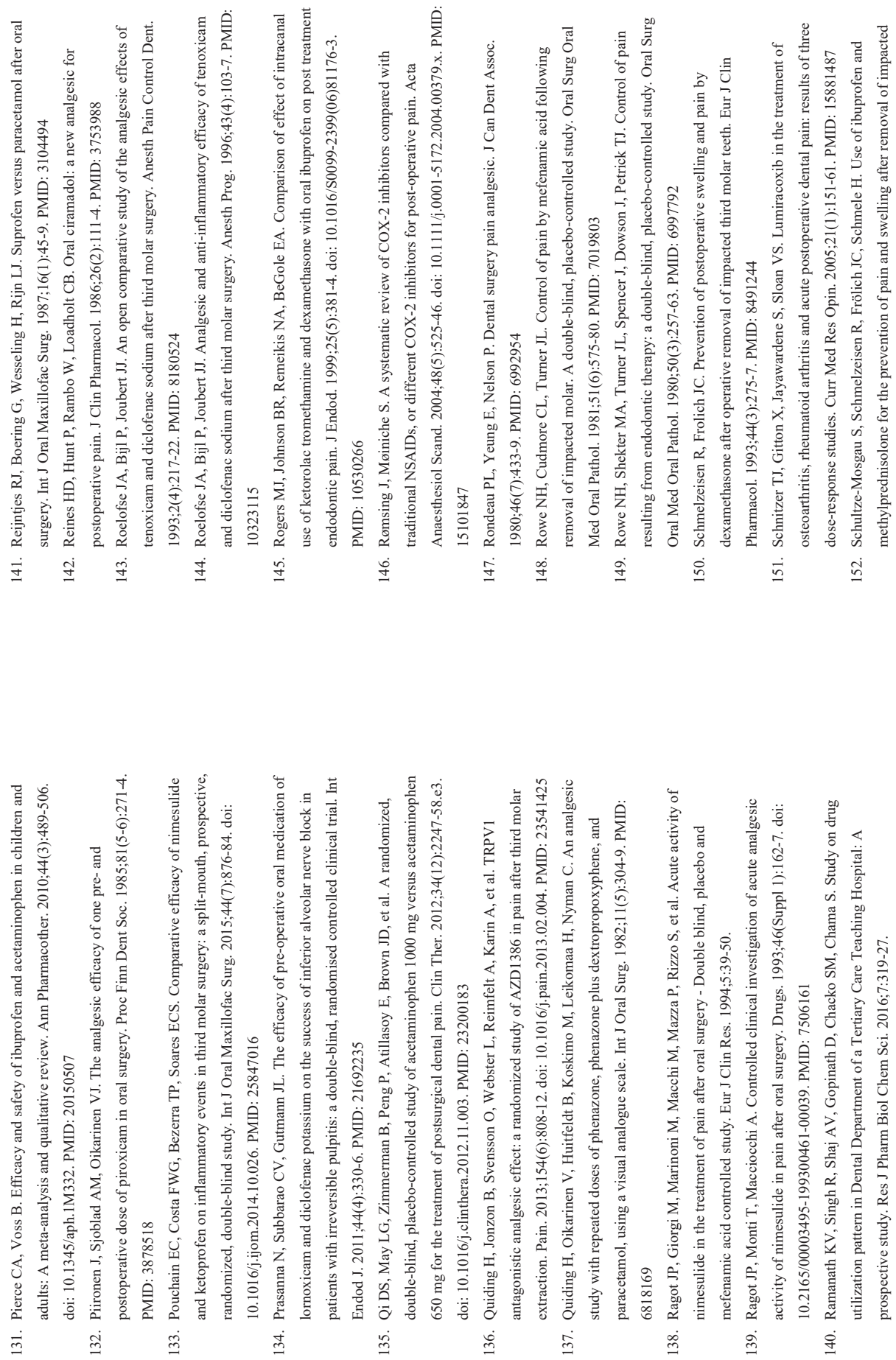

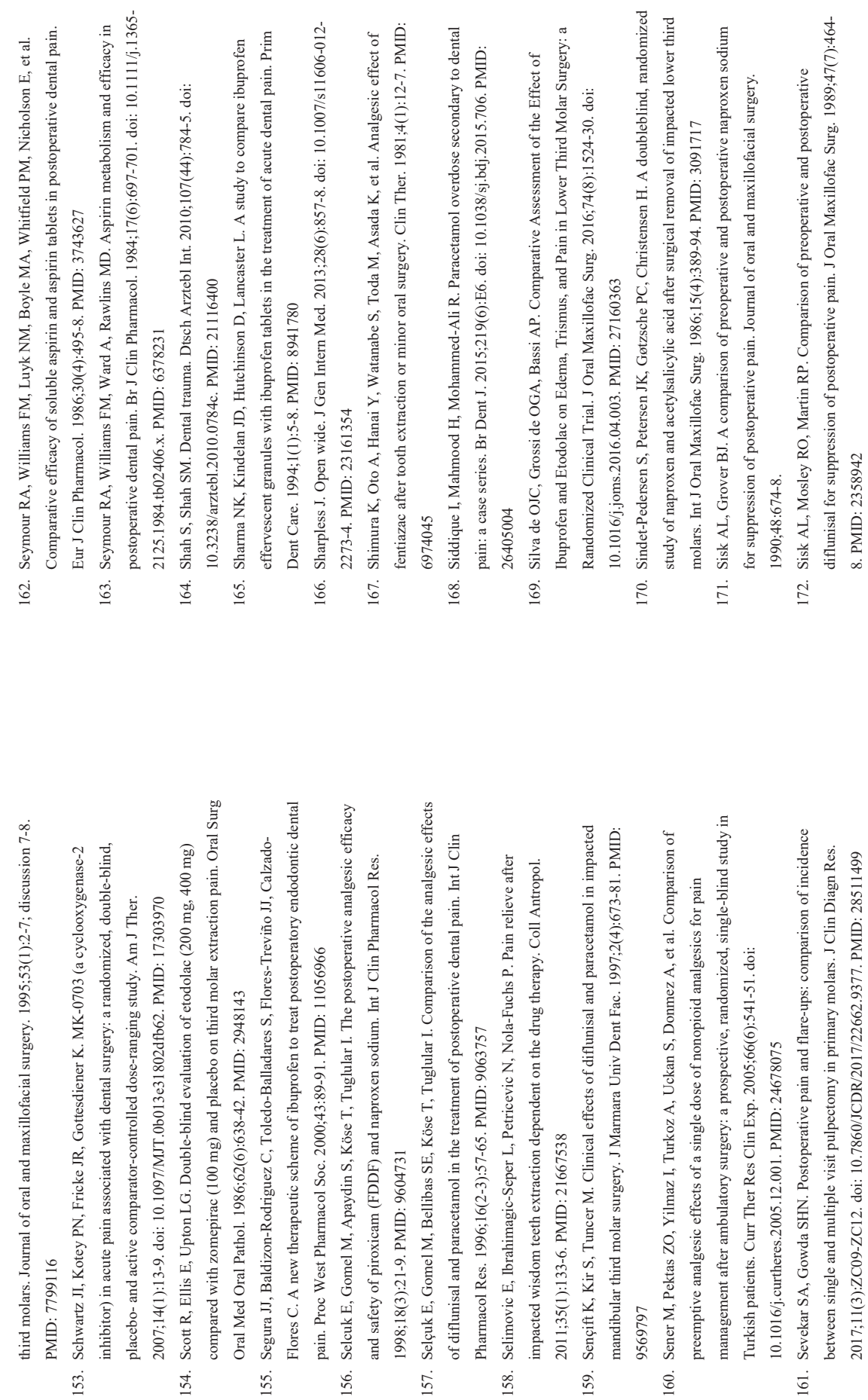

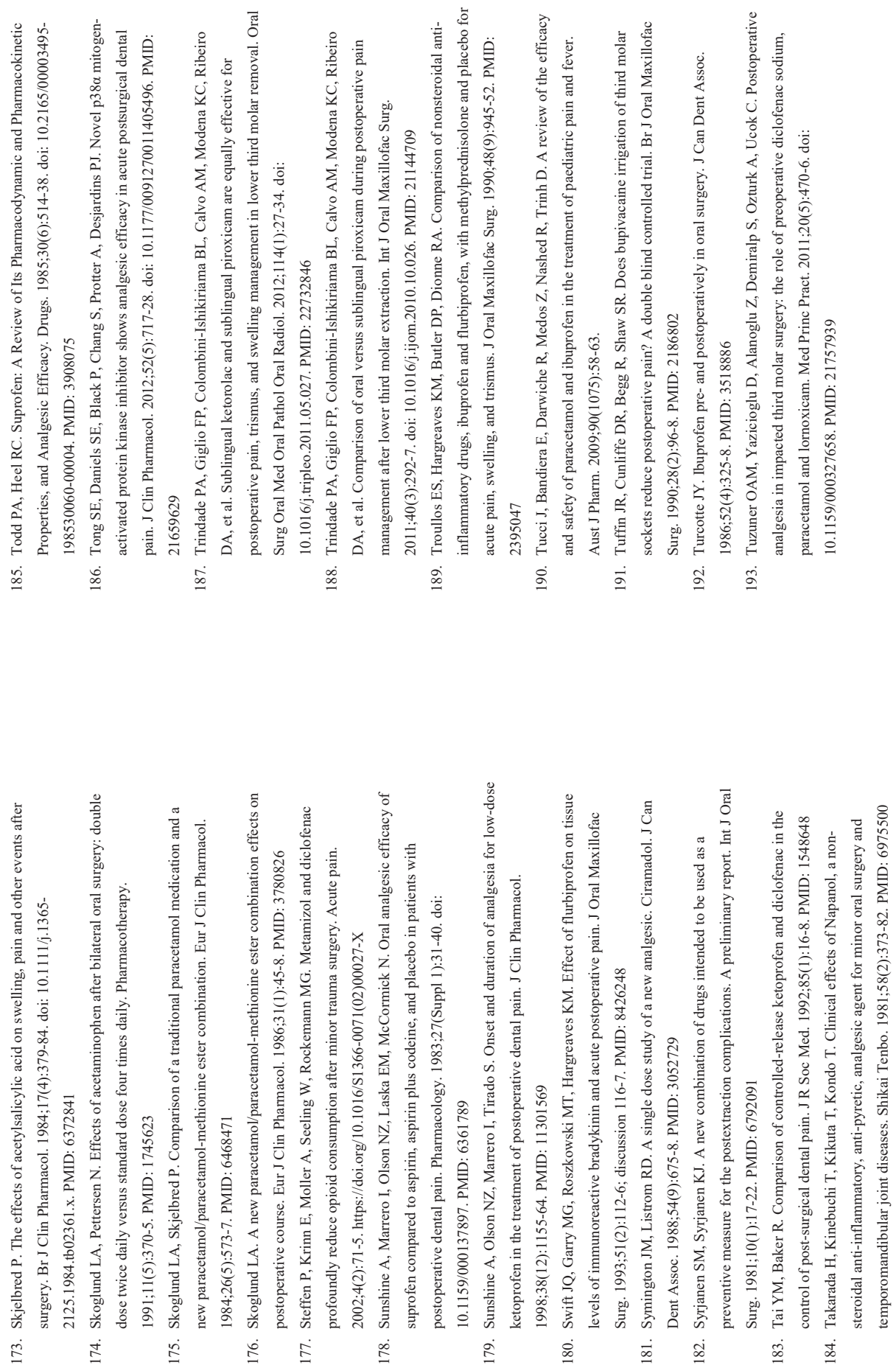

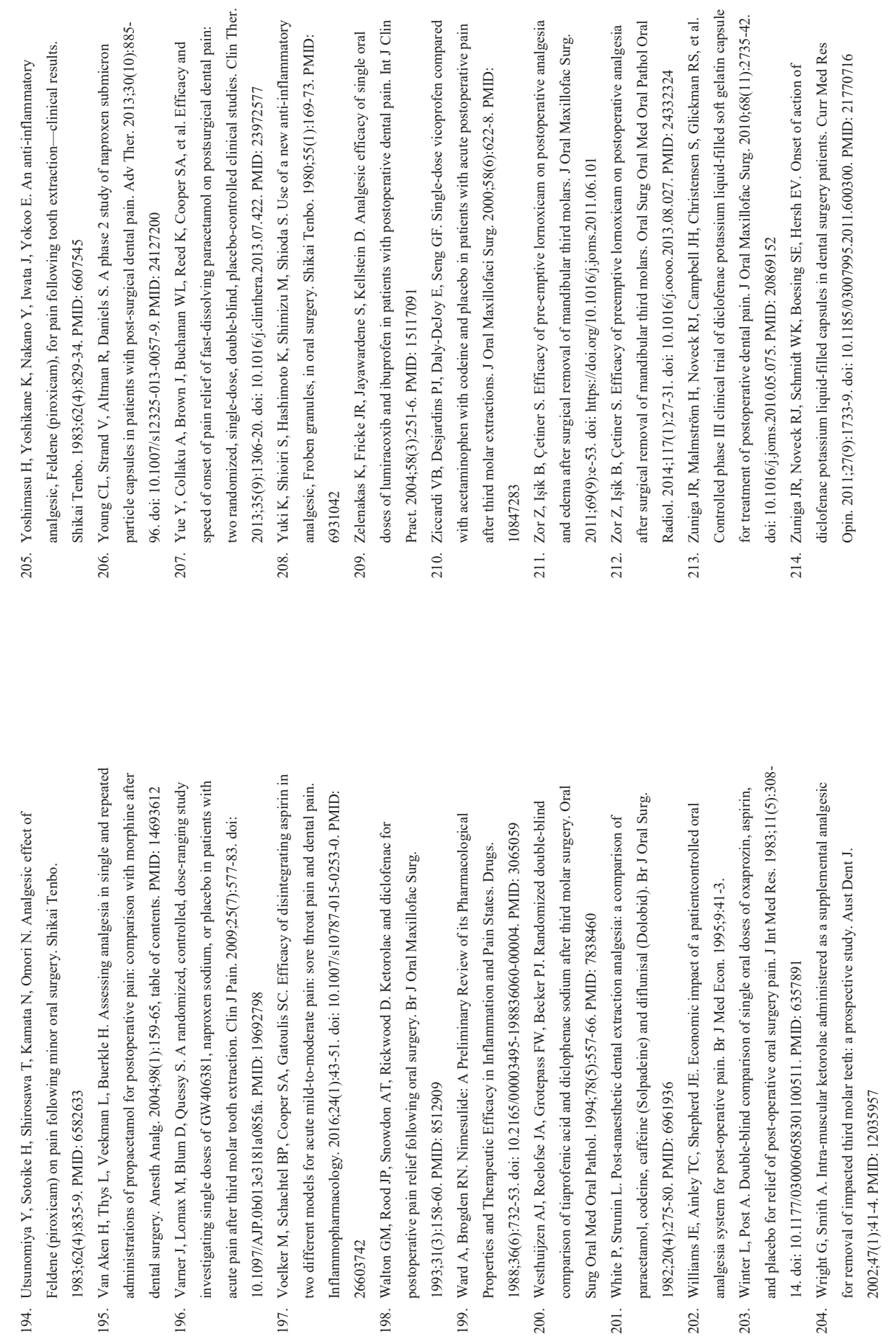


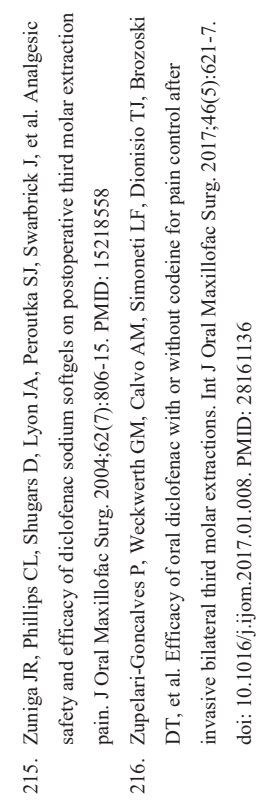





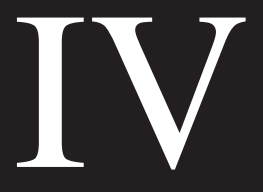





\title{
Children's perceptions and coping of pain in conjunction with orthodontically indicated tooth extractions - a grounded theory study
}

\author{
Henrik Berlin ${ }^{1}$, Ulrika Hallberg ${ }^{1}$, Karin Ridell ${ }^{1}$, Danijela Toft $^{2}$, Gunilla Klingberg ${ }^{1}$ \\ ${ }^{1}$ Department of Pediatric Dentistry, Faculty of Odontology, Malmö University, Malmö, Sweden \\ ${ }^{2}$ Colosseum Smile Dental Group, Malmö, Sweden
}

\begin{abstract}
Children frequently experience pain/discomfort during dental treatment. At the same time there seems to be uncertainty among dentists regarding pain management. Pain research in dentistry has mainly been performed in adults using quantitative methods. Meanwhile, qualitative methods as well as the child's perspective are scarce. This study aims to explore and describe children's experiences/thoughts regarding pain in conjunction with tooth extraction and the subsequent postoperative period, using grounded theory (GT). Qualitative interviews were carried out with eleven 10-16-year-olds. Interviews were transcribed verbatim and analysed in open, as well as focused (selective) coding processes according to GT. A core category was identified and named 'handling the unavoidable unknown'. Instead of focusing on pain, the informants described an urge for more information about the procedure and what to expect in terms of pain/discomfort, during and/or after treatment. They stated that the levels of pain/discomfort were manageable, while the lack of information negatively affected their coping abilities, causing anxiousness. To improve patients' ability to deal with pain in conjunction with dental extraction, the dental team should ensure better information about the treatment. Thus, the use of psychological techniques is a cornerstone in pain management and must be reflected in clinical guidelines.
\end{abstract}

Key words: child, adolescent, dental care, pain, grounded theory

\section{Introduction}

Pain and discomfort are relatively common among children receiving dental treatment, with some procedures perceived as being more painful than others. Pain after tooth extraction was investigated in a study on pain's natural course (1) where $28 \%$ of the extractions $(16 / 57)$ resulted in moderate pain or worse. Another study reported that approximately one third of children experience pain and/or discomfort in conjunction with treatment occasions (2). Despite the high frequency of pain reports, there seems to be uncertainty among Swedish dentists regarding pain management when treating children and adolescents (3). Pain management should include both non-pharmacologic and pharmacologic methods and be scientifically based. The effectiveness of local anaesthesia is well known, while that of oral analgesics has been less investigated. In 2016, an updated Cochrane-review could not show enough scientific evidence to conclude if preoperatively administered oral analgesics had any reducing/preventing effect on postoperative pain after dental treatment under local anaesthetics (4). There is also a lack of evidence regarding postoperatively administered oral analgesics for preventing/reducing postoperative pain (5). Much of the lack of evidence concerns a shortage of well-designed randomised controlled studies. It is difficult to perform pain studies in children for several reasons, not least ethics. One important aspect is also the scarceness of children's points of view regarding dental pain, which needs to be explored before designing these kinds of studies.

Pain is defined as 'an unpleasant sensory and emotional experience associated with actual or potential tissue damage, or described in terms of such damage' (6). Due to pain's subjective nature (6), it can be difficult to measure pain objectively and patient-centred self-report instruments are therefore advocated (7). Much of the performed research in dentistry has used quantitative 
methods, which is important for collecting and generalising objective knowledge. One important aspect might however be lost using quantitative methods, namely the subjective perspective of the individuals participating in the study. The child's experience and understanding of how she/he feels should position the child as an expert, but all too often does not (8).

The aim of this study was to explore and describe, using grounded theory, children's experiences and thoughts of pain in conjunction with tooth extraction and the subsequent postoperative period. Knowledge about these concepts could serve as a basis for future studies, which is a prerequisite to be able to formulate guidelines on pain management for dental personnel treating children and adolescents when there is a risk of pain.

\section{Materials and Methods}

\section{Study group and procedure}

Identification of eligible participants was made during their visits to any of the private orthodontic clinics in Malmö, Sweden. We asked the orthodontists at mentioned clinics to help us with identification of eligible informants. All patients that were planned for fixed appliances, where extraction of premolars also was indicated prior start of orthodontic treatment, were informed about the study, and asked about participation by the orthodontist. The orthodontists had received an informational letter about the study, stating the inclusion and exclusion criteria along with written information for potential participants and their legal guardians. The orthodontist gave written and verbal information to the potential candidate and his or her legal guardian. The legal guardian signed an informed consent form, which was sent to one of the authors of this article (HB). All children received age-appropriate information and assented to participate. The Swedish Ethical Review Authority, Sweden (\# 2019-00121, (2018/1029)) approved the study. Inclusion criteria for the potential participants were: children aged 10-16 requiring extraction of premolars prior to orthodontic treatment. Before being asked about participation in this study, the informants were thoroughly examined by the orthodontist and asked if they were in good general health with no severe medical conditions or disabilities. If so, inclusion was considered possible. The exclusion criterion was if the patient or legal guardian could not understand Swedish. The protocol for this study was registered on ClinicalTrials.gov (NCT04064853), August 22, 2019, available at https://clinicaltrials.gov/ct2/show/NCT04064853?te $\underline{\mathrm{rm}=\text { berlin\&cntry=SE\&draw=2\&rank=1. }}$.

The informants were contacted to schedule a time and place for the interview at least one week after tooth extraction. The interviewer was not known to the participants in advance and did not take part in their dental treatments. We included 11 informants, 10-16-year-olds, all living in the southern parts of Sweden. There were five girls (mean 13.0 years old) and six boys (mean 14.7 years old). Inclusion of informants was performed consecutively to start with. After the initial five interviews the study group was strategically selected in terms of sex, age, and residence (type of housing to mirror socioeconomic background). We also ensured to include informants having experience of both one and two extractions, but also recently initiated orthodontic treatment. According to grounded theory, a strategic sampling of participants is recommended to obtain a heterogeneous group and to maximise the variations of experiences in the studied group (9). After the first five interviews, informants were identified more strategically to ensure that all aspects of the background were included. This strategic selection took place in parallel with the ongoing interviews, to ensure a heterogeneous group of informants, covering as many background characteristics as possible. The informant's experiences from dental treatments varies; however, in general they had few previous experiences with local anaesthetics.

\section{Method}

Grounded theory (GT) was first presented in 1967 by the sociologists GLASER and STRAUSS when they published their book 'The Discover of Grounded Theory'. This book is what shifted the route of the 
social sciences (10), and it also became a contributor to the acceptance and legitimacy of qualitative research in applied social research (11). The classical original version of grounded theory (9) describes the phenomenon under study as a main concern for the informants that has to be solved. Its ontological position is close to positivism due to its adoption that a 'real reality' that is objective and external can be discovered and described without any influence from the 'objective' researcher (12).

In this study, the constant comparative method for grounded theory, described by GLASER \& STRAUSS (9), and advanced by StRAUSS \& CORBIN (13), and CHARMAZ (14), was used in data collection and analysis. Constant comparative method is where data already collected and categorized, is compared with new data, new codes, new theories that emerges along the process of analysing the data. The researcher reading data, codes and theories constantly redesign and reintegrate his notions as he/she reviews his material (15).

The modified version of grounded theory (i.e. the development by STRAUSS \& CORBIN, 1998 (13)), used in this study, argues that reality cannot be fully known but can always be interpreted. STRAUSS \& CORBIN'S version of grounded theory (13) takes a more post-positivistic position, focusing on social processes (12), meaning that the observer cannot stay totally neutral and therefore imposes some shape and sense to the data. This version of GT accepts this and realizes that there is some form of interpretation by the researcher. In classical grounded theory, to be able to solve the main concern, informants use different strategies that are described in different categories. In the various versions of grounded theory, the aim is to make meaning explicit by generating concepts, models, or theories that are grounded in empirical data. The basic principles of grounded theory include theoretical sampling and hierarchical analysis, constant comparisons, theoretical sensitivity, and saturation. Theoretical sampling is the process of data collection in order to generate a theory where the analyst jointly collects, codes, and analyses the data and decides what data to collect next and where to find them, all in order to develop the theory as it emerges (9). This is in contrast to initial sampling where sampling criteria for people, cases, situations, and/or settings before you enter the field. This initial sampling is needed to find suitable and relevant material (in our case informants) for the study. Once this is done, theoretical sampling directs were to go next in the analysis (10). Theoretical sampling is used to reach saturation and is guided by the emerging categories (13). Saturation, although somewhat 'elastic', is reached when new interviews do not bring additional information to the emerging categories, i.e. when new data fit into the categories already devised (13). Theoretical sensitivity refers to the researcher's reflexive way of developing research questions and doing analysis. Grounded theory is rooted in symbolic interactionism and includes that meaning is constructed and changed through interactions between people (14). Accordingly, perceptions of the world are individual and constantly changed by individuals' interaction with it (16).

\section{Qualitative interviews}

Data were collected from April 2019 to February 2020. Open interviews, lasting 30 to 45 minutes were conducted in a conversational style with each informant by the main author of this article ( $\mathrm{HB}, \mathrm{a}$ paediatric dentist). All interviews were taped and carried out either in a quiet room at the dental clinic or at the informant's home. Informants were allowed to have a legal guardian with them, if they wanted. An interview guide was used and it concerned the participants' thoughts and feeling on themes such as earlier experience of dental treatments, thoughts about the treatment, problems related to the dental treatment (pain experienced during treatment and the subsequent post-operative period). Based on these themes, the interviewer asked relevant follow-up and probing questions. During the interview, the informants were informed that they had the possibility to raise questions of relevance to themselves as well.

Qualitative interviews require active and involved engagement of both the interviewer and informant in responding, clarifying, and elaborating communication. Data were generated within this process, and the quality of the data was influenced 
by the trusting relationship between the researcher and the informant (17). Data collection and analysis were conducted simultaneously $(9,13,14)$ and continued until new interviews did not provide additional information - until saturation was reached.

\section{Analyses of data}

The interviews were transcribed verbatim by $\mathrm{HB}$ and analysed by HB, GK (paediatric dentist) and UH (sociologist experienced in research in the field of odontology) in parallel, using a hierarchical coding process, i.e. open and focused (selective) coding (13). Analysis continued until saturation was achieved. By open coding, the interview transcripts included the substance of the data being captured and segmented into substantive codes, which were labelled concretely. The codes were labelled either by using the informant's words (in vivo codes), or words/concepts of the interviewer's disciplines (in vitro codes). The procedure of open coding led to grouping of substantive codes with similar content into summarising categories, which in turn were given more abstract labels than the substantive codes belonging to them. In the next phase, the axial coding process, the categories were further elaborated by identifying their properties and dimensions. Further, relationships between categories were sought and verified in the data. In the selective coding process, categories were saturated with additional information, assessed by new interview or added by re-coding previously assessed data (i.e. theoretical sampling). Analyses and preliminary findings were continuously discussed between $\mathrm{HB}$ and GK, as well as with $\mathrm{UH}$ as an external partner. A core category was identified describing a psychosocial process and this was central to the data and could be related to other relevant dimensions/categories grounded in the data. Throughout the whole process of analysis, memos and notes were written regarding ideas, preliminary assumptions, and theoretical reflections, in order to keep track of the analysis (13).

The interview transcripts were re-contextualised in the final stage to certify that raw data supported the categories, in other words, that the categories were grounded in the data. According to CHARMAZ (14), the unit of analysis in a grounded theory study concerns events and actions in the data rather than the separate individuals per se. Therefore, the number of informants is less interesting than the content and quality of the data.

\section{Results}

The informants' previous experiences of invasive dental treatment (i.e. local anaesthetics, filling therapy, tooth extraction, etc.) were scarce. The common experience was regular dental check-ups. All of the participants expressed some level of worrying prior to their first tooth extraction. Despite that, no one hesitated to carry on with the planned treatment. Instead, they all reported using different coping strategies to handle the situation.

\section{Handling the unavoidable unknown}

The main concern (core category) for the children was handling the unavoidable unknown. Despite the uncertainty about the treatment procedure, and what that could lead to in terms of pain/unpleasantness during the treatment and postoperatively, the participants were 'jumping into the unknown' (solving the main concern) and went through with the treatment. The children were all well aware that the treatment was unavoidable. They went through the whole procedure with many aspects of it being unknown, nor did they have any knowledge of what to expect after the treatment in terms of pain or unpleasantness. Despite the uncertainty surrounding the whole procedure of tooth extraction, the children chose to go through with the treatment. The children reported varying degrees of anxiety before the treatment. The onset of anxiety differed, but in general, it debuted shortly before treatment, often the evening before. In order for the children to deal with the unknown, they used different types of coping strategies, which are described in the five conceptual categories that were generated in the data analysis (clinging to what I can trust, clinging onto earlier experience, striving to be in control, longing to get it over with, and looking forward to a treat) (Table 1). 
The following quote is to exemplify the core category.

'Well, then again they could have informed a bit earlier what it would feel like... this... and, yeah - if they had examples of individuals that like, had felt it was difficult, and so they could have brought that up and like tell - 'oh, it's no big deal' or like 'this is how it's supposed to feel'. Just so you know a bit more, 'cause I have never done this before so I didn't know how I would feel or how it would be... a little.... uhh... I didn't really know anything about it so that's why I took everything they said very literally. So if I felt any discomfort or anything that hurt then I should raise my hand and that's what I did. But uhh...like perhaps be more...tell more'. (ID8)

\section{Conceptual categories}

\section{Clinging to what I can trust}

Clinging to what I can trust was based on children clinging to things the dentist had said before, such as description of tooth extraction and what could be expected during and after the procedure in terms of pain or other types of sensations. One example is that there could be a sensation of pressure in the tissue during the injection of local anaesthetics. Clinging onto concrete information and what seemed plausible was turned into a strategy for coping with treatment and pain.

'They went through each step before they did it. She said 'now we're doing the anaesthetics', 'we...' - so they said exactly where I would... where they would do the injection too. And they told me the whole time during the process what they did and told me, and listened carefully if I were to tell if I wanted to stop, and I did that too when... I clapped my hands so I got more anaesthetics and stuff.' (ID1)

The participants requested an adequate amount of relevant information in order to reduce levels of anxiousness, but not make them frightened/scared.
'I thought it was good that they did not tell, because otherwise I would have been even more nervous if they had told me it would hurt.' (ID5)

\section{Clinging onto earlier experience}

Clinging onto earlier experience emerged as the children used their own previous experiences to cope with treatment and pain. Some of them had undergone this type of treatment before, which gave them confidence for the treatment they underwent in conjunction with the present study. Those children with experiences of less psychologically challenging earlier treatments felt more at ease and could find motivation from those experiences in the present treatment. In contrast, those with more challenging experiences were in need of more calming information to cope with treatment.

'I've had the syringe before. So that was nothing dangerous. I hardly felt it. Didn't really notice that they did it. So that was nice.' (ID2)

Informants interviewed after having two premolars extracted in conjunction with this study felt less distress before the second extraction compared to the first.

'The first time I hadn't felt like that before so that was more jittery. To know what it feels like... but the second time I knew kind of what it feels like and then it was a bit easier.' (ID2)

\section{Striving to be in control}

Striving to be in control is a result of children finding ways to be in control of the situation, which makes them cope with treatment. Instructing the child to raise their hand to stop the treatment immediately, gives the child a feeling of being in control of the situation. The treatment continues only as long as the child wants/gives permission.

'The first time I did but just because... but the second time it went well. I wouldn't 
have needed it the first time either. But it was just to feel comfortable.' (ID3)

Being able to decide for themselves if and/or when to take oral analgesics after arriving home (to reduce or prevent pain), convinces the children that they have control over the situation which helps them to cope with subsequent pain. Regardless of whether they took oral analgesics or not, this possibility to choose gave the children a sense of self-control.

'My mother suggested it but I didn't feel the need.' (ID3)

\section{Longing to get it over with}

Longing to get it over with arose during the interviews as a category of relevance since the children often mentioned that they wanted to get the treatment over with. The wish to some extent made the children more likely to cope with pain and discomfort. It was a way to save themselves from postponing the treatment, thereby prolonging the worries and anxiety. They knew that the extractions were something they had to handle to be able to get further in their treatment plan, since they knew that this would lead to straight teeth.

'No, so-I felt more than in the upper jaw but it didn't hurt that much or I felt it wasn't that uncomfortable that I had to tell. [...] So, I just thought... So, I just thought of getting it over and done with. I just didn't want it to go on and on.' (ID4)

\section{Looking forward to a treat}

Looking forward to a treat emerged through informants' describing positive outcomes in the future that they were eager to reach. It could be a variety of events such as spending a day with mum, choosing what movie to watch the evening of the tooth extraction, watching some Netflix shows, or longing to get their braces. With this in mind, the informants were more motivated to endure the treatment, even when there was a little pain and/or discomfort.
'That's okay too. Because then you get more attention from mum once you get home.' (ID5)

\section{Discussion}

This qualitative study, using grounded theory, explored children's and adolescents' experiences of procedural and postoperative pain connected to tooth extractions. Despite a great deal of uncertainty in terms of what to expect for procedural and postoperative pain, they went through with having their teeth extracted. By using different types of coping strategies, they were handling the unavoidable unknown. All informants showed a great deal of courage by having teeth extracted (on orthodontic indications) without knowing what to expect from the treatment itself or the postoperative period, including some level of anxiety prior to treatment.

The present study shows that although the children and adolescents have different experiences from previous dental treatments, there are similar traits. These are described in the five categories (clinging to what I can trust, clinging to earlier experience, striving to be in control, longing to get it over with, and looking forward to a treat), all representing different ways of coping with the tooth extractions.

Wanting more information emerged as a central part for the informants in the present study, as an aid to cope with the tooth extractions since information given appropriately makes the procedure understandable, lowering levels of fear and anxiety. In this study, the participants expressed thoughts about the information given in conjunction with treatment. The amount of information was described as sufficient; still, informants were anxious during and after treatment. We interpret this as there being a continuous need for information, which must come at an appropriate time. The relationship between dental anxiety and pain experiences, both dental and everyday pains, is well established (18) and individually tailored information about treatment 
should always be a first step in the prevention of both (19). Information has to be age appropriate as well as be continuously provided throughout the whole treatment procedure. Within dental care, the 'tell-show-do' procedure is commonly practiced. When the child/adolescent is guided and gradually exposed to a procedure, this will aid future cooperation with dental treatment. Problems in a dental scenario are most likely to be prevented if time and awareness are devoted (20). Based on the present study's findings, this is important to stress. A child's first treatment must be handled with empathy and understanding from the dental/medical health personnel. Being empathetic to the patient's needs and preferences may be a key factor in establishing an effective working relationship (21), and is likely to lead to future medical/dental care being characterised by cooperation rather than by conflict from the child's perspective (22). With this also comes the patient's right not to know. We as dentists have to take notice of patients' preferences of receiving or not extensive information. Some children said in their interviews that they did not want too much information as it would lead to more worrying. In such cases, it is crucial to be aware that it is not only verbal communication that matters. Nonverbal communication also aids children visiting the dentist (23).

Previous experiences from dental visits are used by the child as a model to predict future treatments (24). In this study, the informants seemed to have had positive to neutral experiences. The first visit within this study seemed to have a positive conditioning effect on the second visit, which has been reported by HEMBRECHT et al. (25), who stated the consecutive dental treatments seem to have a conditioning effect. This is supported in a study of pain's natural course after tooth extractions (on orthodontic indication) where there were no differences in pain profiles after first and second extractions (1). Dental pain and dental fear and anxiety are often seen as closely rated and intertwined and in children, cognitive and emotional development will affect the child's understanding of both as well as the ability to differentiate between them. If a child has an experience with a dental procedure that was perceived as traumatic and/or frightening, future events will be coloured by that. This first experience may also be generalised so that all coming events that remotely resemble the first frightening episode, may cause fear and anxiety (26). Having many non-traumatic dental visits is an important factor in avoiding development of dental fear and anxiety, according to the theory of latent inhibition (27-29). Exposure to several repeated successful and pain-free dental visits leads to 'vaccination' (latent inhibition). If the patient later meets a negative dental experience the likelihood of developing dental fear and anxiety is lower than if this negative experience occurs during one of the first dental visits $(27,28)$.

Being in control of the situation is an important coping strategy. This can be achieved by having the opportunity to pause the treatment with a stop signal, like raising the hand (23). The participants in the present study mentioned this repeatedly. The possibility of stopping the treatment gave the informants a feeling of control. Some tested it, even though they really did not have to. Doing so can be interpreted as them not feeling totally secure in the situation, but when they noticed that the stop hand worked, they felt safer in the situation, having better control. A stop signal is very favourable for the patient and can be easily employed in practice, leading to a lowered reported stress level even if the child does not use the stop signal (23). In a study by RODD et al. (30), children also stated that they hoped that the dental team would listen to them and tell them what was happening. Within the theme of good communication, children wanted to feel in control, by asking the dentist to cease treatment when necessary (30).

The fourth category, longing to get it done with, is a theme that has been described in other studies as well. For example, DAVIES \& BUCHANAN (23) reported that children aged 9-11 preferred getting the treatment over and done with, compared to having a pause, which would prolong the treatment.

The fifth category, looking forward to a treat, points out that motivation can make the child accept the treatment although sometimes painful/unpleasant. The informants in the present 
study defined a treat in different ways. For some it was watching Netflix, while for others it could be having more quality time with their parents. It could also be an eagerness to have braces, because that meant their teeth would be aligned and aesthetically appealing. This motivator to accept treatment has been shown in other studies; for example, VAN MEURS et al. (31) found that $92 \%$ of the children used a strategy called 'I tell myself I have to do this because it is good for my teeth'.

A strength with the present study is that the same person performed all of the interviews and transcriptions. By this measure, a deepened acquaintance and close knowledge of the data was achieved. Also, having a multidisciplinary team reading the transcripts and participating in analyses is a strength as it warranted different views of the information, and led to picking up nuances in the participants' stories that otherwise might have been missed $(32,33)$. In this study we reached saturation already after 9 interviews. The following two were to verify our results. From the 11 interviews we could clearly see that saturation was reached for each category, thanks to all interviews being lengthy and rich in information. Those who analysed the data, individually, concluded this.

When reporting a qualitative study it can sometimes be raised questions regarding sample size. In these types of studies not all who are interested in participating gets a chance to do so. Instead, to get as much variation as possible, a strategic sampling is adopted to look for a certain trait (theoretical sampling) (10). In this study this condition was met by asking the orthodontist helping with us with identification of suitable informants in order to cover as many different background aspects as possible.

We entered this project with the aim as stated in the manuscript. This aim was held quite "open" which is often the case in GT. One important trait with GT is that it is not a hypothesis testing research method, rather hypothesis generating. It is suitable when there is little known about a phenomenon ( 9 , 34). The interviews started with questions regarding the treatment the informant recently had experienced. Based on the informant's answer, relevant follow-up questions were asked.
Therefore, the focus of the interview could go different directions. During the interviews, pain turned out to not be the main focus, rather ways of dealing with it. This shift of focus became evident after only a few interviews, where it became clear that the informants often ended up in a discussion on how they handled the treatment from a more over all perspective.

In general, the pain in conjunction with tooth extraction seems to be manageable. The informants were motivated to go through with the treatment despite some pain and discomfort. Their stories instead focused on the importance of not forgetting the basis in non-pharmacologic pain treatment, namely accurate and individually tailored information about treatment as well as possible pain and discomfort both during extractions and postoperatively. It may be beneficial if more detailed information about dental extraction was already provided at the orthodontist's. Information about the postoperative period also needs more focus from the dentist performing the extractions. Today many children/adolescents have limited experience of invasive dental treatments, due to good oral health. Tooth extraction prior to orthodontic treatment might therefore be a totally novel experience for the patient. This is perhaps the very first invasive treatment, encounter with local anaesthesia, and possible dental pain for many patients in an otherwise dentally healthy population. It is also important to remember that children need dentists with good communication skills, dentists who are both emphatic and capable of preparing them with relevant and realistic information about the dental procedures. They need to be equipped for reality without sugar coating, instead being honest and preparing them the best way possible.

There was in general a very low demand for pharmaceutical aid to cope with pain. Instead, prevention of pain seems to be the main theme based on data in this study. When formulating guidelines, focus should lie on psychological care. 


\section{Conclusions}

Children experience discomfort during and after dental extractions; however, it seems they feel they can cope with it - they are handling the unavoidable unknown. Children want to be well informed about the whole treatment: what to expect before, during, and after the treatment, in this case tooth extractions. With this, they are able to tolerate even some pain/discomfort. It is important that information is individually tailored, and given at the right time, to reduce and/or avoid anxiousness prior to the first treatment.

\section{Author contributions}

$\mathrm{HB}$ and GK conceived the ideas; KR and DT participated in planning the study and recruiting participants; HB performed all interviews; HB, GK and $\mathrm{UH}$ analysed the data; $\mathrm{HB}$ led the writing, and all authors participated in finalising the manuscript.

\section{Compliance with ethical standards}

Written informed consent for study participation was obtained from the legal guardian. All children received age-appropriate information and consented to participate. The research was conducted ethically in accordance with the World Medical Association Declaration of Helsinki. The Swedish Ethical Review Authority, Sweden (\# 201900121, (2018/1029)) approved the study.

\section{Conflict of interest}

The authors declare no conflict of interest.

\section{Funding}

This study was supported by grants from the Swedish Dental Society, and research funds from Oral Health Related Research by Region Skåne (Odontologisk Forskning i Region Skåne, OFRS 569491), Sweden.

\section{References}

1. Berlin H, List T, Ridell K, Davidson T, Toft D, Klingberg G. Postoperative pain profile in 10-15-yr-olds after bilateral extraction of maxillary premolars. Eur Arch Paediatr Dent 2019; 20: 545-555.

2. Ghanei M, ArnRup K, Robertson A. Procedural pain in routine dental care for children: a part of the Swedish BITA study. Eur Arch Paediatr Dent 2018; 19: 365-372.

3. BERLIN H, LIST T, RIDELL K, KLINGBERG G. Dentists' attitudes towards acute pharmacological pain management in children and adolescents. Int J Paediatr Dent 2018; 28: 152-160.

4. Ashley PF, Parekh S, Moles DR, Anand P, MacDonald LC. Preoperative analgesics for additional pain relief in children and adolescents having dental treatment. Cochrane Database Syst Rev 2016; 8 : CD008392.

5. BerLin H, VAll M, Bergenäs E, Ridell K, BROgÅrdh-Roth S, LAGER E, LIST T, DAVIDSON T, KLINGBERg K. Effects and cost-effectiveness of postoperative oral analgesics for additional postoperative pain relief in children and adolescents undergoing dental treatment: Health technology assessment including a systematic review. PLoS One 2019; 14: e0227027. Published 2019 Dec 31.

6. IASP. International Association for the Study of Pain. 2014. https://www.iasp-

pain.org/Education/Content.aspx?ItemNumber=16

98. Updated December 14, 2017. Accessed May 2019.

7. American Academy of Pediatrics. Committee on Psychosocial Aspects of Child And Family Health, TASK FORCE ON PAIN IN INFANTS, CHILDREN, AND AdOLESCENTS. The assessment and management of acute pain in infants, children, and adolescents. Pediatrics 2001; 108: 793-797.

8. Randall D, Hallowell L. 'Making the bad things seem better': coping in children receiving healthcare. $J$ Child Health Care 2012; 16: 305-313.

9. GLASER BG, STRAUSS AL. The discovery of grounded theory: strategies for qualitative research. New York: Aldine de Gruyter, 1967.

10. CHARMAZ K. Constructing Grounded Theory. A practical Guide Through Qualitative Analysis. London: Sage Publications, 2006.

11. ThOMAS G, JAMES D. Reinventing grounded theory: some questions about theory, ground and discovery. British Educational Research Journal, 2006; 32: 767-795.

12. HALLBERG LR. The 'core category' of grounded theory: making constant comparisons. Int I Qual Stud Health Well-being 2006; 1: 141-148. 
13. StRAUSS AL, CORBIN J. Basics of qualitative research. Techniques and procedures for developing grounded theory. Thousand Oaks, CA: Sage, 1998.

14. Charmaz K. Grounded Theory. Objectivist and constructivist methods. In: DENZIN NK, LINCOLN YS, eds. Handbook of qualitative research, 2 nd ed. Thousand Oaks, CA: Sage, 2000; 509-535.

15. GLASER BG. The Constant Comparative Method of Qualitative Analysis. Social Problems 1965; 12: 436445.

16. BLUMER H. Symbolic interactionism: perspective and method. Englewood Cliffs, N.J.: Prentice Hall, 1969.

17. HAMMERSLEY M. What's wrong with ethnography? Methodological explorations. London: Routledge, 1992.

18. Krekmanova L, Bergius M, Robertson a, Sabel $N$, HAFSTRÖM C, KLINGBERG G, BERggREN U. Everyday- and dental-pain experiences in healthy Swedish 8-19 yr olds: an epidemiological study. Int J Paediatr Dent 2009; 19: 438-447.

19. Taddio A, McMurtry CM, Shah V, Riddell RP, Chambers CT, Noel M, MacDonald Ne, Rogers J, Buccl LM, Mousmanis P, Lang E, Halperin SA, Bowles S, HALPERT C, IPP M, AsMUNDSON GJG, Rieder MJ, RobSON K, Uleryk E, Antony MM, Dubey V, Hanrahan A, LOCKETT D, SCOTT J, BLEEKER EV; HELPINKIDS\&ADULTS. Reducing pain during vaccine injections: clinical practice guideline. CMAJ 2015; 187: 975-982.

20. KLingberg G, ARnRUp K. Dental Fear and Behavior Management Problems. In: KOCH G, POULSEN S, ESPELID I, HAUBEK D, eds. Pediatric dentistry: a clinical approach. 3rd edition. Chichester, West Sussex, UK: Wiley-Blackwell, 2017.

21. TEN BERGE M. Dental fear in children: clinical consequences. Suggested behaviour management strategies in treating children with dental fear. Eur Arch Paediatr Dent 2008; 9 (Suppl 1): 41-46.

22. PRINS JM. Anxiety in medical settings. In: OLLENDICK TH, KING NJ, YULE W, eds. International Handbook of Phobic and Anxiety Disorders in Children and Adolescents. [electronic resource] [Internet]. 1st ed. 1994. Springer US; 1994 [cited 2020 Jun 4].

23. Davies EB, Buchanan H. An exploratory study investigating children's perceptions of dental behavioural management techniques. Int J Paediatr Dent 2013; 23: 297-309.
24. Melamed BG, Dearborn M, Hermecz DA. Necessary considerations for surgery preparation: age and previous experience. Psychosom Med 1983; 45: 517-525.

25. Hembrecht EJ, Nieuwenhuizen J, Aartman IH, Krikken J, VEERKAMP JS. Pain-related behaviour in children: a randomised study during two sequential dental visits. Eur Arch Paediatr Dent 2013; 14: 3-8.

26. OlLENDICK TH, KING NJ. Origins of childhood fears: an evaluation of Rachman's theory of fear acquisition. Behav Res Ther 1991; 29: 117-123.

27. DAVEY GC. Dental phobias and anxieties: evidence for conditioning processes in the acquisition and modulation of a learned fear. Behav Res Ther 1989; 27: 51-58.

28. DE JONGH A, MURIS P, TER HORSt G, DUyX MP. Acquisition and maintenance of dental anxiety: the role of conditioning experiences and cognitive factors. Behav Res Ther 1995; 33: 205-210.

29. ten Berge M, Veerkamp JS, Hoogstraten J. The etiology of childhood dental fear: the role of dental and conditioning experiences. J Anxiety Disord 2002; 16: 321-329.

30. Rodd H, Timms L, Noble F, Bux S, Porritt J, Marshman Z. 'Message to Dentist': Facilitating Communication with Dentally Anxious Children. Dent J (Basel) 2019; 7: 69. Published 2019 Jul 1.

31. Van Meurs P, Howard Ke, Versloot J, Veerkamp JS, FREEMAN R. Child coping strategies, dental anxiety and dental treatment: the influence of age, gender and childhood caries prevalence. Eur J Paediatr Dent 2005; 6: 173-178.

32. Hill, C. E., Thompson, B. J., \& Williams, E. N. A guide to conducting consensual qualitative research. Couns Psychol 1997; 25: 517-572.

33. Hill, C. E., KNox, S., Thompson, B. J., Williams, E. N., HESS, S. A., \& LADANY, N. Consensual qualitative research: An update. J Couns Psychol 2005; 52, 196205.

34. Bryant A, Charmaz K. Grounded theory research: methods and practices. In: BRYANT A, CHARMAZ K, eds. The Sage handbook of grounded theory. Thousand Oaks, CA: SAGE, 2007; 1-28. 
Table 1. Core category, conceptual categories, properties, and examples of meaning units regarding 'handling the unavoidable unknown'.

\begin{tabular}{|c|c|c|c|}
\hline Core category & $\begin{array}{l}\text { Conceptual } \\
\text { categories }\end{array}$ & Properties & Examples of meaning units (in vitro codes) \\
\hline \multirow[t]{14}{*}{$\begin{array}{l}\text { Handling the } \\
\text { unavoidable } \\
\text { unknown }\end{array}$} & $\begin{array}{l}\text { Clinging to what I } \\
\text { can trust }\end{array}$ & $\begin{array}{l}\text { Information is crucial in order to reduce } \\
\text { patients' anxiety levels. }\end{array}$ & $\begin{array}{l}\text { Had received information on how it could } \\
\text { feel during and after injection, and also } \\
\text { afterwards. (ID6) } \\
\text { Wishing for more information beforehand } \\
\text { on how it could feel. Especially since no } \\
\text { previous experience from invasive } \\
\text { treatments at all. (ID8) } \\
\text { Got information during treatment, step by } \\
\text { step. (ID10) }\end{array}$ \\
\hline & $\begin{array}{l}\text { Clinging onto earlier } \\
\text { experience }\end{array}$ & $\begin{array}{l}\text { It is important to ask children about } \\
\text { previous experiences so that information }\end{array}$ & $\begin{array}{l}\text { Earlier experience of tooth extraction led } \\
\text { to less anxiousness this time. (ID4) }\end{array}$ \\
\hline & & can be adjusted individually. & $\begin{array}{l}\text { Less nervous prior to second extraction } \\
\text { since the procedure was familiar, and } \\
\text { what to expect from the postoperative } \\
\text { period. (ID8) }\end{array}$ \\
\hline & & & $\begin{array}{l}\text { Less nervous prior to second visit. Knew } \\
\text { what was going to happen. (ID9) }\end{array}$ \\
\hline & & & $\begin{array}{l}\text { Less nervous prior to second treatment. } \\
\text { Pain also passed more quickly. (ID10) }\end{array}$ \\
\hline & $\begin{array}{l}\text { Striving to be in } \\
\text { control }\end{array}$ & $\begin{array}{l}\text { Give the child a possibility to take control } \\
\text { of what is doable in the dental setting. }\end{array}$ & $\begin{array}{l}\text { Got the possibility to choose if one or two } \\
\text { teeth would be extracted at the same } \\
\text { appointment. (ID2) }\end{array}$ \\
\hline & & & Got information about stop-hand. (ID3) \\
\hline & & & $\begin{array}{l}\text { Was asked if it was ok to take out one } \\
\text { more tooth, after the first had been } \\
\text { extracted. (ID7) }\end{array}$ \\
\hline & & & $\begin{array}{l}\text { Feeling a bit worried that the dentist is } \\
\text { going to do something wrong. (ID8) } \\
\text { Was thinking about taking painkillers. But } \\
\text { then it did not feel necessary. (ID11) }\end{array}$ \\
\hline & $\begin{array}{l}\text { Longing to get it over } \\
\text { with }\end{array}$ & $\begin{array}{l}\text { With proper handling, the child is often } \\
\text { strong enough to handle some }\end{array}$ & $\begin{array}{l}\text { Wasn't so bad, that I felt like pausing the } \\
\text { treatment. (ID1) }\end{array}$ \\
\hline & & pain/unpleasantness. & $\begin{array}{l}\text { It did not hurt that much... (ID2) } \\
\text { I take it as it comes. (ID5) }\end{array}$ \\
\hline & $\begin{array}{l}\text { Looking forward to a } \\
\text { treat }\end{array}$ & $\begin{array}{l}\text { Identify motivators for the child; why } \\
\text { treatment (and possible pain/discomfort) } \\
\text { is worth it. }\end{array}$ & $\begin{array}{l}\text { Is fine with having more teeth extracted. It } \\
\text { leads to more attention from mother. } \\
\text { (ID1) }\end{array}$ \\
\hline & & & $\begin{array}{l}\text { Feels motivated to have braces. Is looking } \\
\text { forward to it. (ID5) }\end{array}$ \\
\hline & & & $\begin{array}{l}\text { Got a lot of praise after the treatment. } \\
\text { (ID6) }\end{array}$ \\
\hline
\end{tabular}




ISBN 978-9I-7877-I33-2 (print)

ISBN 978-9I-7877-I34-9 (pdf)

MALMÖ UNIVERSITY 20506 MALMÖ, SWEDEN WWW.MAU.SE 